$$
\begin{gathered}
\text { UNIVERSIDADE DE SÃO PAULO } \\
\text { FFCLRP - DEPARTAMENTO DE FÍSICA } \\
\text { PROGRAMA DE PÓS-GRADUAÇÃO EM FÍSICA APLICADA À } \\
\text { MEDICINA E BIOLOGIA }
\end{gathered}
$$

\title{
Verificação 3D da distribuição da dose em radiocirurgia estereotáxica através de simulação Monte Carlo e dosimetria por ressonância magnética nuclear
}

Mirko Salomón Alva Sánchez

Ribeirão Preto - SP

2012 


\section{Verificação 3D da distribuição da dose em radiocirurgia estereotáxica através de simulação Monte Carlo e dosimetria por ressonância magnética nuclear}

Tese apresentada ao Departamento de Física da Faculdade de Filosofia, Ciência e Letras de Ribeirão Preto da Universidade de São Paulo, como parte das exigências para obtenção do título de Doutor em Ciências.

Área de concentração: Física Aplicada à Medicina e Biologia.

Orientadora: Prof ${ }^{a}$. Dr $\stackrel{a}{\text { a }}$. Patrícia Nicolucci.

Ribeirão Preto - SP

2012 
Autorizo a reprodução e divulgação total ou parcial deste trabalho, por qualquer meio convencional ou eletrônico, para fins de estudo e pesquisa, desde que citada à fonte.

\author{
Catalogação da Publicação \\ Departamento de Física \\ Faculdade de Filosofia, Ciências e Letras de Ribeirão Preto da \\ Universidade de São Paulo
}

Alva Sánchez, Mirko Salomón

Verificação 3D da distribuição da dose em radiocirurgia estereotáxica através de simulação Monte Carlo e dosimetria por ressonância magnética nuclear.

Ribeirão Preto, 2012.

184p.:il.; $30 \mathrm{~cm}$

Tese de doutorado, apresentada ao Departamento de Física da Faculdade de Filosofia, Ciências e Letras de Ribeirão Preto da Universidade de São Paulo Área de concentração: Física Aplicada à Medicina e Biologia.

Orientadora: Prof $^{\mathrm{a}}$.Dr ${ }^{\mathrm{a}}$. Patrícia Nicolucci

1.Radiocirurgia Estereotáxica. 2. Distribuição 3D de dose. 3. MAGIC- $f$ gel.

4. PENELOPE-Monte Carlo. 5. Filme Radiocrômico EBT2 
Dedico este trabalho: a meus pais e irmãos, a minha amada esposa, a minha nova família, e especialmente, em memória, a minha Tia Vilma. 


\section{Agradecimentos}

Esse trabalho é fruto de muitas colaborações, assim, gostaria de agradecer as pessoais que cooperaram para que ele fosse possível:

À Deus, por me permitir ser, saber e fazer.

À minha orientadora, Prof ${ }^{\mathrm{a}} \mathrm{Dr}^{\mathrm{a}}$. Patrícia Nicolucci pela orientação, paciência, compreensão, amizade, ensinamentos e confiança depositada em todos esses anos de convívio, desde o mestrado.

À minha esposa, Thatiane, que ficou sempre ao meu lado em todas as etapas desse trabalho, com todo apoio emocional e na ajuda das discussões e correções.

À Dr. ‥ Cassiana Vicarri de Moares e João pela amizade, incentivo em todos os momentos.

Ao físico do Hospital do Câncer de Barretos, Marcelo Santanna, pela amizade, discussões e possibilidade de realizar as medidas experimentais.

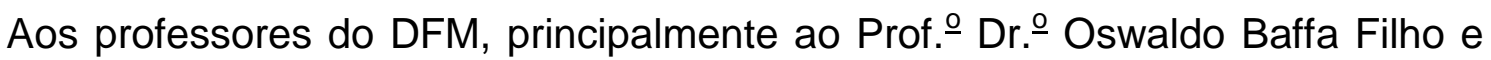

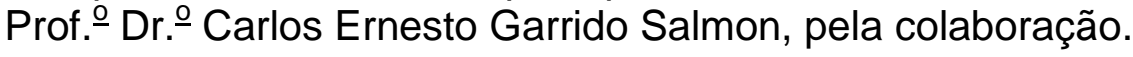

Aos funcionários do DFM, principalmente a Aziani e Nilza, pela disponibilidade e suporte técnico.

Aos funcionários do $\mathrm{HC}$ do setor de radioterapia, especialmente Dr. Harley e físico Leonardo Amaral, pela colaboração com as irradiações.

Aos funcionários do $\mathrm{HC}$ do setor de ressonância magnética pela colaboração com as leituras no tomógrafo.

Aos funcionários do HCB-Barretos, especialmente aos físicos, pela disponibilidade de realizar os procedimentos experimentais.

Aos colegas de grupo pela convivência, incentivo, brincadeiras e companhia sempre indispensáveis.

Aos amigos da faculdade: Moises, Ailton, Lindomar, Lucas Baggio, Jorge, pela amizade, conversas, e brincadeiras.

Aos amigos da ex-república: Gleidson, Glauber e Antonio pela convivência, incentivo, brincadeiras e companhia sempre indispensáveis.

Aos amigos que se somam à lista das minhas amizades, principalmente: Carol e Luis, Karla e Cristiano, Sandra e Deividson, Jonatas e Daniele, Fabio e Milene e Alessandra. 
Aos meus amigos da turma de Física da Universidade Nacional de TrujilloPeru, Lucia, Silvia, Bertha, Edmundo, William, Willard, Melissa, Virginia e Victor pela amizade durante todo o tempo da graduação.

À minha nova família Alves Pianoschi por toda acolhida e compreensão durante o desenvolvimento do doutorado.

Aos meus pais, irmãos, sobrinhos e a toda a minha família, de forma muito especial, mesmo de longe esteve presente todos os dias, incentivando, torcendo pela realização desse trabalho.

À CAPES pelo apoio financeiro.

À USP pela infra-estrutura oferecida. 


\section{Resumo}

Alva Sánchez, M. S. Verificação 3D da distribuição da dose em radiocirurgia estereotáxica através de simulação Monte Carlo e dosimetria por ressonância magnética nuclear. 2012. 184f. Tese (doutorado) - Departamento de Física, Faculdade de Filosofia, Ciências e Letras de Ribeirão Preto, Universidade de São Paulo, Ribeirão Preto, 2012.

A radiocirugia estereotáxica é uma técnica que fornece altas doses de radiação utilizando campos pequenos para conformação da dose no volume alvo do tratamento. Devido à complexidade desta técnica torna-se necessária a verificação da distribuição de dose no volume de tratamento. Neste trabalho, as distribuições tridimensionais (3D) de doses de casos clínicos de neoplasias cranianas foram estudadas utilizando-se um objeto simulador de cabeça. A reconstrução das distribuições de doses nos volumes alvo e nas regiões adjacentes a estes foram avaliadas com o código de simulação PENELOPE, o dosímetro MAGIC- $f$ gel e com o sistema de planejamento iPlan ${ }^{\circledR}$. Filmes radiocrômicos também foram empregados para a determinação das distribuições de dose em planos do tratamento. As respostas obtidas com as ferramentas dosimétricas utilizadas foram analisadas através de distribuições de índices gama, comparando-se os mapas centrais das distribuições de dose obtidas com as quatro ferramentas dosimétricas utilizadas. Usando-se critérios de tolerância de $3 \%$ e $3 \mathrm{~mm}$, a análise realizada na região da prescrição de dose (isodoses de 95\%) mostrou-se equivalente para todas as ferramentas dosimétricas utilizadas; resultado diferente foi observado para isodoses menores, com uma equivalência máxima de $76,5 \%$. As distribuições volumétricas, obtidas através do PENELOPE, MAGIC- $f$ gel e o iPlan ${ }^{\circledR}$, foram comparadas, ainda, através dos histogramas dose-volume, para cada caso estudado, mostrando que $95 \%$ da dose absorvida relativa encontra-se dentro do volume alvo para todos os planos estudados. A probabilidade de controle tumoral, TCP, foi avaliada para os casos de radiocirurgia estudados, a partir das distribuições volumétricas de dose, resultando em uma probabilidade de controle tumoral máxima de $72 \%$, para todos os casos, conforme o modelo matemático de TCP utilizado. Das comparações realizadas pode-se inferir que o dosímetro MAGIC- $f$ gel e o código de simulação PENELOPE-Monte Carlo podem ser utilizados para determinar as distribuições de dose em 3D para a técnica de radiocirurgia estereotáxica. Essas ferramentas dosimétricas podem, dessa forma, auxiliar no comissionamento de unidades de terapia e em verificações 3D de doses do tratamento dos pacientes, permitindo avaliações dentro e ao redor do volume alvo e podendo se tornar ferramentais de rotina nos serviços de radioterapia.

Palavras-chave: Radiocirurgia Estereotáxica. Distribuição 3D de dose. MAGIC- $f$ gel. PENELOPE-Monte Carlo. Filme Radiocrômico EBT2. 


\begin{abstract}
Alva Sánchez, M. S. Dose distribution verification in 3D to stereotactic radiosurgery through Monte Carlo simulation and gel dosimetry with nuclear magnetic resonance 2012. 184f. Tese (doutorado) - Departamento de Física, Faculdade de Filosofia, Ciências e Letras de Ribeirão Preto, Universidade de São Paulo, Ribeirão Preto, 2012.
\end{abstract}

Stereotactic radiosurgery is a technique which delivers high radiation doses using small fields to conform the absorbed dose into the target volume. Due to the complexity of this technique it is necessary to verify the dose distribution in the treatment volume. Thus, in this study the three-dimensional (3D) dose distributions of selected clinical cases of cranial tumors were obtained using a head phantom. The the dose distributions of target volumes and adjacent regions were evaluated with PENELOPE Monte Carlo simulation code, MAGIC- $f$ dosimeter and iPlan® treatment planning system. Radiochromic films were also used to determine the dose distribution on selected plans of the treatment. The obtained results for the proposed dosimetric tools were analyzed by the gamma index distributions, comparing the maps of the central dose distributions obtained with the four dosimetric tools. Using the dose criteria of $3 \%$ in $3 \mathrm{~mm}$, the gamma index test showed equivalence in the region of dose prescription (95\% isodose) and a different result was observed for lower isodoses, with maximum accordance of $76.5 \%$. The volumetric dose distributions obtained with PENELOPE, MAGIC- $f$ and iPlan ${ }^{\circledR}$ were also compared using the dose-volume histograms for each studied case, showing that $95 \%$ of the absorbed dose yield within the target volume. The tumor control probability, TCP, was evaluated for the studied radiosurgery cases, from the dose distributions-volumetric, resulting in a maximum probability of tumor control of $72 \%$ for all cases, for the used mathematical model of TCP. From the results it can be inferred that the MAGIC- $f$ gel dosimeter and the PENELOPE Monte Carlo simulation code can be used to determine 3D dose distributions for stereotactic radiosurgery. These dosimetric tools can assist the commissioning of treatment units and 3D dose verifications of patient's treatments, allowing assessments in and around the target volume and may become routine in radiotherapy services.

Keywords: Stereotactic Radiosurgery. 3D dose distribution. MAGIC- $f$ gel. PENELOPEMonte Carlo. EBT2 radiochromic film. 


\section{Índice de figuras}

Figura 1: Lars Leksell e Borje Larssson preparando ao paciente para 0 tratamento com radiocirurgia em 1958. (Chin et al, 2008).

Figura 2: Acessório estereotáxico, utilizado na técnica de radiocirurgia ou radioterapia estereotáxia para tratamentos de tumores intercranianos (http://www.brainlab.com).

Figura 3: Dosímetro polimérico MAGIC-f gel: (a) amostra não irradiada e (b) amostra irradiada com feixe de fótons de $6 \mathrm{MV}$.

Figura 4: Decaimento do sinal de ressonância magnética nuclear, sendo a amplitude máxima quando todos os spins estão em fase e diminuindo conforme os spins encontram-se defasados (Baert et al, 2007) .................................. 14

Figura 5: Sequencia de pulso de $90^{\circ}$ e $180^{\circ}$ são aplicados ao vetor de magnetização, produzindo um grande sinal, o "spin echo" (Baert et al, 2007).14

Figura 6: Esquema da trajetória de uma partícula sendo transportada em diferentes meios. (Salvat et al, 2009).

Figura 7: Esquema de várias colisões fracas entre duas colisões fortes, simulando eventos artificiais no PENELOPE (Salvat et al, 2009). 19

Figura 8: Visualização com o GeoView de uma geometria cilíndrica com dois corpos, de diferentes materiais, que são representados pelas diferentes cores.

Figura 9: Filme radiocrômico EBT2: (a) sem irradiar e (b) após de ser irradiado. 21

Figura 10: Esquema da orientação da posição do filme radiocrômico EBT2 para realizar o seu escaneamento.

Figura 11: Planejamento de um caso de radiocirurgia com o sistema de planejamento iPlan®, com três arcos dinâmicos. 25

Figura 12: Curvas esquemática de um histograma dose-volume: (a) diferencial, e (b) acumulativo, mostrando um caso ideal (linha vermelha) e um caso real (linha preta).

Figura 13: Curva esquemática da probabilidade de controle tumoral. 29

Figura 14: Objetos simuladores utilizados nesse trabalho. (a) tubos de vidro de $5 \mathrm{ml}$; (b) tubos de vidro de $50 \mathrm{ml}$; (c) paralelepípedo de PPMA; (d) cilindro de PMMA; (e) objeto simulador de cabeça (f). cilíndrico de placas de PPMA...... 35

Figura 15 Aceleradores lineares Varian do HCB - Barretos: (a) 2100c e (b) Varian Generic com acoplamento de colimador multi-folhas. Aparelhos Siemens do HC-Ribeirão Preto: (c) Unidade de Cobalto 60 e (d) acelerador linear $\mathrm{ONCOR}^{\circledR}$. 
Figura 16: Dosímetro MAGIC-f gel: (a) início da preparação, (b) final da preparação, com adição do último elemento.................................................. 38

Figura 17: Tomógrafo NMR Philips, 3,0 Teslas, do HC - Ribeirão Preto, com uma bobina de cabeça.

Figura 18: Cilindro de PMMA usado para o estudo da homogeneidade de campo da bobina de cabeça do aparelho MRI.

Figura 19: Geometria de irradiação para determinar a dependência do MAGIC-f com a dose em um intervalo de 0,5 até 10Gy. (a) arranjo de irradiação (b) tubos de vidro com gel posicionados em suporte de PMMA dentro do OS de água. 43

Figura 20: Objetos simuladores para o estudo da dependência da resposta em função do tempo de espera para leitura após a irradiação. Tubos irradiados com doses de 5 Gy (os três primeiros tubos a partir da esquerda), 10 Gy e $15 \mathrm{~Gy}$, respectivamente.

Figura 21: Geometria para determinação da PDP (a) Geometria completa; (b) Detalhe do tanque de PMMA contento o tubo de vidro, que está centralizado com o campo de irradiação.

Figura 22: Irradiação dos filmes EBT2: (a) filmes e OS, (b) geometria de irradiação. 46

Figura 23: Posicionamento do aparelho estereotáxico no objeto simulador de cabeça (a) e posicionamento do objeto simulador para realização de CT de simulação (b). 51

Figura 24: Planejamento de um caso de meningioma com o sistema de planejamento iPlan®, com três arcos dinâmicos........................................... 52

Figura 25: OS de cabeça: (a) preenchido com MAGIC-f; (b) posicionado para irradiação.

Figura 26: Posicionamento do filme EBT2 dentro OS de cabeça com dois suportes circulares de acrílico. 54

Figura 27: Planejamento do OS de cabeça com 9 campos não coplanares, para a simulação de um tratamento de melanoma.

Figura 28: Planejamento do OS de cabeça com 11 campos não coplanares, para a simulação de um tratamento de neurinoma do acústico. 56

Figura 29: Esquema do posicionamento do objeto simulador cilíndrico de PMMA utilizado no estudo da homogeneidade de campo da bobina de cabeça .

Figura 30: MRI dos cortes axiais das regiões do cilindro de PMMA: (a1) cabeça, (b1) centro, (c1) pés e mapas dos ângulos de fleep para cada região: (a2) cabeça, (b2) centro, (c2). 
Figura 31: Avaliação da homogeneidade de campo da bobina de cabeça em função do tamanho das ROls em três cortes selecionados: cabeça $(\Delta)$, centro $(\bullet)$, pés ( - )

Figura 32: Homogeneidade do campo da bobina de cabeça ao longo do eixo longitudinal do cilindro para todas as ROls analisadas. 62

Figura 33: Comparação das PDP obtidas por simulação: (*) AGUA.mat, ( $\square$ ) MAGIC-f e experimentalmente por $(\boldsymbol{\Lambda})$ câmara de ionização $(\mathrm{Cl})$, para os feixes utilizados: (a) 6MV e (b)10 MV 63

Figura 34: Imagem de ressonância magnética nuclear de amostras de MAGIC-f irradiadas em feixe de fótons de 6MV: (a) Mapa dos tempos de relaxação transversal (T2) e (b) mapa de R2 obtidas com o programa na plataforma de Matlab $^{\circledR}$ 64

Figura 35: Resposta do dosímetro MAGIC-f em função da dose absorvida para os feixes de $6 \mathrm{MV}(\square)$ e $10 \mathrm{MV}(\bullet)$. 66

Figura 36: Resposta relativa do MAGIC-f gel em função da taxa dose para os feixes de $6 \mathrm{MV}((\square)$ e $10 \mathrm{MV}(\bullet)$. 67

Figura 37: Resposta do MAGIC-f gel com o tempo de espera para leitura após irradiação. 68

Figura 38: Curvas de PDP do serviço de radioterapia do HCB-Barretos e as obtidas com MAGIC-f gel, para os feixes de: (a) 6 MV e (b) 10 MV................. 70

Figura 39: Curvas de PDP para os feixes de:(a), (b) $6 \mathrm{MV}$ e (c), (d) $10 \mathrm{MV}$. Em (a), (c) tem-se as curvas de PDP em todas as profundidades e em (b), (d) ressaltam profundidades maiores que $10 \mathrm{~cm}$........................................... 71

Figura 40: Resposta do filme EBT2 em função da dose absorvida para os

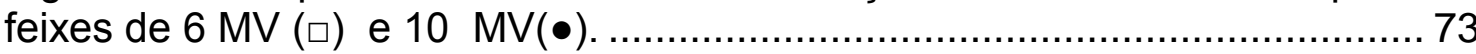

Figura 41: Resposta do filme EBT2 em função da taxa de dose para os feixes

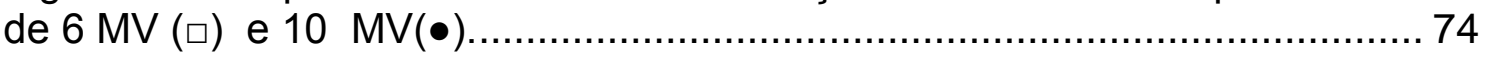

Figura 42: Resposta do filme EBT2 com tempo de espera para leitura após irradiações com doses de 5, 10 e 15 Gy. 75

Figura 43: PDPs obtidas utilizando-se câmaras de ionização (Cl), filme EBT2 e PENELOPE para os feixes de (a) 6MV e (b) $10 \mathrm{MV}$. 76

Figura 44: Distribuições de dose para campo circular de $1 \mathrm{~cm}$ de diâmetro obtidas com: (a) MAGIC-f gel, (b) Filme EBT2, (c) PENELOPE e (d) TPS iPlan ${ }^{\circledR}$.......

Figura 45: Distribuições de dose para campo circular de $2 \mathrm{~cm}$ de diâmetro obtido com: (a) MAGIC-f gel, (b) Filme EBT2, (c) PENELOPE e (d) TPS iPlan ${ }^{\circledR}$. 
Figura 46: Distribuições de dose para campo circular de $3 \mathrm{~cm}$ de diâmetro obtido com: (a) MAGIC-f gel, (b) Filme EBT2, (c) PENELOPE e (d) TPS iPlan ${ }^{\circledR}$.

Figura 47: PDP para o campo circular de $1 \mathrm{~cm}$ de diâmetro obtido com as quatro ferramentas dosimétricas: MAGIC-f gel, filme EBT2, PENELOPE e TPS iPlan ${ }^{\circledR}$.

Figura 48: PDP para o campo circular de $2 \mathrm{~cm}$ de diâmetro obtido com as quatro ferramentas dosimétricas: Magic-f gel, Filme EBT2, PENELOPE e TPS iPlan ${ }^{\circledR}$....... 80

Figura 49: PDP para o campo circular de $3 \mathrm{~cm}$ de diâmetro obtido com as quatro ferramentas dosimétricas: Magic-f gel, Filme EBT2, PENELOPE e TPS iPlan ${ }^{\circledR}$......

Figura 50: Perfil de dose para um campo de $1 \mathrm{~cm}$ de diâmetro na profundidade de dose máxima, $15 \mathrm{~mm}$ (a) e em $50 \mathrm{~mm}$ (b) para um feixe de $6 \mathrm{MV}$..... 83

Figura 51: Perfil de dose para um campo de $2 \mathrm{~cm}$ de diâmetro na profundidade de dose máxima, $15 \mathrm{~mm}$ (a) e em $50 \mathrm{~mm}$ (b) para um feixe de $6 \mathrm{MV}$. 84

Figura 52: Perfil de dose para um campo de $3 \mathrm{~cm}$ de diâmetro na profundidade de dose máxima, $15 \mathrm{~mm}$ (a) e em $50 \mathrm{~mm}$ (b) para um feixe de $6 \mathrm{MV}$. 85

Figura 53: Distribuições de doses obtidas utilizando a) código de simulação PENELOPE e b) MAGGIC-f gel, para 5 campos coplanares de $1 \mathrm{~cm}$ de diâmetro para um feixe de $6 \mathrm{MV}$.

Figura 54: Perfil de dose da composição de 5 campos de $1 \mathrm{~cm}$ de diâmetro obtido através do código de simulação PENELOPE (•) e MAGIC-f gel ( $\square$ ), para o feixe de $6 \mathrm{MV}$.

Figura 55: Distribuição de dose para 6 campos coplanares obtidas para o plano central do volume alvo: (a) PENELOPE, (b) TPS iPlan ${ }^{\circledR}$ e (c) filme EBT2, para o feixe de $6 \mathrm{MV}$.

Figura 56: Mapas dos índices $\gamma$ comparando as distribuições de dose obtidas com o PENELOPE e o TPS iPlan ${ }^{\circledR}$ para a composição de 6 campos coplanares. 90

Figura 57: Mapas dos índices $\gamma$ comparando as distribuições de dose para uma isodose de 40\%: (a) PENELOPE-TPS iPlan, (b) PENELOPE-EBT2 e (c) TPS iPlan ${ }^{\circledR}$-EBT2. 91

Figura 58: Distribuições de dose de uma composição de 7 campos nãocoplanares obtida com: (a) PENELOPE, (b) EBT2 e (c) TPS iPlan ${ }^{\circledR}$................. 92

Figura 59: Mapa dos índices $\gamma$ obtidos referentes da comparação para as seguintes ferramentas dosimétricas: (a) PENELOPE-EBT2, (b) TPS iPlan ${ }^{\circledR}$ EBT2 e (c) PENELOPE-Iplan ${ }^{\circledR}$. 
Figura 60: Distribuições de dose obtidas para uma técnica de radiocirurgia com arco dinâmico com as ferramentas dosimétricas: (a) MAGIC-f, (b) EBT2, (c) TPS iPlan ${ }^{\circledR}$ e (d) PENELOPE. 95

Figura 61: Mapa do índice $\gamma$ comparando as distribuições de dose obtidas com - PENELOPE e o TPS iPlan ${ }^{\circledR}$, para os critérios de $1 \mathrm{~mm}$ e $1 \%$. As linhas brancas mostram as isodoses de $90 \%$ e de $50 \%$, respectivamente. 97

Figura 62: Mapa do índice $\gamma$ comparando as distribuições de dose obtidas com - PENELOPE e o TPS iPlan ${ }^{\circledR}$, para os critérios de $2 \mathrm{~mm}$ e $2 \%$. As linhas brancas mostram as isodoses de $90 \%$ e de $50 \%$, respectivamente. 98

Figura 63: Mapa do índice $\gamma$ comparando às distribuições de dose obtidas com o PENELOPE e TPS iPlan ${ }^{\circledR}$, para os critérios de $3 \mathrm{~mm}$ DTA e $3 \%$ tolerância em dose. As linhas brancas mostram as isodoses de $90 \%$ e de $50 \%$, respectivamente. 99

Figura 64: Histogramas dos índices $\gamma$ comparando as distribuições de dose obtidas com o PENELOPE e TPS iPlan ${ }^{\circledR}$, para os critérios de $3 \mathrm{~mm}$ e $3 \%$ para as isodoses de (a) $90 \%$, (b) $50 \%$ e (c) para o plano todo. 100

Figura 65: Mapa do índice $\gamma$ comparando às distribuições de dose obtidas com - PENELOPE e TPS iPlan ${ }^{\circledR}$ para os critérios de $3 \mathrm{~mm}$ DTA e $5 \%$ tolerância em dose. As linhas brancas mostram as isodoses de $90 \%$ e de $50 \%$, respectivamente. 101

Figura 66: Mapa do índice $\gamma$ comparando as distribuições de dose obtidas com MAGIC-f e EBT2, para os critérios de $1 \mathrm{~mm}$ e $1 \%$. As linhas brancas mostram as isodoses de $90 \%$ e de $50 \%$, respectivamente. 102

Figura 67: Mapa do índice $\gamma$ comparando as distribuições de dose obtidas com o MAGIC-f e EBT2, para os critérios de $2 \mathrm{~mm}$ e $2 \%$. As linhas brancas mostram as isodoses de $90 \%$ e de $50 \%$, respectivamente. 103

Figura 68: Mapa do índice $\gamma$ comparando as distribuições de dose obtidas com MAGIC-f e EBT2, para os critérios de $3 \mathrm{~mm}$ e $3 \%$. As linhas brancas mostram as isodoses de $90 \%$ e de $50 \%$, respectivamente. 104

Figura 69: Mapa do índice $\gamma$ comparando as distribuições de dose obtidas com MAGIC-f e EBT2, para os critérios de $3 \mathrm{~mm}$ e $5 \%$. As linhas brancas mostram as isodoses de $90 \%$ e de $50 \%$, respectivamente. 105

Figura 70: Mapa do índice $\gamma$ comparando as distribuições de dose obtidas com MAGIC-f e PENELOPE, para os critérios de $1 \mathrm{~mm}$ e $1 \%$. As linhas brancas mostram as isodoses de $90 \%$ e de $50 \%$, respectivamente. 106

Figura 71: Mapa do índice $\gamma$ comparando as distribuições de dose obtidas com MAGIC-f e PENELOPE, para os critérios de $2 \mathrm{~mm}$ e $2 \%$. As linhas brancas mostram as isodoses de $90 \%$ e de $50 \%$, respectivamente. 107 
Figura 72: Mapa do índice $\gamma$ comparando as distribuições de dose obtidas com - MAGIC-f e PENELOPE, para os critérios de $3 \mathrm{~mm}$ e $3 \%$. As linhas brancas mostram as isodoses de $90 \%$ e de $50 \%$, respectivamente. 108

Figura 73: Mapa do índice $\gamma$ comparando as distribuições de dose obtidas com MAGIC-f e PENELOPE, para os critérios de $3 \mathrm{~mm}$ e $5 \%$. As linhas brancas mostram as isodoses de $90 \%$ e de $50 \%$, respectivamente. 109

Figura 74: Mapa do índice $\gamma$ comparando as distribuições de dose obtidas com PENELOPE e EBT2, para os critérios de $1 \mathrm{~mm}$ e $1 \%$. As linhas brancas mostram as isodoses de $90 \%$ e de $50 \%$, respectivamente. 110

Figura 75: Mapa do índice $\gamma$ comparando as distribuições de dose obtidas com - PENELOPE e EBT2, para os critérios de $2 \mathrm{~mm}$ e $2 \%$. As linhas brancas mostram as isodoses de $90 \%$ e de $50 \%$, respectivamente. 111

Figura 76: Mapa do índice $\gamma$ comparando as distribuições de dose obtidas com - PENELOPE e EBT2, para os critérios de $3 \mathrm{~mm}$ e $3 \%$. As linhas brancas mostram as isodoses de $90 \%$ e de $50 \%$, respectivamente. 112

Figura 77: Mapa do índice $\gamma$ comparando as distribuições de dose obtidas com PENELOPE e EBT2, para os critérios de $3 \mathrm{~mm}$ e $5 \%$. As linhas brancas mostram as isodoses de $90 \%$ e de $50 \%$, respectivamente. 113

Figura 78: Mapa do índice $\gamma$ comparando as distribuições de dose obtidas com TPS iPlan ${ }^{\circledR}$ e MAGIC-f, para os critérios de $1 \mathrm{~mm}$ e $1 \%$. As linhas brancas mostram as isodoses de $90 \%$ e de $50 \%$, respectivamente. 114

Figura 79: Mapa do índice $\gamma$ comparando as distribuições de dose obtidas com TPS iPlan ${ }^{\circledR}$ e MAGIC-f, para os critérios de $2 \mathrm{~mm}$ e $2 \%$. As linhas brancas mostram as isodoses de $90 \%$ e de $50 \%$, respectivamente. 115

Figura 80: Mapa do índice $\gamma$ comparando as distribuições de dose obtidas com TPS iPlan ${ }^{\circledR}$ e MAGIC-f, para os critérios de $3 \mathrm{~mm}$ e $3 \%$. As linhas brancas mostram as isodoses de $90 \%$ e de $50 \%$, respectivamente. 116

Figura 81: Mapa do índice $\gamma$ comparando as distribuições de dose obtidas com TPS iPlan ${ }^{\circledR}$ e MAGIC-f, para os critérios de $3 \mathrm{~mm}$ e $5 \%$. As linhas brancas mostram as isodoses de $90 \%$ e de $50 \%$, respectivamente. 117

Figura 82: Mapa do índice $\gamma$ comparando as distribuições de dose obtidas com TPS iPlan ${ }^{\circledR}$ e EBT2, para os critérios de $1 \mathrm{~mm}$ e $1 \%$. As linhas brancas mostram as isodoses de $90 \%$ e de $50 \%$, respectivamente. 118

Figura 83: Mapa do índice $\gamma$ comparando as distribuições de dose obtidas com TPS iPlan ${ }^{\circledR}$ e EBT2, para os critérios de $2 \mathrm{~mm}$ e $2 \%$. As linhas brancas mostram as isodoses de $90 \%$ e de $50 \%$, respectivamente. 119 
Figura 84: Mapa do índice $\gamma$ comparando as distribuições de dose obtidas com TPS iPlan ${ }^{\circledR}$ e EBT2, para os critérios de $3 \mathrm{~mm}$ e $3 \%$. As linhas brancas mostram as isodoses de $90 \%$ e de $50 \%$, respectivamente. 120

Figura 85: Mapa do índice $\gamma$ comparando as distribuições de dose obtidas com TPS iPlan ${ }^{\circledR}$ e EBT2, para os critérios de $3 \mathrm{~mm}$ e $5 \%$. As linhas brancas mostram as isodoses de $90 \%$ e de $50 \%$, respectivamente. 121

Figura 86: Curvas de DVH obtidas das distribuições de dose volumétrica das ferramentas dosimétricas: MAGIC-f, e TPS iPlan ${ }^{\circledR}$ e PENELOPE para um caso de meningioma. 124

Figura 87: Histogranas de probabilidade de controle tumoral-volume, para um caso de meningioma, para as ferramentas dosimétricas: MAGIC-f, TPS iPlan ${ }^{\circledR} \mathrm{e}$ PENELOPE, 125

Figura 88: Curvas de TCP-Volume e DVH, para um caso de meningioma, para as ferramentas dosimétricas: MAGIC-f, TPS iPlan ${ }^{\circledR}$ e PENELOPE. 126

Figura 89: Distribuições de dose obtidas para uma técnica de radiocirurgia com 9 campos estáticos com as ferramentas dosimétricas: (a) MAGIC-f, (b) EBT2, (c) TPS iPlan ${ }^{\circledR}$ e (d) PENELOPE 128

Figura 90: Mapa do índice $\gamma$ comparando as distribuições de dose obtidas com PENELOPE e TPS iPlan ${ }^{\circledR}$, para os critérios de $3 \mathrm{~mm}$ e $3 \%$. As linhas brancas mostram as isodoses de $90 \%$ e de $50 \%$, respectivamente. 129

Figura 91: Mapa do índice $\gamma$ comparando as distribuições de dose obtidas com MAGIC-f e EBT2, para os critérios de $3 \mathrm{~mm}$ e $3 \%$. As linhas brancas mostram as isodoses de $90 \%$ e de $50 \%$, respectivamente. 130

Figura 92: Mapa do índice $\gamma$ comparando as distribuições de dose obtidas com MAGIC-f e PENELOPE, para os critérios de $3 \mathrm{~mm}$ e $3 \%$. As linhas brancas mostram as isodoses de $90 \%$ e de $50 \%$, respectivamente. 131

Figura 93: Mapa do índice $\gamma$ comparando as distribuições de dose obtidas com PENELOPE e EBT2, para os critérios de $3 \mathrm{~mm}$ e $3 \%$. As linhas brancas mostram as isodoses de $90 \%$ e de $50 \%$, respectivamente. 132

Figura 94: Mapa do índice $\gamma$ comparando as distribuições de dose obtidas com TPS iPlan ${ }^{\circledR}$ e MAGIC-f, para os critérios de $3 \mathrm{~mm}$ e $3 \%$. As linhas brancas mostram as isodoses de $90 \%$ e de $50 \%$, respectivamente. 133

Figura 95: Mapa do índice $\gamma$ comparando as distribuições de dose obtidas com TPS iPlan ${ }^{\circledR}$ e EBT2, para os critérios de $3 \mathrm{~mm}$ e $3 \%$. As linhas brancas mostram as isodoses de $90 \%$ e de $50 \%$, respectivamente. 134

Figura 96: DVHs obtidos das distribuições de dose volumétrica das ferramentas dosimétricas: MAGIC-f, e TPS iPlan ${ }^{\circledR}$ e PENELOPE para um caso de melanoma. 136 
Figura 97: Histogramas de probabilidade de controle tumoral (TCP)-volume, para um caso de melanoma, para as ferramentas dosimétricas: MAGIC-f, TPS iPlan ${ }^{\circledR}$ e PENELOPE.

Figura 98: Curvas de TCP e DVH, para um caso de melanoma, para as ferramentas dosimétricas: MAGIC-f, TPS iPlan ${ }^{\circledR}$ e PENELOPE. 138

Figura 99: Distribuições de dose obtidas para uma técnica de radiocirurgia com 11 campos estáticos com as ferramentas dosimétricas: (a) MAGIC-f, (b) EBT2, (c) TPS iPlan ${ }^{\circledR}$ e (d) PENELOPE. 139

Figura 100: Mapa do índice $\gamma$ comparando as distribuições de dose obtidas com PENELOPE e TPS iPlan ${ }^{\circledR}$, para os critérios de $3 \mathrm{~mm}$ e $3 \%$. As linhas brancas mostram as isodoses de $90 \%$ e de $50 \%$, respectivamente. 140

Figura 101: Mapa do índice $\gamma$ comparando as distribuições de dose obtidas com MAGIC-f e EBT2, para os critérios de $3 \mathrm{~mm}$ e $3 \%$. As linhas brancas mostram as isodoses de $90 \%$ e de $50 \%$, respectivamente. 141

Figura 102: Mapa do índice $\gamma$ comparando as distribuições de dose obtidas com MAGIC-f e PENELOPE, para os critérios de $3 \mathrm{~mm} \mathrm{e} 3 \%$. As linhas brancas mostram as isodoses de $90 \%$ e de $50 \%$, respectivamente. 142

Figura 103: Mapa do índice $\gamma$ comparando as distribuições de dose obtidas com PENELOPE e EBT2, para os critérios de $3 \mathrm{~mm}$ e $3 \%$. As linhas brancas mostram as isodoses de $90 \%$ e de $50 \%$, respectivamente. 143

Figura 104: Mapa do índice $\gamma$ comparando as distribuições de dose obtidas com TPS iPlan ${ }^{\circledR}$ e EBT2, para os critérios de $3 \mathrm{~mm}$ e $3 \%$. As linhas brancas mostram as isodoses de $90 \%$ e de $50 \%$, respectivamente. 144

Figura 105: Mapa do índice $\gamma$ comparando s distribuições de dose obtidas com TPS iPlan ${ }^{\circledR}$ e EBT2, para os critérios de $3 \mathrm{~mm}$ e $3 \%$. As linhas brancas mostram as isodoses de $90 \%$ e de $50 \%$, respectivamente. 145

Figura 106: Curvas de DVH obtidas das distribuições de dose volumétrica das ferramentas dosimétricas: MAGIC-f, e TPS iPlan ${ }^{\circledR}$ e PENELOPE para um caso de neurinoma do acústico.

Figura 107: Histogramas de probabilidade de controle tumoral (TCP)-Volume, para um caso de neurinoma do acústico, para as ferramentas dosimétricas: MAGIC-f, TPS iPlan ${ }^{\circledR}$ e PENELOPE. 148

Figura 108: Histogramas de probabilidade de controle tumoral (TCP)-Volume e DVH, para um caso de neurinoma do acústico, para as ferramentas dosimétricas: MAGIC-f, TPS iPlan ${ }^{\circledR}$ e PENELOPE. 149 


\section{Índice}

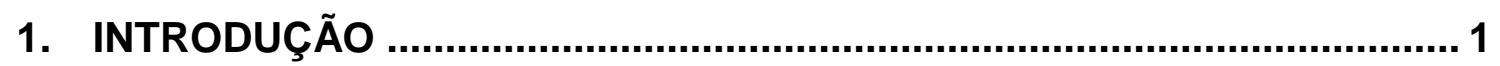

2. FUNDAMENTAÇÃO TEÓRICA …........................................................ 4

2.1. Dosimetria gel: MAGIC-f ........................................................... 7

2.1.1. Processos de polimerização ................................................. 9

2.1.2. Leitura do MAGIC- $f$ através de imagens por ressonância magnética 12

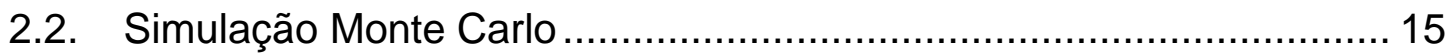

2.2.1. Código de simulação Monte Carlo PENELOPE.............................. 17

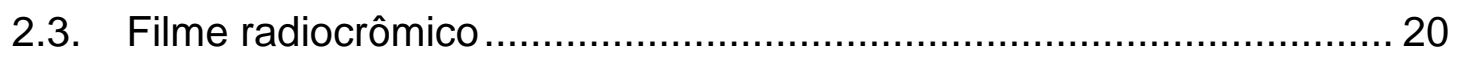

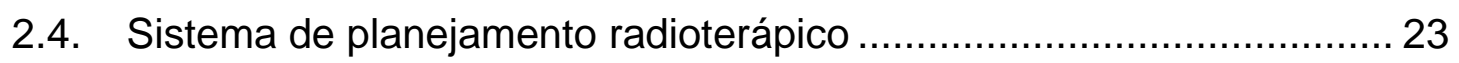

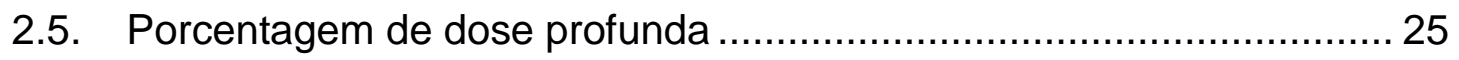

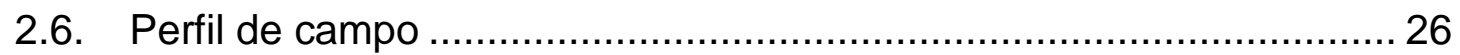

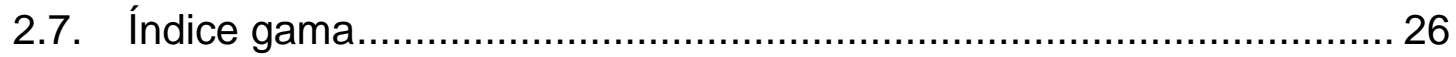

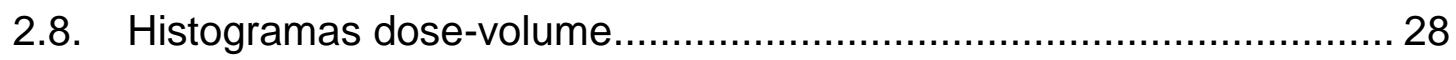

2.9. Probabilidade de controle tumoral................................................ 29

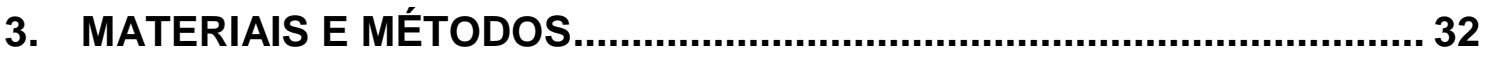

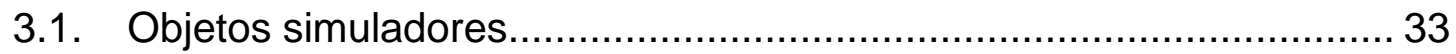

3.1.1. Objetos simuladores para medidas com MAGIC- $f$ gel ................. 33

3.1.2. Objetos simuladores para medidas com o filme radiocrômico EBT2 34

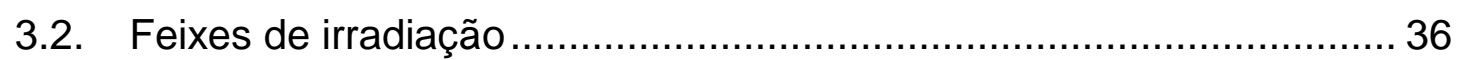

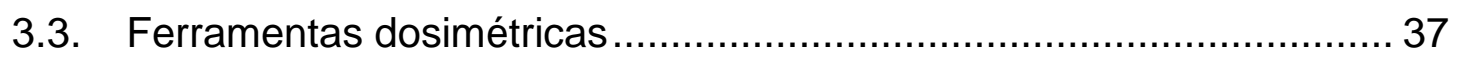

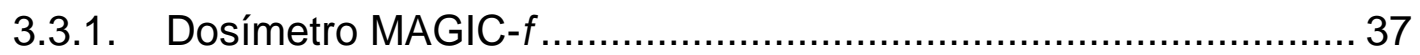

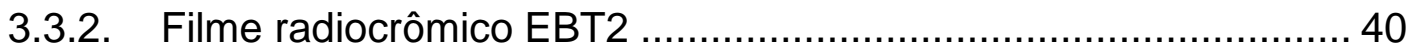

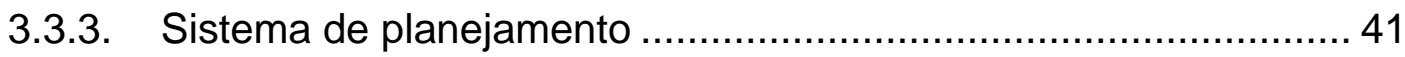

3.3.4. Código de simulação Monte Carlo PENELOPE............................ 41

3.4. Medidas para caracterização da resposta do MAGIC-f...................... 42

3.4.1. Dependência da resposta do MAGIC- $f$ com a dose.................... 42

3.4.2. Dependência da resposta do MAGIC- $f$ com a taxa de dose......... 43

3.4.3. Dependência de resposta do MAGIC- $f$ com tempo de leitura após a

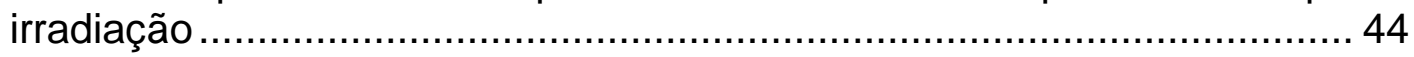

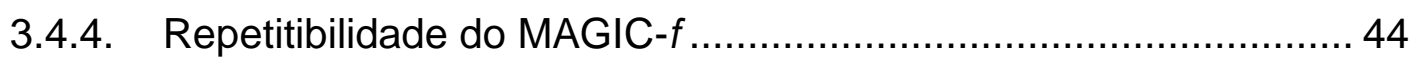

3.4.5. Porcentagem de dose profunda............................................... 44

3.5. Medidas para caracterização da resposta do filme radiocrômico EBT2 46

3.5.1. Dependência de resposta do filme ETB2 com a dose ................. 46 
3.5.2. Dependência de resposta do filme EBT2 com a taxa de dose ..... 47

3.5.3. Dependência de resposta do filme ETB2 com o tempo de leitura

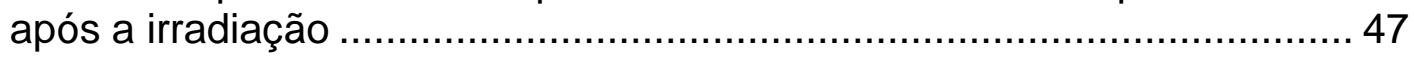

3.5.4. Porcentagem de dose profunda............................................. 47

3.6. Medidas para validação das ferramentas dosimétricas....................... 47

3.7. Irradiações conformacionais com campos pequenos ......................... 48

3.7.1. Irradiação conformacional coplanar …………......................... 49

3.7.2. Irradiação conformacional não coplanar ..................................... 50

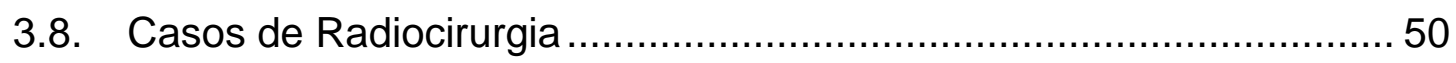

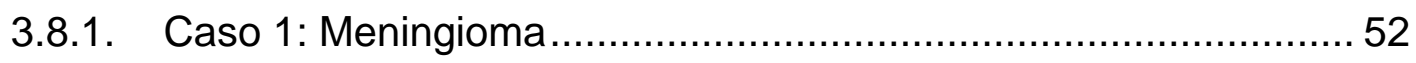

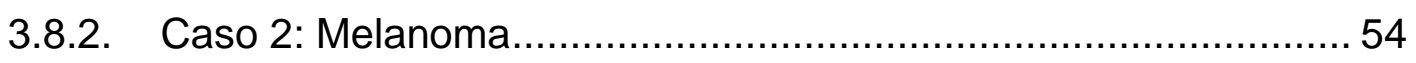

3.8.3. Caso 3: Neurinoma do acústico................................................. 56

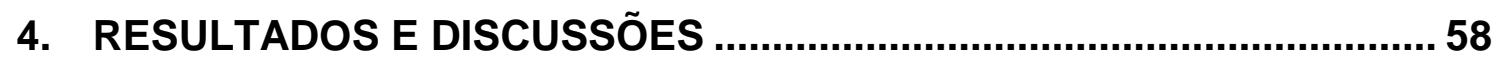

4.1. Medidas prévias realizadas antes da utilização do dosímetro MAGIC-f gel 58

4.1.1. Homogeneidade de campo com a bobina de cabeça................... 58

4.1.2. Simulação da composição do material MAGIC- $f$ gel...................... 62

4.2. Medidas para caracterização da resposta do MAGIC- $f$ gel ................. 64

4.2.1. Dependência de resposta do MAGIC- $f$ com a dose para feixes de

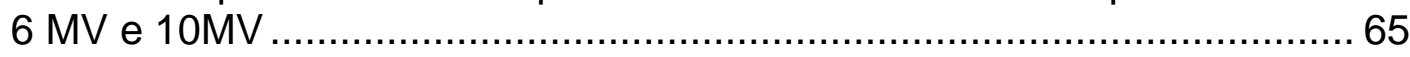

4.2.2. Dependência de resposta do MAGIC- $f$ com a taxa de dose ......... 66

4.2.3. Variação de dependência de resposta do MAGIC- $f$ com o tempo de

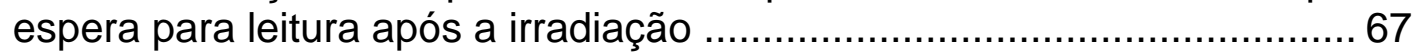

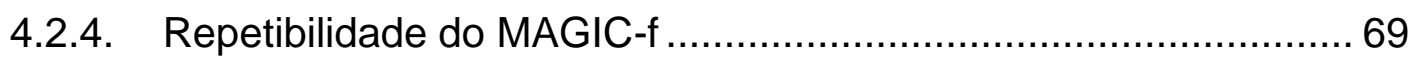

4.2.5. Curvas de porcentagem de dose profunda para $6 \mathrm{MV}$ e $10 \mathrm{MV}$... 70

4.3. Medidas para caracterização da resposta do filme radiocrômico EBT2 72

4.3.1. Dependência da resposta do filme ETB2 com a dose ................. 72

4.3.2. Dependência de resposta do filme ETB2 com a taxa de dose ..... 73

4.3.3. Variação de dependência do filme EBT2 com o tempo de leitura

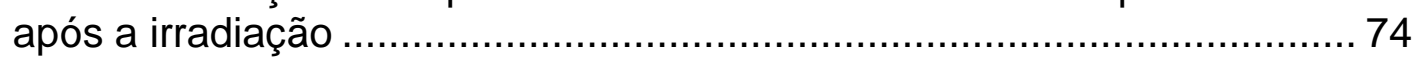

4.3.4. Porcentagem de dose profunda com o filme EBT2 …................. 76

4.4. Medidas para validação das ferramentas dosimétricas........................77

4.4.1. Porcentagem de dose profunda............................................. 79

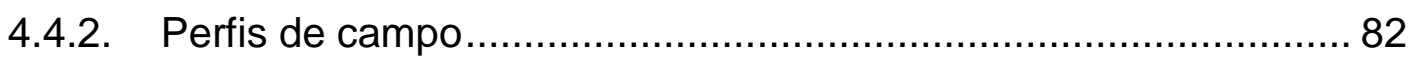

4.5. Irradiações conformacionais com campos pequenos ........................... 86

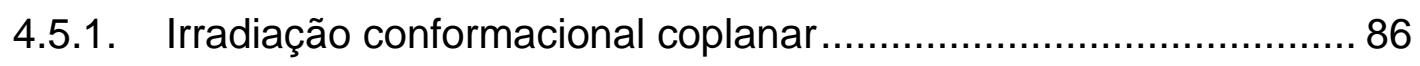

4.5.2. Irradiação conformacional não coplanar ..................................... 92 


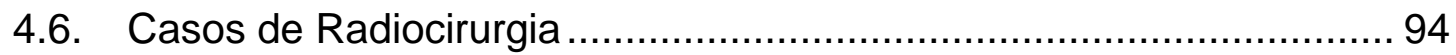

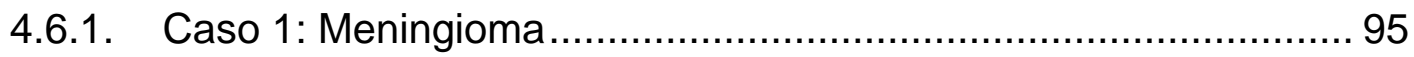

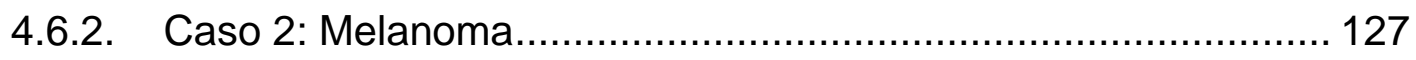

4.6.3. Caso3: Neurinoma do acústico............................................. 138

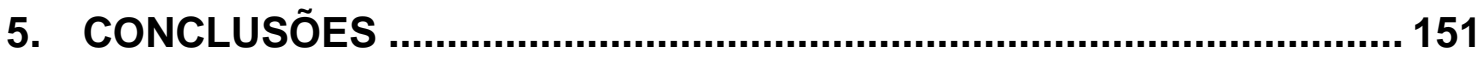

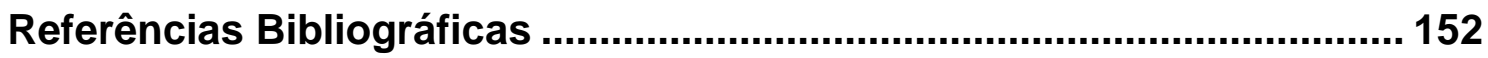

Anexo 


\section{Introdução}

Desde o início do ano 1950 a radiocirurgia é utilizada para tratar alguns tumores, benignos ou malignos, geralmente, intracranianos (AAPM, 1995; Mascarenhas et al, 2005). Essa técnica combina feixes estreitos de radiação ionizante com o uso de um acessório de posicionamento estereotáxico, visando conformar a dose no volume alvo e evitando que tecidos adjacentes recebam altas doses (Mazeron et al 2012; Clark et al, 2001).

A administração da dose de radiação nessa técnica pode ocorrer em uma aplicação com campos coplanares ou não-coplanares, (Audet et al, 2011; Pooter et al, 2006; Wang et al, 2005; Breen et al, 2004; Clark et al, 2001), em que a seleção, ou combinação, destes campos deve minimizar o gradiente de dose nas estruturas que se encontram ao redor do tumor.

Como a radiocirurgia utiliza altas doses com campos pequenos é necessário localizar o volume tumoral, que geralmente é de até $10 \mathrm{~cm}^{3}$, e a posição dos tecidos sadios adjacentes com acurácia superior à requerida em técnicas convencionais (Murthy et al, 2003). As técnicas de localização estereotáxica mais empregadas são: angiografia, tomografia computarizada (CT, da sigla em inglês Computer Tomography) e imagem por ressonância magnética nuclear (MRI, da sigla em inglês Magnetic Ressonance Image), com precisão de $\pm 1 \mathrm{~mm}$ na localização do tumor (AAPM, 1995).

Geralmente, nessa técnica são administradas doses entre 10 - 50 Gy, dependendo do tratamento. Conforme o ICRU (do inglês International Commission on Radiation Unists and Measurementes), a exatidão entre a dose prescrita e a administrada nos tratamentos em radioterapia deve estar dentro de $-5 \%$ e $+7 \%$ (ICRU, 1999).

Os aparelhos adequados para estes tratamentos consistem em Gamma Knifes, aceleradores lineares convencionais com colimadores suplementares para definir campos pequenos, o CyberKnife, além de novas técnicas, como a tomoterapia (Jiang et al, 2012; Jung et al, 2012; Sheehan et al, 2012; Hong et al 2011; Jim et al, 2008, Kim et al, 2008; Sheng et al, 2007; Yoon et al, 2007; Wang et al, 2005; Breen et al, 2004). 
Para verificação da distribuição de doses dentro e ao redor do tumor requer-se uma dosimetria apropriada para tratamentos de radiocirurgia. Dosímetros como câmaras de ionização, filmes, TLDs (do inglês thermoluminescent dosimeter), entre outros, têm sido empregados (Oldham et al, 2001; Ravindram et al, 2001; Guzman et al, 2007), embora esses dosímetros não reproduzam um mapa tridimensional (3D) de dose. Neste contexto, a dosimetria a base de géis poliméricos se apresenta como uma alternativa adequada para medidas de distribuições de dose em 3D, especificamente o MAGIC- $f$ gel devido a suas características de equivalência em água $\left(Z_{\text {eff }}\right.$ de 7,41$)$ e alta resolução espacial (melhor que 0,25 mm) comparada com outros dosímetros (Fernandes et al, 2008).

Outra ferramenta eficaz para o estudo das doses em tratamentos radioterápicos são as simulações computacionais, especificamente utilizando o método Monte Carlo (Yamamoto et al, 2007; De Vlamynck et al, 1999). Os códigos de simulação Monte Carlo mais utilizados em simulações radioterápicas são EGS4, MCNP4 e PENELOPE (Martinez-Rovira et al, 2012; Rodriguez et al, 2012; Kim et al, 2012; Ghassoun et al, 2011; Yamamoto et al, 2007; Pooter et al, 2006; De Vlamynck et al, 1999). A qualidade dos resultados fornecidos pelos diferentes códigos, está diretamente ligada com a exatidão do modelo de transporte implementado e de suas bibliotecas de dados associados à seção de choque das partículas transportadas (Verhaegen, 2002; Poon e Verhaegen, 2005). Dessa forma, o algoritmo misto de transporte de partículas carregadas, implementado pelo código PENELOPE (Sempau et al, 2003), levou à sua intensa utilização em radioterapia (Koivunoro et al, 2012; Sempau et al 2011; Ramirez et al 2011; Brualla et al, 2009; Cintra, Yoriyaz, 2009; Carvajal et al, 2009; Górka et al 2009; Badal et al, 2008; Mesbahi et al, 2006; Roet et al, 2006; Rodríguez et al, 2005; Ye, Naqvi, 2005; Moskvin et al, 2002).

O presente trabalho tem como finalidade a determinação de distribuições de dose de casos selecionados de radiocirurgia, através de uma dosimetria a base de gel utilizando MAGIC- $f$ e por simulação Monte Carlo com o código PENELOPE. Três casos de tratamentos com radiocirurgia estereotáxica foram simulados com o sistema de planejamento radioterápico iPlan®, a partir de dados clínicos de irradiação e um objeto simulador de cabeça. Com as 
mesmas condições de irradiação foram obtidas distribuições de dose utilizando o código de simulação PENELOPE e, experimentalmente, com dosímetro polimérico MAGIC- $f$ gel. As distribuições de doses obtidas foram avaliadas em 2D e 3D nos volumes alvo e nas regiões adjacentes a estes. Filmes radiocrômicos também foram empregados para verificações $2 \mathrm{D}$ em planos centrais dos tratamentos.

Assim, esta tese apresenta, no Capítulo II, a abordagem dos aspectos teóricos ligados à radiocirurgia extereotáxica, dosimetria gel polimérica, simulação Monte Carlo com o código PENELOPE e filme radiocrômico e técnicas de avaliação de distribuições de dose, como o índice gama, histogramas dose-volume e probabilidade de controle tumoral.

Os materiais e métodos empregados no desenvolvimento do trabalho são descritos no Capítulo III. Nesse capítulo, são explicitadas as metodologias de montagem dos experimentos para obtenção de parâmetros dosimétricos para campos pequenos, obtidos através das ferramentas dosimétricas utilizadas. Nesse capítulo é descrito, também, o procedimento para a obtenção das distribuições de doses para os casos de radiocirurgia estereotáxica estudados através de um objeto simulador de cabeça, e o desenvolvimento de uma metodologia para a verificação e/ou comparação dos tratamentos simulados empregando quatro ferramentas dosimétricas.

Os dados obtidos experimentalmente e por simulação Monte Carlo são apresentados, analisados, e discutidos no Capítulo IV.

No Capítulo V são apresentadas as conclusões do trabalho realizado, abordando os aspectos mais relevantes sobre as ferramentas dosimétricas utilizadas para a comparação dos tratamentos com a técnica de radiocirurgia estereotáxica. 


\section{Fundamentação teórica}

\section{Radiocirurgia esterotáxica}

Radiocirurgia estereotáxica (SRS, da sigla em inglês Stereotactic RadioSurgery) e a radioterapia estereotáxica (SRT, das sigla em inglês Stereotactic RadioTherapy) são técnicas de irradiação que utilizam um acessório estereotáxico e feixes estreitos de radiação para tratar uma lesão com uma única dose em SRS, e com fracionamento de dose em SRT.

A modalidade de SRS foi desenvolvida pelo neurocirurgião Lars Leksell no final do ano 1940 (AAPM, 1995), sendo uma modalidade especial da radioterapia caracterizada por administrar altas doses de radiação, com feixes estreitos, em uma só aplicação, para tratar pequenos volumes tumorais intercranianos (Szeifert et al, 2007). A primeira lesão craniana tratada com essa técnica foi à neuralgia do trigêmeo, realizada em 1951, utilizando raios $X$ (AAPM, 1995), como mostrado na Figura 1.

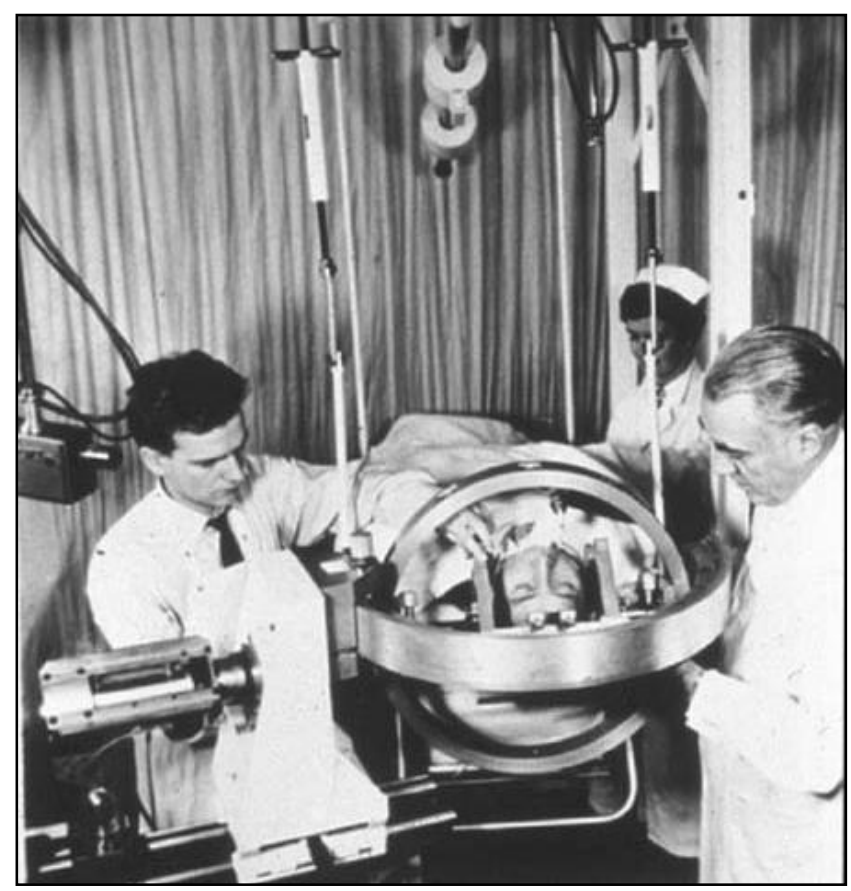

Figura 1: Lars Leksell e Borje Larssson preparando ao paciente para o tratamento com radiocirurgia em 1958. (Chin et al, 2008).

A técnica de SRS é comumente utilizada para tratar tumores cerebrais benignos ou malignos, como: neurinoma do acústico, melanoma, meningioma 
entre outros tumores (Sharma, 2012; Gibney, 2012;Finger 2009) . Esta técnica também é utilizada para o tratamento de desordens funcionais como, por exemplo, malformações arteriovenosas (Hayhurst et al, 2012; Blamek et al, 2011).

Para a localização de uma lesão tumoral intercraniana com esta técnica faz uso de um acessório estereotáxico que é fixado no crânio do paciente, como mostrado na Figura 2. A posição do acessório é localizada através de imagens de tomografia computadorizada (CT, das siglas em inglês Computer Tomography), imagem por ressonância magnética nuclear (MRI, das siglas em inglês Magnetic Resonance Image) e/ou angiografia (do grego, angeion, vaso, e graphein, descrever) que permitem determinar a localização do alvo com referência nos três planos perpendiculares intersecantes: sagital, coronal e axial ou transversal (Chin et al, 2008; Slotman et al, 2006; AAPM, 1995). Com angiografia, pode-se visualizar os vasos sanguíneos com a introdução de um meio de contraste radiopaco, e por meio de imagens de CT ou MRI pode-se visualizar as estruturas cranianas, diferenciando todas as estruturas anatômicas existentes no cérebro do paciente em três dimensões.

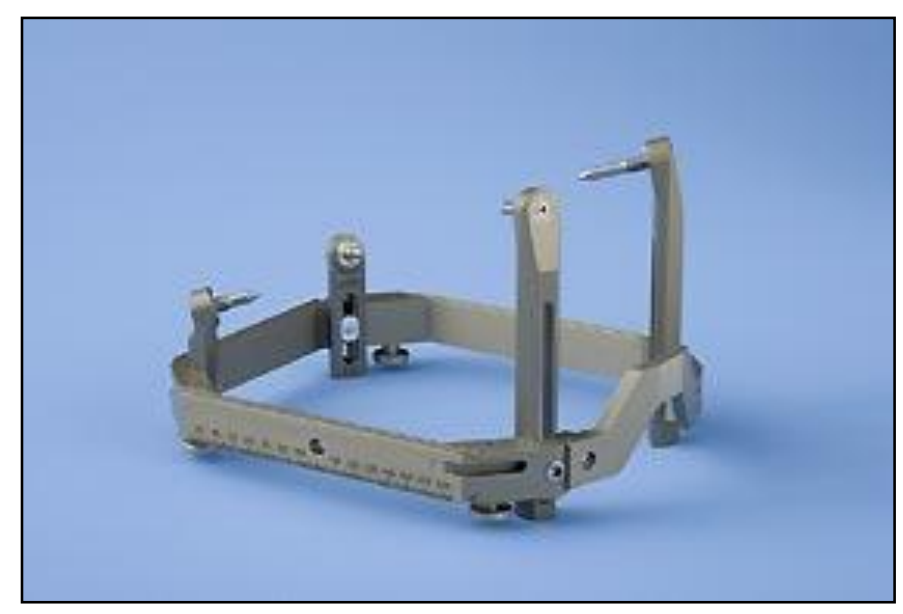

Figura 2: Acessório estereotáxico, utilizado na técnica de radiocirurgia ou radioterapia estereotáxia para tratamentos de tumores intercranianos (http://www.brainlab.com).

As imagens obtidas do crânio dos pacientes, por alguma das técnicas de imagens mencionadas, permitem a localização e descrição precisa do volume alvo do tratamento. Para tanto, essas imagens são transferidas para o sistema de planejamento (TPS, do inglês Treatment Planning System), no qual será, 
ainda, simulada a distribuição das doses de radiação que o volume a ser tratado receberá, bem como as estruturas sadias adjacentes e os órgãos de risco do tratamento. Se essas estruturas receberem doses superiores às restrições de dose do tratamento (limites permitidos) pode-se produzir toxicidade para os tecidos sadios e, consequentemente, prejudicar a eficácia do tratamento (Roos et al, 2012).

Ao longo do tempo, aparelhos adequados para tratamentos radioterápicos foram desenvolvidos especificamente para as técnicas de SRS ou SRT. O Gamma Knife, desenvolvido ao redor do ano de 1960 por Leksell e Larsson, estava constituído de 179 fontes de ${ }^{60} \mathrm{Co}$, posicionados dentro de um arranjo semi-esférico capaz de focalizar a dose em um dado volume, devido a interseção do isocentro de todas as fontes. Em 1987, Lunsford e coloboradores desenvolveram um novo Gamma Knife com 201 fontes de ${ }^{60} \mathrm{Co}$ e atualmente existe uma nova geração dessa unidade com colimação variável, múltiplos isocentros, aprimorando a acurácia e melhorando a capacidade de integração das imagens (Mascarenhas et al, 2005).

Uma alternativa para a técnica SRS é o uso de aceleradores lineares, proposta por Betti em 1984 e Colombo em 1985 em que modificaram os aceleradores lineares utilizando colimação variável, eliminando os feixes indesejados e pesando diferencialmente os isocentros, obtendo distribuições de dose similares as obtidas pelo Gamma Knife (Rowe et al, 2012; Shim et al 2010; Colombo et al 1985; Betti et al, 1984). Atualmente os aceleradores lineares convencionais com colimadores suplementares são os aparelhos mais utilizados para definir campos pequenos e são utilizados para a SRS.

Outros equipamentos para radiocirurgia têm sido propostos, tais como o CyberKnife, que é baseado em um pequeno acelerador linear com um braço robótico com a capacidade para definir campos pequenos (Ho et al, 2012; Vlachopolou et al, 2011).

A acurácia dessa técnica não está relacionada somente ao acessório estereotáxico e à unidade de irradiação, mas, também, ao conhecimento neurológico e da resposta do tumor à radiação. Assim, as incertezas para o posicionamento e localização dos volumes do tratamento são aceitas em até $1 \mathrm{~mm}$ (Wang et al, 2010; Jim et al, 2008; AAPM , 1995). Já as incertezas na deposição de dose podem estar relacionadas aos processos de 
posicionamento e localização do volume alvo e às limitações do aparelho de irradiação na administração da dose. Para a verificação da dose ou distribuição de dose gerada pelos diferentes aparelhos de radiocirurgia é necessária uma dosimetria capaz de realizar medidas adequadas para esta técnica não convencional. Assim, neste trabalho serão estudados alguns casos de SRS, para o tratamento de neoplasias cranianas, que serão avaliadas com dosímetros como: MAGIC- $f$ gel e o filme radiocrômico, assim, também, como duas ferramentas dosimétricas como: o código de simulação PENELOPE e o TPS.

\subsection{Dosimetria gel: MAGIC-f}

Dosímetros poliméricos foram propostos inicialmente em 1954 (Alexander et al, 1954) avaliando os efeitos da radiação ionizante sobre polimetracrilato, seguida de outras pesquisas sobre poliacrilamina (Boni et al, 1961). A partir do ano de 1991, pesquisadores mostraram por ressonância magnética nuclear (NMR, das siglas em inglês Nuclear Magnetic Resonance) que o tempo de relaxação longitudinal dos materiais dos géis poliméricos aumentava proporcionalmente com a dose absorvida (Kennan et al, 1992; Audet et al, 1991).

Em torno de 1992 foi proposta una nova formulação de um gel polimérico, chamado BANANA (da sigla em inglês Bis Acrylamide Nitrous oxide ANd Agarose) (Maryanski et al, 1993), que foi modificado e chamado BANG (da sigla em inglês Bis Acrylamide Nitrous oxide Gel) (Maryanski et al, 1993) e, por último, PAG (da sigla em inglês Polymer Acrylamide Gelatine) (Baldock et al, 1998).

Os compostos monoméricos dos dosímetros BANG e PAG, imersos em uma matriz gelatinosa aquosa, sofrem uma reação polimérica após serem submetidos à irradiação, resultando em uma matriz de gel polimérica. Esta formação rádio-induzida produz mudanças nas propriedades de relaxação de NMR, mudanças que podem ser relacionadas com a deposição de dose absorvida. Apesar desses dosímetros poliméricos terem a vantagem de estabilidade no registro de dose, quando comparados com outros dosímetros a base de géis, eles apresentavam uma limitação no momento da sua 
manufatura, pois eram suscetíveis ao oxigênio atmosférico, que inibe o processo de polimerização. Devido à supressão da polimerização pelo oxigênio nos dosímetros BANG e PAG, durante sua manufatura o oxigênio era retirado através do borbulhamento do nitrogênio na solução do gel, que era protegido em uma caixa plástica, que continha nitrogênio. Assim a preparação de estes dosímetros não se tornou de uso prático.

Em 2001, um significante desenvolvimento na dosimetria polimérica ocorreu quando Fong propôs o gel dosimétrico MAGIC (da sigla em inglês Methacrylic and Ascorbic acid in Gelatin Initiated by Copper) (Fong et al, 2001), formado por uma combinação de materiais a base de metacrilato, ácido ascórbico e sal de cobre; com esta combinação a supressão do oxigênio é dada pelo complexo metalo-orgânico (ácido ascórbico), que é ligada a este complexo removendo-o, e, assim, permitindo que esses géis poliméricos possam ser preparados em condições atmosféricas normais (Zhu et al, 2010; Gustavsson et al, 2003; De Deene et al, 2002; Baldock et al, 2001).

Uma desvantagem dessa formulação proposta do MAGIC gel era a perda de resposta em temperaturas maiores que $25^{\circ} \mathrm{C}$. Assim, Fernandes incorporou formaldeído à solução do MAGIC, aumentando seu ponto de fusão até $69^{\circ} \mathrm{C}$ (Fernandes et al, 2008), permitindo o uso deste dosímetro em locais com altas temperaturas ambientais durante quase todo ano. Desta forma, MAGIC com formaldeído (MAGIC-f), com $Z_{\text {eff }}$ de 7,41 (Fernandes et al, 2008), tem sido estudado para várias aplicações na radioterapia (Pavoni, et al 2012, Alva et al, 2010; Schwarche et al, 2010; Pianoschi et al 2010; Alva et al, 2009; Pianoschi et al 2009; Marques et al, 2009).

O dosímetro MAGIC-f gel com leitura por ressonância magnética nuclear apresenta características como alta resolução espacial e equivalência de tecido com a água. Além disso, sua maior vantagem em comparação aos dosímetros convencionais em radioterapia é a possibilidade de leitura em três dimensões, que permite uma dosimetria volumétrica do alvo irradiado, característica sem equivalente em outros dosímetros convencionais. 


\subsubsection{Processos de polimerização}

MAGIC- $f$ gel é composto de monômeros dispersos em uma matriz gelatinosa com aproximadamente $90 \%$ da água em sua constituição (De Denee, 2004a). Se uma amostra de gel polimérico é submetida à radiação ionizante se produzirá dissociação das moléculas de água em vários radicais livres e íons, processo que é conhecido como a radiólise da água.

Essas ionizações são distribuídas heterogeneamente ao longo do caminho da radiação, formando grupos de espécies, chamados de spurs, que variam de tamanho dependendo da energia depositada pelo elétron secundário (De Denee, 2004b). A equação 1 mostra de forma esquemática o estágio físico de ionizações produzidas no gel,:

$$
\mathrm{H}_{2} \mathrm{O} \underset{\text { Radiação }}{\longrightarrow} \mathrm{H}_{2} \mathrm{O}^{+}+e^{-} .
$$

Em um segundo estágio, denominado estágio físico-químico, as espécies formadas, como $\mathrm{H}_{2} \mathrm{O}^{+}$, reagem com a moléculas de água ao redor do spurs produzindo um produto molecular $\mathrm{H}_{3} \mathrm{O}^{+}$e o radical $\mathrm{OH}^{*}$,como mostrado na equação 2:

$$
\mathrm{H}_{2} \mathrm{O}^{+}+\mathrm{H}_{2} \mathrm{O} \longrightarrow \mathrm{H}_{3} \mathrm{O}^{+}+\mathrm{OH}^{-} .
$$

O elétron liberado, mostrado na equação 1 , reage também com a molécula de água transformando-se em um elétron hidratado, como apresentado na equação 3 :

$$
e^{-}+\mathrm{H}_{2} \mathrm{O} \longrightarrow e_{\text {aquoso }}^{-}
$$

No estágio químico as espécies primárias se difundem e regem com as moléculas de água e entre elas mesmas, produzindo espécies secundárias muito reativas como as mostradas nas equações 4 e 5 :

$$
\begin{aligned}
& \mathrm{H}_{3} \mathrm{O}^{+}+e_{\text {aquoso }}^{-}+\longrightarrow \mathrm{H}^{+}+\mathrm{H}_{2} \mathrm{O} \\
& e_{\text {aquoso }}^{-}+\mathrm{H}_{2} \mathrm{O}^{+} \longrightarrow \mathrm{OH}^{-}+\mathrm{H}^{-}
\end{aligned}
$$


Existem aproximadamente 40 possíveis formações de espécies (Ross et al, 1989), mas os produtos ou as espécies formadas na radiólise e que interagem com os monômeros do MAGIC- $f$ são o elétron hidratado, $e_{\text {aquoso }}^{-}$, hidroxil, $\mathrm{OH}^{*}$, e o íon $\mathrm{H}_{3} \mathrm{O}^{+}$.

A decomposição das moléculas do gel, quando interagem com a radiação, pode ser simplificada em uma reação, mostrada na, equação 6 , em que a taxa de reação, $k_{d}$, é proporcional à dose absorvida:

$$
\mathrm{H}_{2} \mathrm{O} \stackrel{k_{d}}{\longrightarrow} 2 R^{*} .
$$

Os radicais iniciam a polimerização dos monômeros do gel por ligação de um elétron da banda dupla do monômero como o radical, formando assim um radical chamado oligomérico (do grego oligo $=$ pouco, mero $=$ partes $) .0$ processo de essa iniciação de polimerização pode ser descrita como na equação 7 :

$$
R^{*}+M_{n} \stackrel{k 1(n)}{\longrightarrow} R M_{n}^{*}
$$

Inicialmente, não se evidencia a polimerização no gel quando $n=1, R M_{1}^{*}$. Entretanto, quando este radical reage com outro monômero, formando um radical oligomérico de dois monômeros $\mathrm{R} M_{2}^{*}$, que por sua vez reagirá com outro monômero formando um radical oligomérico de três monômeros $\mathrm{R} M_{3}^{*}$, e assim sucessivamente, formando uma cadeia de monômeros em forma de um radical polimérico (do grego poli=vários, mero $=$ partes), como mostrado na equação 8 , o crescimento dessa cadeia de polimerização pode terminar pela combinação de dois radicais, formando uma molécula iniciadora estável, I, como é mostrado nas equações 9,10 e 11, que depende do número de monômeros presentes na cadeia polimérica.

$$
\begin{gathered}
R M_{n}^{*}+M_{n} \stackrel{k 1(n)}{\longrightarrow} R M_{n+m}^{*} . \\
R^{*}+R^{*} \stackrel{\text { Combinação }}{\longrightarrow} R R=I \\
R^{*}+R I \stackrel{\text { Combinação }}{\longrightarrow} I+M_{n} \\
R M_{n}^{*}+R M_{m}^{*} \stackrel{\text { Combinação }}{\longrightarrow} I+M_{n+m}
\end{gathered}
$$


A cadeia polimérica pode terminar o crescimento por transferência do grupo radical para outra molécula do gel, iniciando, assim, outra cadeia polimérica ou para uma molécula de gelatina (De Denee, 2006a, 2006b). Ainda, no caso da existência oxigênio no gel, os radicais formados se ligam ao oxigênio formando peróxidos, que se ligam rapidamente a outros radicais terminando o crescimento da cadeia de polimerização (De Denne, 2004a).

A Figura 3 mostra a polimerização de uma amostra do MAGIC- $f$ gel após de ser irradiada com um feixe de fótons de um acelerador de $6 \mathrm{MV}$.

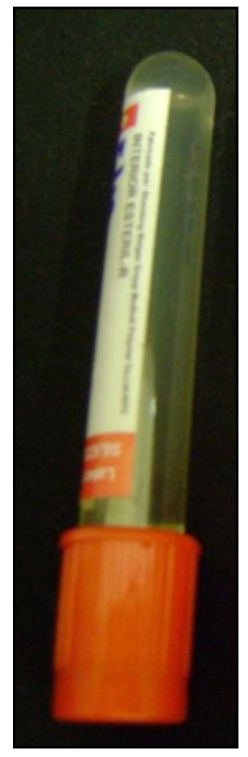

(a)

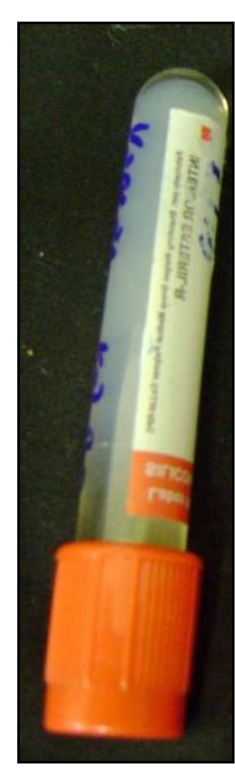

(b)

Figura 3: Dosímetro polimérico MAGIC-f gel: (a) amostra não irradiada e (b) amostra irradiada com feixe de fótons de $6 \mathrm{MV}$.

Na Figura 3 pode-se observar a mudança da coloração do gel após a amostra ser irradiada. Antes da irradiação a amostra possui um tom amarelo muito suave e após a irradiação apresenta-se opaca, com uma tonalidade branca, que evidencia a presença da polimerização causada pela radiação ionizante. 


\subsubsection{Leitura do MAGIC-f através de imagens por ressonância magnética}

A leitura dos dosímetros a base de géis poliméricos está relacionada com os componentes monômeros do gel e com sua polimerização (Crescenti et al, 2007; Mariani et al, 2007; Luci et al, 2007; Hill B et al, 2005). A polimerização induz mudanças nas propriedades de relaxação dos prótons do gel que podem ser quantificadas por técnicas como tomografia ótica (Gore et al, 1996), CT (Hilts et al, 2000) e por MRI (Baras et al, 2002), sendo esta última a técnica utilizada no presente trabalho.

As MRI com técnicas tomográficas, como utilizadas em medicina, produzem imagens anatômicas no plano axial, coronal e sagital que permitem a reconstrução de imagens em 3D, melhorando as possibilidades de visualização e interpretação diagnóstica e a delineação do volume alvo na radioterapia. A vantagem sobre as imagens de CT é que a MRI é uma técnica que não utiliza radiação ionizante para a aquisição das imagens, sendo cada vez mais utilizada na rotina clínica (Bol et al, 2012; Kang et al 2011; Saconn et al, 2010; Baert et al, 2007; Landini et al, 2005; Canet et al, 1991; Smith, Ranallo, 1989; Valk et al, 1985).

Se um corpo é localizado em um tomógrafo de ressonância magnética, este será submetido a um campo magnético estático intenso, fazendo com que as orientações dos momentos magnéticos dos prótons do corpo apontem preferencialmente na direção do campo magnético. Esta cooperação de um grande números de prótons crie um momento magnético total, ou vetor de magnetização, que pode produzir sinais detectáveis, após a aplicação de ondas de radiofrequência pulsadas com a mesma frequência do momento magnético total, provocando ressonância.

Essa onda de radiofrequência também provoca excitação e mudança nos estados de energia dos prótons, provocando uma mudança na direção do vetor de magnetização. Quando as ondas de radiofrequências são interrompidas, os prótons emitem a energia recebida em forma de fótons até retornar ao seu estado inicial. O tempo para que o vetor de magnetização recupere $63 \%$ do seu valor inicial, é chamado tempo de relaxação longitudinal, ou spin-rede, T1, que é uma propriedade utilizada para gerar contraste em MRI. 
Quando um pulso (de 90ㅡㄴ por exemplo) é aplicado ao vetor de magnetização defletindo-o e fazendo-o girar ao redor do seu eixo com a frequência de ressonância ou Larmor, pequenas alterações no valor do campo magnético local são provocadas devido a interações com a vizinhança. Essas interações fazem com que os componentes do vetor de magnetização adquiram frequências ligeiramente diferentes, provocando uma perda de coerência de fase dos componentes do vetor de magnetização, diminuindo o mesmo. O tempo necessário para que a magnetização seja igual a $37 \%$ do valor inicial é chamado de tempo de relaxação transversal, ou spin-spin, T2 (Baert et al, 2007). A equação 12 expressa a dependência do sinal de ressonância magnética.

$$
S(t) \propto e^{i w t} e^{\frac{-t}{T_{2}}}
$$

sendo que $S(t)$ é o sinal de ressonância magnética nuclear, $t$ é o tempo de repetição dos pulsos e $\mathrm{T}_{2}$ é o tempo de relaxação transversal.

O sinal emitido pela defasagem do vetor de magnetização, cujas componentes se orientam em várias direções em um padrão oscilatório, induz um sinal na bobina. Assim, devido aos processos de relaxação, a intensidade da magnetização diminui ao longo do tempo, produzindo um sinal que é chamado de FID (do inglês, Free Induction Decay). A Figura 4 esquematiza o decaimento do sinal de ressonância magnética. 


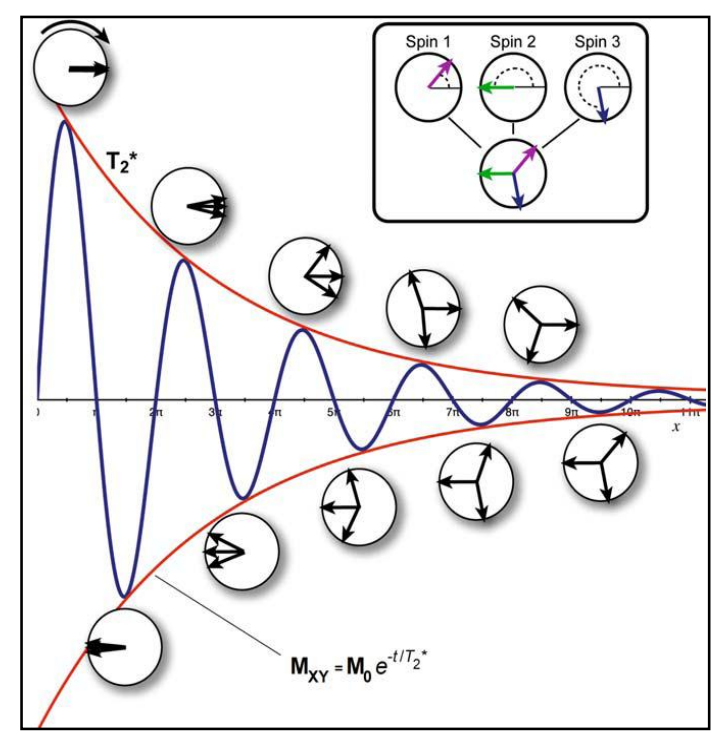

Figura 4: Decaimento do sinal de ressonância magnética nuclear, sendo a amplitude máxima quando todos os spins estão em fase e diminuindo conforme os spins encontram-se defasados (Baert et al, 2007)

A amplitude do sinal de ressonância magnética induzida deveria ser determinada somente pela taxa de relaxação e não deveria ser influenciada pela defasagem dos prótons devido às inhomogeneidades do campo magnético estático, não sendo possível eliminar totalmente essa inhomogeneidade. Sequências de pulsos spin-echo (SE) são empregadas para minimizar essa influência. A Figura 5 esquematiza esta sequência.

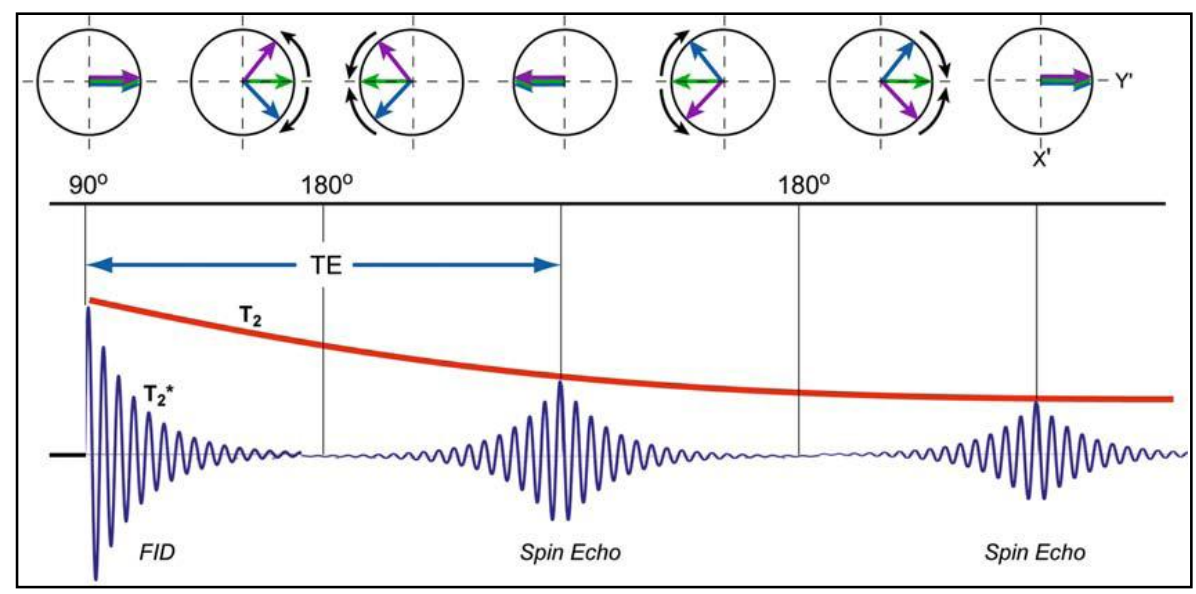

Figura 5: Sequencia de pulso de $90^{\circ}$ e $180^{\circ}$ são aplicados ao vetor de magnetização, produzindo um grande sinal, o "spin echo" (Baert et al, 2007). 


\subsection{Simulação Monte Carlo}

O método Monte Carlo ( $\mathrm{MC}$ ) é utilizado para resolver problemas complexos de física e matemática, através da amostragem de números aleatórios e métodos estatísticos (Yamamoto et al, 2007; Sheikh-Bagheri and Rogers 2002; Rubinstein, 1981). MC utiliza um modelo estocástico, que representa o problema de interesse, e um gerador de números aleatórios de alta qualidade para amostrar a função densidade de probabilidade, que delineia o processo físico do fenômeno observado. Esta função de densidade é definida no modelo e o resultado da simulação dependente tanto dessa função densidade de probabilidade quanto da qualidade de sua amostragem (Yoriyaz, 2009).

Em termos do transporte da radiação por simulação $M C$, o modelo estocástico pode ser entendido como um conjunto de histórias (trajetórias) de partículas, com uma sequência de eventos de interação para cada uma delas, simulando quando uma partícula muda sua direção, e ocasionalmente perde energia, e produz partículas secundárias. Para simular a história de uma partícula é necessário um modelo de interação, com as secções de choque para os mecanismos de interação considerados. As seções de choque caracterizam a trajetória da partícula, o caminho percorrido entre eventos de interação sucessivos, o modo de interação, a perda de energia e a deflexão angular para cada evento em particular (Rogers et al, 2006; Blinder, Heermann, 1988).

A Figura 6 mostra um esquema da simulação do transporte de uma partícula que atravessa três regiões. A história da partícula inicia-se no vácuo e, para cada interação da partícula, associam-se variáveis como energia, direção e posição. Ao cruzar uma interface o código de simulação recalcula as variáveis dessa partícula nesse novo meio para dar continuidade ao transporte. 


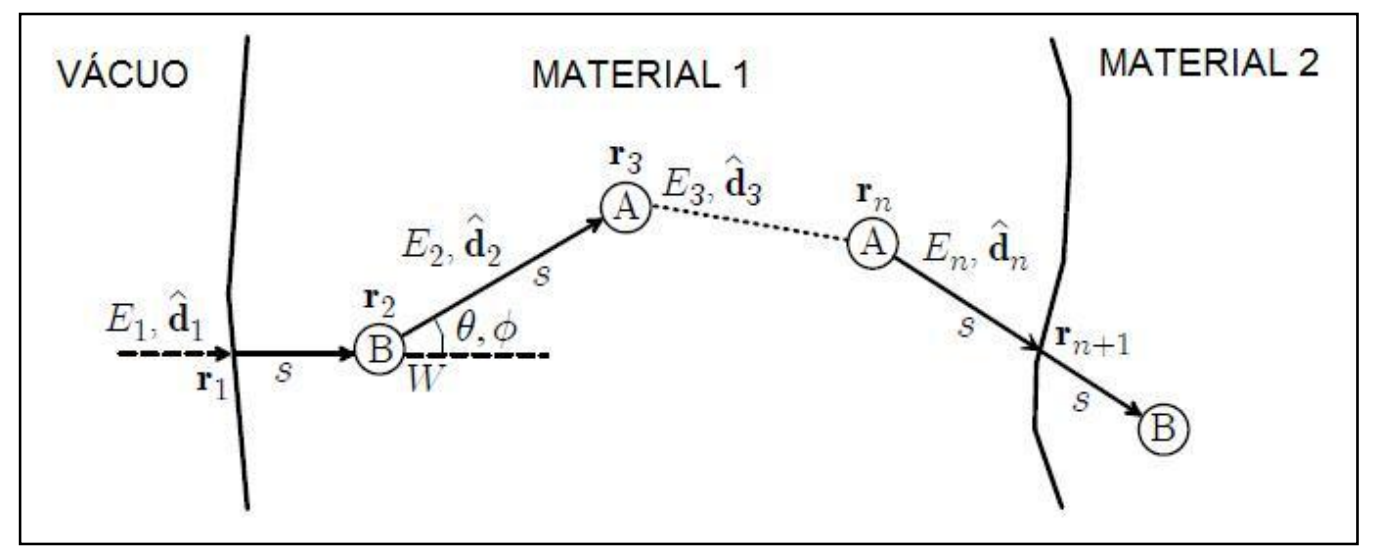

Figura 6: Esquema da trajetória de uma partícula sendo transportada em diferentes meios. (Salvat et al, 2009).

Ao longo do tempo, o método $M C$ tem sido utilizado nas áreas da física médica relacionadas ao diagnóstico e ao tratamento de câncer com radiação ionizante. Este método é uma ferramenta fundamental para avaliar, estudar e estimar grandezas dosimétricas como, por exemplo, a dose absorvida. Devido ao aumento do uso da simulação por método MC, códigos de simulação para aplicações gerais e específicas para cada área surgiram como ferramentas dosimétricas. Na radioterapia, por exemplo, os códigos EGS4, MNCP-4C, GEANT4, PENELOPE estão entre os mais utilizados (Koivunoro et al, 2012; Sempau et al 2011; Ramirez et al 2011; Yamamoto et al, 2007; Pooter et al, 2006; De Vlamynck et al, 1999).

Para utilização em aplicações em medicina e Física Médica, os códigos de simulação baseados em MC são comparados e validados por dosímetros de referência em cada uma dessas áreas de aplicação. A qualidade dos resultados fornecidos pelos diferentes códigos está diretamente ligada com a exatidão do modelo de transporte implementado e pelas bibliotecas que contêm os dados associados à seção de choque das partículas transportadas (Poon, Verhaegen, 2005; Verhaegen, 2002). A acurácia do algoritmo misto de transporte de partículas carregadas, implementado pelo PENELOPE, com simulação condensada e/ou detalhada de eventos de interação fortes de partículas carregadas (Sempau et al, 2003), levou à sua intensa utilização em radioterapia (Koivunoro et al, 2012; Sempau et al 2011; Ramirez et al 2011; Brualla et al, 2009; Cintra, Yoriyaz, 2009; Carvajal et al, 2009; Górka et al 2009; 
Mesbahi et al, 2006; Roet et al, 2006; Rodríguez et al, 2005; Ye, Naqvi, 2005; Moskvin et al, 2002).

Devido ao seu algoritmo de transporte, sua versátil forma de construção da geometria e fácil manuseio para definição dos parâmetros iniciais da simulação, o código de simulação MC PENELOPE foi escolhido como uma das ferramentas dosimétricas utilizadas nesse trabalho.

\subsubsection{Código de simulação Monte Carlo PENELOPE}

PENELOPE (da sigla em inglês PENetration and Energy LOss of Positron and Electrons) é um pacote utilizado para simular o transporte de elétrons, pósitrons e fótons considerando interações dos fótons e de partículas carregadas (como efeito fotoelétrico, espalhamento Rayleigh, espalhamento Compton, produção e aniquilação de pares, colisões elásticas e inelásticas), que são simuladas em geometrias complexas e materiais arbitrários.

No pacote PENELOPE encontram-se sub-rotinas escritas em FORTRAN distribuídas em vários códigos fonte (abertos), aplicativos, uma base de dados com características de diversos materiais, além de exemplos de aplicações. As sub-rotinas FORTRAN são organizadas em quatro arquivos básicos: PENELOPE.f, PENGEOM.f, PENVARED.f e TIMER.f.

PENELOPE.f, contém as sub-rotinas de espalhamento e absorção das partículas simuladas, de geração e armazenamento das partículas primárias e secundárias e de gerenciamento do transporte das partículas e da simulação como um todo.

PENGEOM.f, define as estruturas, ou geometrias, a serem simuladas, que podem estar constituídas de vários corpos homogêneos, definidos por um material especificado e também por seus limites no espaço. As superfícies limitantes dos corpos da geometria são descritas por meio de funções quadráticas, como mostrado na equação 13. Por meio dessas funções, superfícies como planos, pares de planos, esferas, cilindros, cones, elipsoides, parábolas, hiperboloides podem ser definidas. 


$$
\begin{gathered}
\mathrm{F}(\mathrm{x}, \mathrm{y}, \mathrm{z})=\mathrm{A}_{\mathrm{xx}} x^{2}+\mathrm{A}_{\mathrm{xy}} x y+\mathrm{A}_{\mathrm{xz}} x z+\mathrm{A}_{\mathrm{yy}} y^{2}+\mathrm{A}_{\mathrm{yz}} \mathrm{yz}+\mathrm{A}_{\mathrm{zz}} \mathrm{z}^{2}+\mathrm{A}_{\mathrm{x}} \mathrm{x} \\
+\mathrm{A}_{\mathrm{y}} \mathrm{y}+\mathrm{A}_{\mathrm{z}} \mathrm{z}+\mathrm{A}_{\mathrm{o}}=0
\end{gathered}
$$

Para cada corpo definido no arquivo de geometria de uma dada simulação, deve ser definido um índice de material, correspondendo ao material que será o constituinte do corpo, tendo uma concordância entre o arquivo de geometria e o arquivo de materiais. No arquivo de materiais encontram-se, em forma de tabelas, os dados de interação da radiação com o material sendo utilizado, como coeficientes de interação para elétrons, fótons em energias desde $1 \mathrm{eV}$ até $1 \mathrm{GeV}$. Um arquivo de material é criado por meio das sub-rotinas dos códigos-fonte MATERIAL.f e PENELOPE.f. Uma das vantagens do PENELOPE é que este utiliza uma base de dados recente com as características de diversos materiais de interesse em física radiológica (ICRU, 1989) e atuais bibliotecas de seção de choque e outras grandezas necessárias para o transporte das partículas (Salvat et al, 2005).

O código-fonte PENVARED.f, contém sub-rotinas que executam os métodos de redução variacional do pacote, que tentam reduzir, sem o aumento de tempo de simulação, a incerteza estatística dos resultados simulados.

Por último, o código-fonte TIMER.f gerencia o tempo de simulação.

O algoritmo de simulação é baseado em um modelo que combina dados numéricos e analíticos de seções choques para os diferentes tipos de interação e é aplicado para energias iniciais de $1 \mathrm{keV}$ até $1 \mathrm{GeV}$. O transporte de fótons é simulado pelo método convencional, detalhado, e a simulação de elétrons e pósitrons é realizado por meio de um algoritmo misto. Assim, para elétrons e pósitrons, o código PENELOPE difere dos outros códigos de simulação por utilizar um algoritmo misto que implementa dois modelos de simulação: o detalhado, para eventos fortes, definidos a partir da deflexão angular (ângulo de espalhamento) ou perda de energia acima de um valor pré-definido, e o condensado para interações fracas, com deflexão angular ou perda de energia menores que os valores pré-estabelecidos. As interações condensadas são descritas por uma aproximação de múltiplos espalhamentos que consiste em transformar um dado número de interações fracas em um único evento artificial (Sempau, Andero, 2006), como esquematizado na Figura 7. 


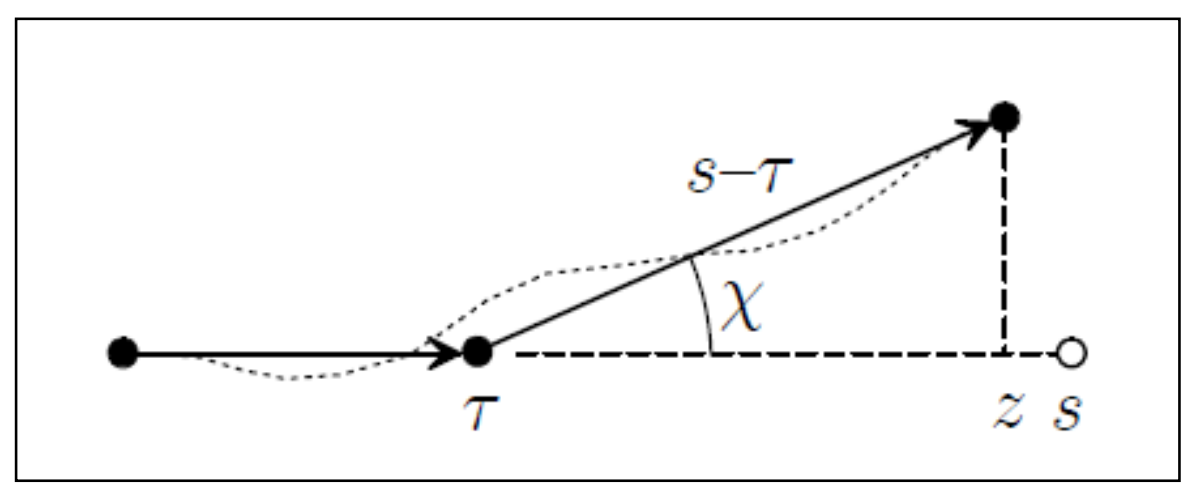

Figura 7: Esquema de várias colisões fracas entre duas colisões fortes, simulando eventos artificiais no PENELOPE (Salvat et al, 2009).

Para desenvolver uma simulação com o PENELOPE, o usuário deve editar um arquivo FORTRAN, usuario.f, com as chamadas das sub-rotinas PENELOPE.f, PENGEOM.f, PENVARED.f e TIMER.f, proporcionando o gerenciamento da simulação como um todo, e criando, com esses cinco arquivos FORTRAN, um arquivo usuario.exe.

A simulação é iniciada pela execução do arquivo usuario.exe que busca informações de entrada fornecidas pelo usuário através do arquivo entrada.in, além de informações da geometria através do arquivo geometria.geo, e informações de seção de choque dos materiais envolvidos na simulação através do arquivo material.mat.

Oferecido juntamente com PENELOPE, há um programa executável, GEOVIEW.exe, que permite a visualização dos corpos definidos e os materiais que constituem uma geometria de simulação. A Figura 8 mostra um exemplo da visualização da geometria, mostrando os diferentes materiais, diferenciando-os pelas cores. 


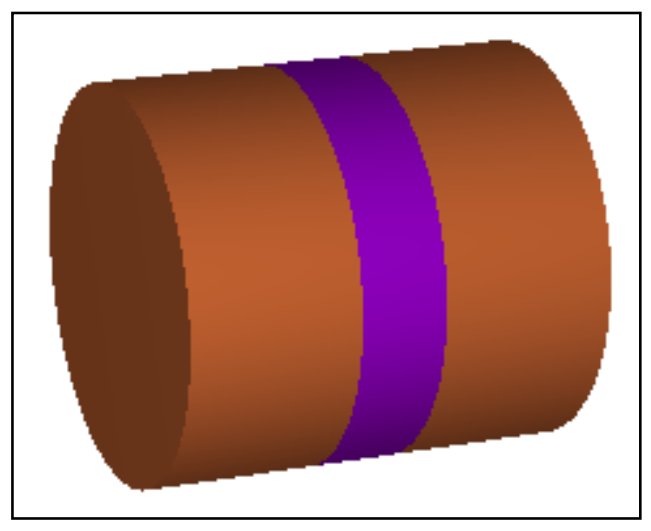

Figura 8: Visualização com o GeoView de uma geometria cilíndrica com dois corpos, de diferentes materiais, que são representados pelas diferentes cores.

\subsection{Filme radiocrômico}

Em meados da década de 60 um novo tipo de filme, conhecido como filme radiocrômico, começou a ser estudado por apresentar características diferenciadas às encontradas em filmes radiográficos convencionais (Roozen et al, 2011; AAPM, 1998). Entre essas características pode-se destacar a relativa insensibilidade à luz visível e a formação da imagem visível sem a necessidade de processamentos químicos. Assim, algumas propriedades dosimétricas desses filmes têm sido estudadas como, resolução espacial, linearidade, saturação, variação com a dose e taxa de dose, para possíveis aplicações em Radioterapia (Aland et al, 2011; Benavente et al, 2011; Hardcastle et al, 2011; Roozen et al, 2011; Gotanda et al, 2011; Butson et al, 2010a; Silva et al, 2010; Sutherland, Rogers, 2010; Zeiden et al 2006).

Os filmes radiocrômicos não irradiados apresentam uma coloração translúcida e depois de irradiados essa coloração é alterada e uma imagem visível é formada. Essa mudança de coloração ocorre por um processo de polimerização, em que energia é transferida dos fótons e/ou partículas carregadas para a parte receptiva da molécula foto-monomérica sem cor, iniciando a formação da coloração por meio de mudanças químicas. Essas alterações químicas resultam em poli-conjugação homogênea ao longo da cadeia de carbono presente no filme, que produz a coloração na região irradiada (AAPM, 1998). A Figura 9 mostra a mudança tonalidade do filme 
radiocrômico, que implica em uma mudança na densidade ótica (DO) quase que imediatamente após de ser submetido à radiação.

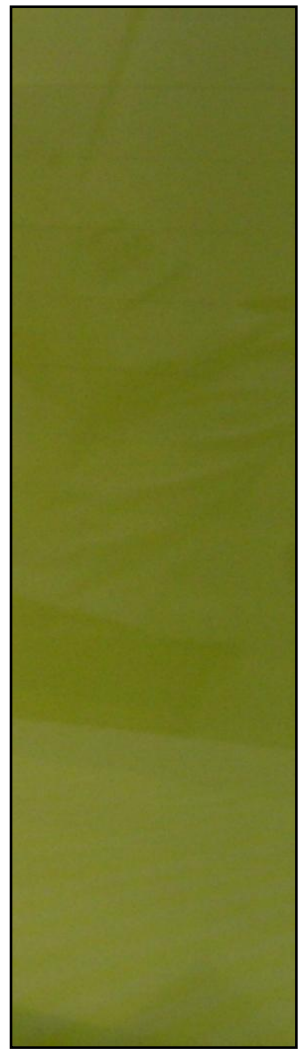

(a)

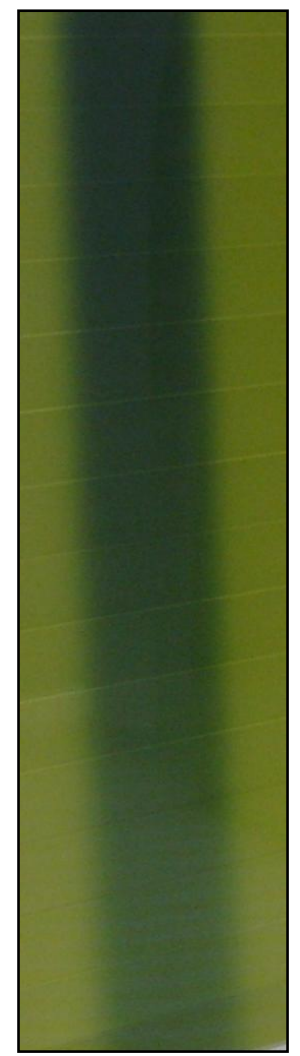

(b)

Figura 9: Filme radiocrômico EBT2: (a) sem irradiar e (b) após de ser irradiado.

Os filmes radiocrômicos, especificamente o EBT2, possuem a vantagem de pouca sensibilidade à luz ultravioleta, possibilidade de submersão na água, resistência a altas temperaturas, e uma característica importante de saturação de dose absorvida somente em 40 Gy (Butson et al, 2009). Por tais motivos, este filme tem sido utilizado em múltiplas aplicações clínicas como comissionamento de fontes de braquiterapia, medidas dosimétricas com feixes de fótons e elétrons e em algumas técnicas de irradiação utilizadas nos serviços de radioterapia (Andrés et al, 2010; Benavente et al, 2011; Hardcastle et al, 2011; Roozen et al, 2011; Gotanda et al, 2011; Butson et al, 2010a; Sutherland, Rogers, 2010; Silvia et al, 2010; Zeiden et al 2006; Aland et al, 2011).

Os filmes EBT2 são constituídos por uma combinação de poliésteres transparente que reveste uma camada fina radiossensível de $30 \mu \mathrm{m}$, composta 
de microcristais orgânicos sem coloração dispersos uniformemente (Sutherland, Rogers, 2010; Aland et al, 2011; Devic et al 2004; Arjomandy et al, 2010; Butson et al, 2009). Devido a sua composição possuem número atômico efetivo entre 6,0 e 6,5 (AAPM, 1998). A relação da dose absorvida no filme pode ser obtida por meio de um densitômetro ou com um escâner, em que se determinam as distribuições de dose de um modo mais prático e rápido, condição importante nos serviços de radioterapia (Devic et al, 2009).

Entretanto, para obter resultados apropriados com esse dosímetro algumas recomendações devem ser seguidas. Primeiramente, deve ser considerando a não homogeneidade de DO para filmes não irradiados, sendo que as diferenças podem chegar até $\pm 3,7 \%$. Considerando-se filmes irradiados até 1,0 Gy, entretanto, essas diferenças podem chegar a 8,7\% (Gotanda et al, 2011; Hartmann et al, 2010). A orientação do filme durante a leitura também é um fator importante, pois as partículas da área sensível do filme estão orientadas ao longo do eixo paralelo, e estas espalham a luz diferentemente na direção ortogonal. Por este motivo, no momento de escaneamento o filme deve ser orientado paralelamente ao seu eixo paralelo (Gafchromic, 2010; Zeidan et al, 2006 ). As folhas do filme são marcadas com um pequeno corte na parte superior, que indica a direção do eixo paralelo do mesmo, como mostrado na Figura 10.

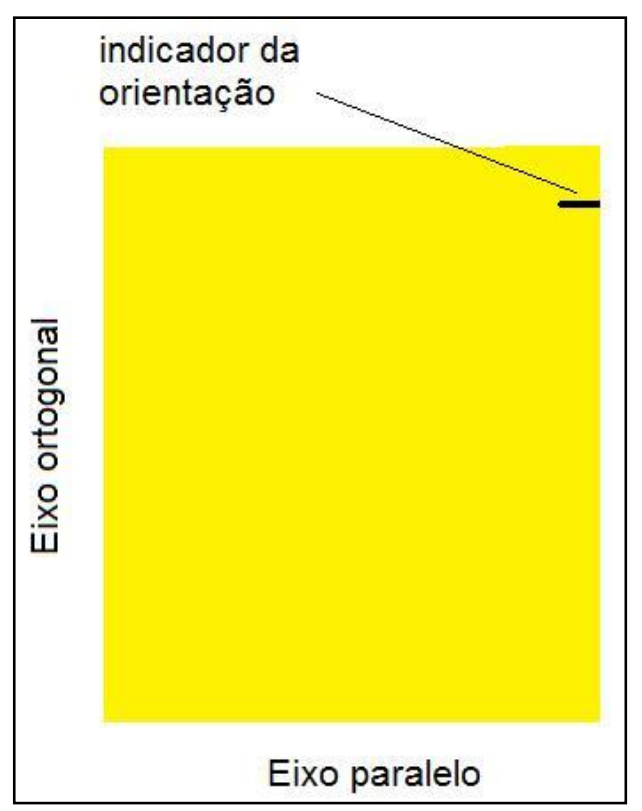

Figura 10: Esquema da orientação da posição do filme radiocrômico EBT2 para realizar o seu escaneamento. 
Características como alta resolução espacial, praticidade de uso e visualização imediata da área irradiada possibilitam as determinações de distribuições de dose, inclusive em geometrias nas quais o dosímetro deve ser posicionado na água. Dessa maneira, o filme radiocrômico EBT2 foi utilizado nesse trabalho para determinação das distribuições de dose em duas dimensões para tratamentos de SRS.

\subsection{Sistema de planejamento radioterápico}

O tratamento de uma neoplasia pode se dividir em três etapas principais: seu diagnóstico, seguido do planejamento do tratamento e por último o procedimento do tratamento. Após o tratamento, prognóstico do paciente é ainda é acompanhado para verificar o sucesso do tratamento.

No planejamento radioterápico é realizado, entre outras etapas, o cálculo do tempo de exposição para aplicação da dose de radiação que o volume a ser tratado receberá, além das estruturas sadias adjacentes e dos órgãos de risco. Se estas estruturas receberem doses superiores ao limite permitido pelas restrições do planejamento, poderá acarrear em toxicidade para os tecidos sadios e consequentemente pode comprometer a eficácia do tratamento. Assim, para garantir a prescrição da dose no volume alvo e evitar doses superiores nas estruturas sadias, é levado em consideração o tipo da técnica de irradiação mais adequada para conformar a dose de radiação ao volume alvo. Dependendo da localização da neoplasia, também são utilizados acessórios no planejamento com o intuito de blindar e modular o feixe de radiação.

Antes da década de 1970, o planejamento de um tratamento radioterapêutico era feito em forma manual, utilizando imagens obtidas através de técnicas com raios $X$ convencionais. $O$ cálculo da dose era feito com ajuda de gráficos de isodoses (que eram considerados como distribuições de dose homogêneas), que eram sobrepostos sobre o esse filme. O tamanho do campo e as blindagens para os órgãos de risco eram também calculadas através dessa imagem.

Com o decorrer dos anos, o desenvolvimento da tecnologia proporcionou que se pudessem obter imagens por tomografia computarizada, 
melhorando, assim, a delimitação dos volumes do tratamento. Os sistemas de planejamento computadorizados incluem softwares e hardwares que possibilitam o uso de imagens anatômicas tridimensionais dos pacientes para realização do planejamento radioterápico, permitindo correções de heterogeneidades e cálculos de dose e distribuições de dose em três dimensões com maior rapidez e precisão (Podgorsak et al, 2005; IAEA, 2004).

Existem diversos TPS, como o Monaco, XiO, PrecisePlan, desenvolvidos pela Elekta; UMplan da Scanditronix; Theraplan Plus do Theratronic; Syntegra, SmartArc, Pinnacle da Philips; o IPlanDose e BrainScan, da BrainLab, o iPlan e Eclipse, da Varian, entre outros, utilizados nos planejamentos das técnicas conformacionais 3D e de intensidade modulada (IMRT da sigla em inglês intensity modulate radiation therapy). Os TPS se baseiam, normalmente, em algoritmos que implementam o método Monte Carlo (Monaco), algoritmos de convolução/superposição (XiO, Eclipse e IPlan), método de Clarkson (PrecisePlan) e pencil beam (iPlanDose e BrainScan), que utilizam dados experimentais de diversos parâmetros físicos e dosimétricos, obtidos com câmara de ionização durante o comissionamento da unidade de terapia (Van et al, 2012, Gershkevitsh et al, 2010; Karlsson et al, 2010; Ishikur, 2008; Rath, 2008; Van, 2008; Camaro et al, 2007; Able et al, 2005; Mijnheer, 2004). Devido às diferenças nos algoritmos de cálculos dos TPS, testes de exatidão dos mesmos devem ser realizados como parte do controle da qualidade da Radioterapia (IAEA, 2008; 2007; ICRU,1999).

A Figura 11 mostra uma tela de um planejamento realizado com o TPS iPlan ${ }^{\circledR}$ para um caso de radiocirurgia, através de imagens de CT de um objeto simulador. O planejamento foi realizado no centro do objeto simulador, com feixe de fótons de $6 \mathrm{MV}$, com três arcos dinâmicos e tamanho de campo de 2 $\mathrm{cm}$ de diâmetro e a distancia fonte superfície de $100 \mathrm{~cm}$. 


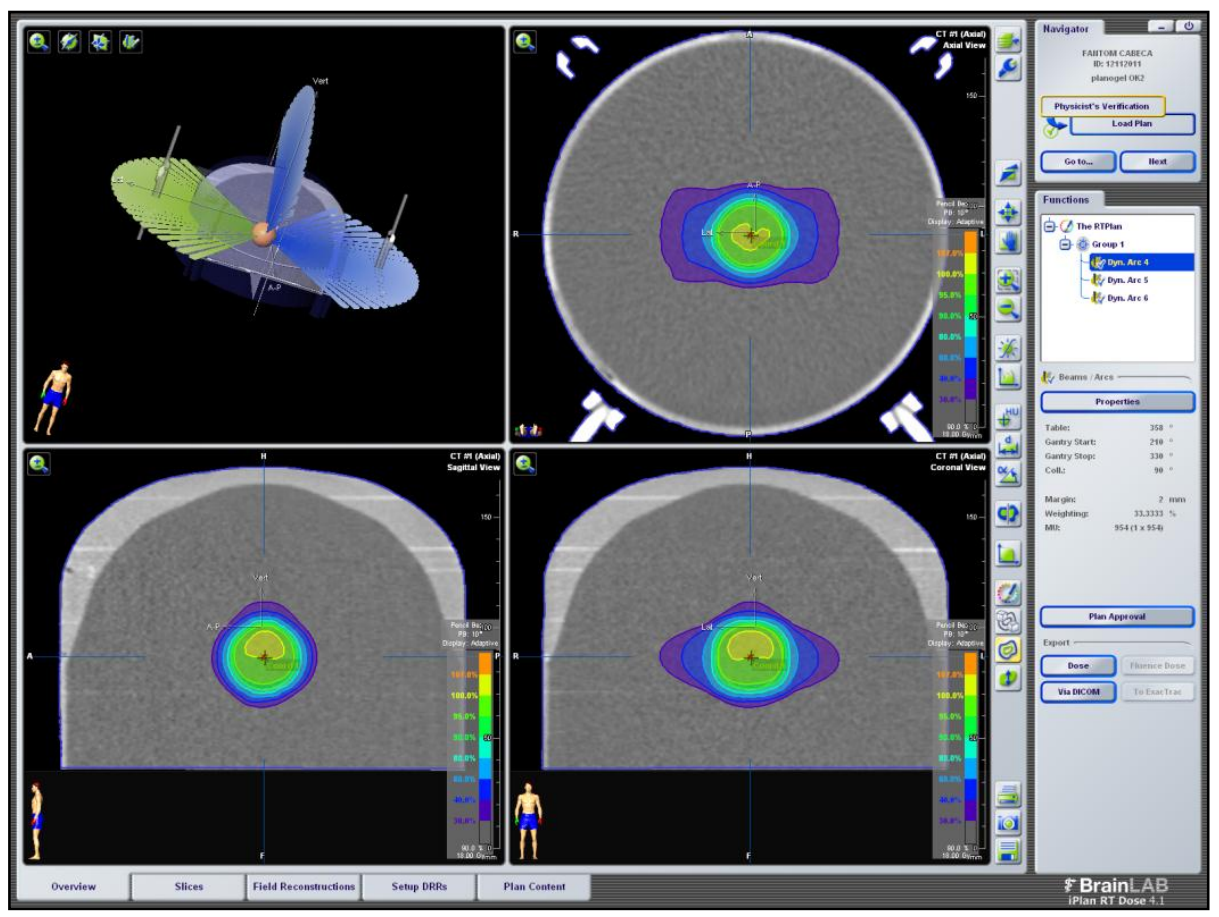

Figura 11: Planejamento de um caso de radiocirurgia com o sistema de planejamento iPlanß, com três arcos dinâmicos.

\subsection{Porcentagem de dose profunda}

Os feixes de radiação são caracterizados por parâmetros dosimétricos como a porcentagem de dose profunda, perfil de campo, entre outros. Estes parâmetros dependem dos parâmetros físicos como: distância fonte superfície (DFS), tamanho de campo, profundidade e energia do feixe (Khan, 2010; IAEA, 2000; Scaff, 1987).

A porcentagem de dose profunda (PDP) expressa à porcentagem de dose absorvida, ao longo do eixo central do feixe de irradiação, em profundidade do paciente ou de um objeto simulador. A equação 14, mostra a formulação da PDP para um profundidade de interesse, $D_{d}$, relativa à dose absorvida na profundidade de dose máxima, $\mathrm{D}_{\mathrm{m}}$.

$$
P D P(d)=\frac{D_{d}}{D_{m}} \times 100 \%
$$

As curvas de PDP para uma determinada energia, tamanho de campo, DFS e feixe de irradiação são estabelecidas para cada tipo aparelho de 
irradiação, e são obtidas com um dosímetro de referência (câmara de ionização).

\subsection{Perfil de campo}

Perfil de campo é um parâmetro dosimétrico que fornece a informação da dose ao longo de um dos eixos perpendiculares ao eixo central do campo de radiação, dado como a razão da dose em um ponto ao longo da direção x ou y do campo, $D_{x}$, e a dose no eixo central do campo de radiação, na profundidade de dose máxima, $D_{m}$, para no objeto simulador. A equação 15 mostra a formulação do perfil de campo:

$$
\text { Perfil de campo }=\frac{D_{x}}{D_{m}}
$$

Com a informação de perfil de campo pode-se determinar a penumbra, planura e a simetria do campo de irradiação, que, para condições de referência, dependendo do tipo e energia do feixe, sendo estabelecidos para cada aparelho de tratamento através do uso de uma câmara de ionização e um objeto simulador de água.

\section{7.Índice gama}

Uma metodologia de comparação de distribuições de dose, que considera valores de tolerância em relação à dose e a posição, foi estabelecida por Low (Low et al, 1998) e é conhecida como análise do índice gama, $\gamma$.

O índice $\gamma$ estabelece a comparação entre duas distribuições de dose considerando dois parâmetros: a distância de concordância (DTA em inglês distance-to-agreeming) e diferença de dose para valores de dose comparados entre os pontos de duas distribuições de dose. Assim, o parâmetro DTA, compara a localização de um ponto de uma matriz, ou da distribuição de dose de referência, com a localização desse ponto em uma vizinhança estabelecida da outra matriz, sendo que a concordância na localização deve ser encontrada dentro de uma circunferência de raio, $\mathrm{d}_{\mathrm{m}}$. Por sua vez, o parâmetro relacionado 
com a diferença de dose, compara os valores de doses obtidos nas diferentes matrizes entre os pontos que estão sendo comparados.

Dessa forma, a formulação para determinação do $\gamma$, combinando os dois critérios, DTA e de tolerância em dose, está expressa na equação 16:

$$
\Gamma=\sqrt{\frac{r^{2}\left(r_{m}, r\right)}{\Delta d_{M}^{2}}+\frac{\delta\left(r_{m}, r\right)}{\Delta D_{M}^{2}}}
$$

em que

$r\left(r_{m}, r\right)=\left|r-r_{m}\right|$ é a diferença entre a posição de um ponto da matriz de referência, $r_{m}$, com a matriz que está sendo analizada, $r$;

$\delta\left(r_{m}, r\right)=D(r)-D_{m}\left(r_{m}\right)$ é a diferença de doses nas posições $r$ e $r_{m}$ e $\Delta d_{M}^{2}$ e $\Delta D_{M}^{2}$ são os critérios de DTA e diferença de dose, respectivamente.

Assim, a comparação de um pixel de um mapa de dose de referência e de um segundo mapa de dose, considerando uma diferença na posição, se obterá vários $\gamma$. Deste modo, o $\gamma$ para qualquer ponto dentro do intervalo de $r-r_{m}$ é escolhido como o valor mínimo dentro esse intervalo, que é expresso pela equação 17:

$$
\gamma(r m)=\min \{\Gamma(r m, r)\} \forall\{r\} .
$$

O $\gamma$ indica, desta forma, se as distribuições de dose comparadas podem ser consideradas semelhantes dentro dos critérios de comparação de DTA e de diferença de dose, tomando-se:

$\gamma\left(r_{m}\right) \leq 1$, indica que a comparação é aceitável, $\gamma\left(r_{m}\right)>1$, indica que a comparação não é aceitável. 


\subsection{Histogramas dose-volume}

O histograma dose-volume (DVH) é um instrumento utilizado para avaliar se um dado planejamento radioterápico respeita as restrições de dose e a prescrição de dose estipulada pelo radioterapêuta dentro do volume tumoral e nos órgãos de risco.

O DHV é um gráfico em 2D que condensa a distribuição de dose em 3D e pode ser expresso na forma diferencial ou na forma acumulativa. Na forma diferencial, o DVH é, geralmente, dado como um gráfico de barras normalizadas para $100 \%$ em que a altura da barra representa uma quantidade de volume que recebe um determinado intervalo de dose (por exemplo, de 0 até $1 \mathrm{~Gy}$ ), e os intervalos são divisões dentro dos limites de dose mínima e máxima. A Figura 12 (a) mostra um DVH na forma diferencial. $\mathrm{Na}$ forma acumulativa, normalmente utilizada, o DVH é apresentado como um gráfico de linhas normalizadas para $100 \%$, em que cada ponto da linha representa a somatória das porcentagens de volume que recebem certa porcentagem de dose, sempre relativo ao volume total (Drzymala et al, 1991). A Figura 12 (b) mostra uma DVH na forma acumulativa obtida através do TPS para um caso de radiocirurgia.

Os TPS incluem a construção de curvas de DVHs para verificação dos planejamentos nos volumes de interesse. O planejamento é ideal quando $100 \%$ do volume alvo recebe $100 \%$ da dose prescrita pelo médico, como mostrado na Figura 12. Para os órgãos de risco, idealmente $100 \%$ do volume não recebe qualquer dose. 


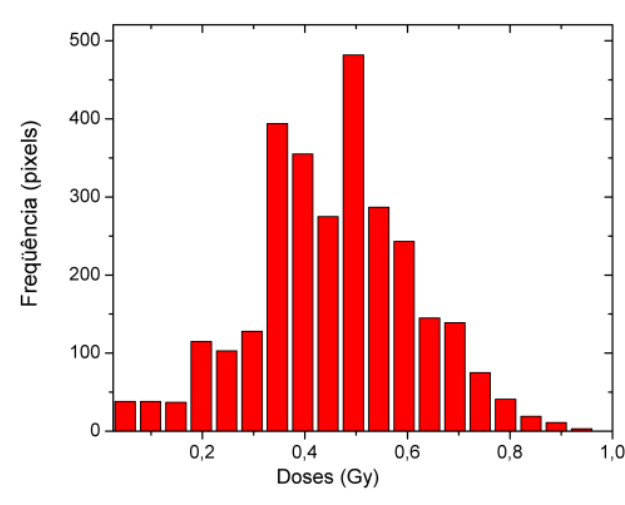

(a)

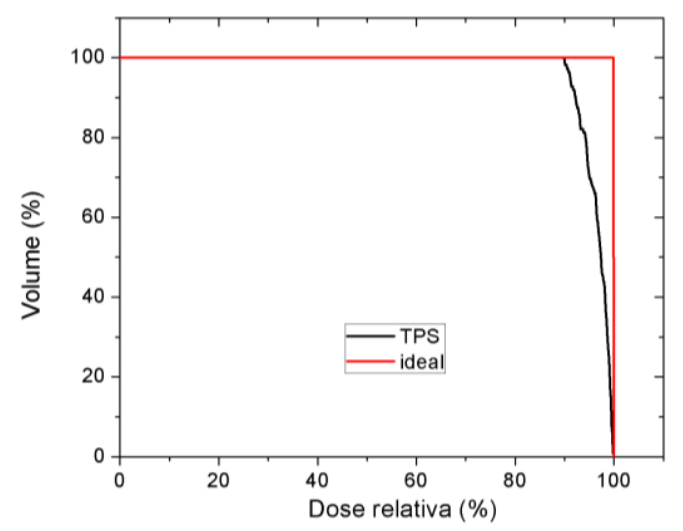

(b)

Figura 12: Curvas esquemática de um histograma dose-volume: (a) diferencial, e (b) acumulativo, mostrando um caso ideal (linha vermelha) e um caso real (linha preta).

\subsection{Probabilidade de controle tumoral}

Como citado na seção anterior, o DVH é utilizado para verificação das doses depositadas em volumes de interesse em planejamentos radioterápicos. A verificação das doses depositadas é importante, pois a probabilidade de controle tumoral (TCP do inglês, Tumour Control Probability) é função da dose, como mostrado na Figura 13. Desta forma, embora esse parâmetro não seja utilizado cotidianamente na clínica, ele pode ser uma nova ferramenta nos serviços de radioterapia para validação dos planejamentos e técnicas radioterápicas (Jin, Kong, 2011; Hall, 2000; Puck, Marcus, 1956).

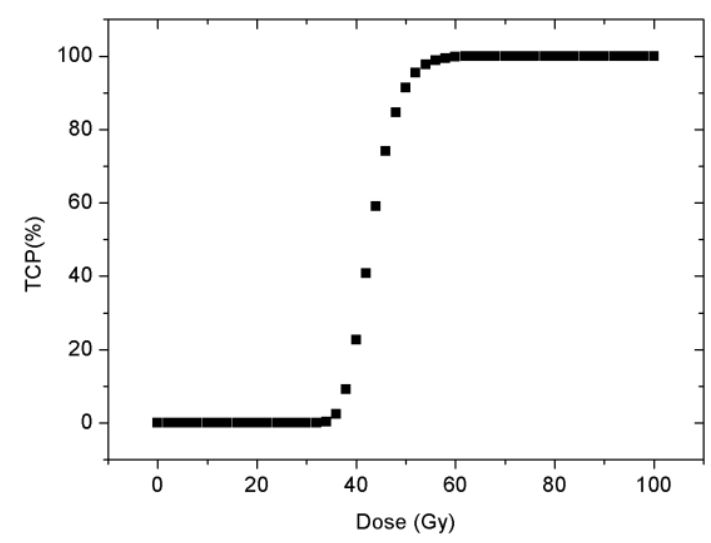

Figura 13: Curva esquemática da probabilidade de controle tumoral. 
Existem vários modelos matemáticos, que também são conhecidos como modelos radiobiológicos, que relacionam a dose absorvida com a resposta biológica do tecido. (Shibamoto et al, 2012; Levitt et al, 2012; Chatterjee, et al 2011). Dentre os modelos radiobiológicos, o mais comum é o modelo linear quadrático (LQ), em que se assume que a morte celular radioinduzida depende de duas componentes: uma componente, $\alpha$, proporcional à dose e correspondente às quebras simples da molécula do DNA, e outra componente, $\beta$, proporcional ao quadrado da dose $e$ correspondente às quebras duplas do DNA. A relação entre as duas componentes, o fator $\alpha / \beta$, pode ser entendido com o grau de radiosensibilidade do tecido a uma dada radiação e esquema de irradiação. (Levitt et al, 2012; Ko, Forsythe, 2011; Barazzuol et al, 2010). A determinação de parâmetros radiobiológicos como $\circ \alpha / \beta$, é realizada a partir de estudos em culturas celulares in vitro (Sharon Qi et al 2012; Folwer et al, 2001). A equação 18 mostra a formulação matemática do modelo $L Q$ :

$$
N_{S}=N_{o} e^{-\alpha D-\beta D^{2}}
$$

sendo $\mathrm{N}_{\mathrm{s}}$ o número de células sobreviventes à uma dada dose de radiação, $\mathrm{N}_{\circ}$ o número de células iniciais e $\mathrm{D}$ a dose total.

A razão $N_{s} / N_{0}$ é chamada de fração de sobrevivência, de modo que a relação entre o TCP e a curva de sobrevivência pelo modelo LQ é dada pela equação 19:

$$
T C P=e^{-N_{0} e^{-\alpha D-\beta D^{2}}}
$$

Entretanto, o TCP pode ser determinado por outros métodos, como o proposto por Kim e Tome (Kim e Tome, 2010). Nesse modelo, o TCP de uma matriz de dados pode ser determinado através da equação 20 :

$$
T C P(D)=\frac{1}{1+\left(\frac{D_{50}}{D}\right)^{4 \gamma_{50}}}
$$


sendo $D_{50}$ a dose que corresponde a um controle tumoral de $50 \%$ para todo o volume alvo e $\gamma_{50}$ é o gradiente da curva dose-resposta em uma reposta de $50 \%$, figura 13 .

Atualmente, alguns parâmetros biológicos, como 0 fator de radiosensibilidade, $\alpha / \beta$, estão sendo considerados nos TPS para uma melhor quantificação da eficácia dos tratamentos radioterápicos. Dessa forma, os TPS seriam avaliados não somente pelos critérios físicos, como as distribuições de dose, mas também por critérios biológicos como as probabilidades de controle tumoral. Entretanto, ainda existem limitações a respeito dos modelos e os parâmetros a serem utilizados (AAPM, 2012). 


\section{Materiais e Métodos}

Neste capítulo são apresentados os materiais utilizados, assim como os métodos empregados para caracterização dos dosímetros e para validações das quatro ferramentas dosimétricas utilizadas: código de simulação PENELOPE, dosímetro MAGIC- $f$ gel, filme radiocrômico EBT2 e o TPS Iplan ${ }^{\circledR}$ RT Dose 4.1 (BrainLab ${ }^{\circledR}$.

Inicialmente, foram realizadas medidas para a caracterização do dosímetro MAGIC- $f$ determinando sua dependência em função da dose absorvida, taxa de dose e dependência do sinal do MAGIC- $f$ com o tempo de leitura após a irradiação.

Do mesmo modo, foram realizadas medidas para a caracterização do filme EBT2, determinando a sua dependência em função da dose absorvida, taxa de dose e dependência de leitura após a irradiação.

As ferramentas dosimétricas utilizadas nesse trabalho foram validadas determinando-se e comparando-se dois parâmetros dosimétricos: a porcentagem de dose profunda (PDP) e o perfil de campo.

Como medidas preliminares foram obtidas as distribuições de doses para campos coplanares, utilizando-se campos pequenos (5 campos e 6 campos), com PENELOPE e MAGIC-f. Para campos não-coplanares, utilizouse 7 campos.

Para a continuidade desse trabalho de pesquisa, foram analisados três casos clínicos de radiocirurgia do serviço de radioterapia do Hospital do Câncer de Barretos (HCB-Barretos). As avaliações dos tratamentos de radiocirurgia foram feitas com um objeto simulador de cabeça, do qual foram obtidas imagens por CT e utilizadas para os planejamentos das irradiações. Nessas mesmas condições dos planejamentos, foram simulados os tratamentos com o código de simulação PENELOPE e medidas experimentalmente foram feitas com os dosímetros MAGIC- $f$ e EBT2.

As distribuições de dose obtidas pelas quatro ferramentas (TPS iPlan, MAGIC-f, PENELOPE-MC e EBT-2) foram analisadas com os métodos de comparação do índice gama e do DVH. Atualmente, as tolerâncias, tanto de posição como de diferença de dose não estão bem estabelecidas para a 
utilização em radiocirurgia, de modo que foram testados vários limites de diferenças na posição e dose, tendo em consideração as particularidades da técnica de radiocirurgia.

\subsection{Objetos simuladores}

As imagens de CT dos objetos simuladores (OS) utilizados neste trabalho foram realizadas no tomógrafo LightSpeed VCT, multislice de 64 canais, da marca GE do Hospital do Câncer de Barretos, e foram utilizadas para determinar os planejamentos e as mesmas geometrias que foram simuladas através do código de simulação PENELOPE. Esses OS foram, também, utilizados para realização das medidas experimentais com os dosímetros MAGIC- $f$ gel e filme radiocrômico EBT2

\subsubsection{Objetos simuladores para medidas com MAGIC-f gel}

As determinações das curvas de calibração, dependência com a dose, taxa de dose e com o tempo de leitura após a irradiação foram realizadas com tubos de vidro de $5 \mathrm{ml}$ (Vacutainer ${ }^{\circledR}$ para coleta de sangue), com $5 \mathrm{~cm}$ de comprimento e 0,8 cm de diâmetro, mostrado na Figura 14 (a). Os mesmos também foram utilizados no estudo de repetibilidade de resposta do gel.

Para a determinação das PDPs com campos de $10 \times 10 \mathrm{~cm}^{2}$ foram utilizados tubos de vidro de $50 \mathrm{ml}$, com $16 \mathrm{~cm}$ de comprimento por $1,5 \mathrm{~cm}$ de diâmetro, como mostrado na Figura 14 (b).

Para as determinações das curvas de PDP e perfil de dose, para campos pequenos, formam utilizados paralelepípedos de PPMA, com dimensões de $5 \mathrm{x}$ $5 \times 20 \mathrm{~cm}^{3}$, como mostrado na Figura 14 (c).

Para a determinação das distribuições de dose para campos coplanares, um OS cilíndrico de PPMA, de $10 \mathrm{~cm}$ de diâmetro e $15 \mathrm{~cm}$ de altura, foi confeccionado, como mostrado na Figura 14 (d).

Para as avaliações dos casos de radiocirurgia, um OS de cabeça foi especialmente confeccionado, no qual a parte cilíndrica possui $18 \mathrm{~cm}$ de diâmetro e $15 \mathrm{~cm}$ de altura, a parte superior, "ovalada", possui um perímetro de $23 \mathrm{~cm}$, como mostrado na Figura 14 (e). 
Todos os OS utilizados neste trabalho possuem uma espessura adequada para evitar a penetração de oxigênio na amostra do gel a fim de não impedir a formação da polimerização do gel irradiado.

\subsubsection{Objetos simuladores para medidas com o filme radiocrômico EBT2}

Foram utilizadas placas de $30 \times 30 \mathrm{~cm}^{2}$ de água sólida (RMI-457) usada para a avaliação da resposta com dose e taxa de dose. Um OS cilíndrico, composto de placas de acrílico, de $18 \mathrm{~cm}$ de altura e $20 \mathrm{~cm}$ de diâmetro, foi utilizado para as determinações das PDPs e perfis de campo para campos pequenos, como mostrado na Figura 14 (f).

Para as avaliações dos casos de radiocirurgia, foi utilizado o mesmo OS de cabeça utilizado com o dosímetro gel polimérico, como mostrado na Figura 14 (d), porém foi acoplado um suporte para o posicionamento do filme. 


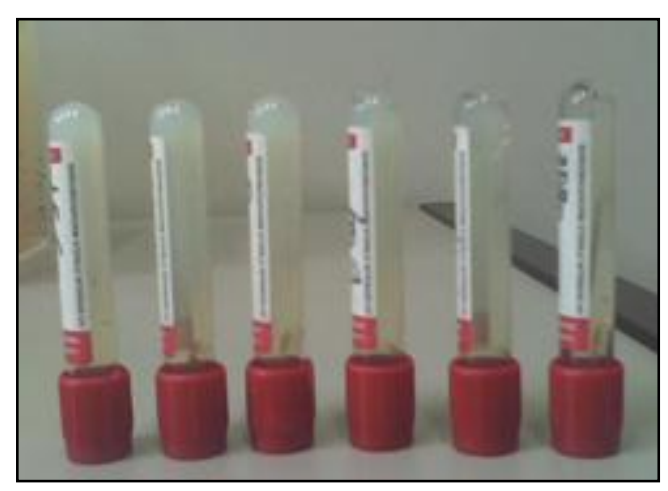

(a)

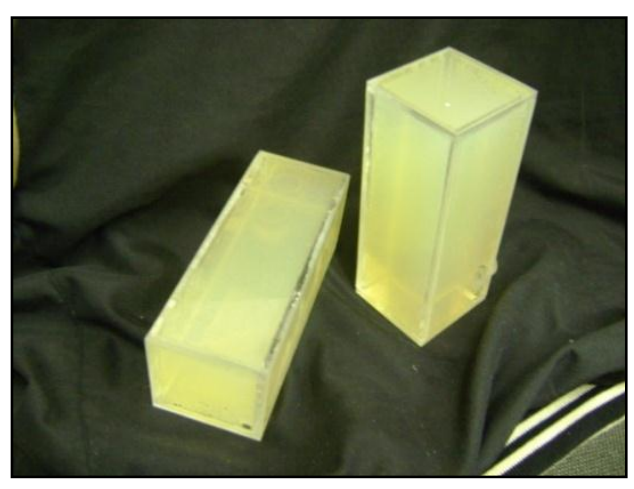

(c)

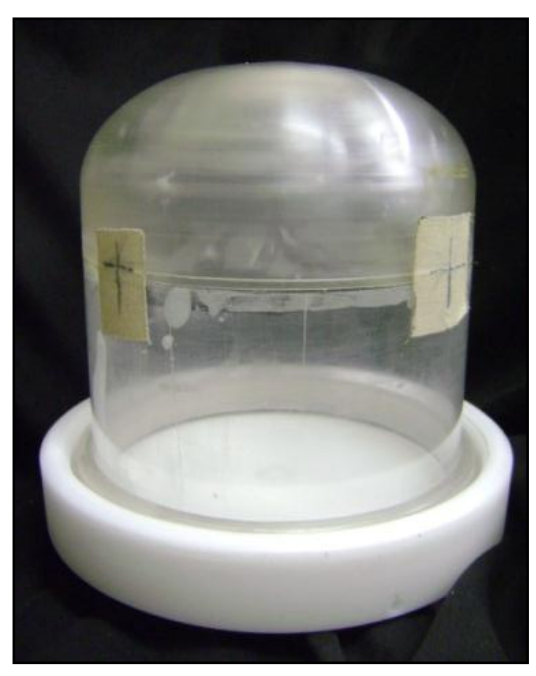

(e)

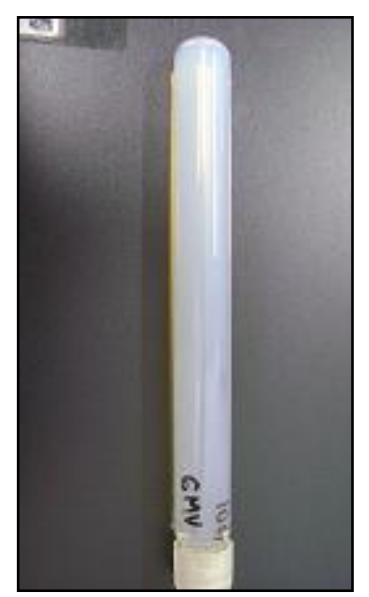

(b)

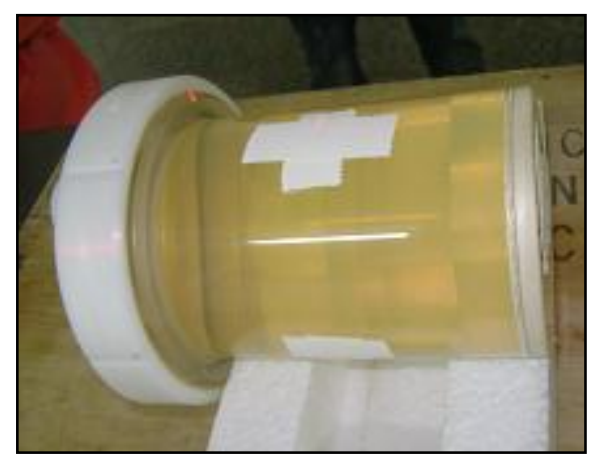

(d)

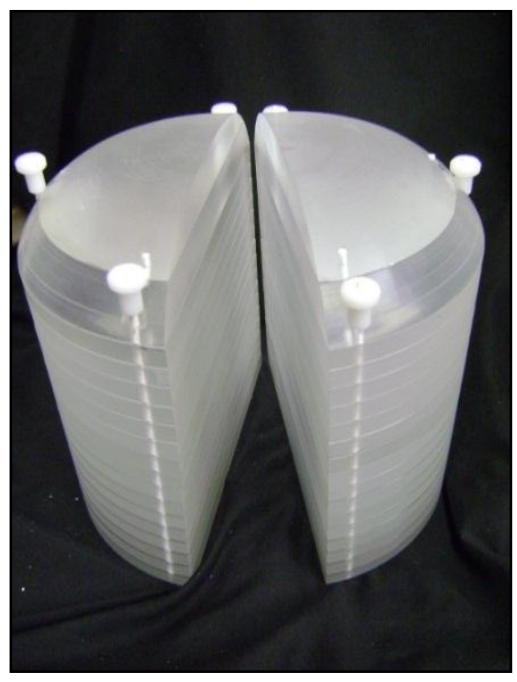

(f)

Figura 14: Objetos simuladores utilizados nesse trabalho. (a) tubos de vidro de $5 \mathrm{ml}$; (b) tubos de vidro de $50 \mathrm{ml}$; (c) paralelepípedo de PPMA; (d) cilindro de PMMA; (e) objeto simulador de cabeça (f). cilíndrico de placas de PPMA. 


\subsection{Feixes de irradiação}

As diversas irradiações foram realizadas com feixes de fótons de $6 \mathrm{MV}$ e $10 \mathrm{MV}$, de um acelerador linear Varian 2100c e, para as distribuições de dose dos casos de radiocirurgia, foi utilizado, também, um acelerador linear Varian Generic, com acoplamento de colilmador multi-folhas (MLC-BrainLab m3), do HCB-Barretos. A taxa de dose padrão utilizada para ambos aparelhos foi de 400cGy/min. A Figura 15 (a) e (b) mostra essas unidades de terapia.Excepcionalmente, para o estudo da dependência do MAGIC- $f$ com o tempo de leitura após a irradiação foi utilizada uma unidade de Cobalto 60, Siemens Gamatron II S80 e para os testes de distribuição de dose para campos coplanares foi utilizado o acelerador linear ONCOR ${ }^{\circledR}$, Siemens, com feixes de fótons de $6 \mathrm{MV}$, ambos pertencentes ao HC-Ribeirão Preto,como mostrado na Figura 15 (c) e (d).

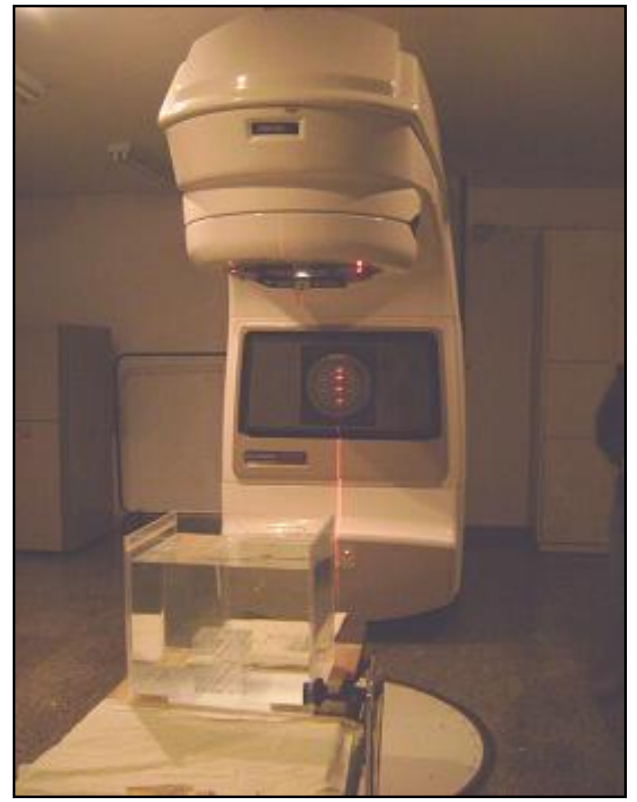

(a)

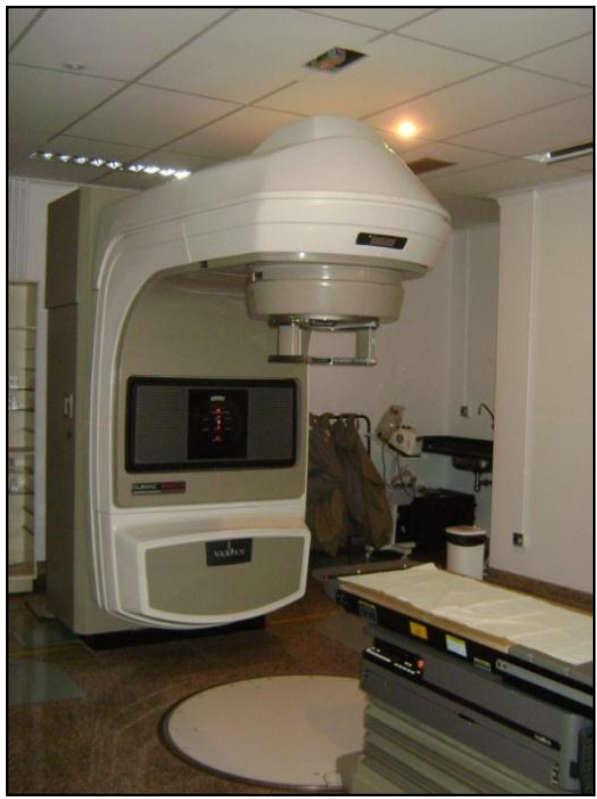

(b)

Figura 15: Aceleradores lineares Varian do HCB - Barretos: (a) 2100c e (b) Varian Generic com acoplamento de colimador multi-folhas. Aparelhos Siemens do HC-Ribeirão Preto: (c) Unidade de Cobalto 60 e (d) acelerador linear ONCOR ${ }^{\circledR}$. Continua. 


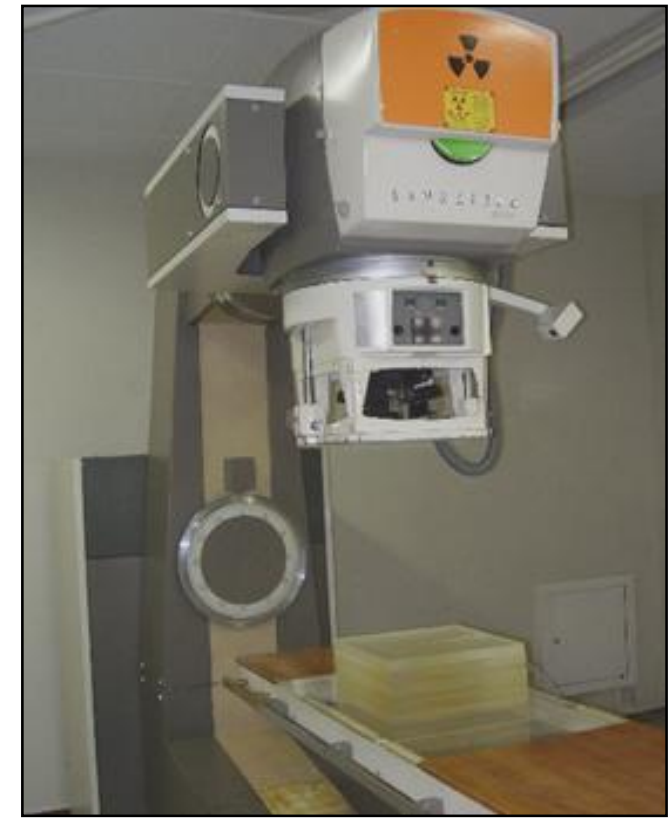

(c)

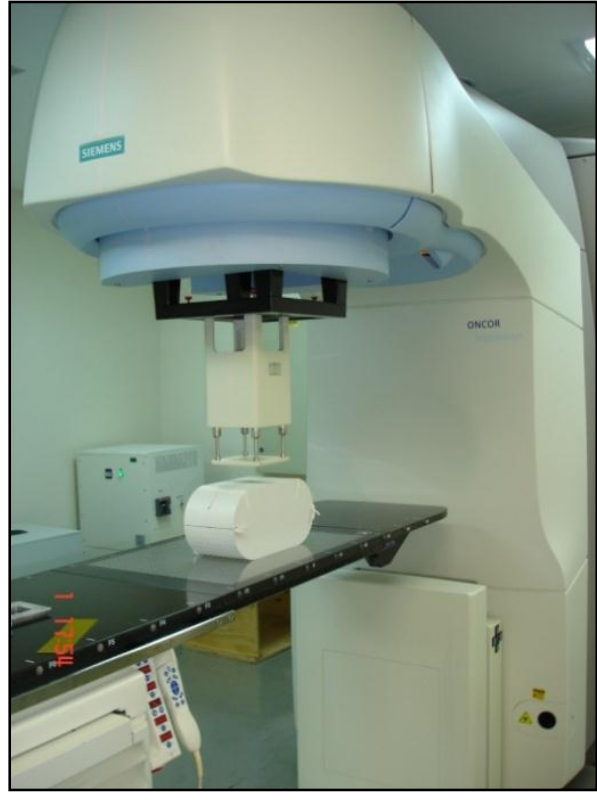

(d)

Figura 15 Aceleradores lineares Varian do HCB - Barretos: (a) 2100c e (b) Varian Generic com acoplamento de colimador multi-folhas. Aparelhos Siemens do HC-Ribeirão Preto: (c) Unidade de Cobalto 60 e (d) acelerador linear ONCOR ${ }^{\circledR}$.

\subsection{Ferramentas dosimétricas}

As ferramentas dosimétricas utilizadas para o desenvolvimento desse trabalho foram: dosímetro MAGIC- $f$ gel, filme radiocrômico EBT2, TPS iPlan ${ }^{\circledR}$ RT Dose 4.1 (BrainLab m3) e o código MC-PENELOPE, versão 2008.

\subsubsection{Dosímetro MAGIC-f}

O dosímetro a base de gel que foi utilizado neste trabalho foi o dosímetro polimérico MAGIC- $f$ gel, com número atômico efetivo de 7,41 , que foi preparado seguindo o protocolo de Fernandes (Fernandes et al, 2008), com os componentes mostrados na Tabela 1. 
Tabela 1: Componentes do MAGIC-f para um litro de solução.

\begin{tabular}{c|c}
\hline Componente & Quantidades \\
\hline Água Mili-Q & $840 \mathrm{ml}$ \\
\hline Gelatina 250 Bloom & $82 \mathrm{~g}$ \\
\hline Sulfato de cobre & $20 \mathrm{ml}$ \\
\hline Ácido ascórbico & $59 \mathrm{ml}$ \\
\hline Ácido metacrílico & $352 \mathrm{mg}$ \\
\hline Formaldeído & $30 \mathrm{ml}$
\end{tabular}

Para se assegurar a reprodutibilidade do dosímetro, todas as amostras desse trabalho foram preparadas mantendo-se as mesmas condições e proporções para os componentes mostrados na Tabela 1. A Figura 16 mostra parte da preparação do dosímetro MAGIC-f gel, seguindo o protocolo de preparação utilizado (Fernandes et al, 2008).

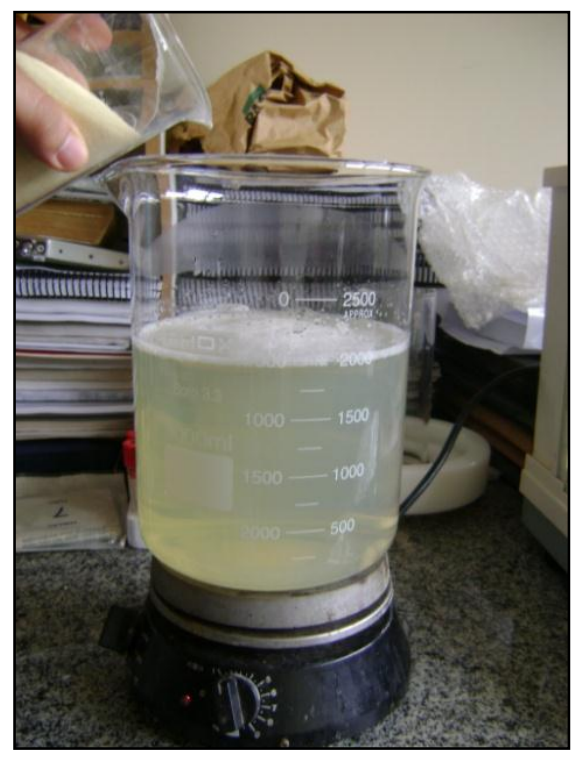

(a)

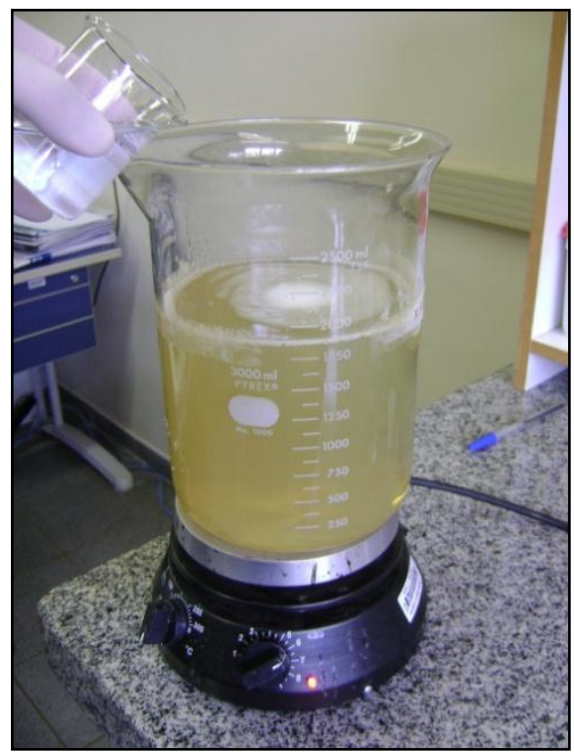

(b)

Figura 16: Dosímetro MAGIC-f gel: (a) início da preparação, (b) final da preparação, com adição do último elemento.

\subsubsection{Leitura do MAGIC-f}

As amostras com MAGIC-f foram lidas utilizando uma sequência de relaxometria, em T2, em um o tomógrafo de MRI, Philips, Achieva de 3,0 Tesla, 
em uma bobina de cabeça, do HC-Ribeirão Preto, como mostrado na Figura 17. Todas as leituras para as diferentes irradiações, com exceção ao estudo para a dependência do tempo de leitura após a irradiação, foram feitas, em aproximadamente, 24 horas.

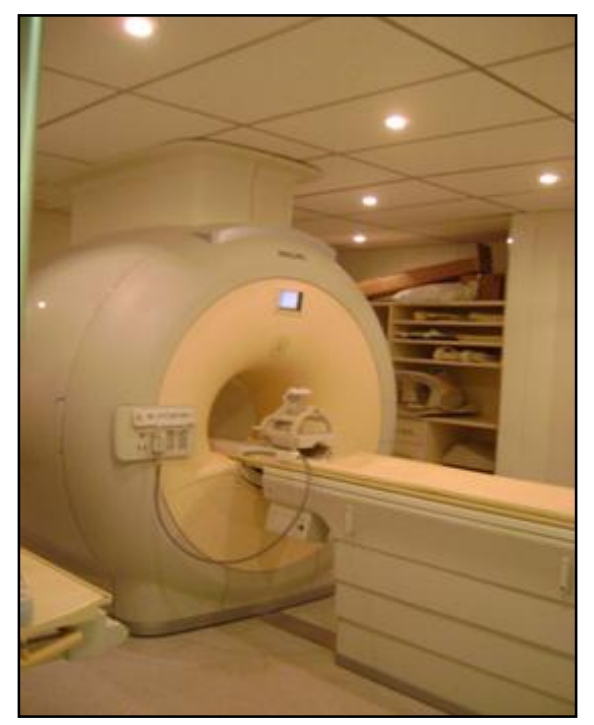

Figura 17: Tomógrafo NMR Philips, 3,0 Teslas, do HC - Ribeirão Preto, com uma bobina de cabeça.

As imagens foram adquiridas com uma sequência multi spin-eco, com 16 ecos, tempo ao eco, TE, de20 ms e tempo de repetição, TR, de 4000 ms, com matrizes de 250 × 250 pixels, fatias de espessura de $1 \mathrm{~mm}$ e o campo de visão (FOV) variável de acordo com o experimento.

Para o processamento e análise das imagens obtidas foi desenvolvido um aplicativo em plataforma MatLab ${ }^{\circledR}$, versão 7.6, que carregava as imagens DICOM para cada TE adquirido, obtendo os mapas de R2 através do logaritmo natural dado na equação 12. Foram construídas curvas de $\ln (\mathrm{S}(\mathrm{t})$ ) versus $\mathrm{t}$ (que são os tempos ao echo,TE), para cada ponto das imagens, fornecendo, assim, mapas de R2, que são os coeficientes angulares da curva, para cada TE , como apresentado no Anexo. 


\subsubsection{Teste da homogeneidade de campo da bobina de cabeça}

A homogeneidade da de campo bobina de cabeça do tomógrafo por MRI foi estudada utilizando-se um cilindro de PMMA de $20 \mathrm{~cm}$ de raio e $25 \mathrm{~cm}$ de altura, que continha $0,144 \mathrm{~g}$ de $\mathrm{MnCl}_{2}$ (concentração de $0,1 \mathrm{mM}$ ) e $6 \mathrm{~g} \mathrm{NaCl}$ diluídos em 8 litros de água. O tamanho do cilindro foi confeccionado para cobrir toda a área interna da bobina de cabeça. A Figura 18 mostra um esquema do cilindro utilizado para este estudo.

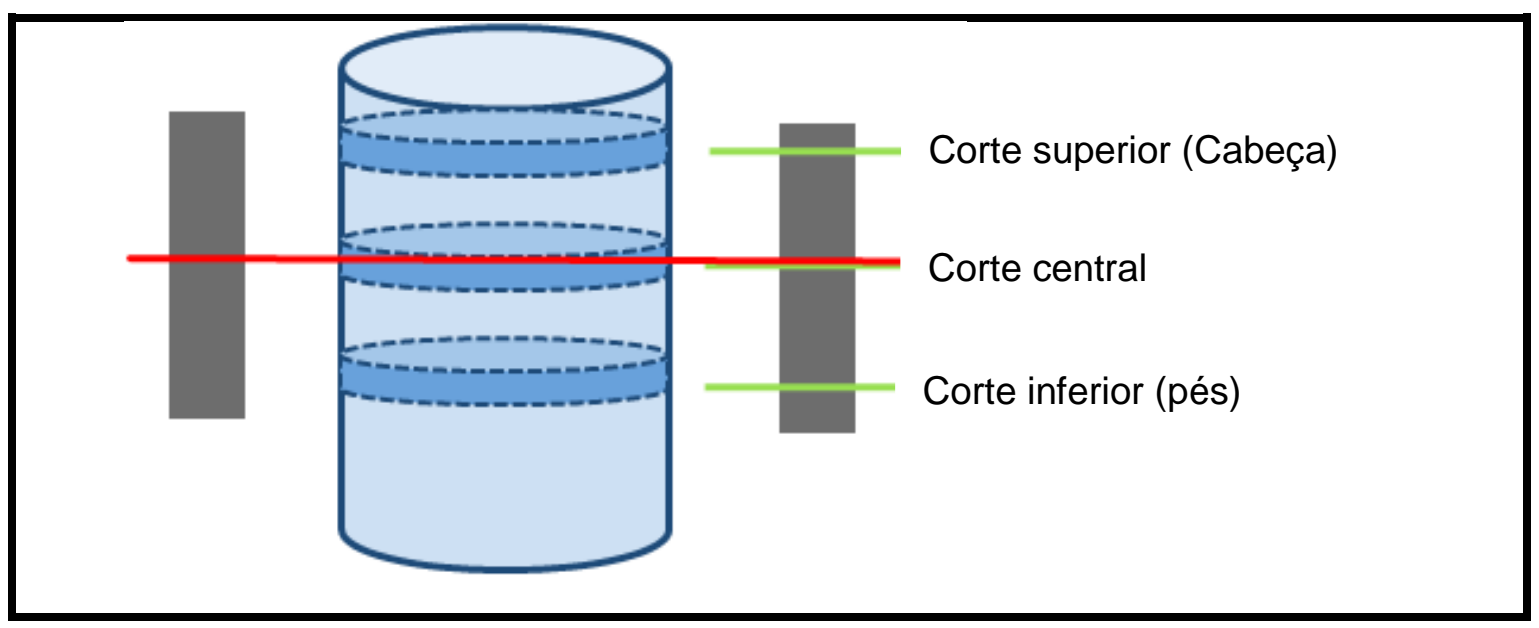

Figura 18: Cilindro de PMMA usado para o estudo da homogeneidade de campo da bobina de cabeça do aparelho MRI.

O estudo da homogeneidade de campo foi feito em cortes axiais na parte superior, central e inferior do cilindro, como mostrado Figura 18. Nessas posições foram avaliadas regiões de interesse (ROI, do inglês region of interest) com círculos de raios de 1,5; 3,0;4,5;6,0;7,0 e 9,0 cm, nos quais se determinava a média dos valores de R2, para cada ROI. Também foi feita a avaliação da homogeneidade em um corte longitudinal.

\subsubsection{Filme radiocrômico EBT2}

Filmes radiocrômicos IEA EBT-2 do lote FN 3099293 foram utilizados tanto para a determinação da sua dependência de resposta com a dose, taxa de dose e com o tempo de leitura após irradiação, sendo estas medidas para 
caracterização do filme utilizado. Também foram determinadas curvas de PDP e perfis de campo, que foram utilizadas para a validação do uso dos filmes.

As determinações das distribuições dose para a técnica conformacional com campos coplanares e não coplanares (como os casos de radiocirurgia) com o filme EBT2 foram realizadas com os mesmos sendo posicionados no eixo central do campo de irradiação.

A leitura do filme foi realizada em um escâner Vidar-DiagnosticPro com 300 dpi do HC-Ribeirão Preto seguindo as recomendações do fabricante.

\subsubsection{Sistema de planejamento}

O sistema de planejamento (TPS) utilizado neste estudo foi o iPlan ${ }^{\circledR}$ RT Dose 4.1 (BrainLab m3), cujo algoritmo de cálculo de dose é o PencilBeam. Esse sistema determina o planejamento radioterápico considerando a definição geométrica das projeções desejadas (tamanho e angulação dos campos estático ou dinâmico), otimizando as características físicas das lâminas de colimação e, também, a contribuição através dos colimadores multi-folhas (Delgado et al 2006).

O TPS iPlan ${ }^{\circledR}$ foi utilizado para as determinações dos parâmetros dosimétricos (PDPs e perfis de dose), para campos circulares pequenos de 1,0; 2,0; $3,0 \mathrm{~cm}$ de raio, com o espectro de energia do feixe de fótons de $6 \mathrm{MV}$, na modalidade de DFS.

Por meio do TPS também foi possível realizar o planejamento de campos coplanares e não coplanares com a técnica de radiocirurgia, com a modalidade de distância fonte alvo (técnica isocêntrica), com campos de até $3 \mathrm{~cm}$ de raio. Todos os planejamentos foram realizados a partir das imagens de CT dos OS de cabeça.

\subsubsection{Código de simulação Monte Carlo PENELOPE}

O código PENELOPE, versão 2008, (Salvat et al, 2009) foi utilizado para simular distribuições de dose para validações das ferramentas dosimétricas com campos pequenos e também para determinar as distribuições de dose com a técnica conformacional coplanar e não coplanar, para os casos de 
radiocirurgia, utilizando os espetros dos feixes de $6 \mathrm{MV}$ e $10 \mathrm{MV}$ dos aceleradores lineares Varian.

Para as simulações foram consideradas as mesmas condições experimentais, como as energias dos feixes, as geometrias e materiais de irradiação. O número de partículas primárias simuladas foi da ordem de $10^{9}$ partículas. Uma resolução espacial melhor que $0,125 \mathrm{~mm}$ foi utilizada para a simulação das distribuições de doses. Os resultados de energia depositada em cada voxel dos OS foram analisados com um aplicativo desenvolvido em plataforma MatLab ${ }^{\circledR}$ e foram determinadas curvas de PDP, perfis de dose, distribuições de dose, índice gama, DVHs e TCPs.

\subsubsection{Simulação do material do MAGIC-f gel}

As simulações os tratamentos foram realizadas com os OS formados por água. Entretanto, para avaliar a resposta do material do gel polimérico, também utilizando simulação, foi criado um arquivo de material com a composição do dosímetro experimental MAGIC-f.

Para esse estudo foi considerada uma geometria com um OS cúbico de $30 \mathrm{~cm}$ de aresta para descrever a geometria de irradiação, nas condições de referência, campo $10 \times 10 \mathrm{~cm}^{2}$, distância fonte superfície de $100 \mathrm{~cm}$, espectros de energia de $6 \mathrm{MV}$ e $10 \mathrm{MV}$.

\subsection{Medidas para caracterização da resposta do MAGIC-f}

Para caracterização do MAGIC-f gel foram utilizadas diversos OS, específicos para cada estudo. Todas as irradiações foram realizadas em um acelerador linear Varian 2100c, como mostrado na Figura 15(a). Excepcionalmente, foi utilizada a Unidade de Cobalto 60 para a medida da dependência do gel com o tempo de leitura após a irradiação, Figura 15(c).

\subsubsection{Dependência da resposta do MAGIC-f com a dose}

A resposta do MAGIG- $f$ gel com a dose foi avaliada em um intervalo de 0,5 a 10 Gy. Um lote de $90 \mathrm{ml}$ de gel foi preparado e distribuído em OS como 
mostrado a Figura 14(a). Os OS foram posicionados dentro de um paralelepípedo de PMMA de $5 \times 5 \times 10 \mathrm{~cm}^{3}$, na profundidade de máxima dose, ou seja, em 1,5 cm e 2,5 cm para os feixes de $6 \mathrm{MV}$ e $10 \mathrm{MV}$, respectivamente. Esse conjunto, OS mais paralelepípedo de PMMA, foi posicionado dentro de um cubo de PMMA de $50 \times 50 \times 50 \mathrm{~cm}^{3}$, preenchido com água. A Figura 19 mostra a geometria de irradiação. A irradiação foi feita em condições convencionais, campo de $10 \times 10 \mathrm{~cm}^{2}$, DFS de $100 \mathrm{~cm}$, taxa de dose de 400 cGy/min para as energias de $6 \mathrm{MV}$ e $10 \mathrm{MV}$.

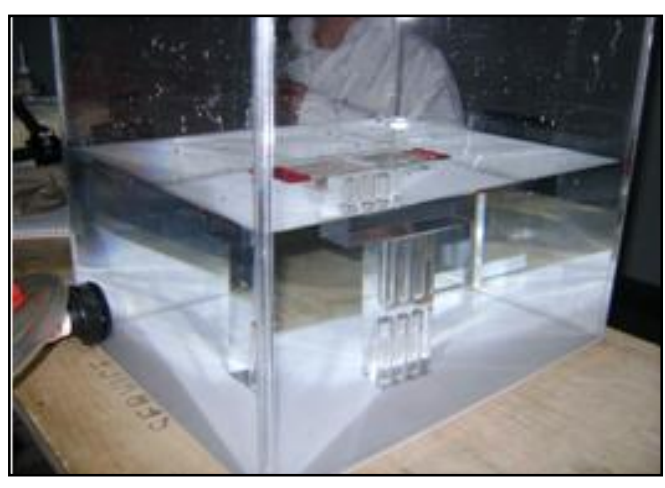

(a)

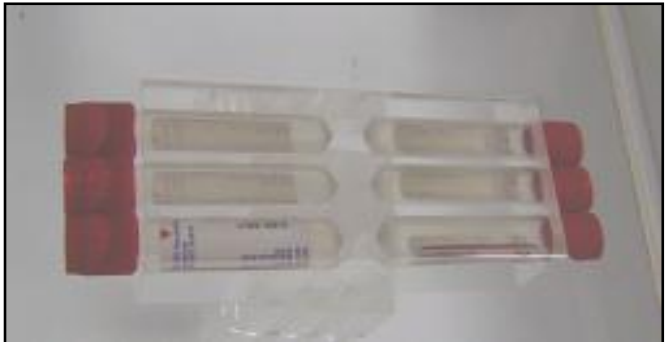

(b)

Figura 19: Geometria de irradiação para determinar a dependência do MAGICf com a dose em um intervalo de 0,5 até 10Gy. (a) arranjo de irradiação (b) tubos de vidro com gel posicionados em suporte de PMMA dentro do OS de água.

\subsubsection{Dependência da resposta do MAGIC- $f$ com a taxa de dose}

Para avaliar a dependência de resposta do MAGIC- $f$ gel em diferentes taxas de dose foram utilizados os mesmos OS e mesma geometria de irradiação do estudo para dependência com a dose, descrito no item 4.2.2. O intervalo de taxa de dose estudado foi de 80 até 400 cGy/min, com uma dose 2 Gy para os feixes de 6 e $10 \mathrm{MV}$. 


\subsubsection{Dependência de resposta do MAGIC-f com tempo de leitura após a irradiação}

Para o estudo da dependência do sinal do MAGIC- $f$ em função do tempo de espera após a irradiação, foram utilizados três tubos de coleta de sangue de $5 \mathrm{ml}$, Figura 14 (a), preenchido com MAGIC- $f$ gel, irradiados com 5 Gy e dois tubos irradiados com doses de 10 e 15 Gy cada um, como mostrado na Figura 20. Um campo de $10 \times 10 \mathrm{~cm}^{2}$ e DFS de $80 \mathrm{~cm}$ para um feixe de Cobalto 60 foi utilizado. As leituras das amostras foram realizadas em um intervalo de 0,5 até 9,15 dias após a irradiação.

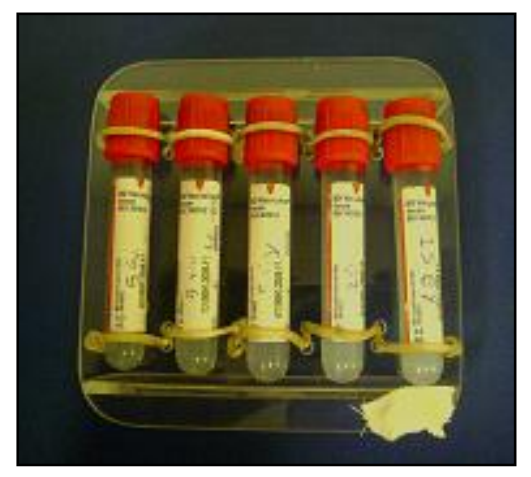

Figura 20: Objetos simuladores para o estudo da dependência da resposta em função do tempo de espera para leitura após a irradiação. Tubos irradiados com doses de 5 Gy (os três primeiros tubos a partir da esquerda), 10 Gy e 15Gy, respectivamente.

\subsubsection{Repetitibilidade do MAGIC-f}

A repetitibilidade do dosímetro foi avaliada determinando-se o desvio padrão do sinal de RMN obtido em amostras irradiadas e processadas nas mesmas condições. Para esse estudo foram utilizados três tubos de coleta de sangue de $5 \mathrm{ml}$, Figura 14 (a), irradiados com 5 Gy em condições convencionais de irradiação, campo $10 \times 10 \mathrm{~cm}^{2}$, DFS $80 \mathrm{~cm}$ para a energia de Cobalto 60 .

\subsubsection{Porcentagem de dose profunda}

Para as medidas da PDPs com MAGIC-f, para os feixes de fótons de 6 MV e $10 \mathrm{MV}$, foram utilizados tubos de vidro de $50 \mathrm{ml}$ (16 cm de comprimento 
por $1,5 \mathrm{~cm}$ de diâmetro) preenchido com MAGIC- $f$ gel, Figura 14 (b). O tubo foi posicionado alinhando-se o seu comprimento paralelamente ao eixo central do feixe de irradiação, no centro de um cubo de PMMA de $50 \times 50 \times 50 \mathrm{~cm}^{3}$, preenchido com água e irradiado com 10 Gy nas condições convencionais de irradiação, para ambos os feixes.

A montagem de irradiação para cada medida de PDP é mostrada na Figura 21.

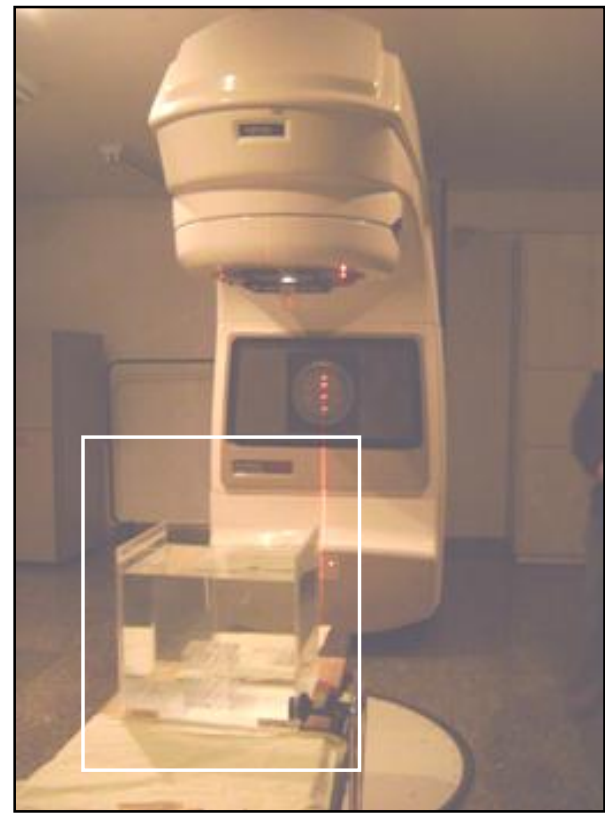

(a)

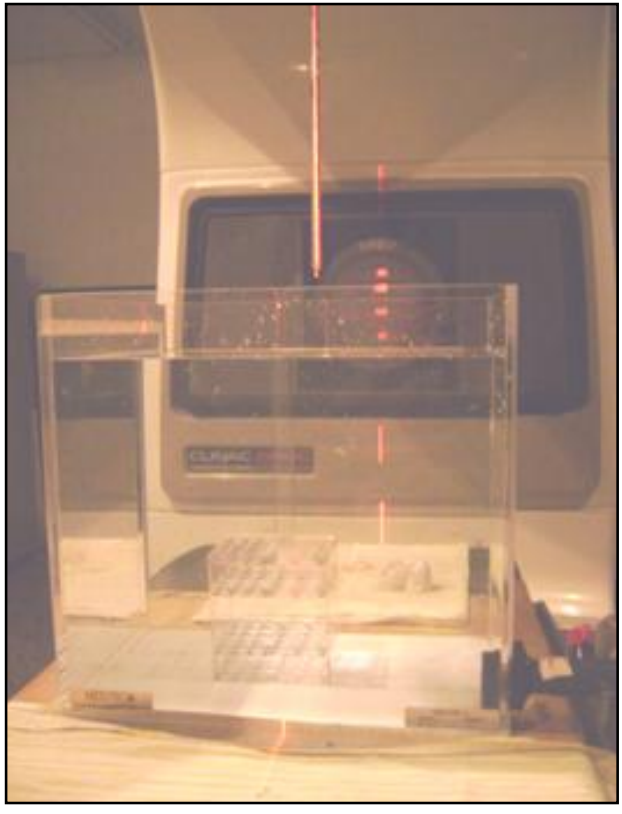

(b)

Figura 21: Geometria para determinação da PDP (a) Geometria completa; (b) Detalhe do tanque de PMMA contento o tubo de vidro, que está centralizado com o campo de irradiação.

A leitura das amostras, no tomógrafo de RNM, foi realizada por meio de um corte longitudinal, paralelo ao comprimento do tubo. As imagens obtidas foram analisadas pelo programa mencionado na seção 3.3.1.1 e os valores relativos de dose na linha central de cada tubo foram determinados. A partir de esses valores foram determinadas as PDP, seguindo a equação 14.

Foram realizadas simulações utilizando o código PENELOPE para as determinações das PDP de $6 \mathrm{MV}$ e $10 \mathrm{MV}$, nas mesmas condições e geometria de irradiação. 


\subsection{Medidas para caracterização da resposta do filme radiocrômico EBT2}

Filmes radiocrômicos foram caracterizados e utilizados para as determinações das distribuições de dose. A leitura do filme foi realizada em um escâner Vidar-DiagnosticPro com 300 dpi do HC-Ribeirão Preto seguindo as recomendações do fabricante.

Para a caracterização do filme EBT2 as irradiações foram realizadas em um acelerador linear $\mathrm{ONCOR}^{\circledR}$, Figura 15, para as energias de $6 \mathrm{MV}$ e $10 \mathrm{MV}$.

\subsubsection{Dependência de resposta do filme ETB2 com a dose}

Para avaliar a dependência do filme radiocrômico EBT2 com a dose, duas folhas desse filme foram utilizadas e cortadas com tamanho de $7 \times 7 \mathrm{~cm}^{2}$. Cada parte do filme foi irradiada com uma dose diferente; o intervalo de dose utilizada foi de 0 a 18 Gy.

Para a irradiação, os filmes foram posicionados entre placas de água sólida de $30 \times 30 \times 30 \mathrm{~cm}^{3}$ na profundidade de dose máxima, ou seja, em 1,5 $\mathrm{cm}$ para uma energia de $6 \mathrm{MV}$, DFS $100 \mathrm{~cm}$, campo de $5 \times 5 \mathrm{~cm}^{2}$ e taxa de dose de 400 cGy/min, como mostrado na Figura 22.

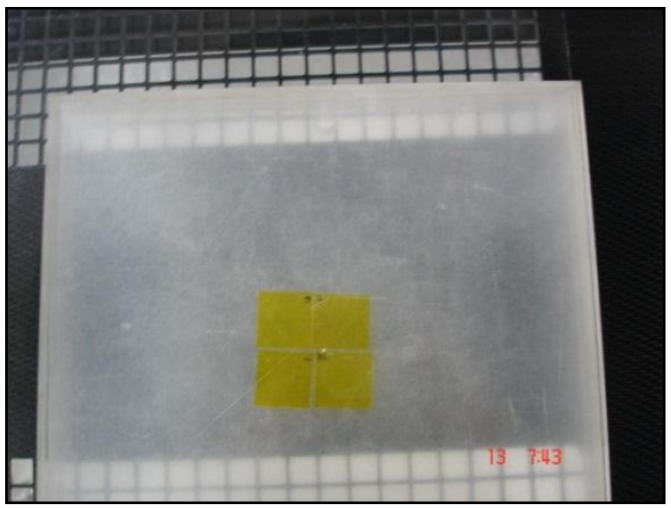

(a)

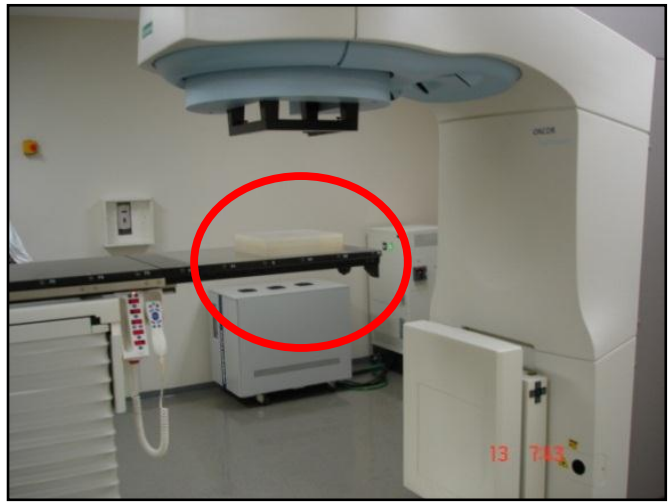

(b)

Figura 22: Irradiação dos filmes EBT2: (a) filmes e OS, (b) geometria de irradiação. 


\subsubsection{Dependência de resposta do filme EBT2 com a taxa de dose}

Para a determinação da dependência do filme EBT2 com a taxa de dose, foi considerado um intervalo de $80 \mathrm{~Gy} / \mathrm{min}$ até $400 \mathrm{~Gy} / \mathrm{min}$ nas mesmas condições e geometria de irradiação do item 3.6.1, com doses de 5 Gy.

\subsubsection{Dependência de resposta do filme ETB2 com o tempo de leitura após a irradiação}

Para a avaliação da dependência do EBT2 com o tempo de espera para leitura após a irradiação, os filmes foram irradiados e lidos em um intervalo de tempo que variou de 8 a 96 horas após a irradiação. A irradiação foi realizada na profundidade de dose máxima, ou seja, em 1,5 cm para uma energia de 6 MV, DFS $100 \mathrm{~cm}$, campo de $5 \times 5 \mathrm{~cm}^{2}$, com doses de 5, 10 e 15 Gy e taxa de dose de 400 cGy/min.

\subsubsection{Porcentagem de dose profunda}

Para as medidas da PDPs com o filme EBT2, para os feixes de fótons de $6 \mathrm{MV}$, foram utilizados o OS cilindro, mostrado na Figura 14 (f). Os filmes foram posicionados, no centro do OS, alinhando-se o seu comprimento paralelamente ao eixo central do feixe de irradiação. A irradiado foi feita com 10 Gy nas condições convencionais de irradiação, para o feixe de fótons de $6 \mathrm{MV}$.

\subsection{Medidas para validação das ferramentas dosimétricas}

As irradiações para validação das ferramentas dosimétricas utilizadas foram realizadas no HCB-Barretos, utilizando o acelerador linear de $6 \mathrm{MV}$ mostrado na Figura 15 (a).

Inicialmente, foram adquiridos dados de dose no plano central ao longo da direção do feixe de irradiação com o TPS iPlan ${ }^{\circledR}$, para três campos pequenos de irradiação: 1, 2 e $3 \mathrm{~cm}$ de diâmetro para o feixe de $6 \mathrm{MV}$. Com o 
código PENELOPE foram simulados os campos de irradiação, nas mesmas condições e energia, e foram obtidas as distribuições de dose dos planos centrais para cada campo.

Nas mesmas condições da simulação e TPS foram feitas medidas experimentais, para a determinação das distribuições de doses nos planos centrais de cada campo, utilizando OS mostrado na Figura 14(c), preenchido com MAGIC-f. Também foi utilizado OS mostrado na Figura 14(d), para posicionar o filme EBT2.

Através dos respectivos sistemas de leituras do gel e do filme foram determinadas as distribuições de dose no plano central do feixe de irradiação.

As distribuições de dose dos planos centrais obtidas com o MAGIC-f, PENELOPE, filme radiocrômico EBT2 e TPS iPlan ${ }^{\circledR}$ foram analisadas através de programas específicos que foram desenvolvidas (na plataforma de Matlab ${ }^{\circledR}$ ) para cada ferramenta dosimétrica. Assim, as distribuições de doses obtidas foram validadas através dos parâmetros dosimétricos PDP, equação 14, e perfis de campo, seguindo a equação 15 . Os perfis de dose foram obtidos em duas profundidades especificas: profundidade de dose máxima, ou seja, em 1,5 $\mathrm{cm}$ para o feixe de $6 \mathrm{MV}$ e em $5 \mathrm{~cm}$ de profundidade.

\subsection{Irradiações conformacionais com campos pequenos}

Estudos preliminares foram realizados para determinar distribuições de dose para técnicas conformacionais com campos pequenos coplanares e nãocoplanares. Foram simulados dois casos de irradiações coplanares: 5 e 6 campos e posteriormente, um caso de não coplanar: 7 campos. Os planejamentos foram realizados para o acelerador linear Varian, 2100CD de 6MV.

As distribuições de dose obtidas com as ferramentas dosimétricas foram comparadas através da determinação do perfil de campo e do índice $\gamma$. Para a comparação das distribuições de dose pelo índice $\gamma$ foi desenvolvido um programa na plataforma do MatLab ${ }^{\circledR}$ que quantifica os valores dos incides $\gamma$ gerando uma mapa desses índices. 


\subsubsection{Irradiação conformacional coplanar}

Para a obtenção das distribuições de doses para uma irradiação coplanar de 5 campos, utilizou-se um OS cilíndrico de PPMA, Figura 14 (e), preenchido como MAGIC-f. A irradiação foi planejada através de imagens de CT do OS, com o alvo no isocentro, utilizando-se 5 campos de $1 \times 1 \mathrm{~cm}^{2}$, com o gantry do acelerador linear posicionado em $0^{\circ}, 45^{\circ}, 90^{\circ}, 135^{\circ}$ e $180^{\circ}$, como mostrado na Figura 15 (a). O OS foi irradiado com uma dose de 2 Gy, com feixe de fótons de $6 \mathrm{MV}$, taxa de dose de 400 cGy/min e distância fonte isocentro de $100 \mathrm{~cm}$.

A distribuição de dose foi obtida em corte axial no isocentro do OS, e a análise de essa imagem foi feita no programa desenvolvido em Matlab®. Os dados com MAGIC- $f$ foram comparados com obtidos por PENELOPE, para as mesmas condições e geometria de irradiação.

Para a irradiação com 6 campos, foram realizadas imagens de CT do OS utilizado na irradiação de 5 campos, com cortes de $1 \mathrm{~mm}$. Através das imagens de CT foi planejada uma técnica de irradiação coplanar com ângulos de $0^{\circ}, 20^{\circ}, 50^{\circ}, 70^{\circ}, 100^{\circ}, 140^{\circ}$, com tamanho de campo de $1 \mathrm{~cm}$ de diâmetro, irradiado com uma dose de 2 Gy, para um feixe de 6 MV e a uma distância fonte isocentro de $100 \mathrm{~cm}$.

Nessas mesmas condições de geometria e irradiação foi feita a simulação dos 6 campos utilizando o código PENELOPE.

Experimentalmente, foi realizada, ainda, a irradiação com filme EBT2 dentro do OS, na mesma altura em que foi planejado o centro do alvo irradiado. A irradiação do OS com o filme foi planejada com o alvo no isocentro, girandose o gantry do acelerador linear, como mostrado na Figura 15 (a), nas mesmas condições que o TPS iPlan ${ }^{\circledR}$, e com uma taxa de dose de 400 cGy/min.

A distribuição de dose obtida com EBT2 foi comparada com as distribuições de doses determinadas através do TPS e PENELOPE. Para a comparação dos mapas de dose foi utilizado o índice $\gamma$, com parâmetros de 3 mm (DTA) e 3\% de diferença em dose. 


\subsubsection{Irradiação conformacional não coplanar}

Para a obtenção da distribuição de dose em um planejamento com 7 campos não coplanares utilizou-se um OS cilíndrico de PMMA (o mesmo utilizado para as irradiações com campos coplanares), como mostra na Figura 15 (e). Imagens de CT do OS foram utilizadas para planejar uma irradiação com 7 campos de $1 \mathrm{~cm}$ de diâmetro, com angulação dos campos mostradas na Tabela 2. O alvo foi posicionado no isocentro, a uma distância fonte-isocentro de $100 \mathrm{~cm}$ e feixe de fótons de $6 \mathrm{MV}$.

Tabela 2: Angulações do gantry e da mesa para o teste com 7 campos de irradiação não coplanares.

\begin{tabular}{l|c|c|c|c|c|c|c}
\hline Campo & 1 & 2 & 3 & 4 & 5 & 6 & 7 \\
\hline Mesa $\left(^{\circ}\right)$ & 10 & 10 & 60 & 60 & 60 & 60 & 90 \\
\hline Gantry $\left(^{\circ}\right)$ & 100 & 260 & 60 & 120 & 240 & 300 & 340 \\
\hline
\end{tabular}

O filme radiocrômico EBT2 foi posicionando na metade do OS para realizar a irradiação nas mesmas condições do TPS utilizando uma taxa de dose de 400 cGy/min, dose de 2Gy com o acelerador linear mostrado na Figura 15(d). Após a irradiação o filme foi lido e as imagens obtidas foram analisadas por um programa desenvolvido na plataforma de Matlab® para determinação da distribuição de dose.

A distribuição de dose para o planejamento também foi determinada com o código PENELOPE, nas mesmas condições e geometria de irradiação. Os resultados foram comparados com as distribuições de doses determinadas com TPS e ETB2 utilizando a comparação do índice $\gamma$, com parâmetros de $3 \mathrm{~mm}$ (DTA) e $3 \%$ de diferença em dose.

\subsection{Casos de Radiocirurgia}

Foram estudados três casos de tratamentos com a técnica de radiocirurgia do serviço de radioterapia do HCB-Barretos. Os parâmetros utilizados para tratamentos de pacientes foram utilizados para o planejamento desses tratamentos através do uso do OS de cabeça, Figura 14 (d). As imagens de CT do OS de cabeça com o aparelho estereotáxico, como 
mostrado na Figura 23, foram utilizadas para os planejamentos dos casos de radiocirurgia estudados: meningioma, melanoma e neurinoma do acústico.

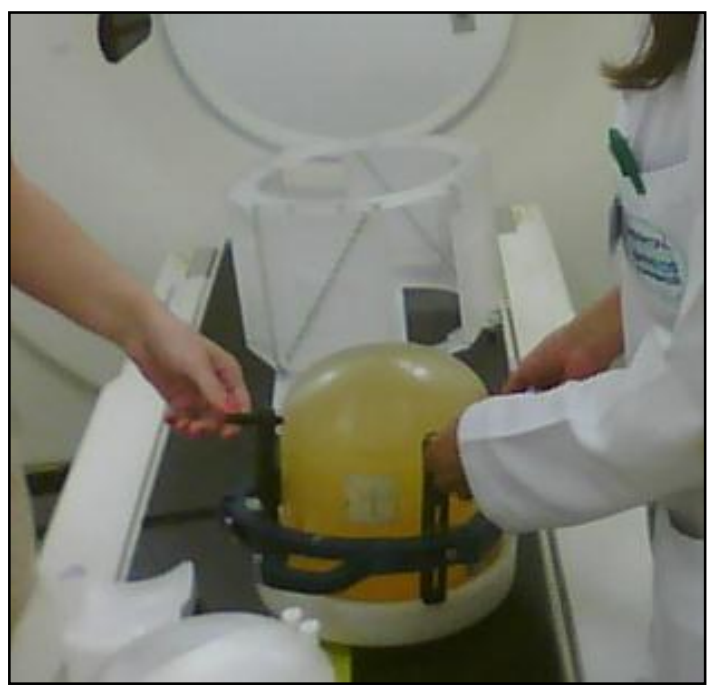

(a)

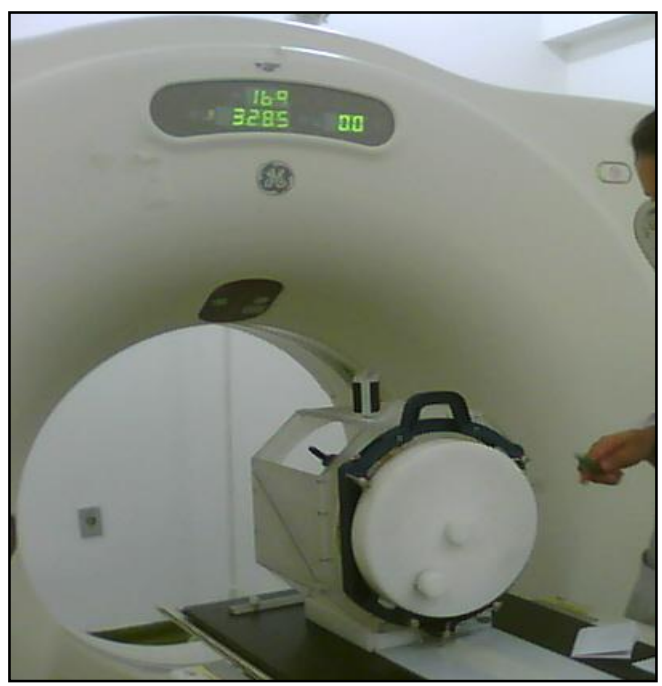

(b)

Figura 23: Posicionamento do aparelho estereotáxico no objeto simulador de cabeça (a) e posicionamento do objeto simulador para realização de CT de simulação (b).

As distribuições de dose obtidas através das quatro ferramentas dosimétricas foram analisadas e comparadas através índice $\gamma$, seguindo a equação 16. Assim, um programa desenvolvido na plataforma MatLab ${ }^{\circledR}$ determinava os mapas do índice $\gamma$.

Também, foram determinadas as curvas de DVH para as ferramentas dosimétrica para os três casos de radiocirurgia estudado.

Os planejamentos também foram analisados através de curvas de TCP, determinadas através da equação 20 com parâmetros encontrados na literatura para lesões tratadas com a técnica de SRS sendo: $\gamma_{50}=0,8 \mathrm{~Gy}^{-1}$ e $\mathrm{D}_{50}=16,9$ Gy (Andisheh et al, 2009). Por meio de um programa desenvolvido na plataforma MatLab ${ }^{\circledR}$ foram determinadas os TCP, voxel a voxel para os volumes de planejamento, para as ferramentas dosimétricas utilizadas. Mapas TCP foram elaborados em planos centrais dos tratamentos. Após a determinação dos mapas de TCP, foram gerados os histogramas acumulativos 
de TCP versus volume alvo, histograma TCP-Volume, como proposto por Bloch (Bloch, 2012).

\subsubsection{Caso 1: Meningioma}

Um tratamento de meningioma foi simulado com três arcos dinâmicos, em um OS de cabeça foi irradiado de acordo com o planejamento, para um feixe de fótons de $6 \mathrm{MV}$, campo de irradiação de $3 \mathrm{~cm}$ de diâmetro, distância fonte-isocentro de $100 \mathrm{~cm}$, taxa de dose de $400 \mathrm{cGy} / \mathrm{min}$ e dose total de 20 Gy. A Figura 24 mostra alguns planos do tratamento no TPS, com arcos dinâmicos para este caso.
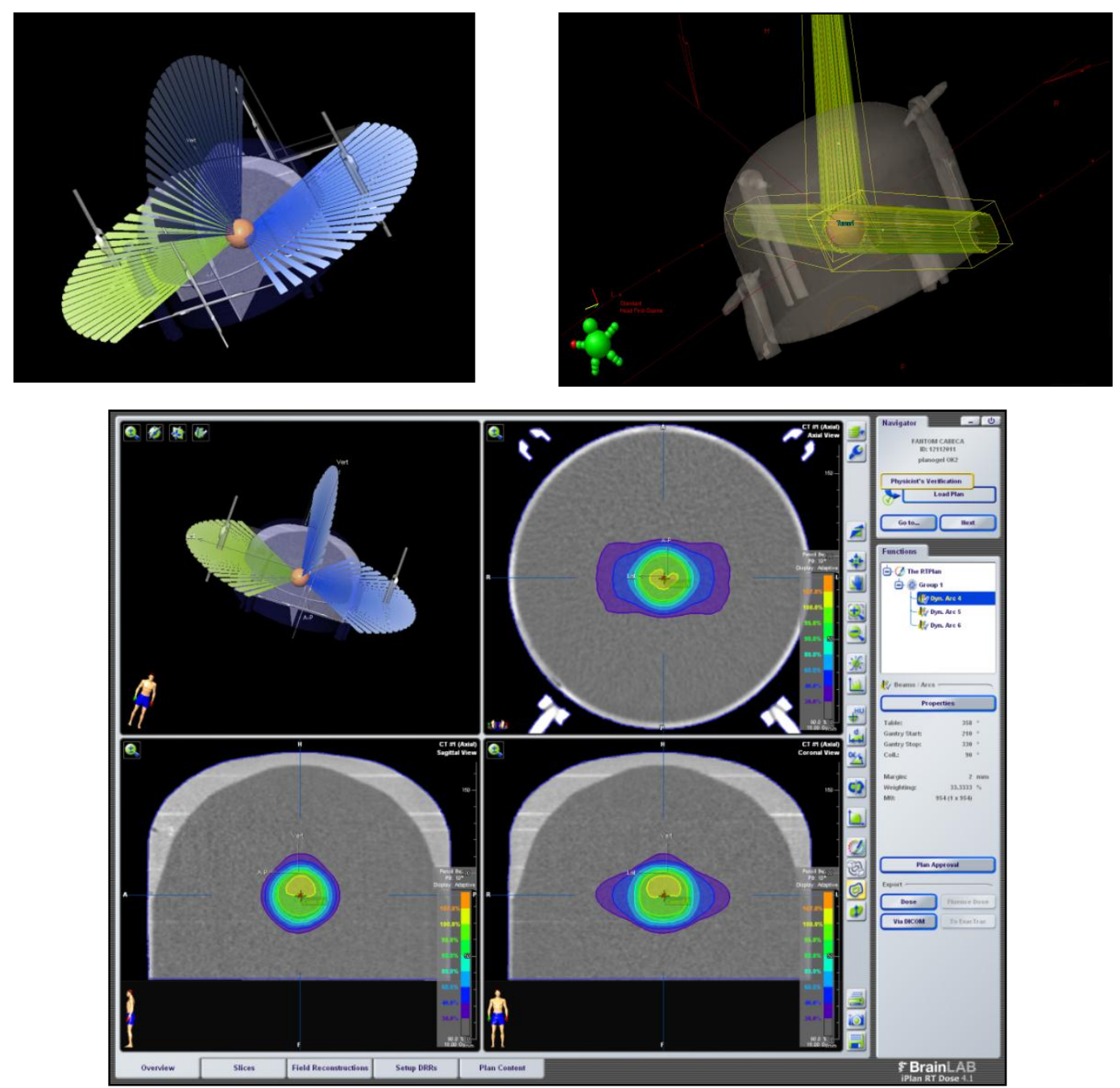

Figura 24: Planejamento de um caso de meningioma com o sistema de planejamento iPlan®, com três arcos dinâmicos. 
A tabela 3 mostra as angulações do gantry e da mesa para três arcos dinâmicos utilizados nesse estudo.

Tabela 3: Angulações do gantry e da mesa para três arcos dinâmicos planejados para o caso de meningioma.

\begin{tabular}{c|c|c|c}
\hline Arco & Mesa $\left(^{\circ}\right)$ & Gantry inicial $\left(^{\circ}\right)$ & Gantry final $\left(^{\circ}\right)$ \\
\hline 1 & 358 & 210 & 330 \\
\hline 2 & 90 & 30 & 150 \\
\hline 3 & 0 & 30 & 150 \\
\hline
\end{tabular}

Com as mesmas condições planejadas, o OS de cabeça foi irradiado duas vezes. Primeiramente, preenchido com MAGIC- $f$ e depois utilizando filme radiocrômico EBT2. O filme foi posicionado na metade do OS, apoiado em duas placas circulares de PPMA, e depois o OS foi preenchido com água. As figuras 25 e 26 mostram o OS preenchido com MAGIC- $f$ e o posicionamento do EBT2, respectivamente.

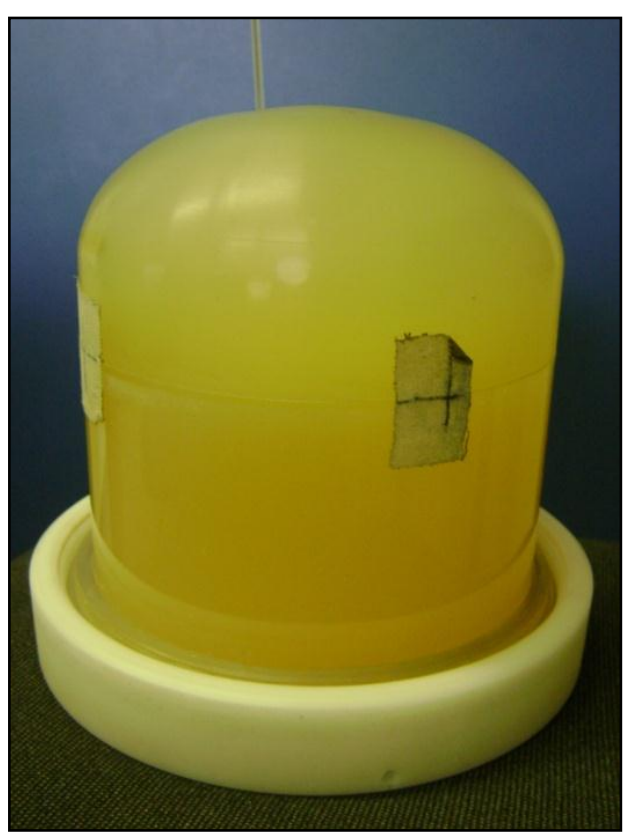

(a)

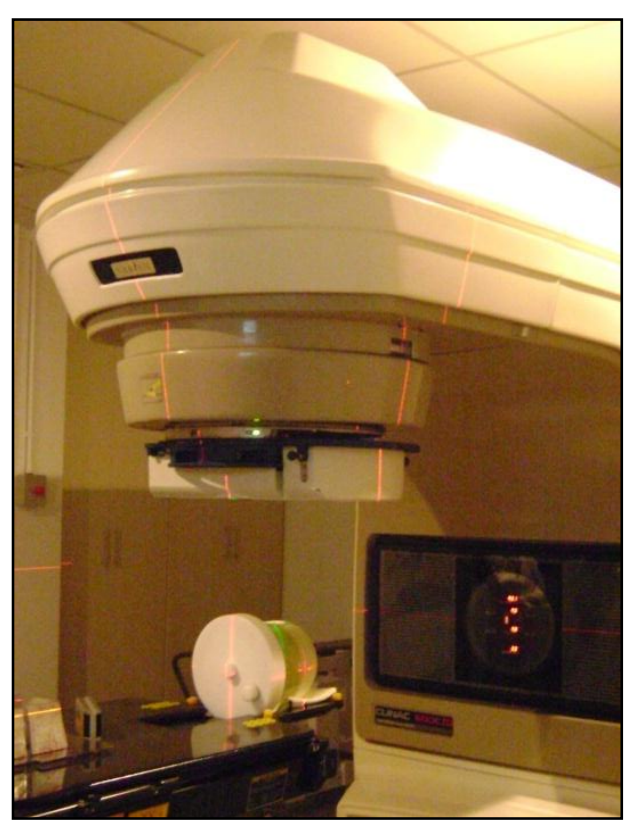

(b)

Figura 25: OS de cabeça: (a) preenchido com MAGIC-f; (b) posicionado para irradiação. 

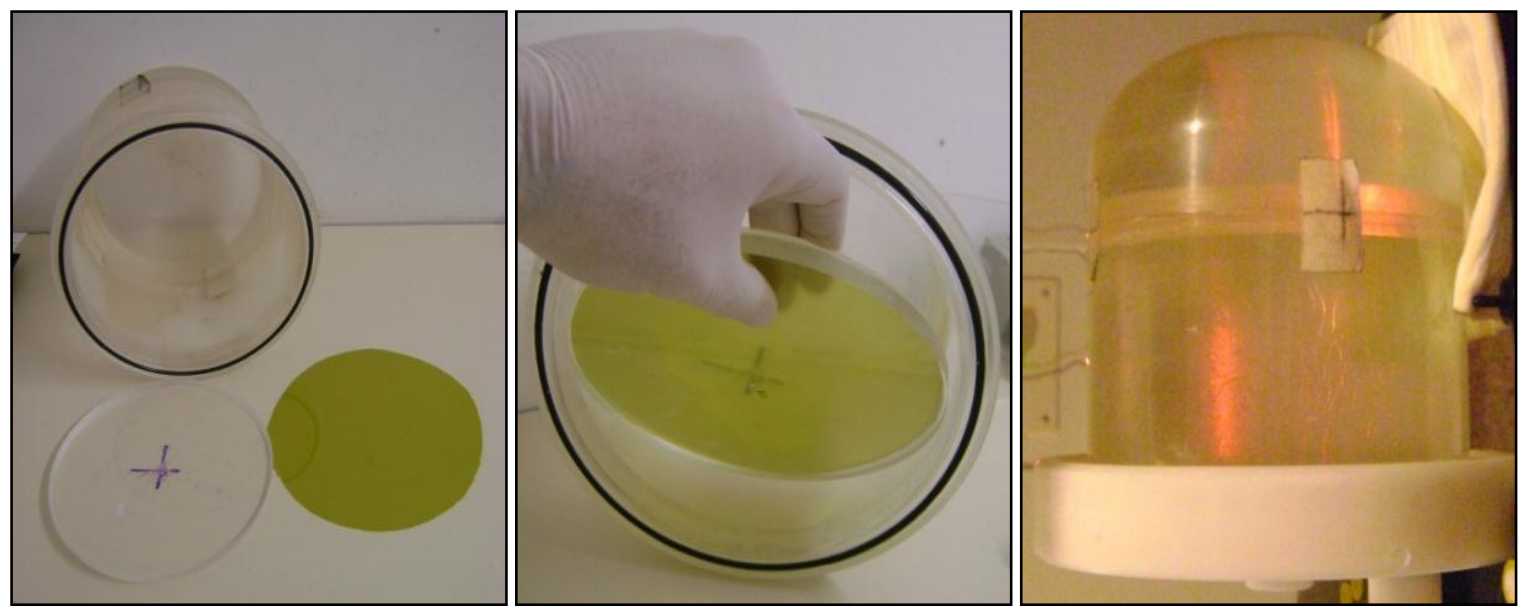

Figura 26: Posicionamento do filme EBT2 dentro OS de cabeça com dois suportes circulares de acrílico.

Este tratamento foi, ainda, simulado com o código PENELOPE, na mesma geometria e condições utilizadas para TPS iPlan ${ }^{\circledR}$, MAGIC- $f$ e EBT2.

A comparação das distribuições de doses obtidas com as quatro ferramentas dosimétricas foi avaliada através do índice gama. Um programa foi desenvolvido na plataforma de Matlab® para as análises. No programa, os critérios para a análise do índice $\gamma$, que são o DTA e a tolerância em dose, podem ser estabelecidos pelo usuário. Na prática clínica, para o caso de radiocirurgia, esses critérios ainda não são bem estabelecidos. Assim, nessas comparações foram estudadas as combinações de diversos critérios de DTA, de $1 \mathrm{~mm}$ a $3 \mathrm{~mm}$, e de tolerância de dose, de $1 \%$ até $5 \%$, para o primeiro caso de estudo de radiocirurgia. Os melhores resultados com estes critérios foram, então, aplicados para os casos seguintes.

\subsubsection{Caso 2: Melanoma}

O tratamento de um caso de melanoma foi planejado e irradiado para 0 OS de cabeça, com 9 campos estáticos, como mostrado na Tabela 4, para um feixe de fótons de $6 \mathrm{MV}$, utilizando-se campos circulares de $2,3 \mathrm{~cm}$ de diâmetro, distância fonte-isocentro de $100 \mathrm{~cm}$, taxa de dose de $400 \mathrm{cGy} / \mathrm{min}$ e dose total de 20 Gy. A Figura 27 mostra alguns planos do planejamento com TPS para este caso. 
Tabela 4: Angulações do gantry e da mesa para o planejamento com 9 campos estáticos para o caso de melanoma.

\begin{tabular}{l|c|c|c|c|c|c|c|c|c}
\hline Campo & 1 & 2 & 3 & 4 & 5 & 6 & 7 & 8 & 9 \\
\hline Mesa $\left(^{\circ}\right)$ & 70 & 287 & 320 & 85 & 54 & 26 & 27 & 342 & 324 \\
\hline Gantry $\left(^{\circ}\right)$ & 90 & 245 & 309 & 49 & 134 & 95 & 51 & 256 & 208 \\
\hline
\end{tabular}

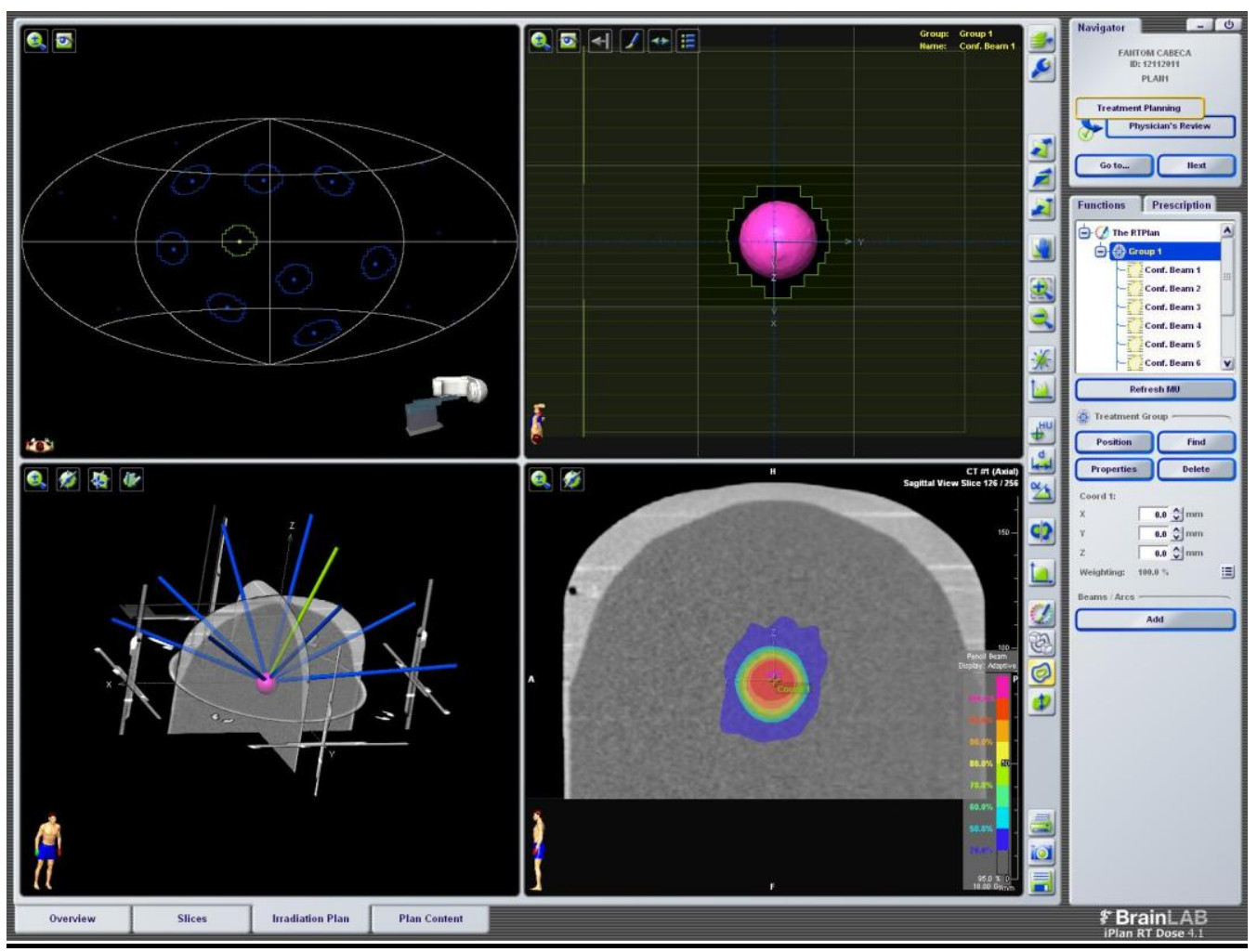

Figura 27: Planejamento do OS de cabeça com 9 campos não coplanares, para a simulação de um tratamento de melanoma.

Assim como no caso 1, com as mesmas condições planejadas, o OS de cabeça foi irradiado duas vezes: preenchido com MAGIC- $f$ e depois utilizandose o filme EBT2. O filme foi posicionado na metade do OS, apoiado em duas placas circulares de PMMA, e depois o OS foi preenchido com água.

Este tratamento também foi simulado com o código PENELOPE, na mesma geometria e condições utilizadas no TPS iPlan ${ }^{\circledR}$, MAGIC- $f$ e EBT2.

As comparações das distribuições de dose foram realizadas através do programa desenvolvido para determinar os índices gama, com os critérios de $3 \mathrm{~mm}$ de DTA e de 3, 4 e 5\% de tolerância de dose. 


\subsubsection{Caso 3: Neurinoma do acústico}

Um tratamento de neurinoma do acústico foi planejado e irradiado utilizabndo-se o OS de cabeça, com 11 campos estáticos, como mostrado na Tabela 5, para um feixe de fótons de $6 \mathrm{MV}$, campos circulares de 2,3 cm de diâmetro, distância fonte-isocentro de $100 \mathrm{~cm}$, taxa de dose de $400 \mathrm{cGy} / \mathrm{min}$ e dose total de 20 Gy. A Figura 28 mostra alguns planos do TPS iPlan ${ }^{\circledR}$ para este caso.

Tabela 5: Angulações do gantry e da mesa para o planejamento com 11 campos estáticos, para o caso do neurinoma do acústico.

\begin{tabular}{l|l|l|l|l|l|l|l|l|l|l|l}
\hline Campo & 1 & 2 & 3 & 4 & 5 & 6 & 7 & 8 & 9 & 10 & 11 \\
\hline Mesa $\left(^{\circ}\right)$ & 0 & 0 & 0 & 0 & 0 & 325 & 325 & 275 & 275 & 30 & 70 \\
\hline Gantry $\left(^{\circ}\right)$ & 90 & 55 & 350 & 315 & 270 & 335 & 310 & 300 & 270 & 60 & 60 \\
\hline
\end{tabular}

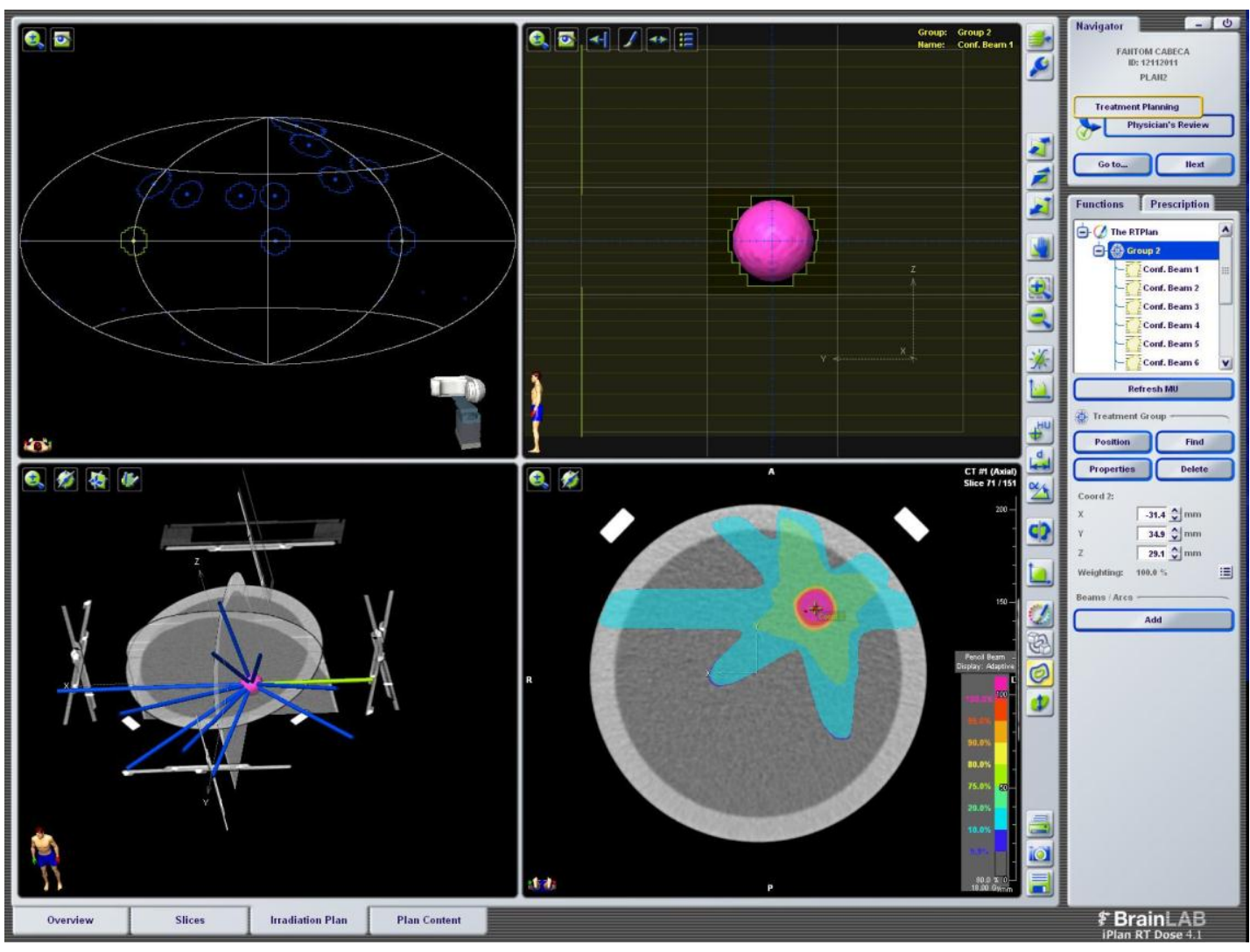

Figura 28: Planejamento do OS de cabeça com 11 campos não coplanares, para a simulação de um tratamento de neurinoma do acústico. 
Assim como no caso 1 e 2, com as mesmas condições planejadas, o OS de cabeça foi irradiado duas vezes: primeiramente preenchido com MAGIC- $f$ e depois utilizando-se o filme EBT2. O filme foi posicionado na metade do OS, apoiado em duas placas circulares de PMMA e depois o OS foi preenchido com água.

Este tratamento foi, também simulado com código PENELOPE, na mesma geometria e condições utilizadas para o planejamento no TPS iPlan ${ }^{\circledR}$, e irradiação do MAGIC-f e do filme EBT2.

As comparações das distribuições de dose foram realizadas através do programa desenvolvido para determinar os índices gama, com os critérios de $3 \mathrm{~mm}$ de DTA e de 3,4 e $5 \%$ de tolerância de dose. 


\section{Resultados e Discussões}

Nesse capítulo são apresentados os resultados e as discussões das medidas feitas para a caracterização do MAGIC- $f$ gel e do filme EBT2, assim como também, os resultados das validações das ferramentas dosimétricas: o código de simulação PENELOPE, o MAGIC- $f$ gel, o filme EBT2 e o TPS iPlan ${ }^{\circledR}$, para campos de irradiação pequenos, geralmente utilizados na radiocirurgia.

Também são mostrados os resultados das distribuições de dose para campos pequenos em planejamentos coplanares e não coplanares, e os resultados das distribuições de dose para casos de tratamentos de radiocirurgia utilizando o objeto simulador de cabeça descrito na seção 3.1.

\subsection{Medidas prévias realizadas antes da utilização do dosímetro MAGIC- $f$ gel}

Antes da utilização do dosímetro MAGIC- $f$ gel, medidas relacionadas à técnica de leitura do gel foram realizadas, como, por exemplo, a determinação da homogeneidade do campo magnético com a utilização da bobina de cabeça e o teste de equivalência em tecido do material do gel a partir de simulações com o código PENELOPE.

\subsubsection{Homogeneidade de campo com a bobina de cabeça}

As avaliações da homogeneidade de campo com o uso da bobina de cabeça do tomógrafo por MRI foram realizadas em cortes axiais de um cilindro de PMMA contendo uma solução aquosa como descrito no item 3.3.1.2. A Figura 29 mostra o esquema dos cortes axiais das imagens do objeto simulador cilíndrico usado para avaliação da homogeneidade do campo da bobina utilizada. 


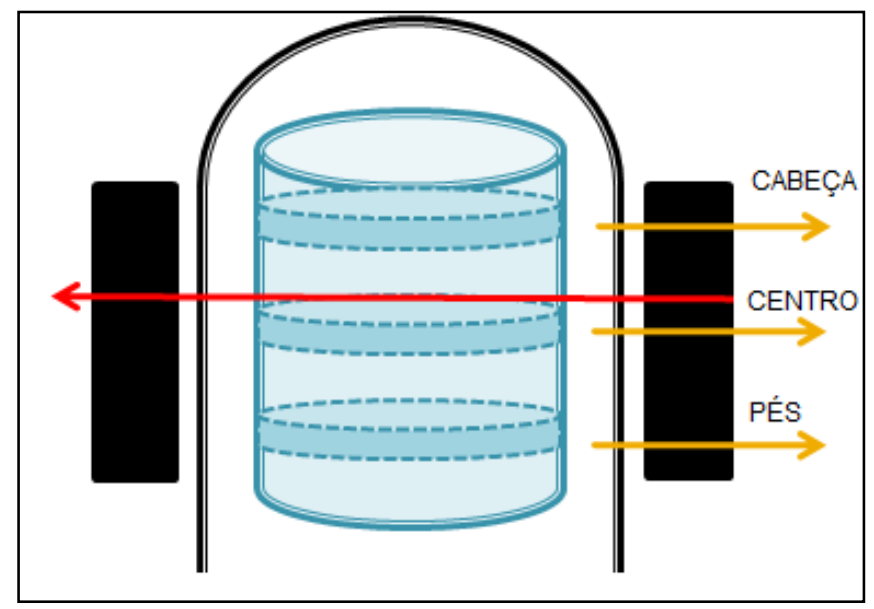

Figura 29: Esquema do posicionamento do objeto simulador cilíndrico de PMMA utilizado no estudo da homogeneidade de campo da bobina de cabeça .

As imagens de ressonância magnética, ponderadas em T2, e os mapas dos ângulos de fleep das regiões do cilindro (cabeça, centro e pés) são mostrados na Figura 30.

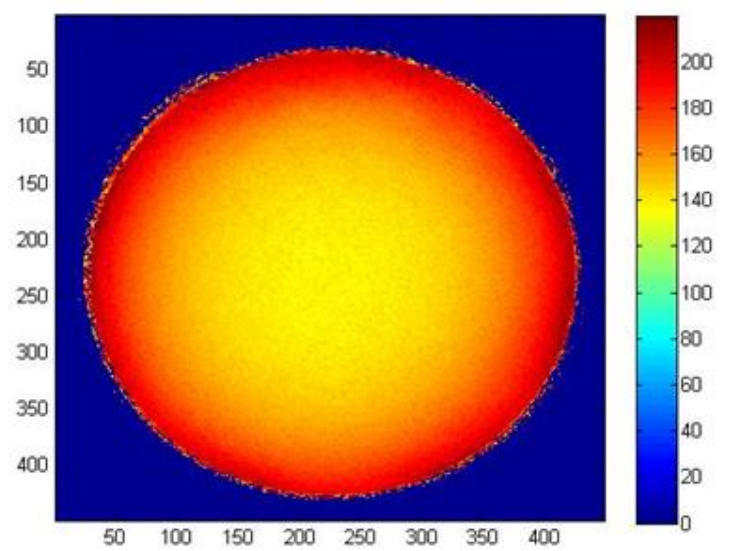

(a1)

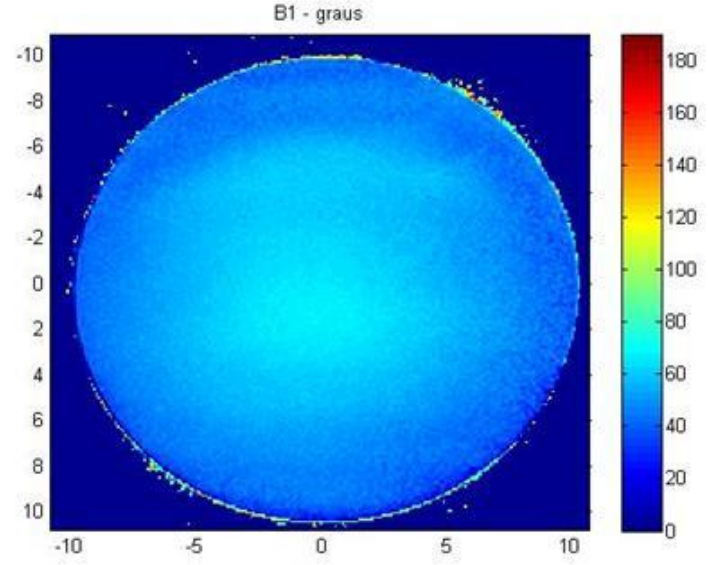

(a2)

Figura 30: MRI dos cortes axiais das regiões do cilindro de PMMA: (a1) cabeça, (b1) centro, (c1) pés e mapas dos ângulos de fleep para cada região: (a2) cabeça, (b2) centro, (c2). Continua. 


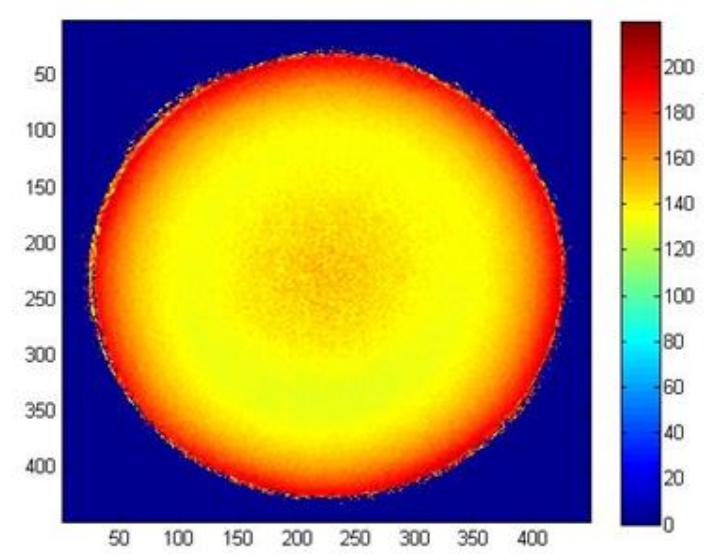

(b1)

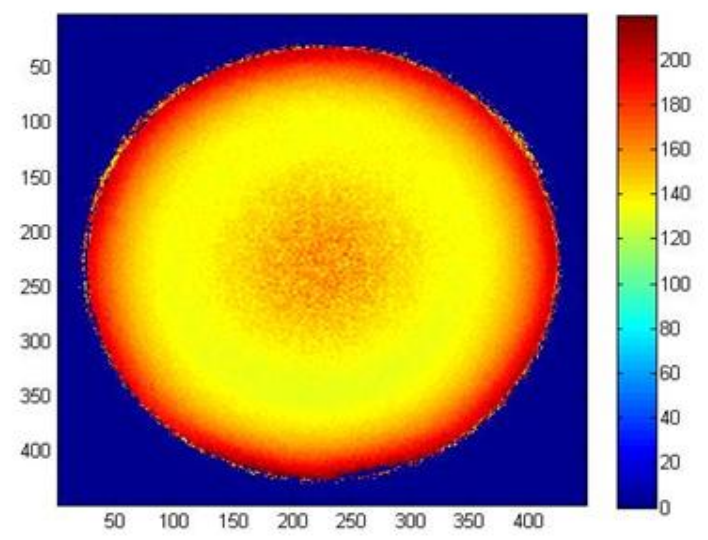

(c1)

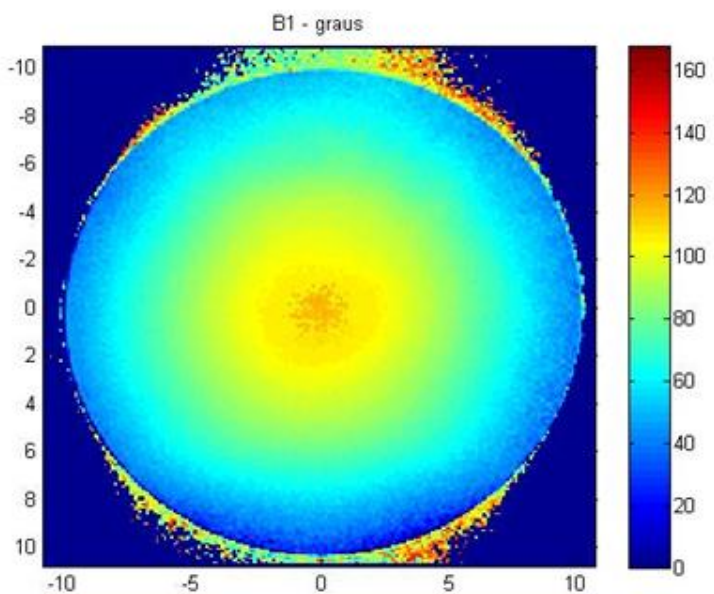

(b2)

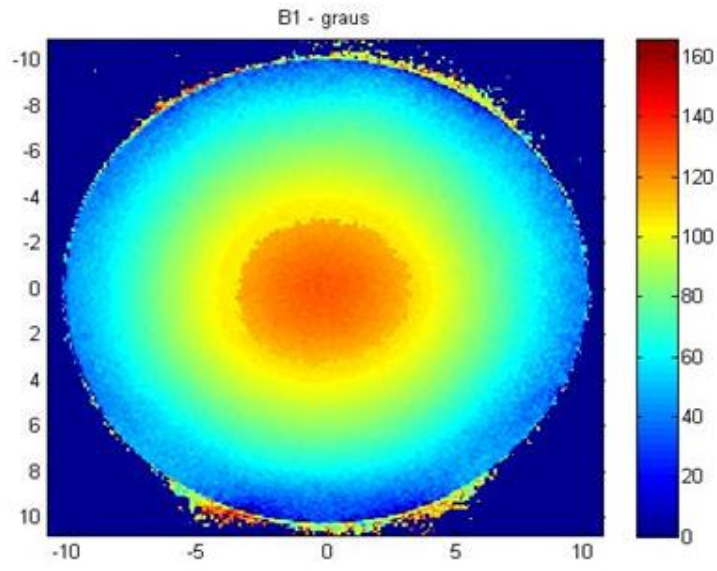

(c2)

Figura 300: MRI dos cortes axiais das regiões do cilindro de PMMA: (a1) cabeça, (b1) centro, (c1) pés e mapas dos ângulos de fleep para cada região: (a2) cabeça, (b2) centro, (c2).

A homogeneidade do campo no interior da bobina de cabeça foi analisada em regiões de interesses, ROls (do inglês Region Of Intertest), que eram concêntricas ao centro de cada imagem de RM, com raios de 1,5; 3,0; 4,5; 6,0; 7,0 e $9,0 \mathrm{~cm}$, nos diferentes cortes. O resultado das análises das ROls é apresentado na Figura 31. 


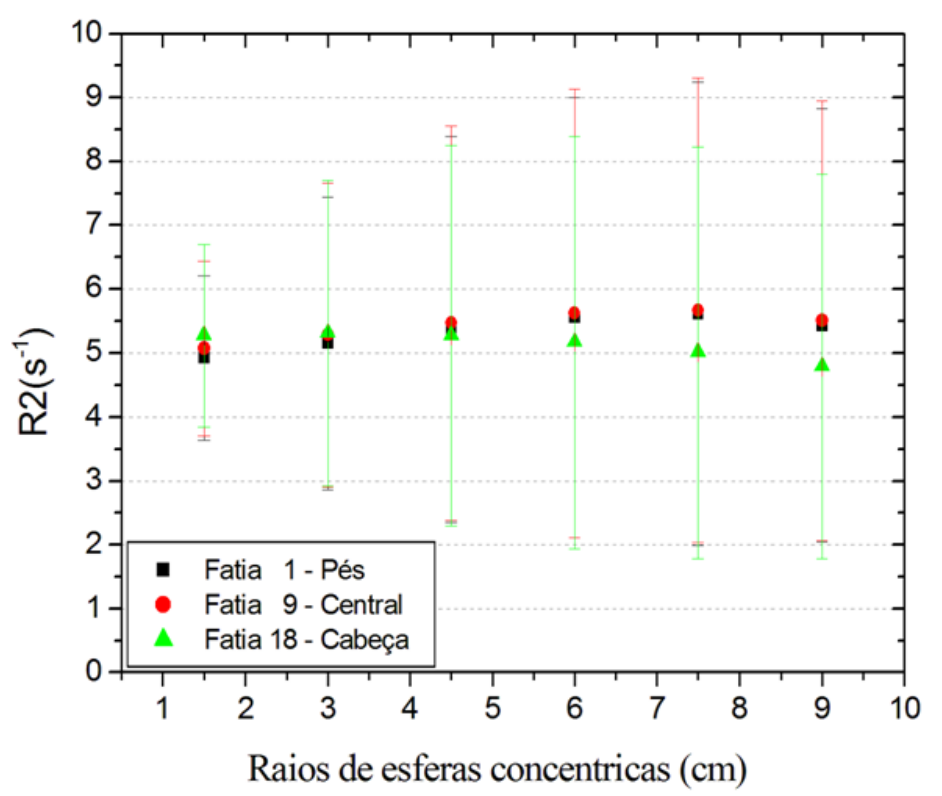

Figura 31: Avaliação da homogeneidade de campo da bobina de cabeça em função do tamanho das ROls em três cortes selecionados: cabeça $(\Delta)$, centro $(\bullet)$, pés ( $\bullet$ ).

A Figura 31 mostra que a heterogeneidade das imagens de ressonância magnética são maiores à medida que o diâmetro da ROI aumenta, com um desvio padrão percentual de até $62 \%$ para os três cortes analisados. Entretanto, comparando-se as ROls de raios 1,$5 ; 3,0$ e $4,5 \mathrm{~cm}$, para os três cortes, a diferença percentual encontrada para o valor médio do sinal de cada ROI foi de $1,3 \% ; 7,3 \%$ e $8,4 \%$, para a cabeça, região central e pés, respectivamente. A comparação para as ROls com raios de 6,0; 7,0 e 9,0 cm apresentaram diferenças de $10 \%, 11 \%$ e $13 \%$, para a cabeça, região central e pés, respectivamente.

A mesma análise foi realizada para todos os corte ao longo do eixo longitudinal do cilindro, como mostrado na Figura 32. 


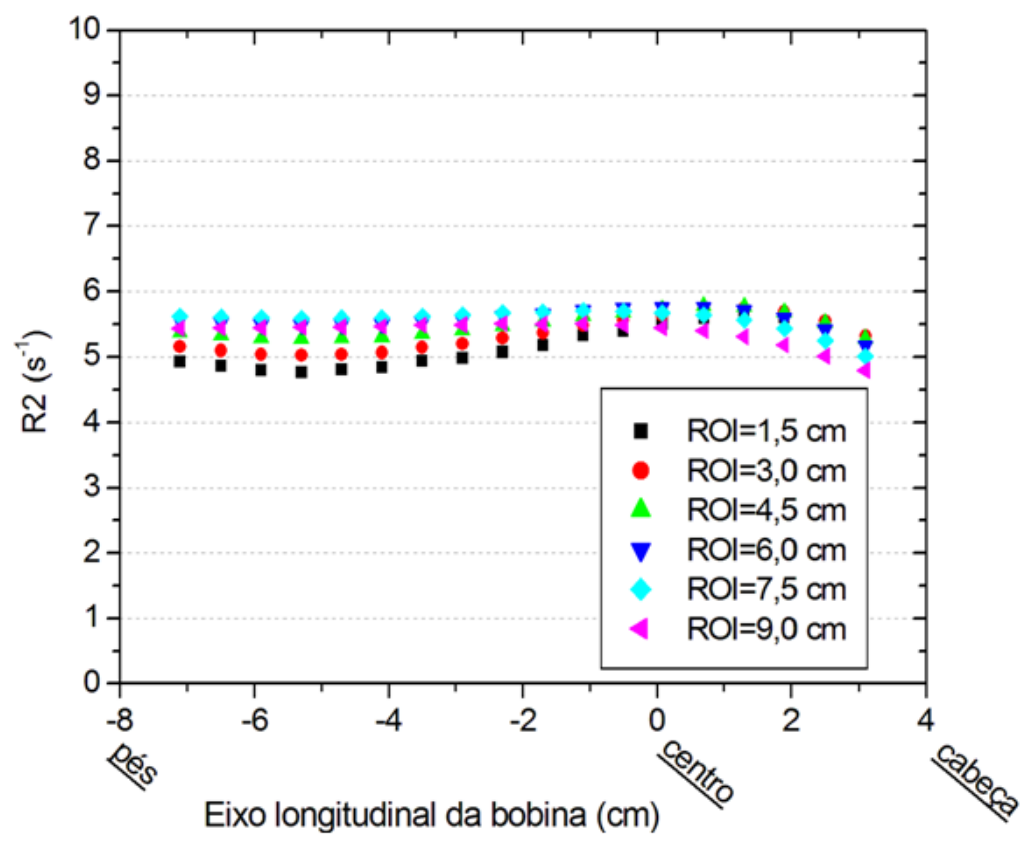

Figura 32: Homogeneidade do campo da bobina de cabeça ao longo do eixo longitudinal do cilindro para todas as ROls analisadas.

Comparando-se o valor médio do sinal obtido e os valores obtidos para cada uma das ROls, de 1,5 a $9 \mathrm{~cm}$, obteve-se diferenças máximas de $7 \%, 8 \%$, $8,5 \%, 8 \%, 10 \%$ e $12,5 \%$, respectivamente.

A partir dos resultados, infere-se que no eixo axial da bobina as três regiões apresentaram uma variação significativa no sinal para ROls da ordem de alguns centímetros de raio. Para o eixo longitudinal, as regiões mais homogêneas foram entre corte no sentido dos pés do cilindro até o centro da bobina. Assim, definiu-se que as regiões de interesse das amostras de MAGIC- $f$ gel são lidas dentro dessas regiões, para minimizar os artefatos por não-homogeneidade de campo nas imagens.

\subsubsection{Simulação da composição do material MAGIC- $f$ gel}

A avaliação da equivalência de tecido entre a água e o material do gel MAGIC-f foi realizada através da comparação de curvas de PDP simuladas no PENELOPE utilizando-se o arquivo de material MAGIC-f.mat construído no PENELOPE utilizando-se a composição química constituinte do dosímetro gel, e o arquivo de material da água do próprio código. Além disso, também foram realizadas medidas de PDP com câmara de ionização na água e estas foram 
comparadas com os resultados com o MAGIC-f, como descrito na seção 4.3.1.

A Figura 33 mostra a comparação das curvas de PDP dos dados obtidos experimentalmente e por simulação Monte Carlo para os dois feixes utilizados, de $6 \mathrm{MV}$ e $10 \mathrm{MV}$.

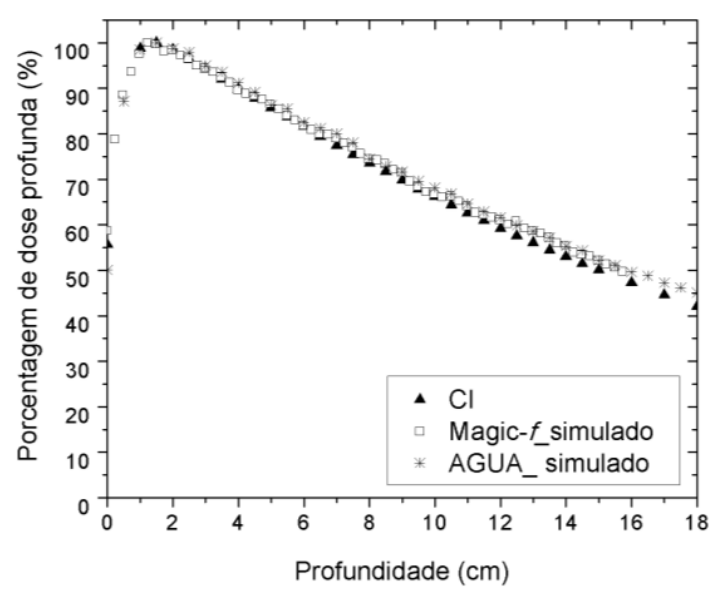

(a)

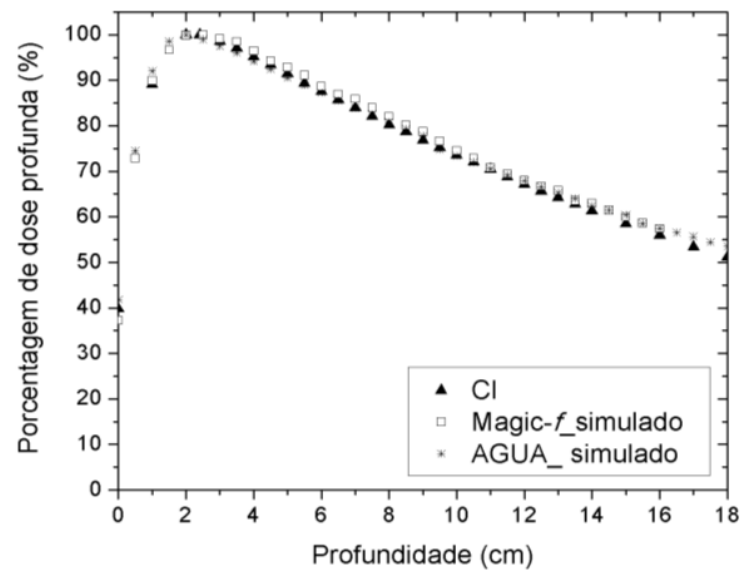

(b)

Figura 33: Comparação das PDP obtidas por simulação: (*) AGUA.mat, ( $\square$ ) MAGIC-f e experimentalmente por $(\boldsymbol{\Delta})$ câmara de ionização $(\mathrm{Cl})$, para os feixes utilizados: (a) 6MV e (b)10 MV.

Comparando-se as curvas de PDP determinadas por simulação para a água e o MAGIC-f, foi encontra-se uma diferença máxima de 1,93\% e 1,88\% para os feixes de 6MV e $10 \mathrm{MV}$, respectivamente. Quando os resultados para a água são comparados com dados clínicos obtidos com a câmara de ionização, obteve-se uma diferença de máxima de $4,3 \%$ na profundidade de $17 \mathrm{~cm}$ para 0 feixe de 6 MV. Para o feixe de 10 MV a máxima diferença na PDP foi de 3,87\% em $18 \mathrm{~cm}$ de profundidade. A comparação dos dados clínicos com os do material MAGIC - $f$ simulado apresenta máximas diferenças percentuais de até $4,72 \%$ na profundidade de $12,5 \mathrm{~cm}$ e 2,62\% em uma profundidade de $14 \mathrm{~cm}$ para os feixes de $6 \mathrm{MV}$ e $10 \mathrm{MV}$, respectivamente (Alva et al, 2010). A concordância entre os dados simulados, com ambos os materiais, e os dados clínicos evidencia a acurácia das simulações realizadas com PENELOPE, bem como a adequação do espectro de energia utilizado nas simulações.

A concordância entre os resultados obtidos com o material simulado do MAGIC-f e os dados clínicos confirma as características da equivalência na 
água e do dosímetro MAGIC-f gel, para essa composição química (Fernandes et al, 2008), validando, ainda, a utilização do código PENELOPE para simulações do arquivo de materiais para composição de dosímetros poliméricos.

Apesar dos resultados concordantes entre o material do MAGIC-f e da água para as PDPs obtidas, todas as simulações de tratamentos nesse trabalho foram realizadas com o arquivo de material da AGUA.mat já que o TPS não realiza as simulações dos tratamentos no material do gel.

\subsection{Medidas para caracterização da resposta do MAGIC-f gel}

Nesta seção são apresentados os resultados da caracterização da resposta do dosímetro MAGIC- $f$ gel em função da dose absorvida, taxa de dose, tempo de espera para leitura após a irradiação e teste de repetibilidade.

A resposta (sinal) do MAGIC-f gel foi obtida com o programa desenvolvido na plataforma de Matlab $^{\circledR}$, realizando a média dos valores de R2 de uma região de interesse. A Figura 34 mostra o mapa de R2 para a curva de calibração da resposta do MAGIC-f para o feixe de 6 MV. Na Figura 34 é mostrada a imagem do plano central perpendicular a diversos tubos de gel irradiados com diferentes doses, além de um tubo com eixo paralelo ao plano da imagem.

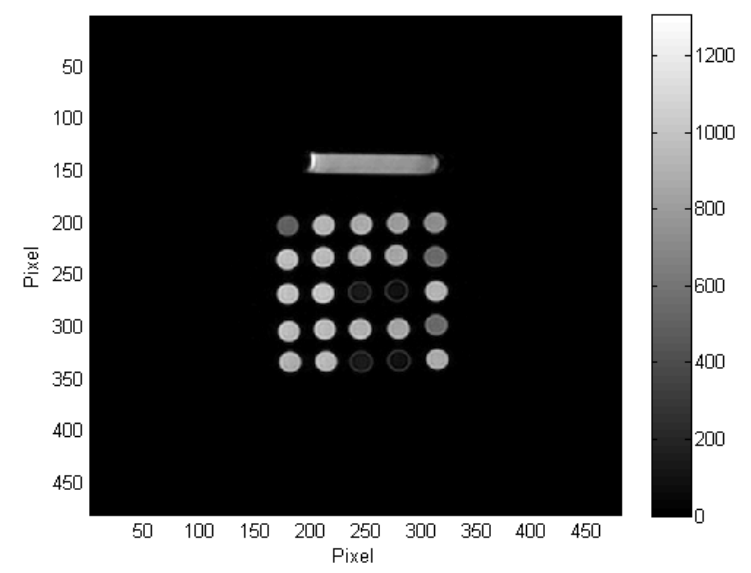

(a)

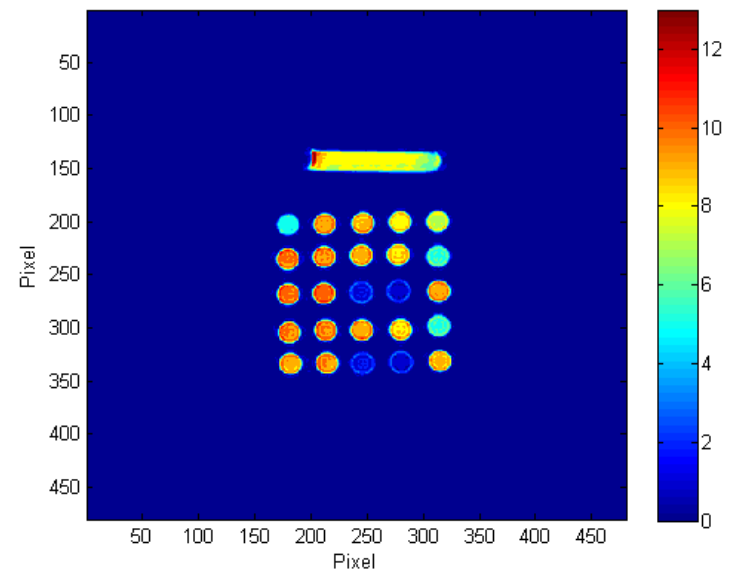

(b)

Figura 34: Imagem de ressonância magnética nuclear de amostras de MAGIC-f irradiadas em feixe de fótons de 6MV: (a) Mapa dos tempos de relaxação transversal (T2) e (b) mapa de R2 obtidas com o programa na plataforma de Matlab ${ }^{\circledR}$. 


\subsubsection{Dependência de resposta do MAGIC- $f$ com a dose para feixes de $6 \mathrm{MV}$ e $10 \mathrm{MV}$}

A curva mostrada na Figura 35 representa a dependência de resposta do gel em função das doses absorvidas para os dois feixes utilizados nesse estudo, 6MV e $10 \mathrm{MV}$. A partir dessas curvas pode-se utilizar um ajuste linear para a resposta do gel em função da dose absorvida para ambas as energias, com coeficientes de correlação de 0,997 e 0,998 para a energia de $6 \mathrm{MV}$ e 10 $\mathrm{MV}$, respectivamente. Deve-se ressaltar, entretanto, que o uso de um ajuste linear para a resposta do MAGIC-f em função da dose é válido para a faixa de doses apresentada, desde que espera-se uma saturação do sinal para altas doses. Da mesma forma, há evidências de que a resposta do gel siga um comportamento não linear para um pequeno intervalo de doses baixas, devido à perda de sinal por processos de interrupção de polimerização por recombinação, como explicitado na seção 2.1.1.

Diferentes coeficientes angulares foram encontrados: 1,32 e 1,47 s'-1/Gy para feixes de $6 \mathrm{MV}$ e $10 \mathrm{MV}$, respectivamente, evidenciando uma dependência energética para esse dosímetro. Analisando-se os ajustes lineares realizados para os dados observa-se, também, que o sinal de R2 para o feixe de $10 \mathrm{MV}$ é maior, para uma mesma dose, em comparação com o de 6 MV. Como explicitado na seção 2.1.1, a formação das cadeias poliméricas no gel dependem da interação entre radicais formados pela radiação, criando cadeias oligoméricas, de modo que o padrão espacial de deposição de dose pela radiação influenciará no tamanho das cadeias formadas no gel para uma mesma dose total depositada. Desta forma, diferentes energias de feixes de radiação produzirão a formação de cadeias poliméricas de diferentes tamanhos, que apresentarão diferentes tempos de relaxação, influenciando o sinal obtido. Observa-se, ainda, na Figura 35 um sinal de fundo de aproximadamente $1,5 \mathrm{~s}^{-1}$ para o dosímetro, para as duas energias utilizadas, correspondendo ao sinal relativo ao material do gel não-irradiado. 


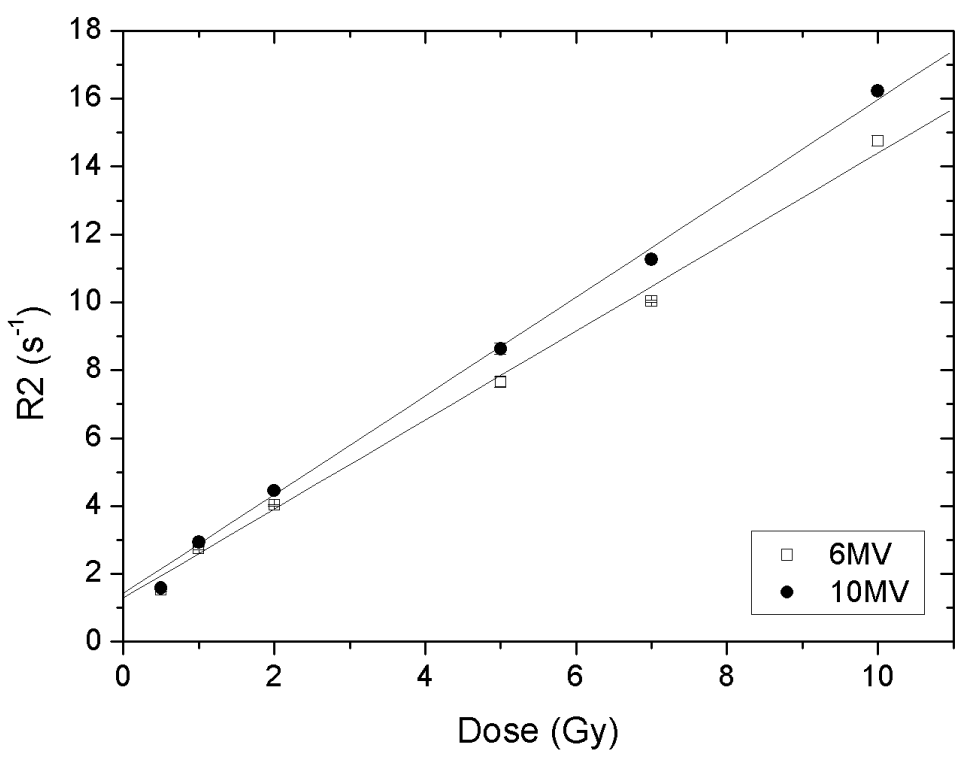

Figura 35: Resposta do dosímetro MAGIC-f em função da dose absorvida para os feixes de $6 \mathrm{MV}(\square)$ e $10 \mathrm{MV}(\bullet)$.

\subsubsection{Dependência de resposta do MAGIC- $f$ com a taxa de dose}

A Figura 36 mostra a dependência de resposta do MAGIC- $f$ gel em função da taxa de dose para feixes de $6 \mathrm{MV}$ e $10 \mathrm{MV}$, normalizada para o valor de $400 \mathrm{cGy} / \mathrm{min}$ do feixe de $6 \mathrm{MV}$. Nessa figura também são mostrados valores médios do sinal obtido (linhas na direção horizontal), de $0,99 \mathrm{~s}^{-1}$ (com desvio padrão de $0,81 \%$ ) e de $1,07 \mathrm{~s}^{-1}$ (com desvio padrão de $0,81 \%$ ), para os feixes de 6 e 10MV, respectivamente. Como explicado anteriormente, para uma mesma dose de radiação, há uma variação de resposta em função da energia do feixe, fazendo com que o sinal relativo médio para o feixe de $10 \mathrm{MV}$, normalizado para a resposta obtida com o feixe de $6 \mathrm{MV}$, seja maior que a unidade. Os desvios padrão dos sinais relativos médios, para ambas as energias evidenciam, entretanto, um padrão de variação de resposta semelhante para as duas energias. A pequena variação de resposta encontrada é devida ao intervalo de taxas de doses estudado, que é relativamente alta. A utilização de baixas taxas de dose poderia influenciar mais severamente o comportamento do sinal devido a efeitos de quebras de ligações poliméricas ao longo da irradiação 


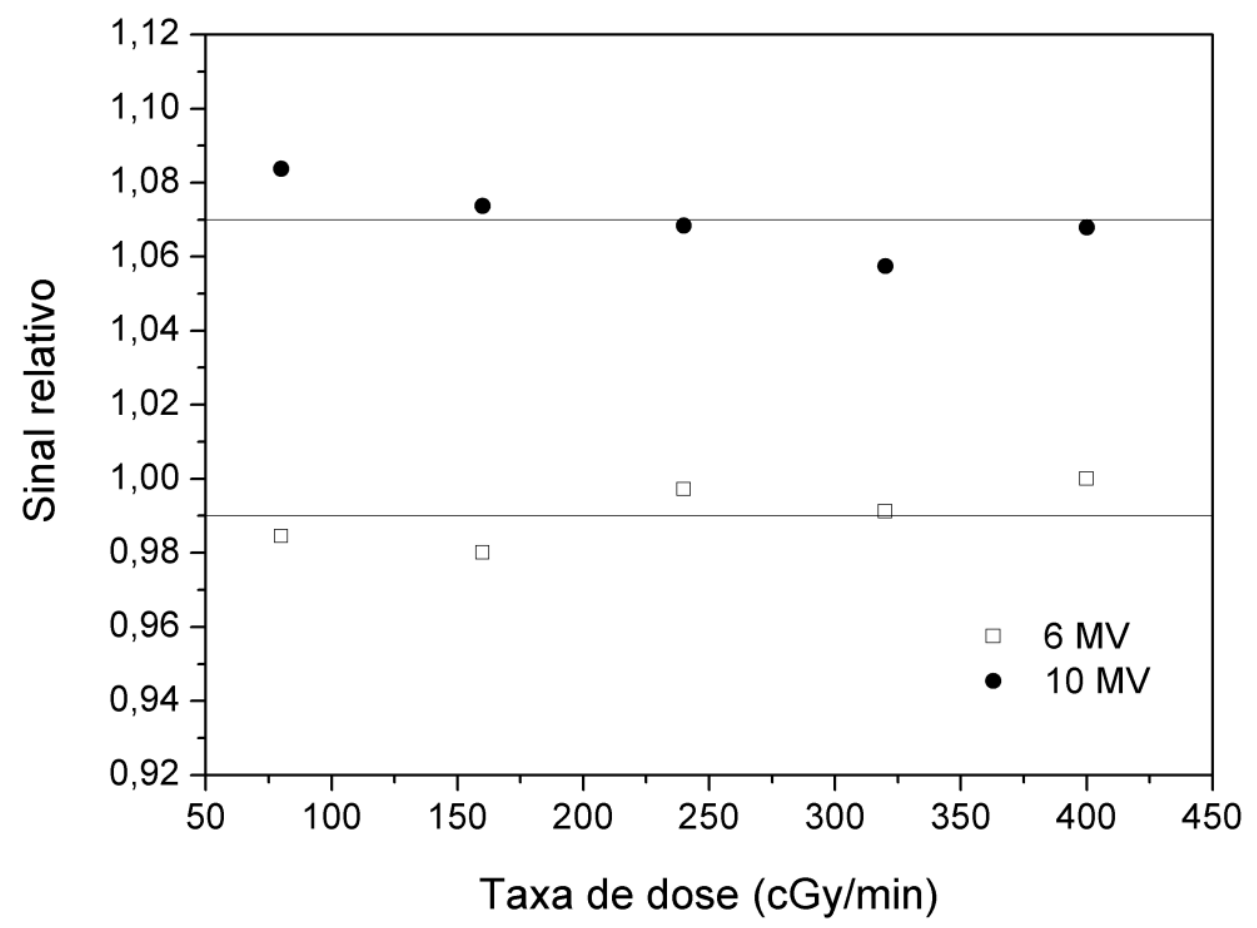

Figura 36: Resposta relativa do MAGIC-f gel em função da taxa dose para os feixes de $6 \mathrm{MV}((\square)$ e $10 \mathrm{MV}(\bullet)$.

Todos os outros experimentos deste trabalho foram feitos com a taxa de 400 cGy/min, taxa típica em tratamentos radioterápicos e utilizada no serviço de radioterapia do HCB-Barretos.

\subsubsection{Variação de dependência de resposta do MAGIC-f com 0 tempo de espera para leitura após a irradiação}

A Figura 37 mostra a evolução temporal do sinal do dosímetro MAGIC- $f$ gel, irradiado com doses de 5, 10 e 15 Gy, quando a amostra foi lida em tempos após a irradiação de 0,5 até 9,15 dias. 


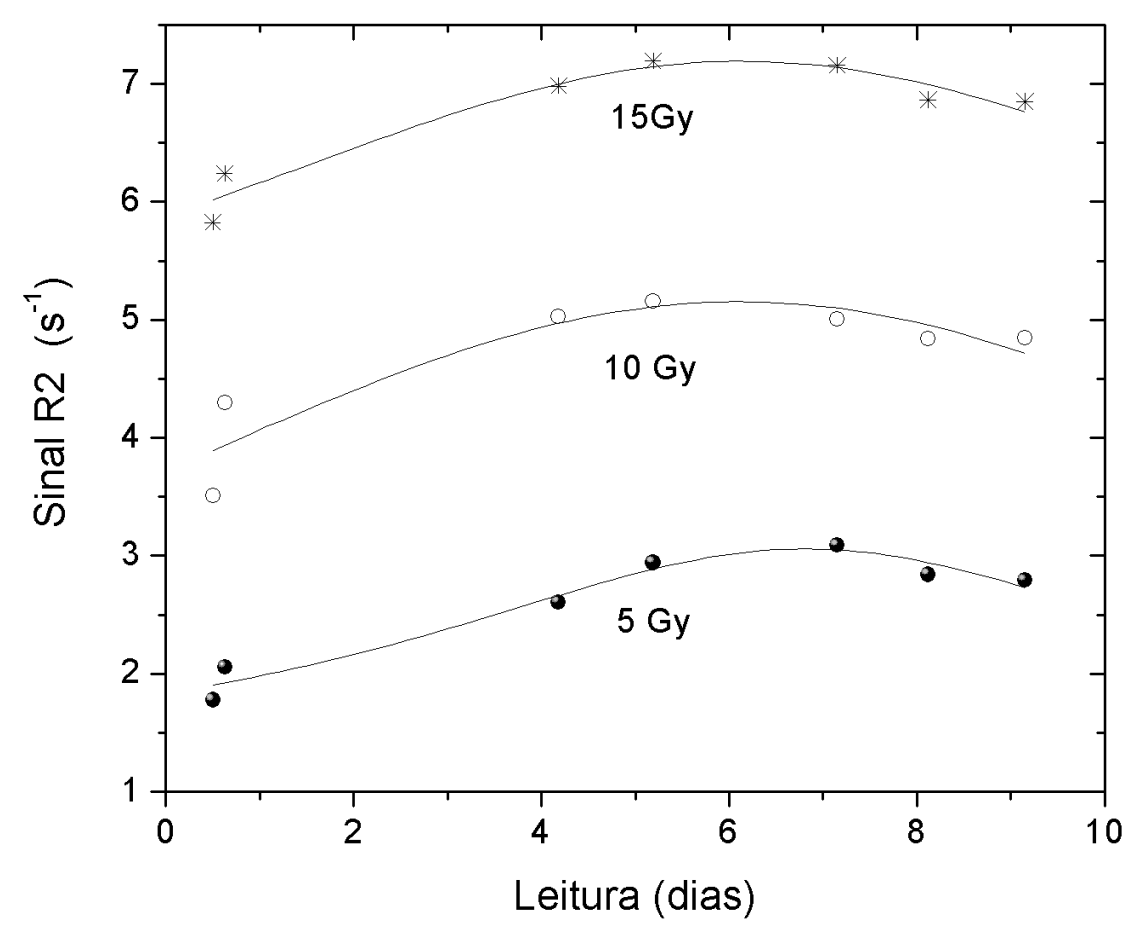

Figura 37: Resposta do MAGIC- $f$ gel com o tempo de espera para leitura após irradiação.

Com os resultados da Figura 37 pode se observar que, para as três doses utilizadas neste estudo, as curvas do sinal de R2 versus o tempo de espera para leitura após irradiação possuem um comportamento similar, com aumento do sinal até, aproximadamente, o sétimo dia de leitura, o tempo em que a formação das cadeias poliméricas chega ao estado de saturação.

Possíveis perdas de sinal poderiam ser observadas em função do tempo de espera para leitura caso as condições de armazenamento do gel durante o tempo de espera não sejam as adequadas. Fatores como temperatura de armazenamento, maiores que a estabelecida (Fernandes et al, 2008), e presença de fontes de luz ultra-violeta ou de alta intensidade podem influenciar significativamente a leitura do gel após a irradiação. Desta forma, neste trabalho adotaram-se condições de armazenamento padronizadas após a irradiação, mantendo-se as amostras em temperatura de $-10^{\circ} \mathrm{C}$ e protegidas da luz. Para essas condições, a máxima diferença entre as medidas máxima e mínima foi de 2,8 $\mathrm{s}^{-1}$ para dose de 15Gy. Este comportamento é similar ao apresentado na literatura (De Deene et al, 2000).

Tendo em vista este o comportamento de resposta do gel com o tempo de espera para leitura após irradiação, neste trabalho adotou-se o protocolo de 
leitura de Fernandes (Fernandes et al, 2008), que estabelece um tempo de, aproximadamente, $24 \mathrm{~h}$, já que em aplicações clínicas de dosimetria gel, um tempo de espera prolongado pode não ser conveniente.

\subsubsection{Repetibilidade do MAGIC-f}

Baseado na resposta do gel para diferentes doses, o estudo da repetibilidade foi realizada para uma única dose, de $5 \mathrm{~Gy}$, com tubos de vidro contento solução do mesmo lote. Além disso, para determinar a reprodutibilidade do sinal com o tempo de leitura após a irradiação, as leituras foram feitas em tempos diferentes após a irradiação.

A Tabela 6 mostra o repetibilidade de resposta das amostras pelo desvio padrão e a reprodutibilidade obtida para cada leitura das amostras. Embora os sinais médios das amostras variem com o tempo, devido ao efeito de formação e estabilidade das cadeias poliméricas formadas, como explicitado na seção 4.2.3, o desvio padrão de cada média do sinal, para cada tempo de espera para leitura, permite concluir que há uma boa repetibilidade para a resposta do gel, dentro de até $0,5 \%$, para todos os tempos de espera para leitura, evidenciando a homogeneidade de resposta do lote de gel manufaturados. Para minimizar efeitos de não homogeneidade entre lotes, em cada experimento deste trabalho foram construídas curvas de calibração específicas para cada lote de gel manufaturado. Tais diferenças, entretanto, não influenciam na obtenção de distribuições de doses normalizadas.

Tabela 6: Desvios padrão das leituras de três amostras do dosímetro MAGIC-f gel em diferentes tempos para aquisição de imagens.

\begin{tabular}{|c|c|c|r|r|r|r|r}
\hline \multicolumn{1}{c}{} & \multicolumn{7}{c}{ Tempo de leitura (dias) } \\
\cline { 2 - 7 } \multicolumn{1}{c|}{0,5} & 0,63 & 4,18 & 5,19 & 7,17 & 8,12 & 9,15 \\
\hline $\begin{array}{c}\text { Desvio } \\
\text { Padrão de } \\
\text { R2 (\%) }\end{array}$ & 0,12 & 0,05 & 0,13 & 0,49 & 0,31 & 0,16 & 0,17 \\
\hline
\end{tabular}




\subsubsection{Curvas de porcentagem de dose profunda para $6 \mathrm{MV}$ e $10 \mathrm{MV}$}

A Figura 38 mostra as PDP do serviço de radioterapia do HCB, obtidas com $\mathrm{Cl}$ na água, e com o MAGIC- $f$ gel para os feixes de $6 \mathrm{MV}$ e $10 \mathrm{MV}$ em condições de referência de irradiação (distancia fonte superfície de $100 \mathrm{~cm}$ e tamanho de campo de irradiação de $10 \times 10 \mathrm{~cm}^{2}$ ).

Comparando-se os dados clínicos e do MAGIC-f, primeiramente para o feixe de $6 \mathrm{MV}$, observa-se que, para profundidades de até $10 \mathrm{~cm}$, as curvas compartam-se da mesma forma, com uma diferença máxima de 3,20\% na profundidade de $9 \mathrm{~cm}$. Para profundidades maiores que $10 \mathrm{~cm}$, as diferença máxima aumentam para até $4,65 \%$, na profundidade de $12 \mathrm{~cm}$. Essa mesma comparação foi feita para o feixe de $10 \mathrm{MV}$, obtendo-se uma diferença máxima de $1,93 \%$ em $7 \mathrm{~cm}$ e, a partir de $10 \mathrm{~cm}$, obteve-se uma diferença máxima de $2,62 \%$ na profundidade de $14 \mathrm{~cm}$.

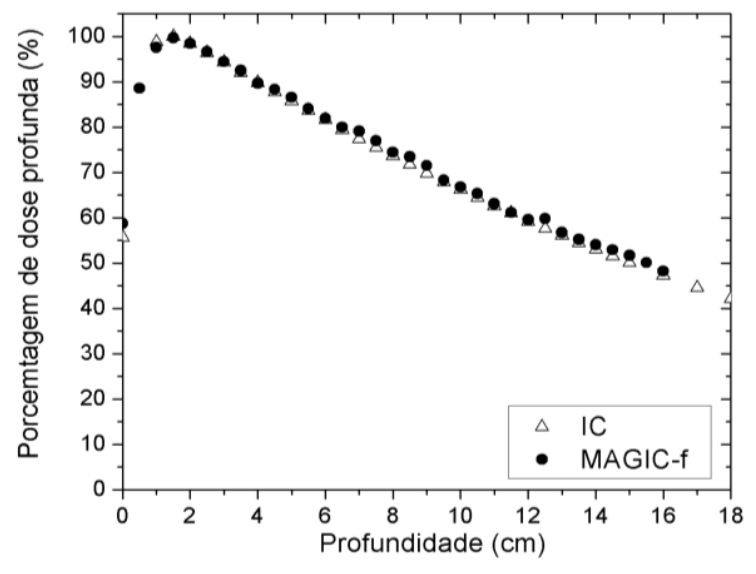

(a)

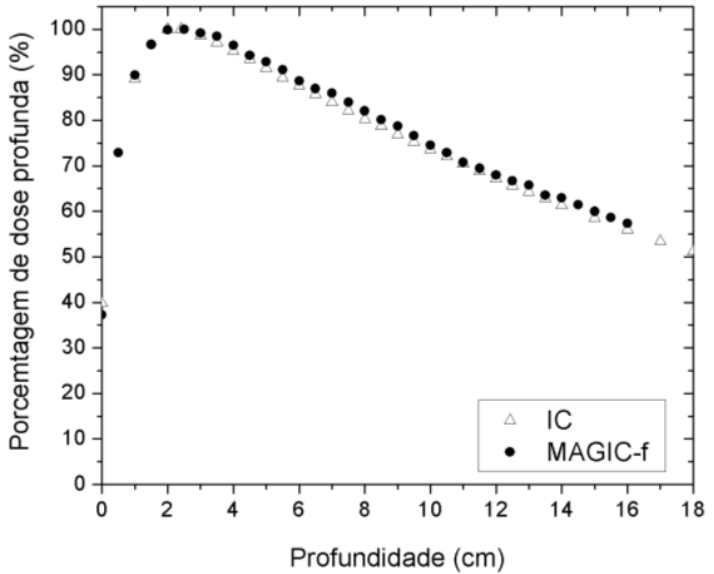

(b)

Figura 38: Curvas de PDP do serviço de radioterapia do HCB-Barretos e as obtidas com MAGIC- $f$ gel, para os feixes de: (a) 6 MV e (b) 10 MV.

As comparações entre os valores das PDP simuladas com PENELOPE, obtidas experimentalmente com o gel e do HCB são mostradas na Figura 39, sendo que a Figura 39 (b) e (d) evidenciam as diferenças encontradas para profundidades maiores que $10 \mathrm{~cm}$ para os dois feixes estudados. 


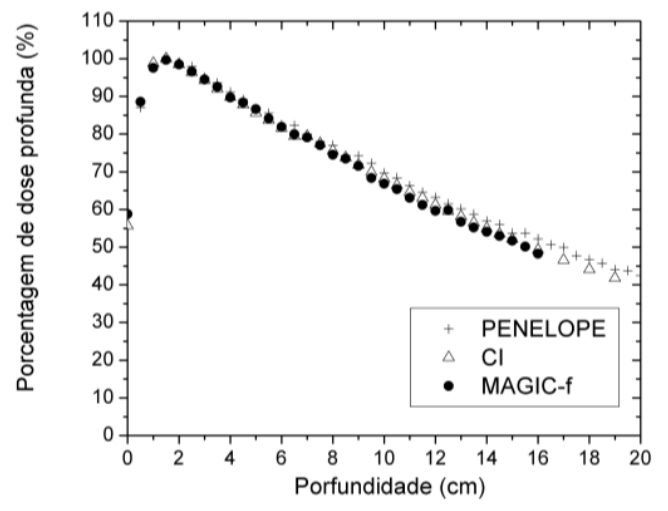

(a)

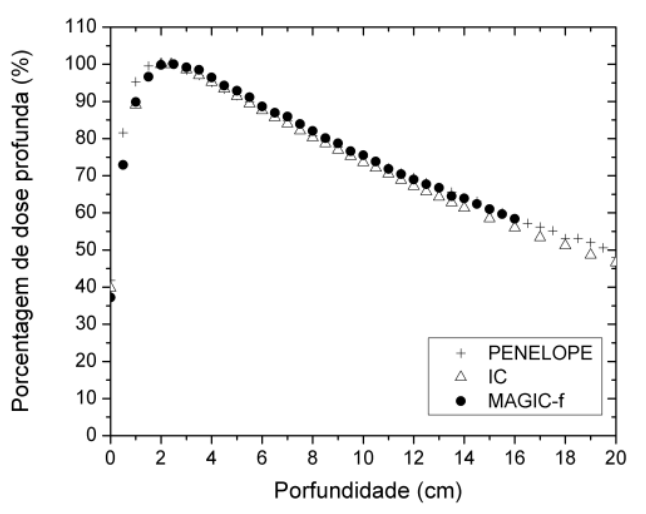

(c)

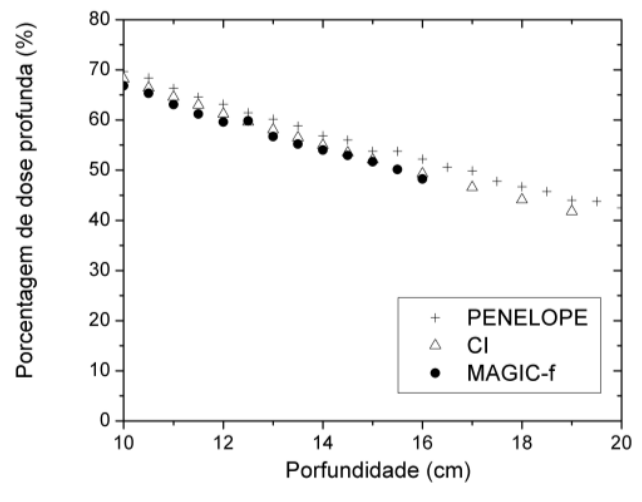

(b)

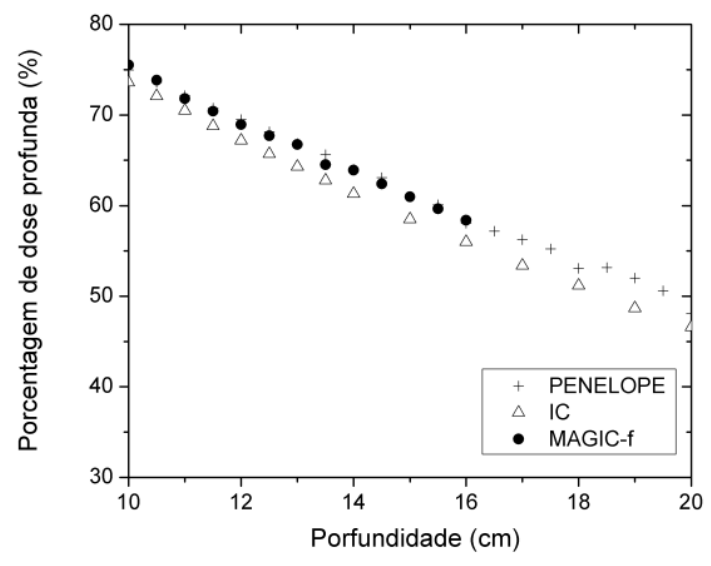

(d)

Figura 39: Curvas de PDP para os feixes de:(a), (b) $6 \mathrm{MV}$ e (c), (d) $10 \mathrm{MV}$. Em (a), (c) tem-se as curvas de PDP em todas as profundidades e em (b), (d) ressaltam profundidades maiores que $10 \mathrm{~cm}$.

Comparando-se as PDP determinadas com MAGIC- $f$ e PENELOPE a máxima diferença foi $1,46 \%$, na profundidade de $0,5 \mathrm{~cm}$. Comparando dados simulados com os dados HCB a diferença máxima foi de 4,3\%, na profundidade de $17 \mathrm{~cm}$, para o feixe de $6 \mathrm{MV}$.

As mesmas comparações foram feitas para o feixe de $10 \mathrm{MV}$, obtendo-se uma diferença máxima de $2,14 \%$ a $1 \mathrm{~cm}$ de profundidade, quando se comparam os valores da PDP do PENELOPE e do MAGIC-f. Da comparação dos valores do PENELOPE e o HCB obteve-se uma diferença máxima de $3,87 \%$ na profundidade de $18 \mathrm{~cm}$.

Dos resultados obtidos, para ambos os feixes de radiação, pode-se inferir que as curvas de PDP obtidas com MAGIC- $f$ são próximas às obtidas com simulação, validando-se assim as simulações do dosímetro utilizado. Também 
se observa que, tanto os valores do MAGIC- $f$ e da simulação são próximos aos valores obtidos com $\mathrm{Cl}$ até aproximadamente $10 \mathrm{~cm}$ de profundidade.

As diferenças das PDP para profundidades maiores que $10 \mathrm{~cm}$ encontradas para o dosímetro MAGIC- $f$ gel e dados do HCB podem estar relacionadas com as características intrínsecas do dosímetro, como dependência energética. Este comportamento também foi mostrado na literatura (Fernandes et al, 2008).

\subsection{Medidas para caracterização da resposta do filme radiocrômico EBT2}

As medidas de caracterização da resposta do filme EBT2 coma dose, taxa de dose e a dependência com o tempo de espera para leitura foram realizadas no serviço de radioterapia do HCB.

\subsubsection{Dependência da resposta do filme ETB2 com a dose}

A Figura 40 mostra a dependência do filme radiocrômico EBT2 quando submetido a uma variação da dose para os feixes de $6 \mathrm{MV}$ e $10 \mathrm{MV}$. 


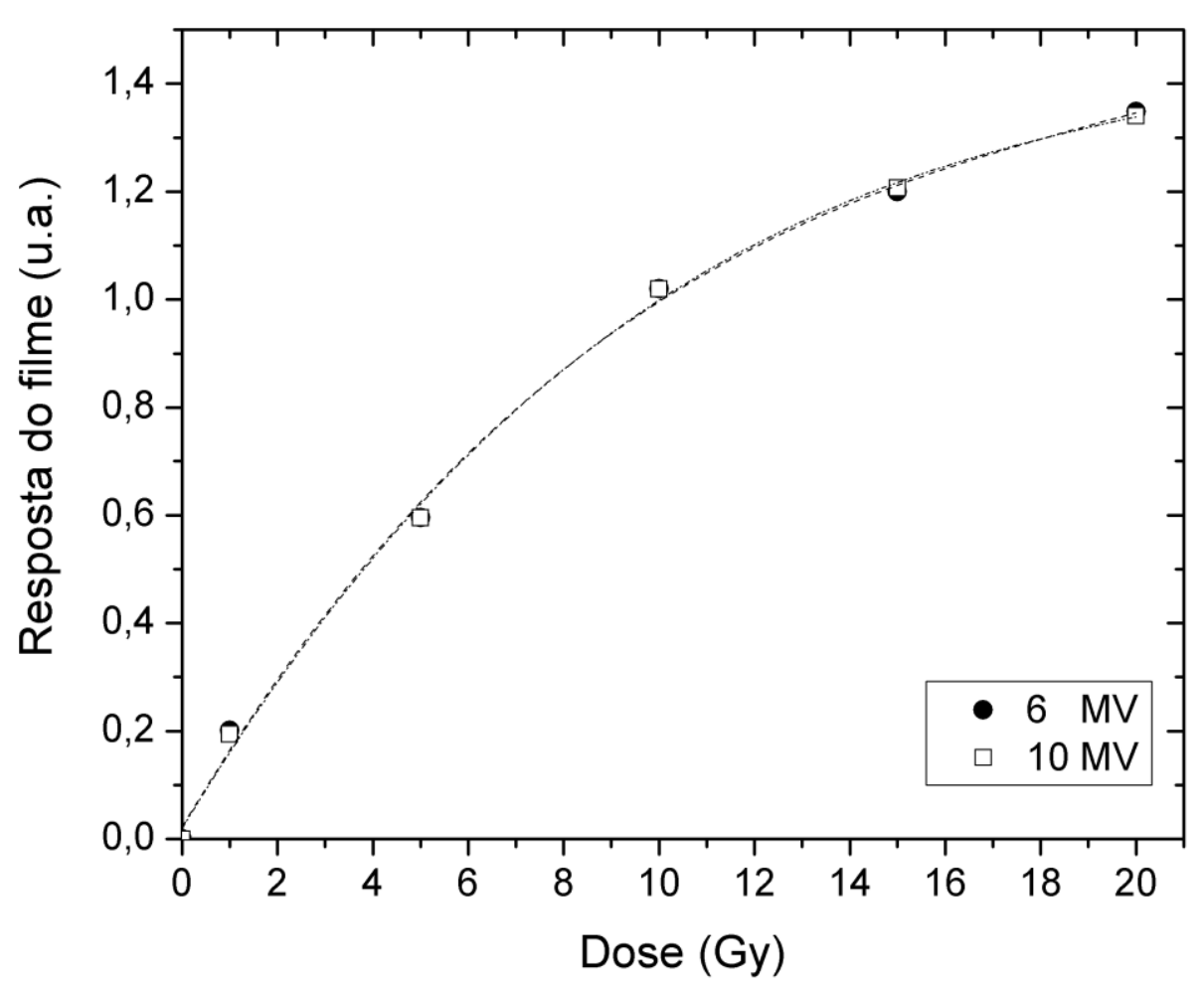

Figura 40: Resposta do filme EBT2 em função da dose absorvida para os feixes de $6 \mathrm{MV}(\square)$ e $10 \mathrm{MV}(\bullet)$.

As respostas relativas do filme mostradas na Figura 40 são uma média das regiões irradiadas dos filmes, e apresentam desvio padrão máximo de $2,15 \%$, para ambos os feixes.

De acordo com os resultados, o filme EBT2 mostra baixa dependência energética com uma variação máxima de $0,5 \%$, quando comparado os feixes de $6 \mathrm{MV}$ e $10 \mathrm{MV}$. Este resultado é similar ao encontrado na literatura (Aland et al, 2011; Andrés et al, 2010; Arjomandy et al, 2010; Butson et al, 2010b; Sutherland, Rogers et al, 2010; Rink et at, 2007; Devic et al 2004).

\subsubsection{Dependência de resposta do filme ETB2 com a taxa de dose}

A Figura 41 mostra a dependência de resposta do filme EBT2 em função da taxa de dose para feixes de $6 \mathrm{MV}$ e $10 \mathrm{MV}$. 


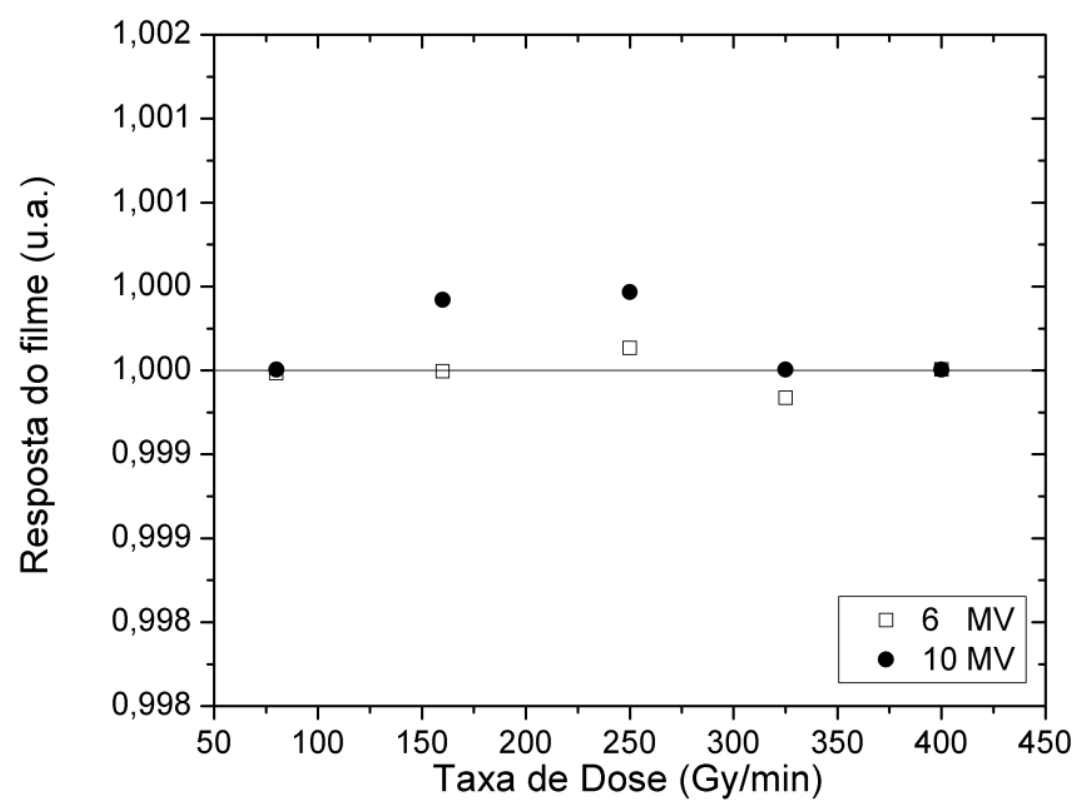

Figura 41: Resposta do filme EBT2 em função da taxa de dose para os feixes de $6 \mathrm{MV}(\square)$ e $10 \mathrm{MV}(\bullet)$.

De forma similar à análise anterior, os valores resposta mostradas são uma média das regiões irradiadas dos filmes, com desvio padrão máximo de $1,90 \%$, para ambos os feixes.

Para todas as taxas de doses estudadas, de 80 até $400 \mathrm{~Gy} / \mathrm{min}$, obtiveram se valores médios aproximadamente de 0,60 para o feixe de $10 \mathrm{MV}$ e para o feixe de $6 \mathrm{MV}$, e o desvio padrão percentual de ambos os valores médios foi menor que $2,2 \%$.

Os resultados confirmam que o filme EBT2, além de possuir baixa dependência energética, também não possui dependência com a taxa de dose considerável para ambos os feixes estudados.

\subsubsection{Variação de dependência do filme EBT2 com o tempo de leitura após a irradiação}

A Figura 42 mostra a resposta do filme EBT2 para diferentes tempos de espera antes da leitura após o mesmo ser submetido a doses de 5, 10 e 15 Gy. 


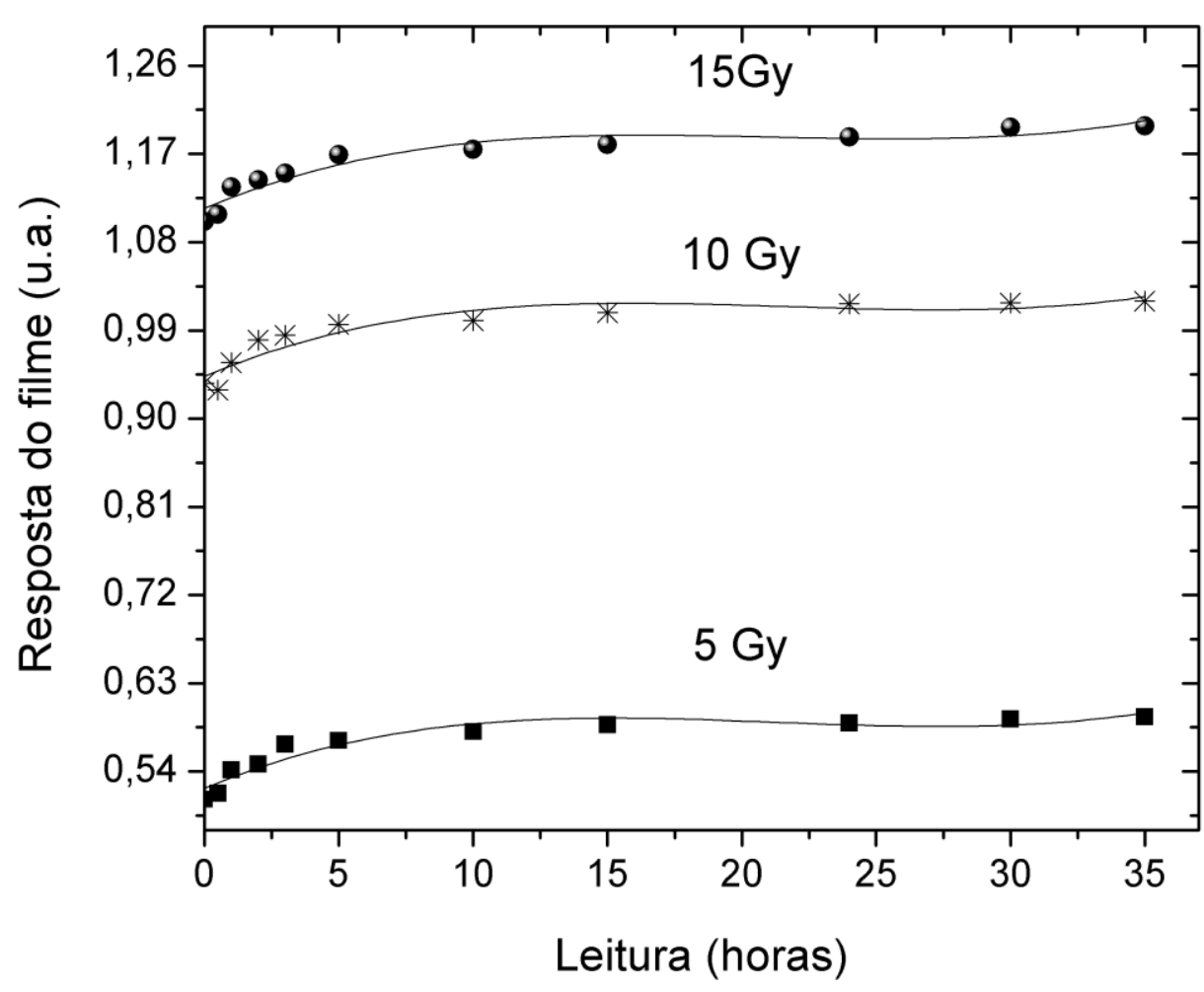

Figura 42: Resposta do filme EBT2 com tempo de espera para leitura após irradiações com doses de 5, 10 e 15 Gy.

Da Figura 42 pode se observar que, para as três curvas correspondentes às doses de 5,10 e $15 \mathrm{~Gy}$, as respostas obtidas versus o tempo de espera para a leitura após irradiação possuem um comportamento similar, aumentando o sinal até, aproximadamente, 15 horas. A diferença máxima entre a medida mínima e máxima encontradas foi de 0,45 u.a para a dose de $15 \mathrm{~Gy}$, que é menor do que a dependência do MAGIC- $f$ com o tempo de espera para leitura após irradiação. O comportamento mostrado na Figura 42 é similar ao apresentado na literatura (Aland et al, 2011; Andrés et al, 2010).

Neste trabalho, todos os filmes foram lidos em, aproximadamente, 24 horas após a irradiação,de modo que a determinação de distribuições de dose relativas não seriam modificadas pelo tempo de espera para leitura. Entretanto, para um estudo quantitativo da dose de radiação, a curva da Figura 40 pode ser utilizada para correções por tempo de leitura após de irradiação, da mesma forma que acontece com o dosímetro MAGIC-f. 


\subsubsection{Porcentagem de dose profunda com o filme EBT2}

A Figura 43 mostra as PDPs do serviço de radioterapia do HCB, do filme EBT2 e da simulação PENELOPE para os feixes de $6 \mathrm{MV}$, Figura 43 (a), e 10 MV, Figura 43 (b), para condições de referência de irradiação (distancia fonte superfície de $100 \mathrm{~cm}$ e tamanho de campo de irradiação de $10 \times 10 \mathrm{~cm}^{2}$ ).

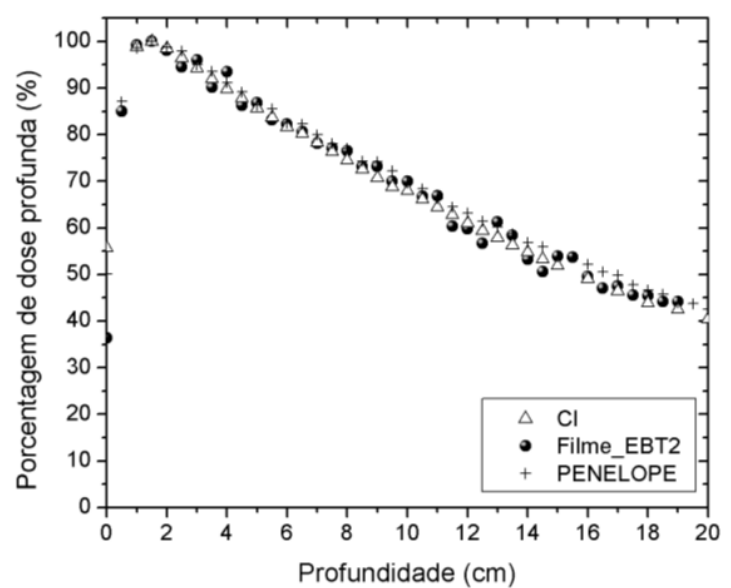

(a)

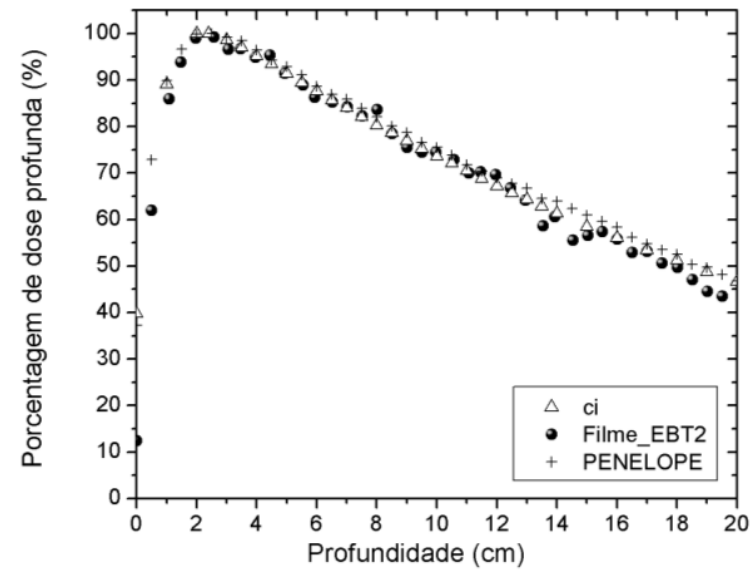

(b)

Figura 43: PDPs obtidas utilizando-se câmaras de ionização (CI), filme EBT2 e PENELOPE para os feixes de (a) 6MV e (b) $10 \mathrm{MV}$.

Como mostrado na Figura 43, as curvas das PDPs do filme tem um comportamento similar às curvas obtidas com a $\mathrm{Cl}$ e com PENELOPE, para ambos os feixes utilizados.

Da comparação das PDPs do serviço do HCB e as obtidas com o filme, para o feixe de $6 \mathrm{MV}$, obteve-se uma diferença máxima de 3,65\% em uma profundidade de $4 \mathrm{~cm}$. Essa mesma comparação foi feita para o feixe de 10 MV, obtendo-se uma diferença máxima de 3,89\% em $19,5 \mathrm{~cm}$.

Comparando os resultados obtidos das PDPs com o filme e com o código de simulação PENELOPE obteve-se uma diferença máxima de 5,33 \% em 14,5 $\mathrm{cm}$, para o feixe de $6 \mathrm{MV}$. Para o feixe de $10 \mathrm{MV}$ a diferença máxima encontrada foi de $4,7 \%$ em $19,5 \mathrm{~cm}$. 


\subsection{Medidas para validação das ferramentas dosimétricas}

As ferramentas dosimétricas foram validadas através das distribuições de doses para campos pequenos de irradiação, com 1, 2 e $3 \mathrm{~cm}$ de diâmetro para a energia de $6 \mathrm{MV}$. Os dados das distribuições obtidas com MAGIC- $f$ gel, filme radiocrômico EBT2, código de simulação PENELOPE e com o TPS iPlan ${ }^{\circledR}$ foram processados e analisados em um programa desenvolvido na plataforma de Matlab ${ }^{\circledast}$. As distribuições de dose obtidas nos planos centrais dos volumes irradiados são mostradas nas figuras 44,45 e 46 para cada campo de irradiação.

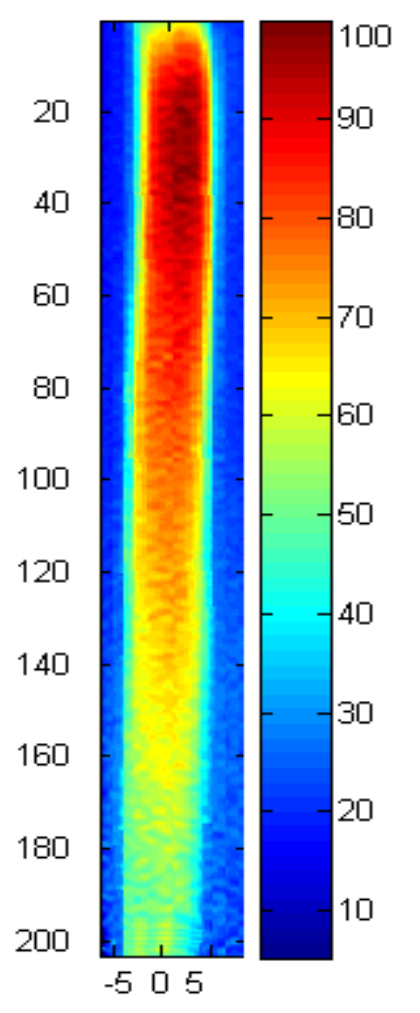

(a)

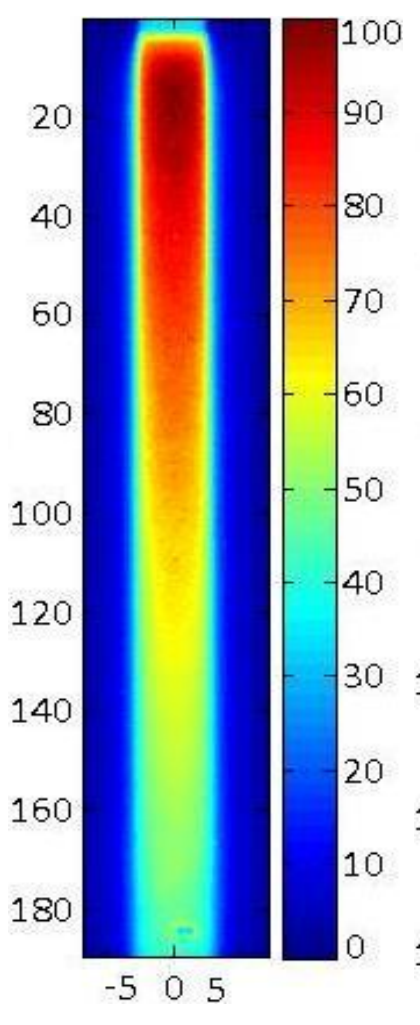

(b)

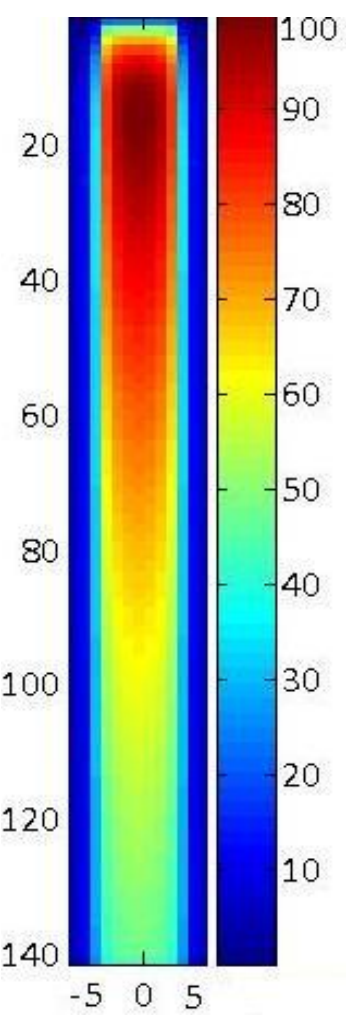

(c)

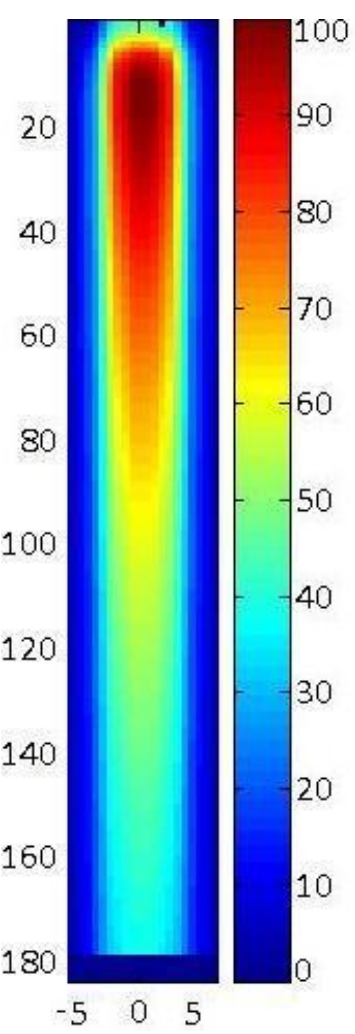

(d)

Figura 44: Distribuições de dose para campo circular de $1 \mathrm{~cm}$ de diâmetro obtidas com: (a) MAGIC-f gel, (b) Filme EBT2, (c) PENELOPE e (d) TPS iPlan ${ }^{\circledR}$. 


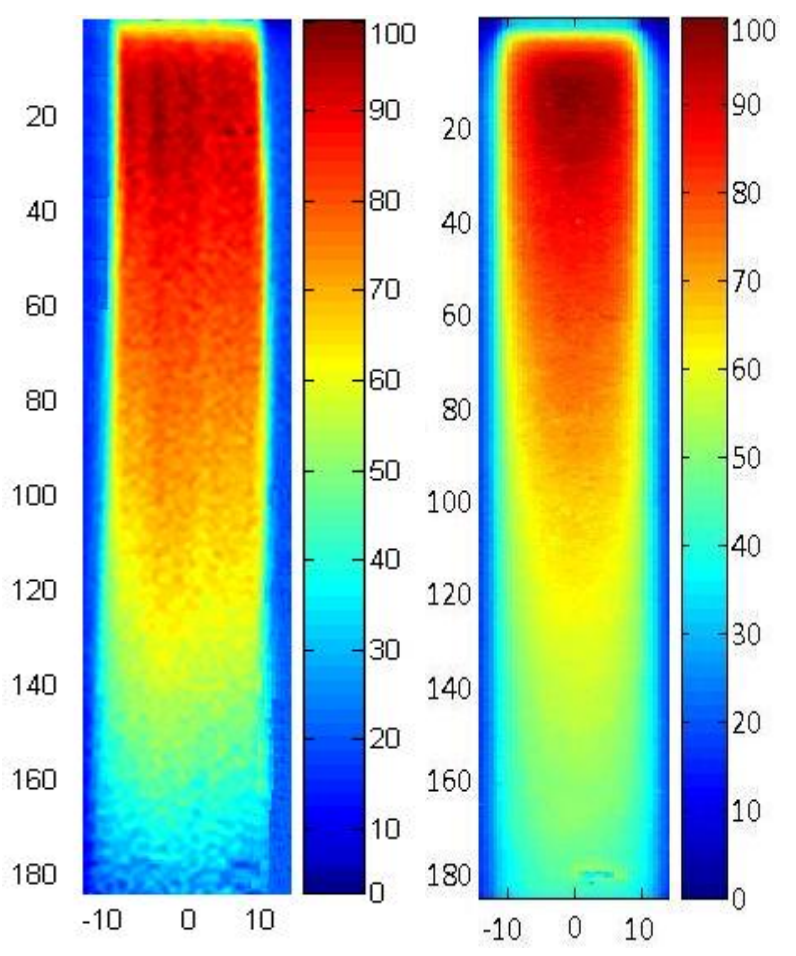

(a)

(b)

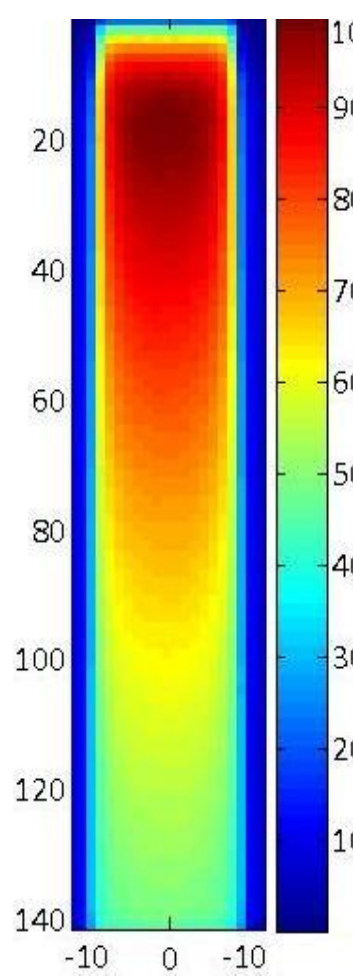

(c)

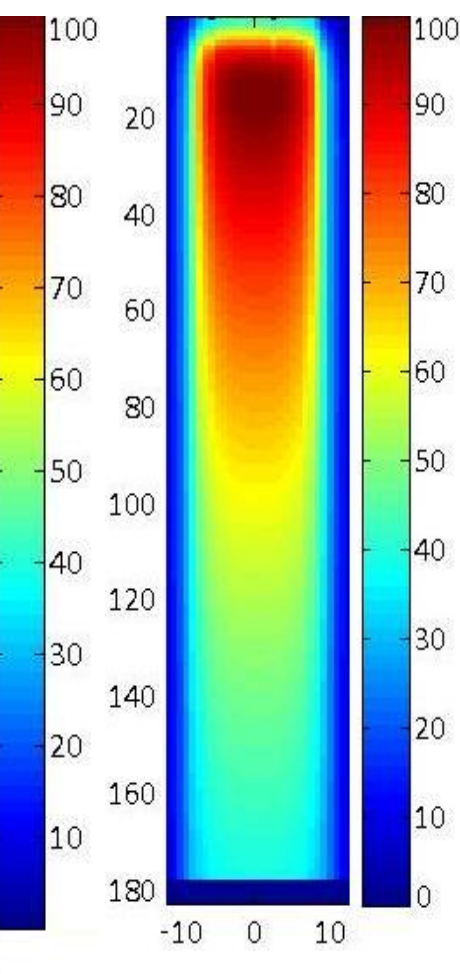

(d)

Figura 45: Distribuições de dose para campo circular de $2 \mathrm{~cm}$ de diâmetro obtido com: (a) MAGIC- $f$ gel, (b) Filme EBT2, (c) PENELOPE e (d) TPS iPlan ${ }^{\circledR}$.

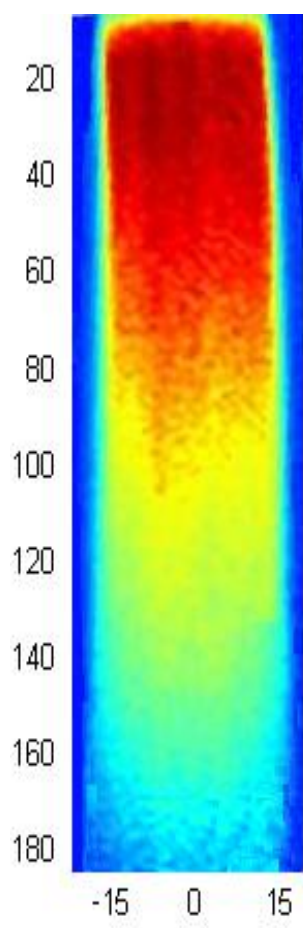

(a)

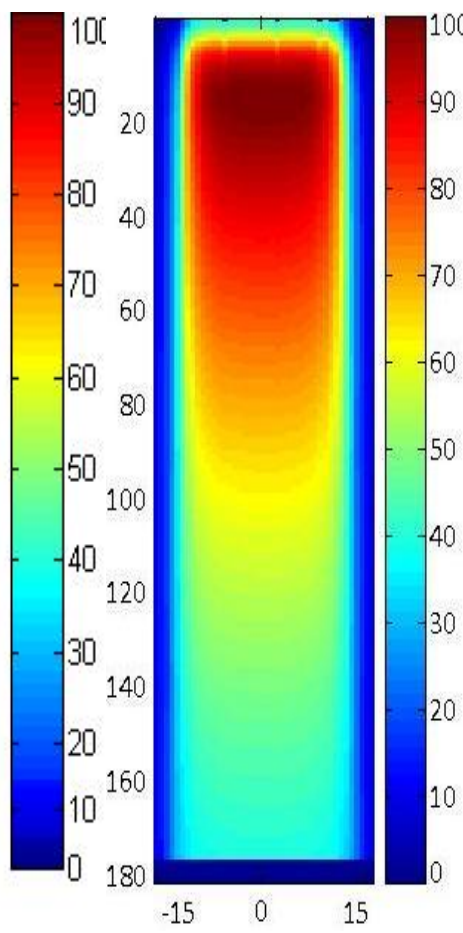

(b)

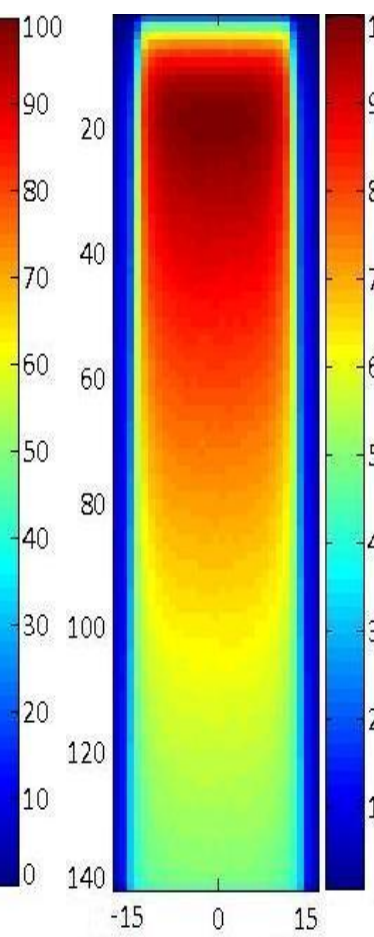

(c)

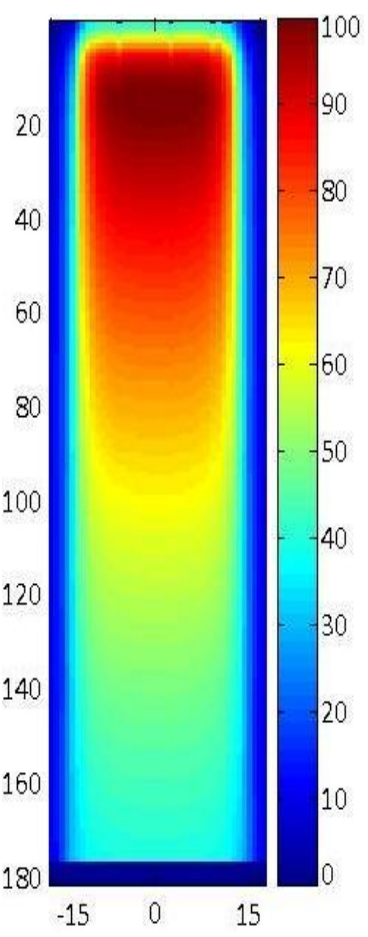

(d)

Figura 46: Distribuições de dose para campo circular de $3 \mathrm{~cm}$ de diâmetro obtido com: (a) MAGIC-fgel, (b) Filme EBT2, (c) PENELOPE e (d) TPS iPlan ${ }^{\circledR}$. 
A partir dessas distribuições de doses foram obtidas PDPs, para cada campo circular utilizado, como mostrado nas figuras 47, 48 e 49. Também, foram obtidos perfis dose, para cada ferramenta dosimétrica, nas profundidades de $1,5 \mathrm{~cm}$ e $5 \mathrm{~cm}$ para o feixe de $6 \mathrm{MV}$.

\subsubsection{Porcentagem de dose profunda}

\subsubsection{Campo circular com $1 \mathrm{~cm}$ de diâmetro}

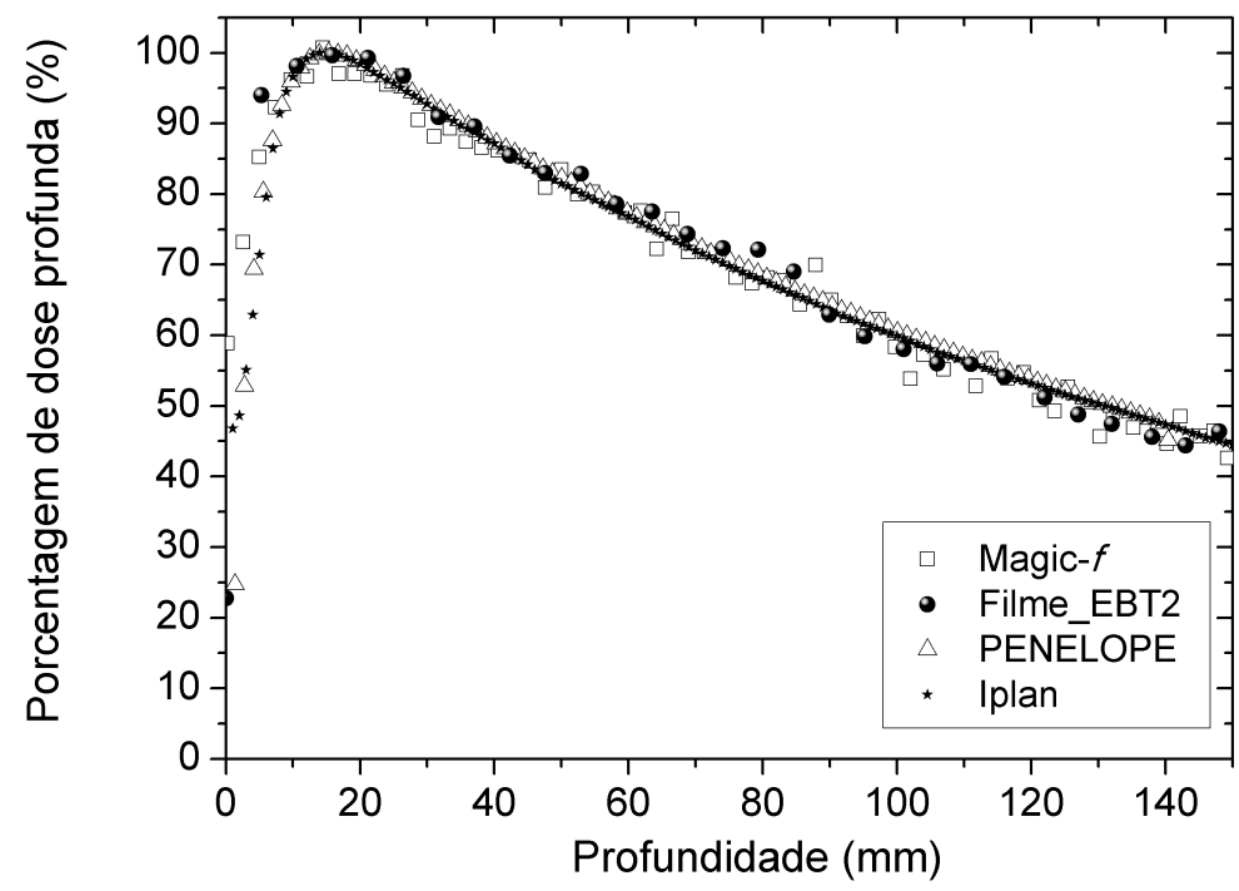

Figura 47: PDP para o campo circular de $1 \mathrm{~cm}$ de diâmetro obtido com as quatro ferramentas dosimétricas: MAGIC- $f$ gel, filme EBT2, PENELOPE e TPS iPlan ${ }^{\circledR}$.

As PDPs obtidas para o campo de irradiação de $1 \mathrm{~cm}$ diâmetro com as quatro ferramentas dosimétricas foram comparadas e as máximas diferenças percentuais encontradas são mostradas na Tabela 7. 
Tabela 7: Diferenças percentuais máximas entre as PDPs obtidas com das quatro ferramentas dosimétricas para o campo de irradiação de $1 \mathrm{~cm}$ de diâmetro.

\begin{tabular}{|c|ccccc}
\cline { 2 - 5 } \multicolumn{1}{c|}{} & MAGIC- $f$ gel & Filme EBT2 & PENELOPE & |plan $^{\circledR}$ \\
\cline { 2 - 5 } MAGIC- $f$ gel & --- & 7,02 & 5,02 & 4,60 \\
\cline { 2 - 5 } Filme EBT2 & --- & --- & 4,61 & 5,52 \\
PENELOPE & --- & --- & --- & 3,41 \\
\cline { 2 - 5 } & & &
\end{tabular}

4.4.1.2. Campo circular com $2 \mathrm{~cm}$ de diâmetro

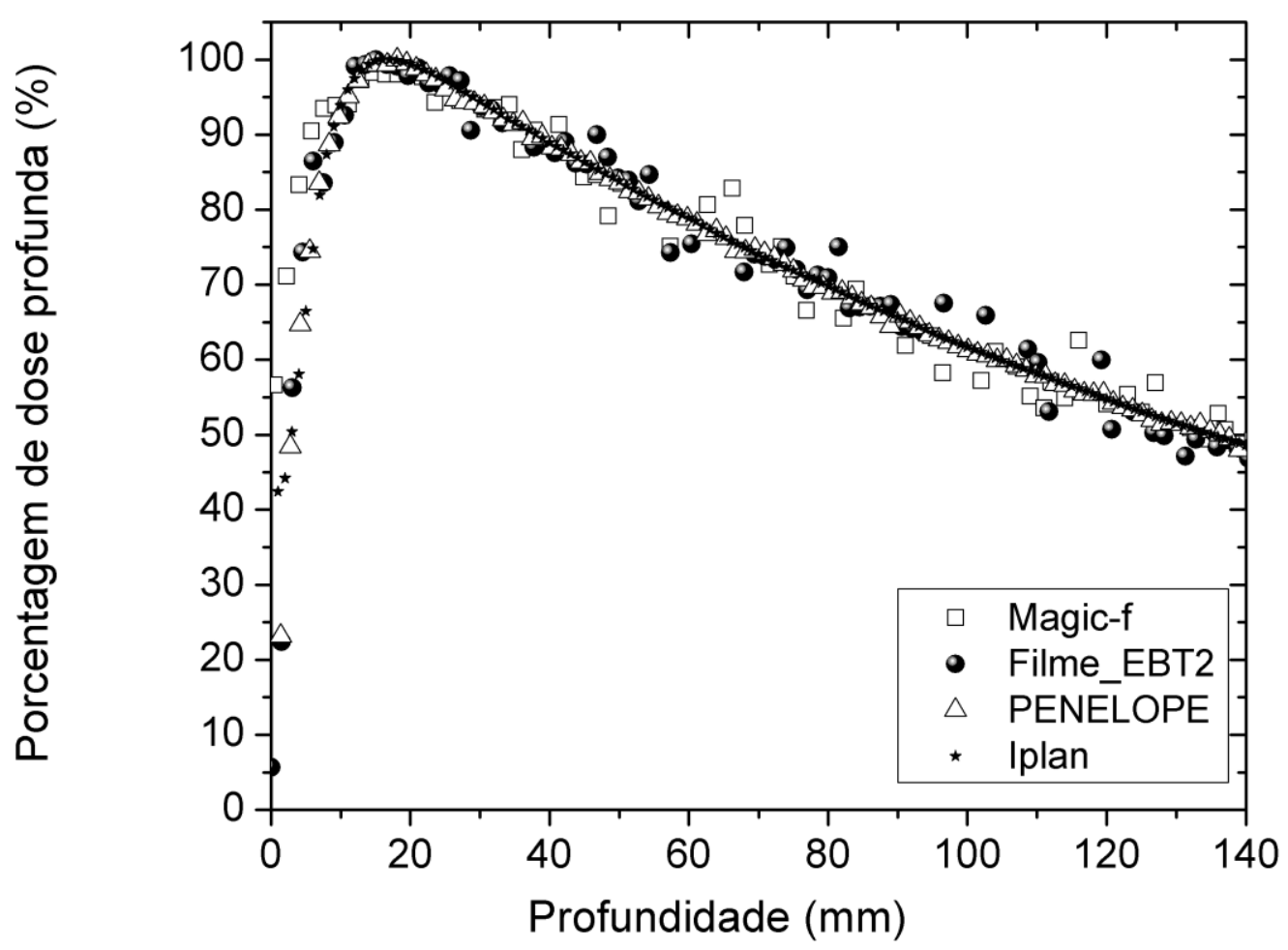

Figura 48: PDP para o campo circular de $2 \mathrm{~cm}$ de diâmetro obtido com as quatro ferramentas dosimétricas: Magic-f gel, Filme EBT2, PENELOPE e TPS iPlan ${ }^{\circledR}$. 
As PDPs obtidas para o campo de irradiação de $2 \mathrm{~cm}$ diâmetro com as quatro ferramentas dosimétricas foram comparadas e as máximas diferenças percentuais encontradas são mostradas na Tabela 8.

Tabela 8: Diferenças percentuais máximas entre as PDPs obtidas com as quatro ferramentas dosimétricas para o campo de irradiação de $2 \mathrm{~cm}$ de diâmetro.

\begin{tabular}{|c|c|c|c|c|}
\hline & MAGIC- $f$ gel & Filme EBT2 & PENELOPE & TPS iPlan ${ }^{\circledR}$ \\
\hline MAGIC- $f$ gel & --- & 7,95 & 7,96 & 6,59 \\
\hline Filme EBT2 & --- & --- & 5,30 & 5,36 \\
\hline PENELOPE & --- & --- & --- & 4,58 \\
\hline
\end{tabular}

4.4.1.3. Campo circular com $3 \mathrm{~cm}$ de diâmetro

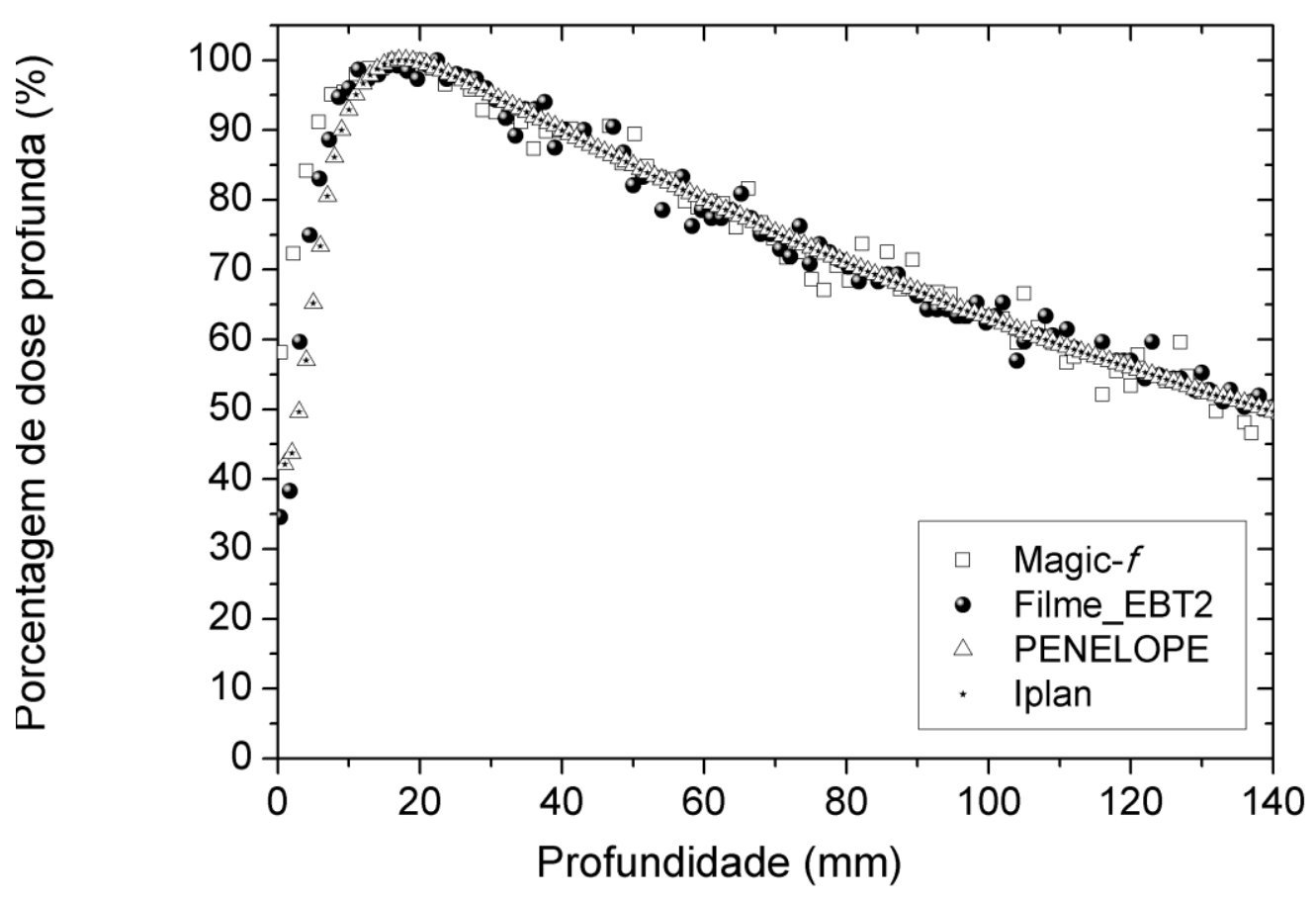

Figura 49: PDP para o campo circular de $3 \mathrm{~cm}$ de diâmetro obtido com as quatro ferramentas dosimétricas: Magic- $f$ gel, Filme EBT2, PENELOPE e TPS iPlan ${ }^{\circledR}$. 
As PDPs obtidas para o campo de irradiação de $3 \mathrm{~cm}$ diâmetro com as quatro ferramentas dosimétricas foram comparadas e as máximas diferenças percentuais encontradas são mostradas na Tabela 9.

Tabela 9: Diferenças percentuais máximas entre as PDPs obtidas com as quatro ferramentas dosimétricas para o campo de irradiação de $3 \mathrm{~cm}$ de diâmetro.

\begin{tabular}{|l|cccc|c}
\cline { 2 - 5 } \multicolumn{1}{c|}{} & MAGIC- $f$ gel & \multicolumn{2}{c}{ Filme EBT2 } & PENELOPE & ${\text { TPS } \text { iPlan }^{\circledR}}^{\circledR}$ \\
\cline { 2 - 6 } MAGIC-f gel & --- & 5,44 & 4,69 & 4,80 \\
\cline { 2 - 5 } Filme EBT2 & --- & -- & 6,57 & 5,16 \\
PENELOPE & --- & --- & --- & 3,28 \\
\cline { 2 - 5 } & & &
\end{tabular}

A partir das curvas das PDPs determinadas para os campos de irradiação estudados com as quatro ferramentas dosimétricas, pode-se observar que todas as ferramentas reproduzem a forma funcional de uma curva de PDP para um feixe de $6 \mathrm{MV}$. Além disso, as PDPs simuladas com o código PENELOPE apresentaram as maiores concordâncias com os valores obtidos com o TPS iPlan, com diferença máxima de 4,58\% para o campo circular de $2 \mathrm{~cm}$ de diâmetro. Ainda em comparação com o iPlan, o MAGIC-f apresentou concordância de $6,59 \%$, para o campo de $2 \mathrm{~cm}$ de diâmetro, e melhor que $4,80 \%$ para os outros campos, e o filme apresentou concordância melhor que $5,52 \%$ para todos os campos.

As incertezas máximas referentes a cada ferramenta dosimétrica, para todos os tamanhos de campo estudados, foram determinadas através dos desvios padrão Assim, as incertezas para o gel foram de até $4,5 \%$ e para filme de $3,7 \%$. As incertezas associadas ao código PENELOPE e ao TPS iPlan ${ }^{\circledR}$ foram de até $2 \%$.

\subsubsection{Perfis de campo}

As distribuições de dose também foram analisadas através da construção de perfis de dose em profundidades da dose máxima (1,5 $\mathrm{cm}$ ) e em $5 \mathrm{~cm}$ de profundidade. As figuras 51 e 52 mostram os perfis de dose para os campos de 1,2 e $3 \mathrm{~cm}$ de diâmetro, para um feixe de 6 
MV. Os dados obtidos dos perfis, com as quatro ferramentas dosimétricas, foram comparadas obtendo-se diferenças máximas percentuais mostradas nas tabelas 10,12 e 14 para a profundidade de $15 \mathrm{~mm}$ e nas tabelas 11,13 e 15 para a profundidade de $50 \mathrm{~mm}$.

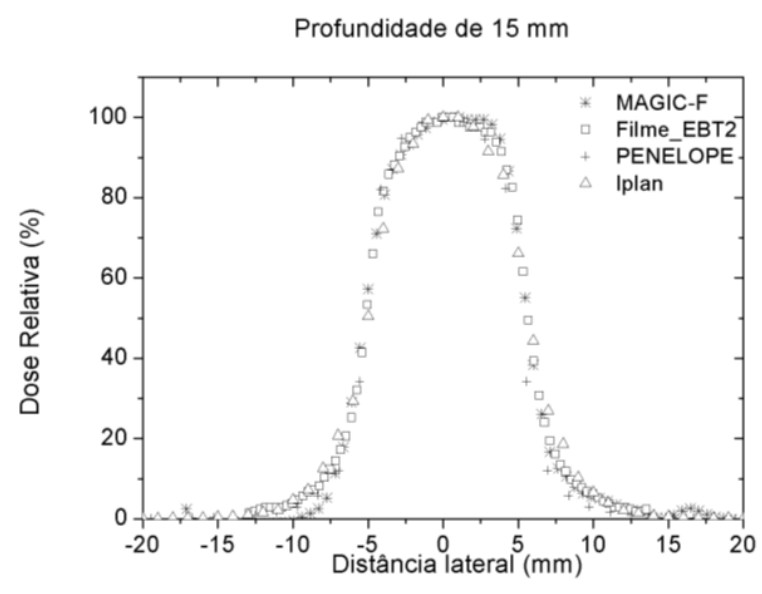

(a)

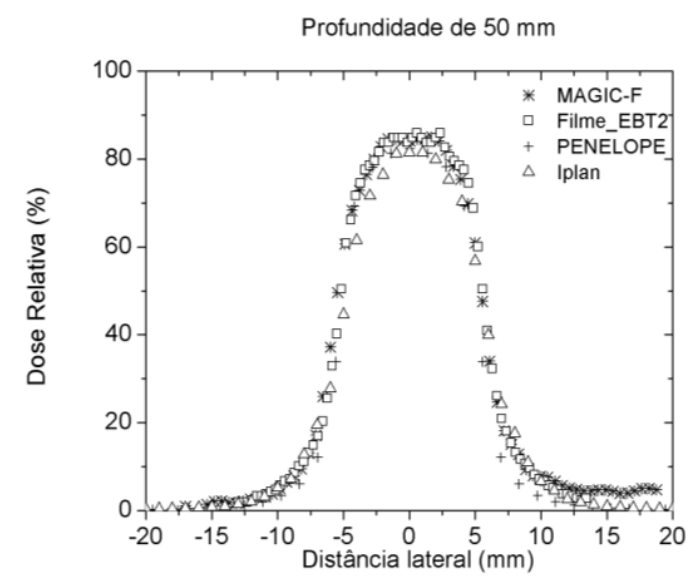

(b)

Figura 50: Perfil de dose para um campo de $1 \mathrm{~cm}$ de diâmetro na profundidade de dose máxima, $15 \mathrm{~mm}$ (a) e em $50 \mathrm{~mm}$ (b) para um feixe de $6 \mathrm{MV}$.

Tabela 10: Diferenças percentuais máximas obtidas na determinação do perfil de campo para as quatro ferramentas dosimétricas para o campo de irradiação de $1 \mathrm{~cm}$ de diâmetro na profundidade de $15 \mathrm{~mm}$.

\begin{tabular}{|c|c|c|c|c}
\cline { 2 - 5 } \multicolumn{1}{c|}{} & \multicolumn{1}{c}{ MAGIC- $f$ gel } & Filme EBT2 & PENELOPE & TPS iPlan $^{\circledR}$ \\
\cline { 2 - 5 } MAGIC-f gel & --- & 5,4 & 4,48 & 5,99 \\
Filme EBT2 & --- & --- & 6,36 & 6,33 \\
PENELOPE & --- & -- & --- & 3,19 \\
\cline { 2 - 5 } & & &
\end{tabular}

Tabela 11: Diferenças percentuais máximas obtidas na determinação do perfil de campo para as quatro ferramentas dosimétricas para o campo de irradiação de $1 \mathrm{~cm}$ de diâmetro na profundidade de $50 \mathrm{~mm}$.

\begin{tabular}{|l|cccc|c}
\cline { 2 - 5 } \multicolumn{1}{c|}{} & MAGIC- $f$ gel & Filme EBT2 & PENELOPE & ${\text { TPS } \text { iPlan }^{\circledR}}^{\circledR}$ \\
\cline { 2 - 5 } & MAGIC- $f$ gel & -- & 3,71 & 2,99 & 3,62 \\
Filme EBT2 & --- & --- & 3,91 & 5,92 \\
PENELOPE & --- & --- & --- & 3,08 \\
\cline { 2 - 5 } & & &
\end{tabular}




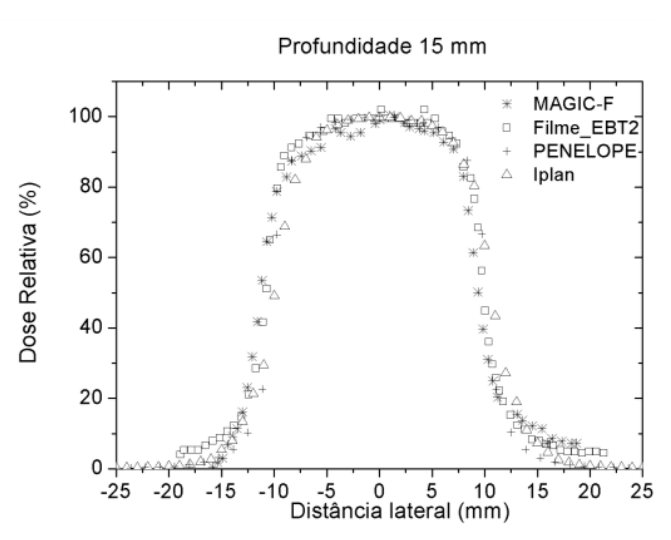

(a)

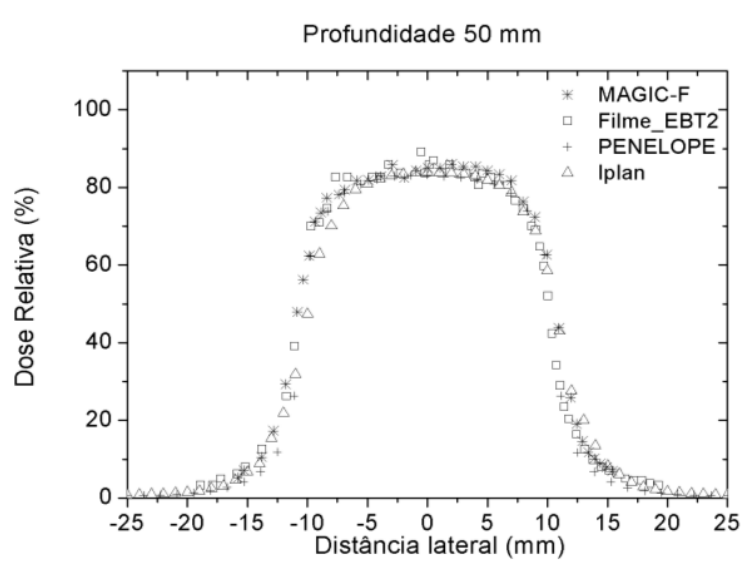

(b)

Figura 51: Perfil de dose para um campo de $2 \mathrm{~cm}$ de diâmetro na profundidade de dose máxima, $15 \mathrm{~mm}$ (a) e em $50 \mathrm{~mm}$ (b) para um feixe de $6 \mathrm{MV}$.

Tabela 12: Diferenças percentuais máximas obtidas na determinação do perfil de campo para as quatro ferramentas dosimétricas para o campo de irradiação de $2 \mathrm{~cm}$ de diâmetro na profundidade de $15 \mathrm{~mm}$.

\begin{tabular}{|l|ccccc}
\cline { 2 - 5 } \multicolumn{1}{c|}{} & MAGIC- $f$ gel & Filme EBT2 & PENELOPE & TPS iPlan $^{\circledR}$ \\
\cline { 2 - 5 } MAGIC- $f$ gel & --- & 4,82 & 3,96 & 3,83 \\
\cline { 2 - 5 } Filme EBT2 & --- & --- & 4,93 & 5,62 \\
PENELOPE & --- & --- & --- & 2,99 \\
\cline { 2 - 5 } & & &
\end{tabular}

Tabela 13: Diferenças percentuais máximas obtidas na determinação do perfil de campo para as quatro ferramentas dosimétricas para o campo de irradiação de $2 \mathrm{~cm}$ de diâmetro na profundidade de $50 \mathrm{~mm}$.

\begin{tabular}{|c|c|c|c|c|}
\hline & MAGIC- $f$ gel & Filme EBT2 & PENELOPE & TPS iPlan ${ }^{\circledR}$ \\
\hline MAGIC- $f$ gel & --- & 4,39 & 4,01 & 4,18 \\
\hline Filme EBT2 & --- & --- & 5,16 & 4,89 \\
\hline PENELOPE & --- & --- & -- & 3,21 \\
\hline
\end{tabular}




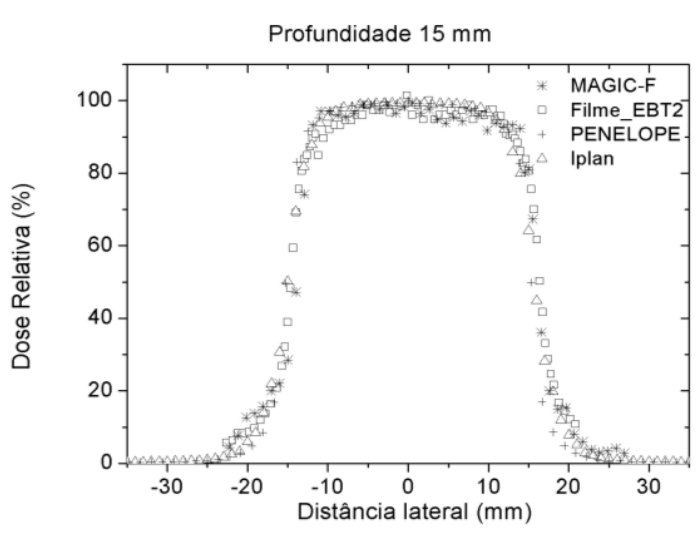

(a)

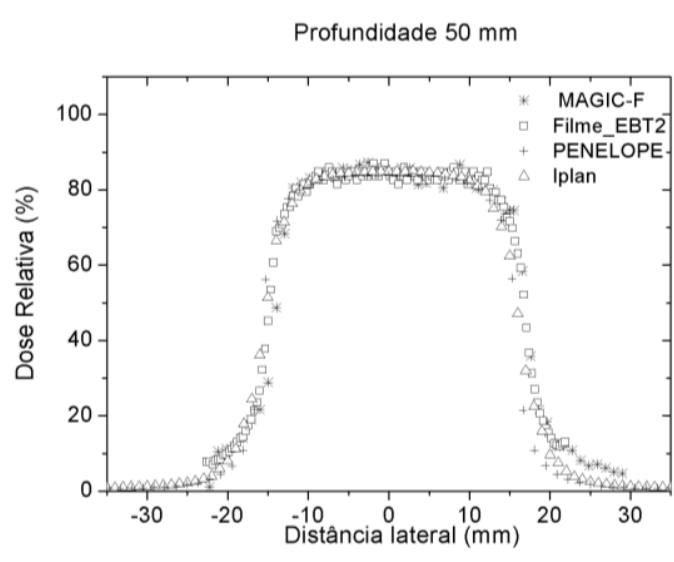

(b)

Figura 52: Perfil de dose para um campo de $3 \mathrm{~cm}$ de diâmetro na profundidade de dose máxima, $15 \mathrm{~mm}$ (a) e em $50 \mathrm{~mm}$ (b) para um feixe de $6 \mathrm{MV}$.

Tabela 14: Diferenças percentuais máximas obtidas na determinação do perfil de campo para as quatro ferramentas dosimétricas para o campo de irradiação de $3 \mathrm{~cm}$ de diâmetro na profundidade de $15 \mathrm{~mm}$.

\begin{tabular}{|l|c|c|c|c}
\cline { 2 - 5 } \multicolumn{1}{c|}{} & MAGIC- $f$ gel & Filme EBT2 & PENELOPE & TPS $_{\text {iPlan }}{ }^{\circledR}$ \\
\cline { 2 - 5 } MAGIC- $f$ gel & --- & 5,02 & 4,33 & 4,68 \\
\cline { 2 - 5 } Filme EBT2 & --- & --- & 5,45 & 5,29 \\
PENELOPE & --- & --- & --- & 2,89 \\
\cline { 2 - 5 } & & &
\end{tabular}

Tabela 15: Diferenças percentuais máximas obtidas na determinação do perfil de campo para as quatro ferramentas dosimétricas para o campo de irradiação de $3 \mathrm{~cm}$ de diâmetro na profundidade de $50 \mathrm{~mm}$.

\begin{tabular}{|l|c|c|c|c}
\cline { 2 - 5 } \multicolumn{1}{c|}{} & MAGIC- $f$ gel & Filme EBT2 & PENELOPE & TPS iPlan $^{\circledR}$ \\
\cline { 2 - 5 } MAGIC- $f$ gel & --- & 4,87 & 4,91 & 4,88 \\
\cline { 2 - 5 } Filme EBT2 & --- & --- & 4,95 & 5,31 \\
PENELOPE & --- & --- & --- & 3,15 \\
\cline { 2 - 5 } & & &
\end{tabular}

Os resultados encontrados para as curvas de PDP e dos perfis de dose para os campos circulares de 1,2 e $3 \mathrm{~cm}$ de diâmetro evidenciam que as ferramentas dosimétricas podem reproduzir as formas funcionais dos parâmetros dosimétricos determinados, apesar das diferenças encontradas. De forma geral, assim como ocorreu para as PDPs, os perfis de campos e doses 
do PENELOPE são os que mais concordam com os valores obtidos com o TPS iPlan, com diferença máxima de 3,80\% para o campo circular de $1 \mathrm{~cm}$ de diâmetro à $5 \mathrm{~cm}$ de profundidade. Ainda em comparação com 0 iPlan, 0 MAGIC-f apresentou concordância melhor que 5,99\% para todos os campos de radiação e profundidades estudadas. O filme apresentou concordância melhor que $6,33 \%$ para todos os campos e as duas profundidades estudadas, em relação aos dados do TPS iPlan.

\subsection{Irradiações conformacionais com campos pequenos}

Para os estudos preliminares para determinar distribuições de dose com campos pequenos coplanares e não-coplanares, foram simulados dois casos de irradiações coplanares (5 e 6 campos) e, posteriormente, um caso não coplanar (7 campos).

\subsubsection{Irradiação conformacional coplanar}

\subsubsection{Composição com 5 campos coplanares}

A Figura 53 (a) e (b) mostram as distribuições de dose obtidas com PENELOPE e MAGIC- $f$ gel, respectivamente, para o plano de 5 campos coplanares. 


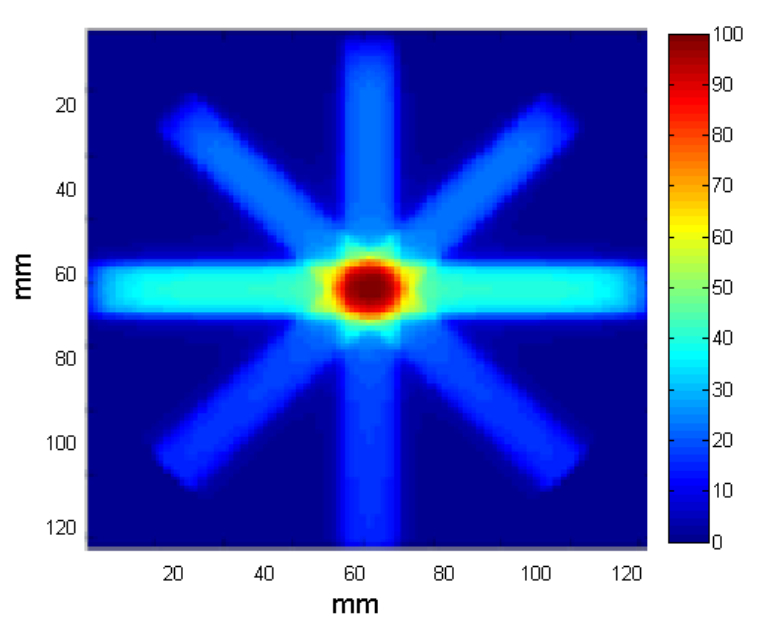

(a)

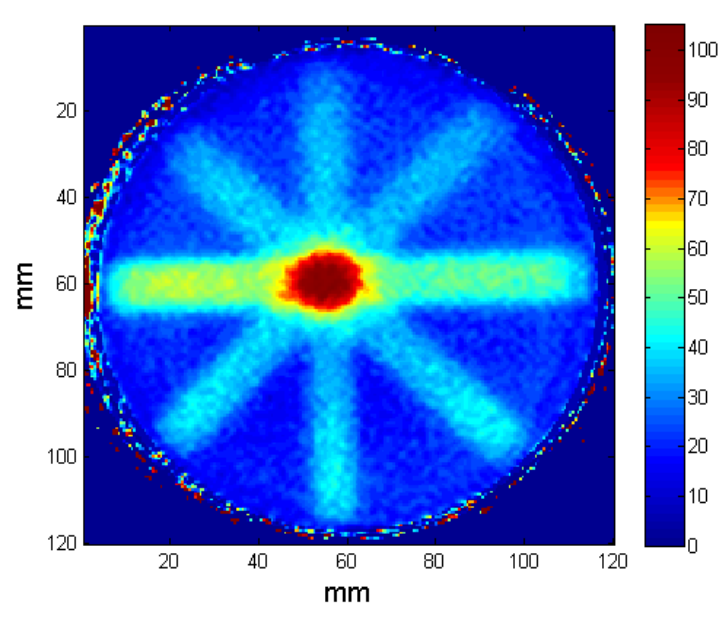

(b)

Figura 53: Distribuições de doses obtidas utilizando a) código de simulação PENELOPE e b) MAGIC- $f$ gel, para 5 campos coplanares de $1 \mathrm{~cm}$ de diâmetro para um feixe de $6 \mathrm{MV}$.

Para a avaliação das distribuições de dose obtidas com as duas ferramentas dosimétricas foram comparadas os perfis de dose ao longo do eixo dos campos paralelo opostos, no eixo central do volume. Como mostrado na Figura 54, a máxima diferença encontrada foi de $0,60 \%$ a $0,55 \mathrm{~cm}$ do centro do campo, posição aproximada da metade do campo de radiação. A partir desta distância as diferenças são de até $8,50 \%$,

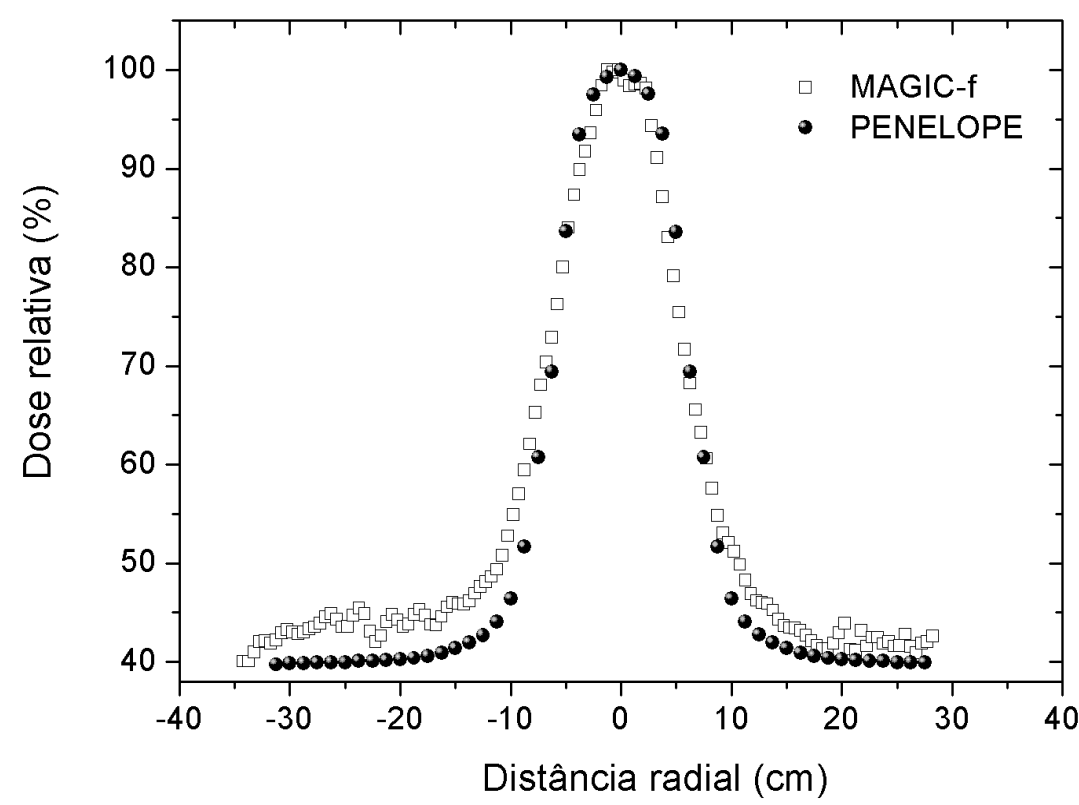

Figura 54: Perfil de dose da composição de 5 campos de $1 \mathrm{~cm}$ de diâmetro obtido através do código de simulação PENELOPE (•) e MAGIC-f gel ( $\square$ ), para o feixe de $6 \mathrm{MV}$. 
A partir das diferenças encontradas, pode-se inferir que ambas as ferramentas dosimétricas respondem de forma semelhante na região dos campos de irradiação, posição relativa do volume alvo do tratamento. Já nas posições fora do volume alvo há discrepâncias que podem ser significativas. Dessa forma, conclui-se que o dosímetro MAGIC-f é capaz de reproduzir a distribuição de doses no volume alvo de uma composição de campos pequenos.

\subsubsection{Composição com 6 campos coplanares}

Uma composição com 6 campos coplanares foi utilizada para avaliação da possibilidade da utilização de filme EBT2 na determinação da uma distribuição de dose de casos de irradiação coplanar de campos pequenos.

Nessas mesmas condições e geometria de planejamento utilizando TPS iPlan ${ }^{\circledR}$ foram realizadas simulações com o código PENELOPE e irradiações com filme EBT2 dentro do OS. A Figura 55 mostra as distribuições de dose, para o plano todo, obtidas com as ferramentas dosimétricas. 


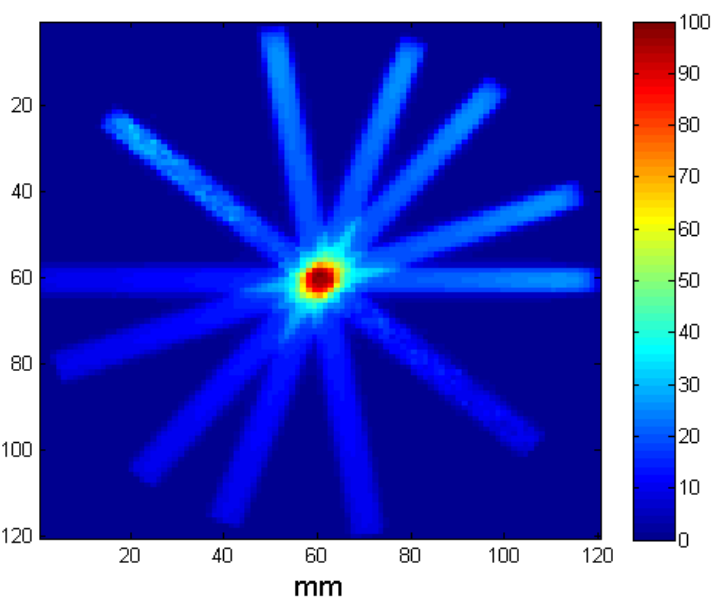

(a)

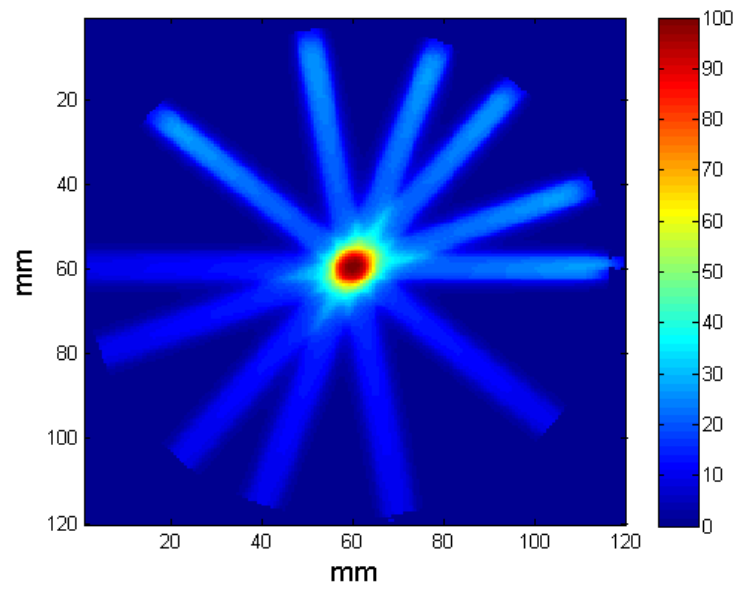

(b)

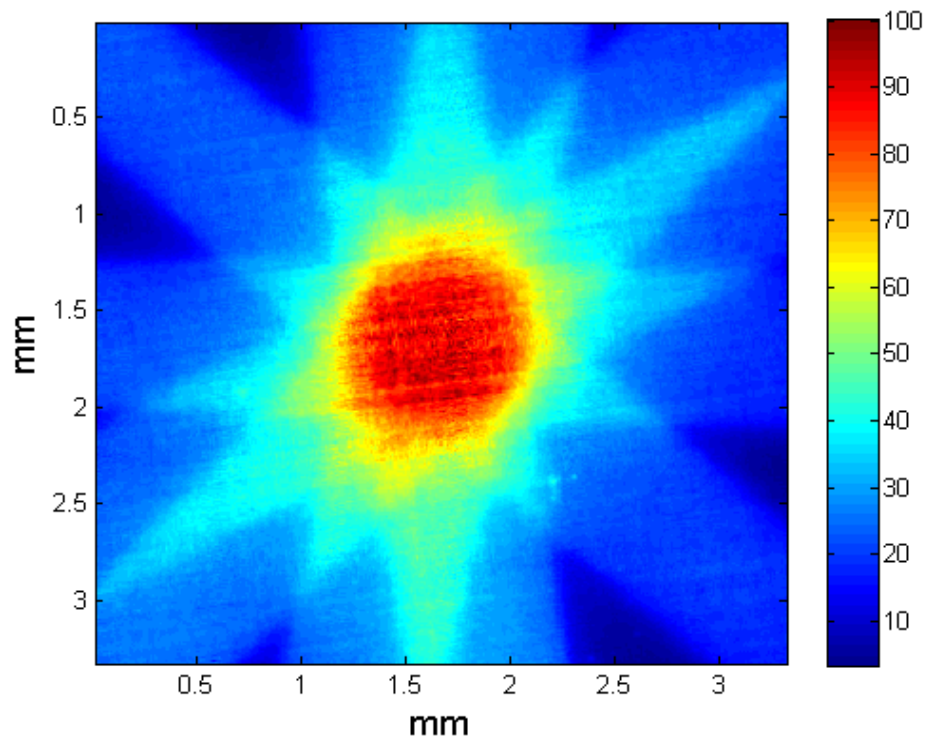

(c)

Figura 55: Distribuição de dose para 6 campos coplanares obtidas para 0 plano central do volume alvo: (a) PENELOPE, (b) TPS Plan $^{\circledR}$ e (c) filme EBT2, para o feixe de $6 \mathrm{MV}$.

As distribuições de dose obtidas foram avaliadas com a técnica de comparação dos índices $\gamma$, com parâmetros de $3 \mathrm{~mm}$ (DTA) e 3\% de diferença em dose, que são parâmetros padrão para essa análise (Stock et al, 2005; Harms et al, 1998; Low et al, 1998).

A Figura 56 mostra o mapa dos índices $\gamma$, obtidos comparando as distribuições de dose obtidas com o PENELOPE e TPS iPlan ${ }^{\circledR}$. 


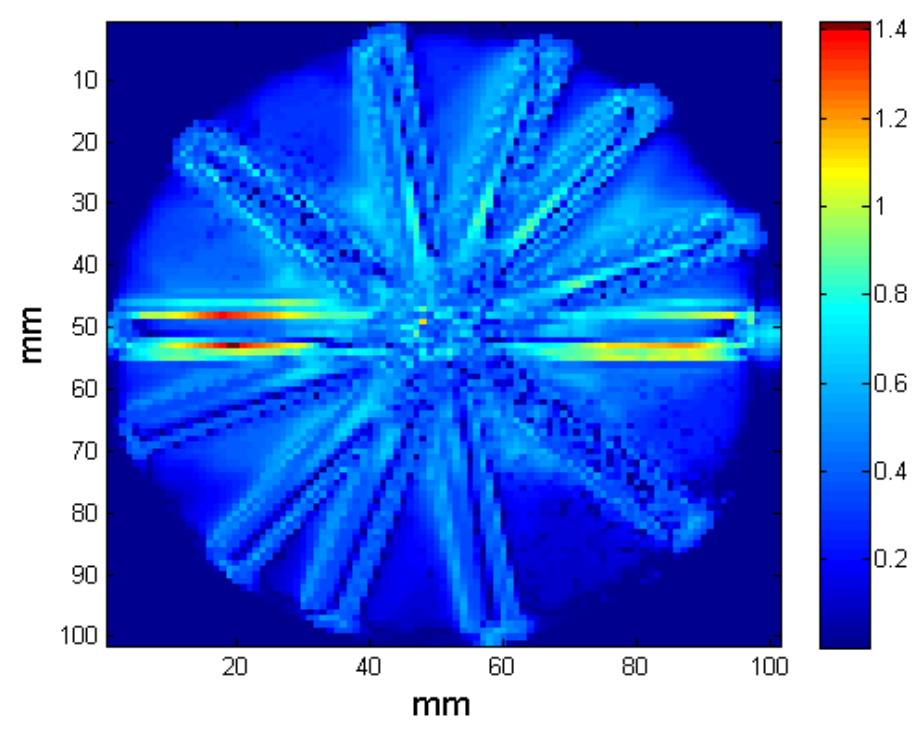

Figura 56: Mapas dos índices $\gamma$ comparando as distribuições de dose obtidas com o PENELOPE e o TPS iPlan ${ }^{\circledR}$ para a composição de 6 campos coplanares.

Dos dados do mapa dos índices $\gamma$ mostrados na figura Figura 56, notase que $85 \%$ dos pixels das imagens apresentaram índices $\gamma$ menores que 1 , passando pelo teste com uma concordância de $100 \%$, os outros $15 \%$ dos pixels apresentam de valores de até 1,4, não passando pelo teste.

A Figura 57 mostra os mapas dos índices $\gamma$ comparando as distribuições de dose das três ferramentas utilizadas na região central da distribuição de dose, para uma isodose de, aproximadamente, $40 \%$. 


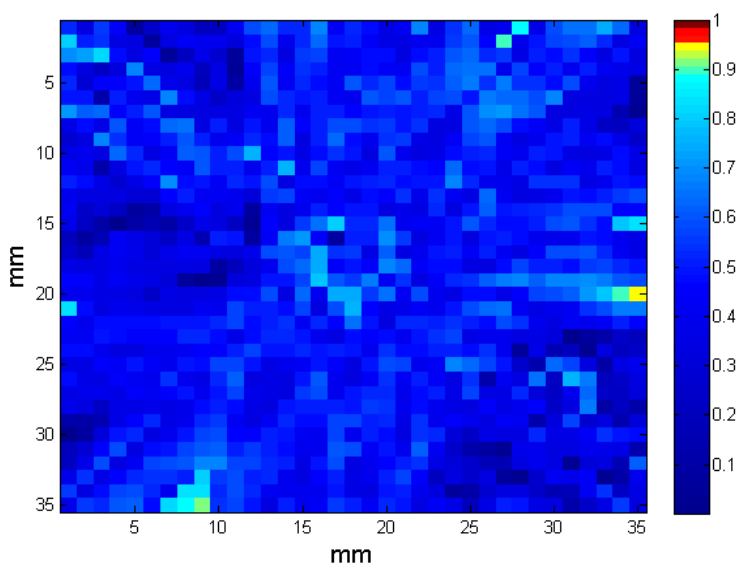

(a)

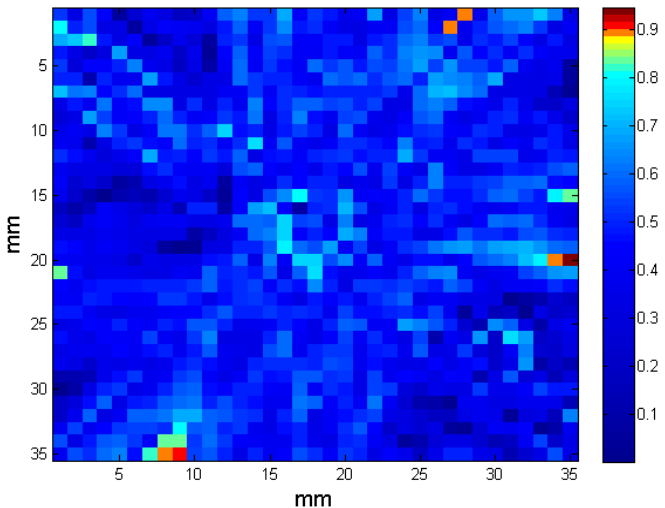

(b)

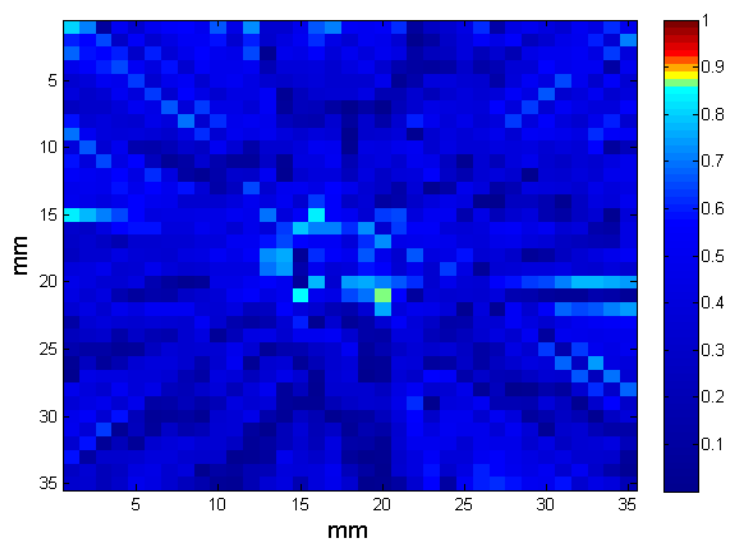

(c)

Figura 57: Mapas dos índices $\gamma$ comparando as distribuições de dose para uma isodose de 40\%: (a) PENELOPE-TPS iPlan, (b) PENELOPE-EBT2 e (c) TPS iPlan ${ }^{\circledR}$-EBT2.

A Figura 57 mostra que 100\% dos pixels dos mapas de índices $\gamma$ possuem valores de até 1 , indicando que a comparação das distribuições de dose obtidas através do PENELOPE, TPS iPlan ${ }^{\circledR}$ e EBT2 são semelhantes utilizando-se os critérios de avaliação de 3\% de diferença em dose e tolerância de $3 \mathrm{~mm}$ na posição (DTA).

Com os dados mostrados dos índices $\gamma$ para o teste de 6 campos coplanares pode-se inferir que o filme EBT2 pode ser utilizado na reprodução de uma distribuição de dose de uma composição com campos pequenos, tanto em posições de altas doses quanto em regiões fora do volume alvo do tratamento. Entretanto, dados os resultados dos parâmetros dosimétricos PDP e perfis de campo obtidos para os filmes, que possuíam a pior concordância 
com o TPS iPlan, uma composição com 7 campos não-coplanares foi, ainda testada com o filme EBT2.

\subsubsection{Irradiação conformacional não coplanar}

\subsubsection{Composição com 7 campos não coplanares}

As distribuições de dose obtidas com o TPS iPlan ${ }^{\circledR}$, filme radiocrômico EBT2 e o código de simulação PENELOPE são mostradas na Figura 58.

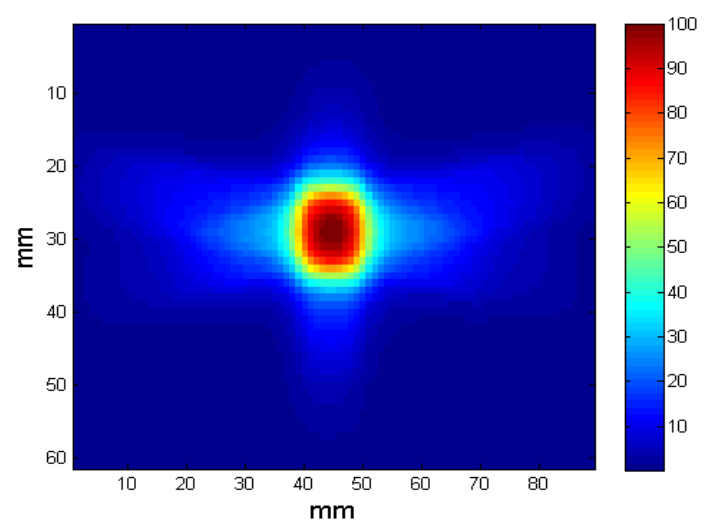

(a)

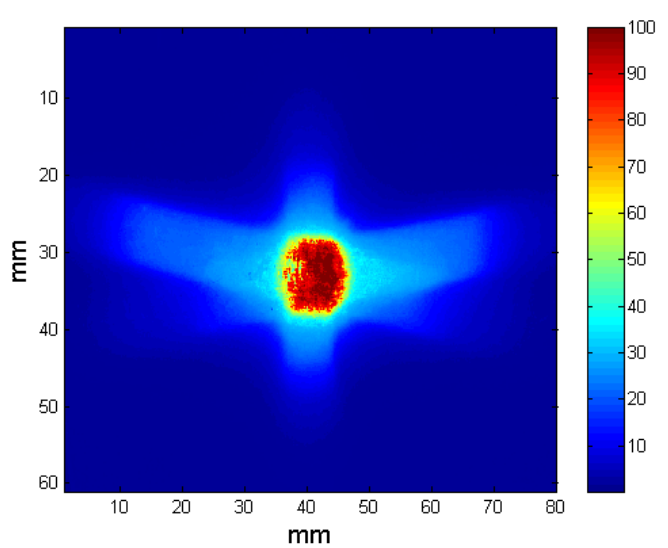

(b)

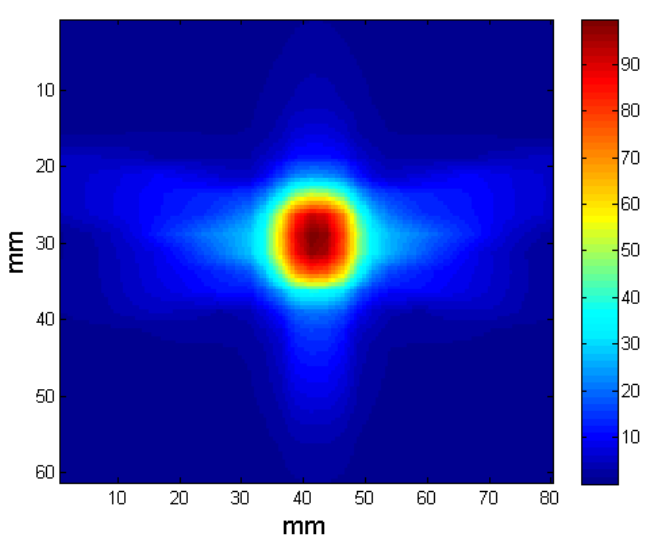

(c)

Figura 58: Distribuições de dose de uma composição de 7 campos nãocoplanares obtida com: (a) PENELOPE, (b) EBT2 e (c) TPS iPlan ${ }^{\circledR}$. 
As distribuições de dose com as três ferramentas dosimétricas foram comparadas com a técnica do índice $\gamma$, com parâmetros de $3 \mathrm{~mm}$ (DTA) e 3\% de diferença em dose, mostrados na Figura 59.

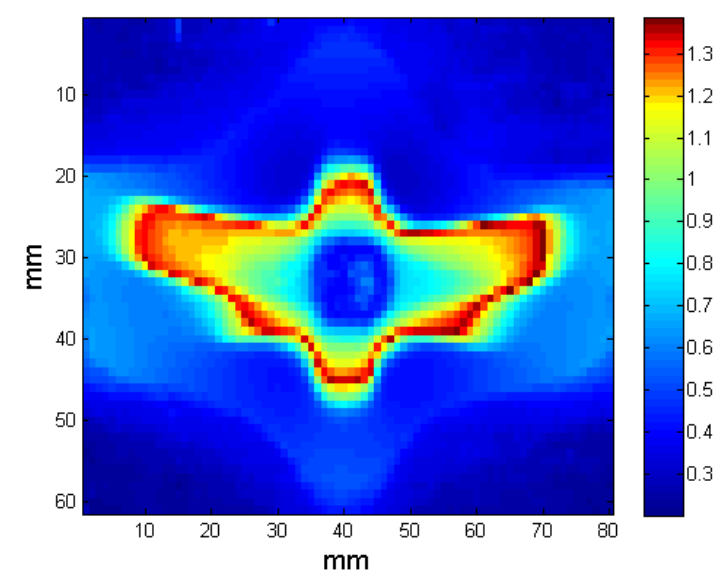

(a)

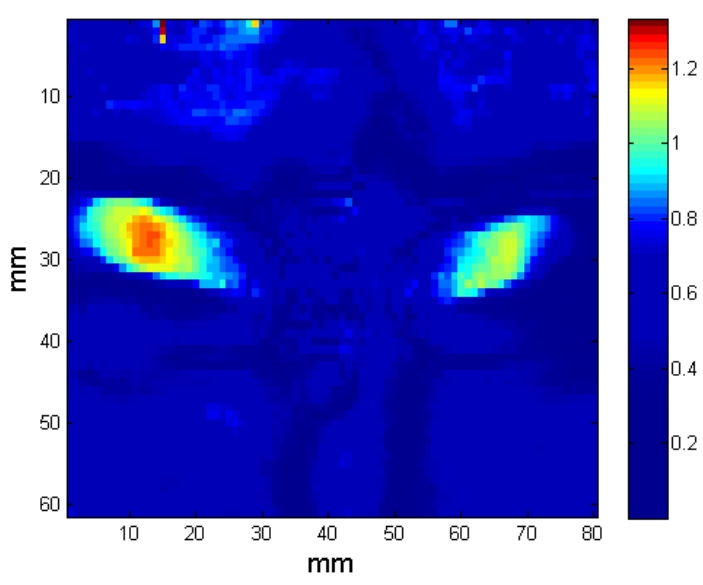

(b)

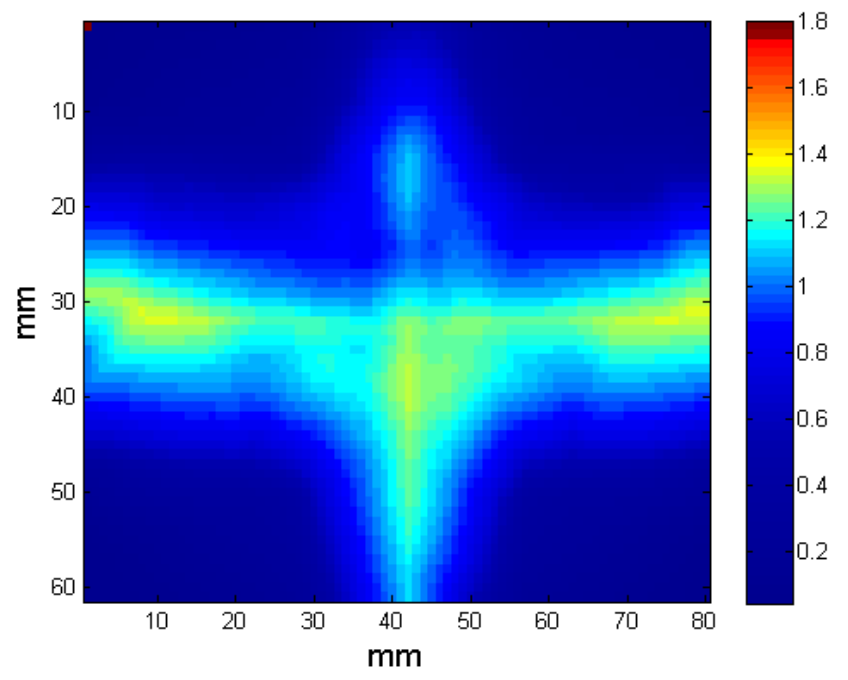

(c)

Figura 59: Mapa dos índices $\gamma$ obtidos referentes da comparação para as seguintes ferramentas dosimétricas: (a) PENELOPE-EBT2, (b) TPS iPlan ${ }^{\circledR}$ EBT2 e (c) PENELOPE-Iplan ${ }^{\circledR}$.

Das comparações feitas em todo o plano do mapa de doses, através do índice $\gamma$, mostrou-se um total de $84,55 \%$; $97,06 \%$; e $71,55 \%$ dos pixels de cada mapa com índice $\gamma$ menor ou igual a 1, portanto passando no teste. Tomandose em consideração a região de altas doses, no centro da distribuição e que engloba a isodose de $90 \%$, todos os pixels passaram o teste. Pode-se notar, entretanto, nas distribuições de doses da Figura 59 que há uma diferença de 
dose na região central da distribuição. Desta forma, a aprovação no teste foi devida à escolha do valor de $3 \mathrm{~mm}$ para a distância da dose (DTA).

A partir dos resultados avaliados, pode observar que o filme EBT2 também reproduz a distribuição de dose para campos pequenos não coplanares, que são o tipo de conformação utilizado nos tratamentos de radiocirurgia.

\subsection{Casos de Radiocirurgia}

Os resultados apresentados abaixo são referentes ao objetivo principal desse trabalho de pesquisa, a avaliação das distribuições de doses para casos de radiocirurgia. Assim, foram planejados e irradiados três casos utilizando a técnica de radiocirurgia utilizando-se objetos simuladores de cabeça. As distribuições de dose foram obtidas com as quatro ferramentas dosimétricas: PENELOPE, TPS, EBT2 e MAGIC-f. As distintas distribuições de dose obtidas foram avaliadas entre si através da técnica de comparação dos índices $\gamma$, DVH e TCP.

Para os casos de composições coplanares e não-coplanares apresentados, os critérios de índice $\gamma$ utilizados foram: $3 \mathrm{~mm}$ e $3 \%$, valores padrão conforme encontrado na literatura (Stock et al, 2005; Harms et al, 1998; Low et al, 1998 ). Para técnicas como as de intensidade modulada os valores dos critérios do índice gama são variados na literatura: $1 \mathrm{~mm}$ e $2 \%$ (McNiven et al, 2012; Falk et al, 2010; Winiecki et al, 2009), 4mm e 7\% utilizado no Radiological Physics Center (RPC) (Molineu et al, 2010), de 3mm e 4\% para European Society for Radiotherapy and Oncology (ESTRO) (Gillis et all, 2005) e para a American Assosciation of Physicits in Medicine (AAPM) os critérios adotados são de $3 \mathrm{~mm}$ e $3 \%$ (AAPM, 2011). Da mesma forma, para a técnica de radiocirurgia, especificamente, também se encontram critérios variados na literatura: de 3mm e 3\% ( $\mathrm{Li}$ et al, 2011; Gospishankar et al, 2010), de 2mm e $2 \%$ da AAPM (AAMP, 2011) e, recentemente, uma publicação reportou a utilização de 0,5 mm e 0,5\% de dose (Park et al, 2011).

Dessa forma, para a técnica de radiocirurgia, ainda não há um consenso a respeito critérios específicos para o índice $\gamma$. Assim, para o primeiro caso 
radiocirurgia desse trabalho de pesquisa foram avaliados diversos valores para os critérios DTA (1 a $3 \mathrm{~mm})$ e diferença de dose (1\% até $5 \%$ ) afim de proporcionar-se uma base para discussão de um critério apropriado a ser utilizado para a técnica.

\subsubsection{Caso 1: Meningioma}

As distribuições de dose do plano central dos volumes de irradiações são mostradas na Figura 60, para MAGIC-f, EBT2, TPS iPlan ${ }^{\circledR}$ e PENELOPE.

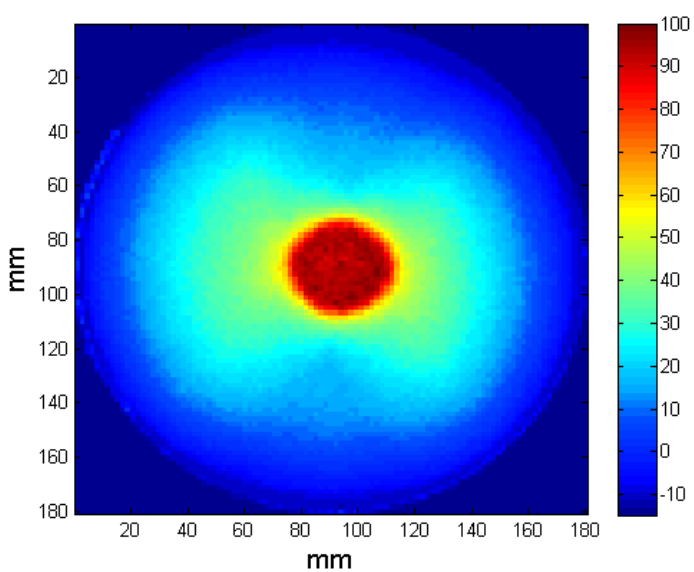

(a)

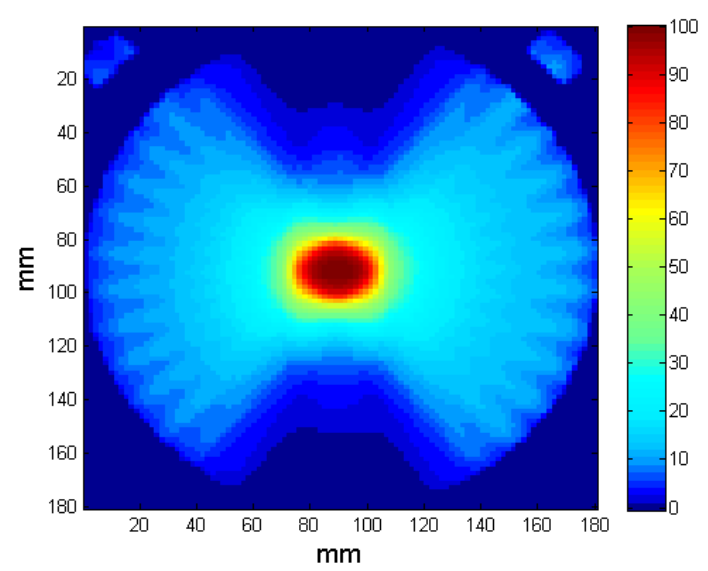

(c)

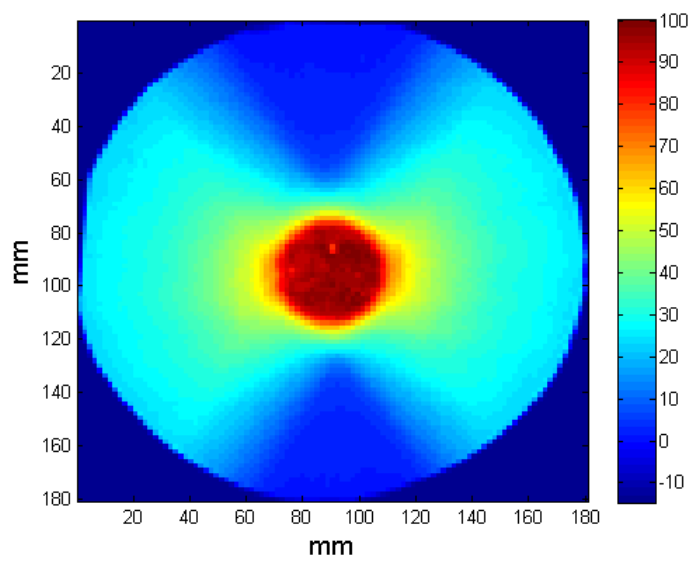

(b)

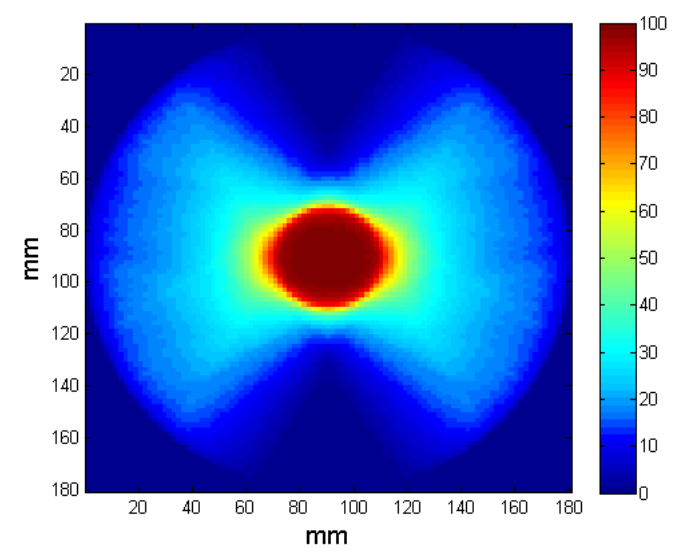

(d)

Figura 60: Distribuições de dose obtidas para uma técnica de radiocirurgia com arco dinâmico com as ferramentas dosimétricas: (a) MAGIC-f, (b) EBT2, (c) TPS iPlan ${ }^{\circledR}$ e (d) PENELOPE. 
As comparações com o índice $\gamma$ foram feitas para todo o plano, e nas isodoses de $90 \%$ e $50 \%$ desse mesmo plano, representadas pelos círculos brancos. Os mapas dos índices $\gamma$ obtidos a partir das comparações das distribuições de dose das quatro ferramentas dosimétricas, são apresentadas entre as Figura 61 à Figura 85, com os critérios de comparação de 1mm, 1\%; $2 \mathrm{~mm}, 2 \%$; $3 \mathrm{~mm}, 3 \%$ e $3 \mathrm{~mm}, 5 \%$. Para o critério $3 \mathrm{~mm}$ e $3 \%$, para as distribuições obtidas para o PENELOPE e o TPS iPlan ${ }^{\circledR}$, são também mostrados os histogramas de índices $\gamma$ para a isodose de $90 \%$, de $50 \%$ e para o plano todo. Por simplicidade, esses histogramas não serão apresentados, sob forma de figura, para as outras combinações de critérios de DTA e diferença de dose estudados. Os dados desses histogramas são, entretanto, apresentados sob forma de tabela ao final da seção. Da mesma forma, a discussão das distribuições de índice gama será realizada ao final da seção.

\subsubsection{Avaliação do índice $\gamma$ entre PENELOPE e TPS iPlan ${ }^{\circledR}$}

\subsection{Critérios do índice $\gamma: 1 \mathrm{~mm}$ e 1\%}

A Figura 61 apresenta o mapa do índice $\gamma$ comparando as distribuições de dose obtidas com o PENELOPE e o TPS iPlan ${ }^{\circledR}$, para os critérios $1 \mathrm{~mm}$ e $1 \%$. 


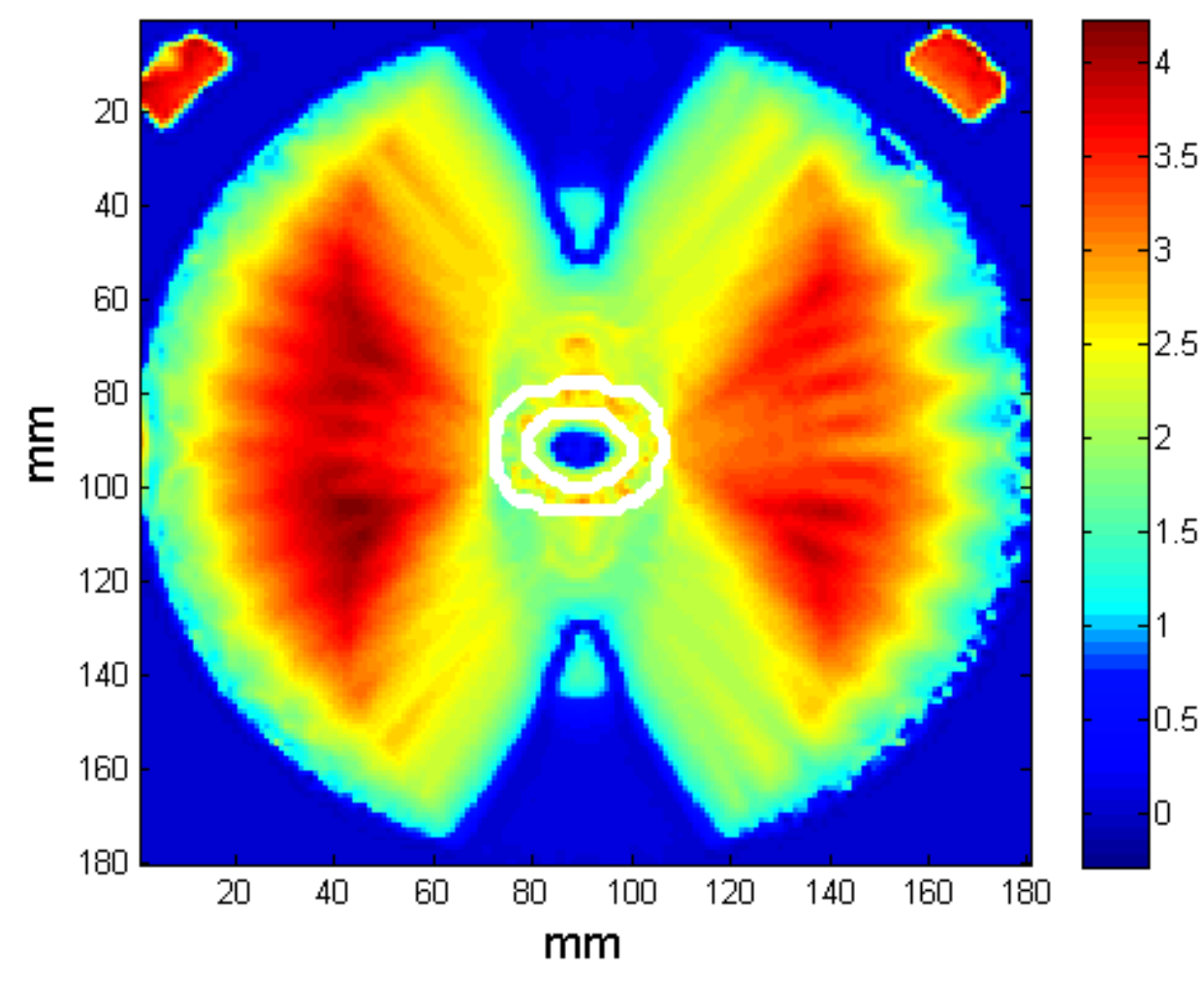

Figura 61: Mapa do índice $\gamma$ comparando as distribuições de dose obtidas com - PENELOPE e o TPS iPlan ${ }^{\circledR}$, para os critérios de $1 \mathrm{~mm}$ e $1 \%$. As linhas brancas mostram as isodoses de $90 \%$ e de $50 \%$, respectivamente.

\subsection{Critérios do índice $\gamma: 2 \mathrm{~mm}$ e $2 \%$}

A Figura 62 apresenta o mapa do índice $\gamma$ comparando as distribuições de dose obtidas com PENELOPE e TPS iPlan ${ }^{\circledR}$, para os critérios de $2 \mathrm{~mm}$ e $2 \%$. 


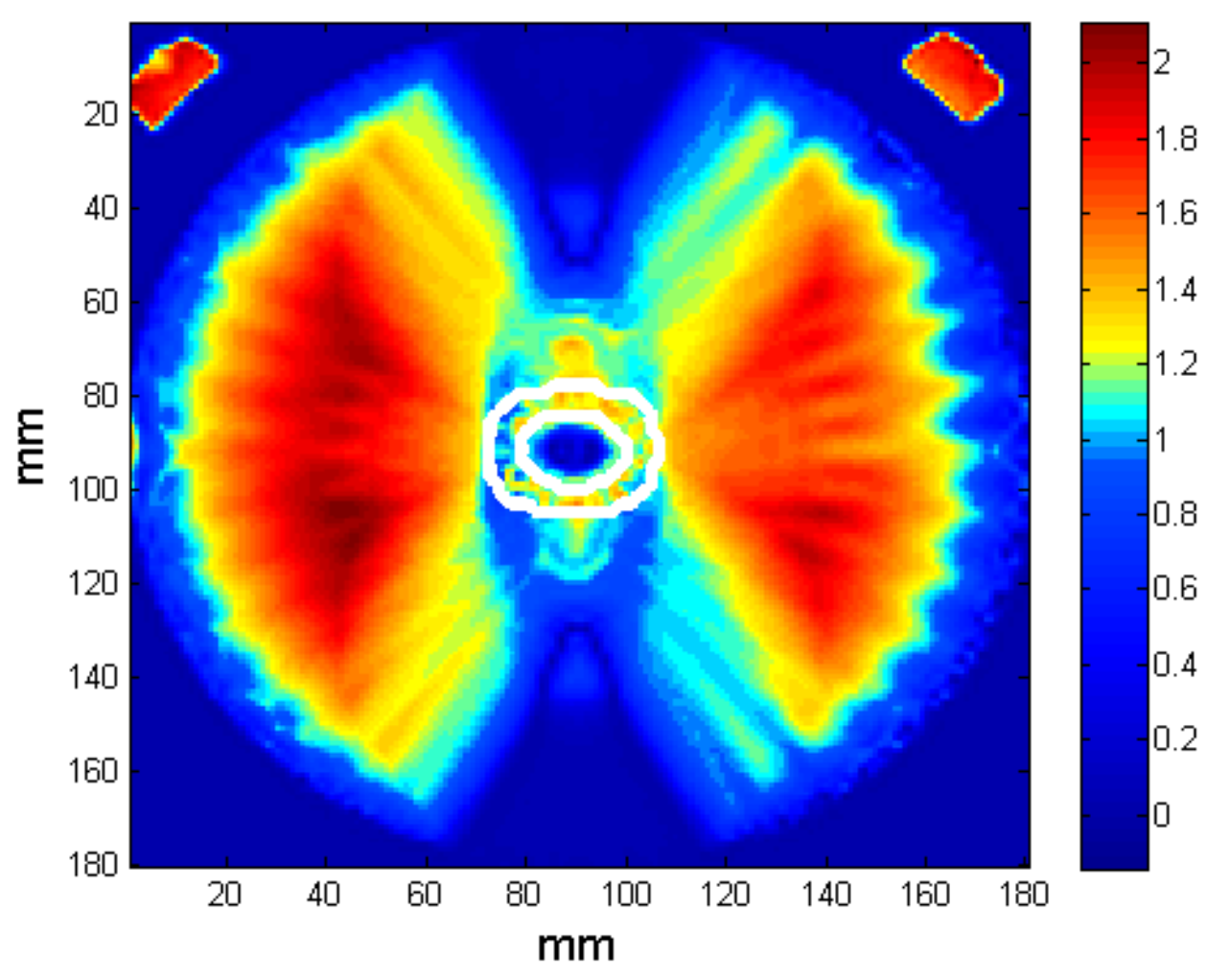

Figura 62: Mapa do índice $\gamma$ comparando as distribuições de dose obtidas com o PENELOPE e o TPS iPlan ${ }^{\circledR}$, para os critérios de $2 \mathrm{~mm}$ e $2 \%$. As linhas brancas mostram as isodoses de $90 \%$ e de $50 \%$, respectivamente.

\subsection{Critérios do índice $\gamma: 3 \mathrm{~mm}$ e $3 \%$}

A apresenta o mapa do índice $\gamma$ comparando as distribuições de dose obtidas com o PENELOPE e o TPS iPlan ${ }^{\circledR}$, para os critérios $3 \mathrm{~mm}$ e $3 \%$. 


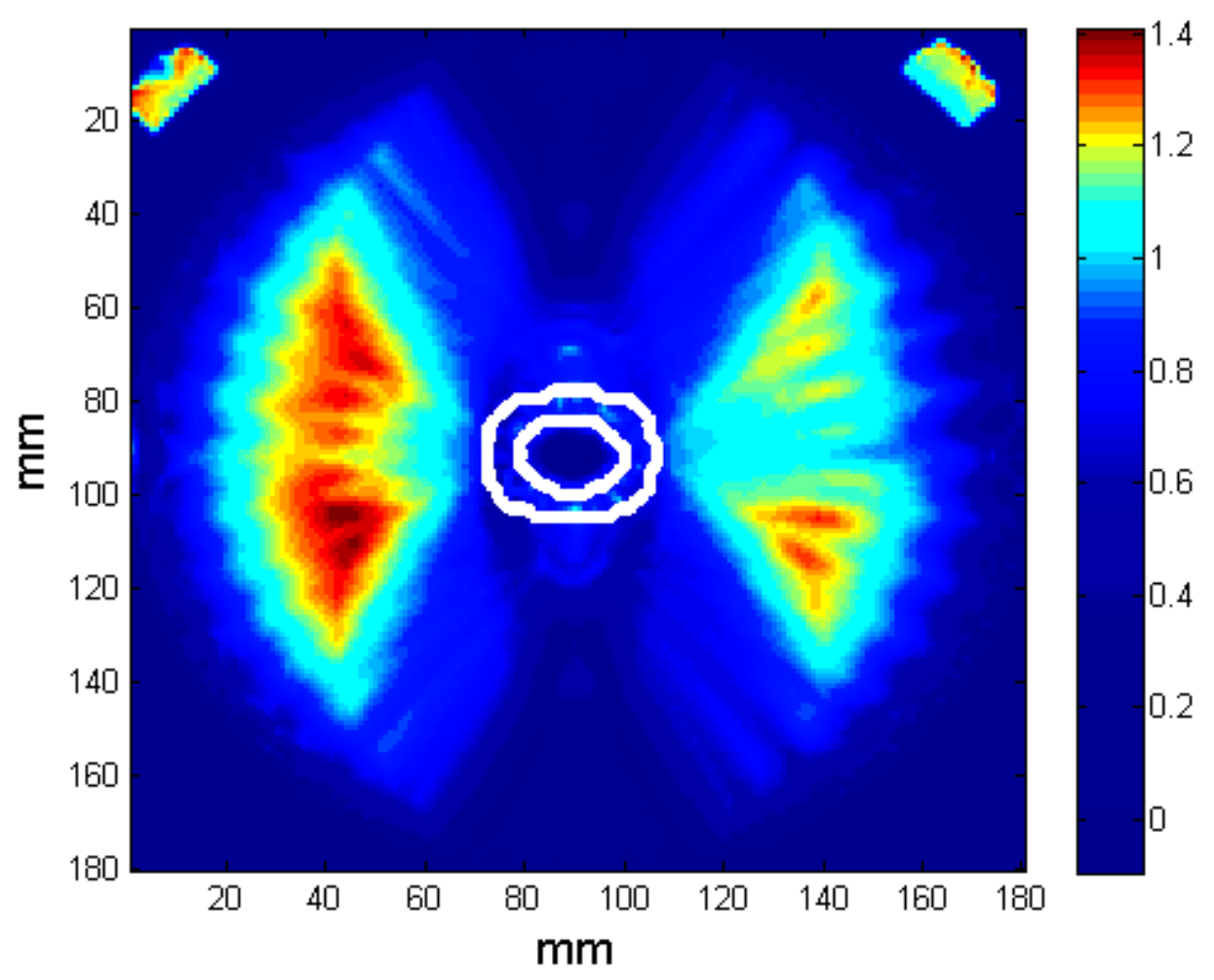

Figura 63: Mapa do índice $\gamma$ comparando às distribuições de dose obtidas com - PENELOPE e TPS iPlan ${ }^{\circledR}$, para os critérios de $3 \mathrm{~mm}$ DTA e $3 \%$ tolerância em dose. As linhas brancas mostram as isodoses de $90 \%$ e de $50 \%$, respectivamente.

A Figura 64 mostra os histogramas dos índices $\gamma$ das mesmas distribuições para as isodoses de (a) $90 \%$, (b) $50 \%$ e (c) para o plano todo. 


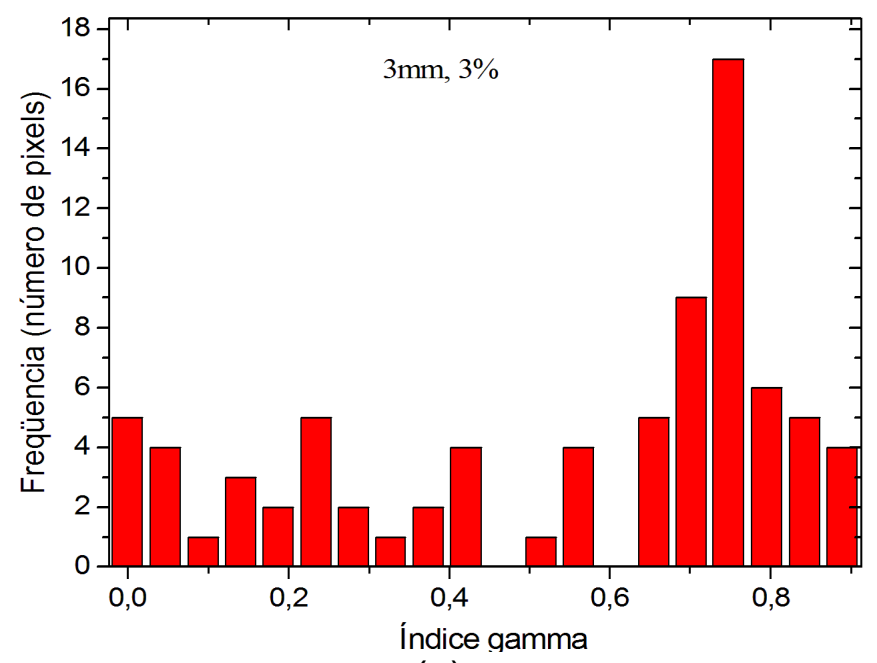

(a)

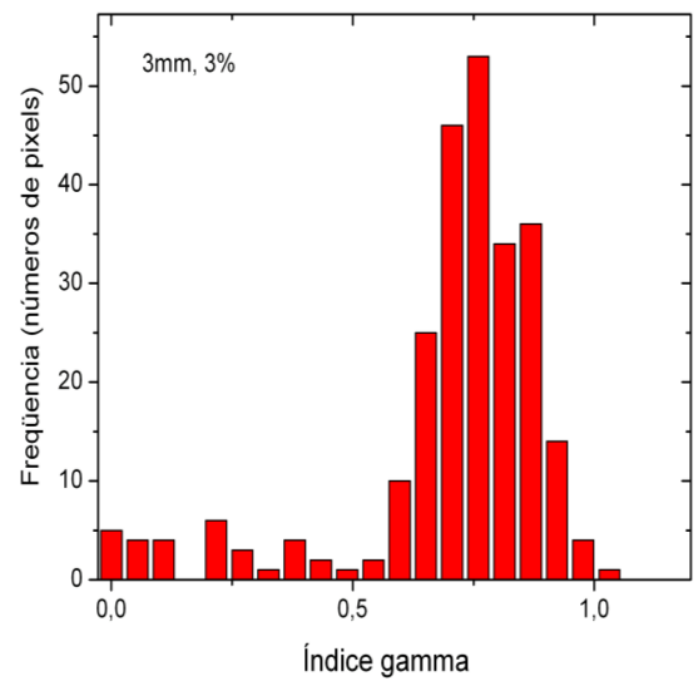

(b)

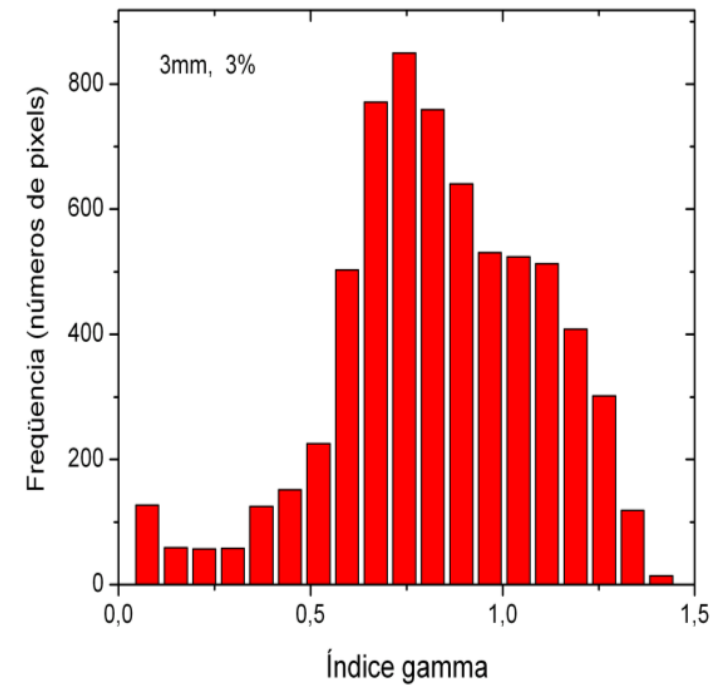

(c)

Figura 64: Histogramas dos índices $\gamma$ comparando as distribuições de dose obtidas com o PENELOPE e TPS iPlan ${ }^{\circledR}$, para os critérios de $3 \mathrm{~mm}$ e $3 \%$ para as isodoses de (a) $90 \%$, (b) $50 \%$ e (c) para o plano todo.

\subsection{Critérios do índice $\gamma: 3 \mathrm{~mm}$ e 5\%}

A Figura 65 apresenta o mapa do índice $\gamma$ comparando as distribuições de dose obtidas com o PENELOPE e o TPS iPlan ${ }^{\circledR}$, para os critérios $3 \mathrm{~mm}$ e $5 \%$. 


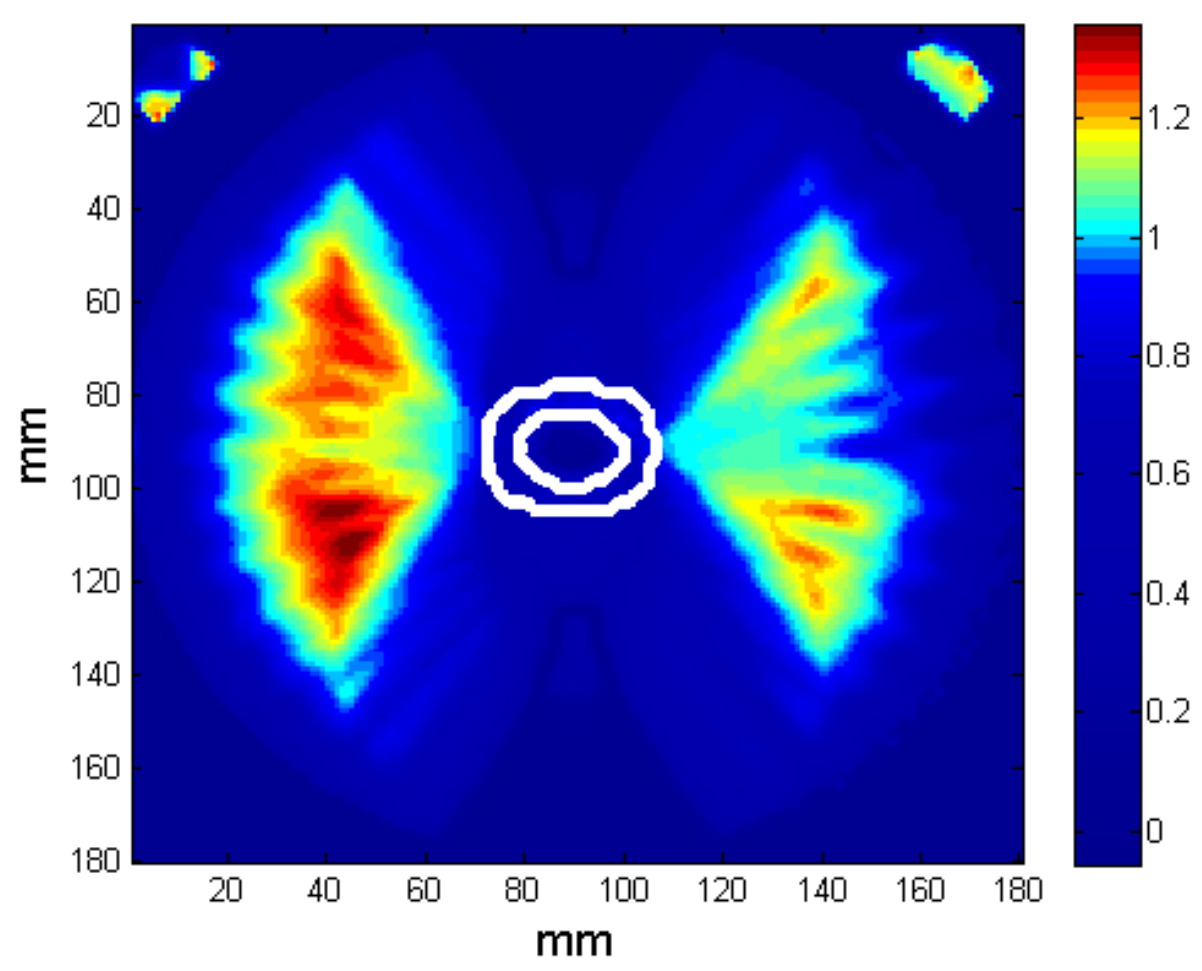

Figura 65: Mapa do índice $\gamma$ comparando às distribuições de dose obtidas com - PENELOPE e TPS iPlan ${ }^{\circledR}$ para os critérios de $3 \mathrm{~mm}$ DTA e $5 \%$ tolerância em dose. As linhas brancas mostram as isodoses de $90 \%$ e de $50 \%$, respectivamente.

\subsubsection{Avaliação do índice $\gamma$ entre MAGIC-f e EBT2}

\subsection{Critérios do índice $\gamma: 1 \mathrm{~mm}$ e $1 \%$}

A Figura 66 apresenta o mapa do índice $\gamma$ comparando as distribuições de dose obtidas com MAGIC-f e filme EBT2 para os critérios $1 \mathrm{~mm}$ e $1 \%$. 


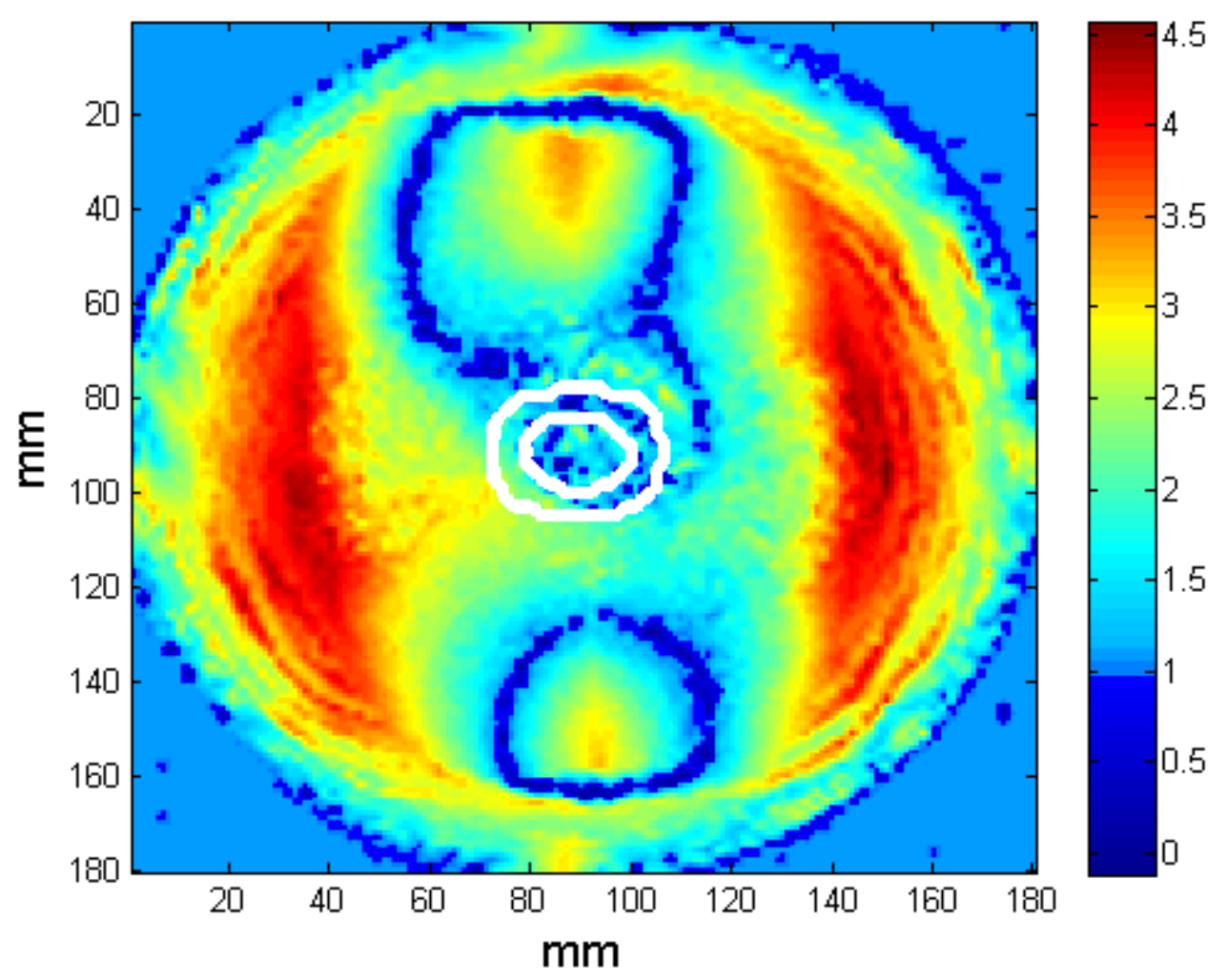

Figura 66: Mapa do índice $\gamma$ comparando as distribuições de dose obtidas com MAGIC-f e EBT2, para os critérios de $1 \mathrm{~mm}$ e $1 \%$. As linhas brancas mostram as isodoses de $90 \%$ e de $50 \%$, respectivamente.

\subsection{Critérios do índice $\gamma: 2 \mathrm{~mm}$ e $2 \%$}

A Figura 67 apresenta o mapa do índice $\gamma$ comparando as distribuições de dose obtidas com MAGIC-f e filme EBT2 para os critérios $2 \mathrm{~mm}$ e $2 \%$. 


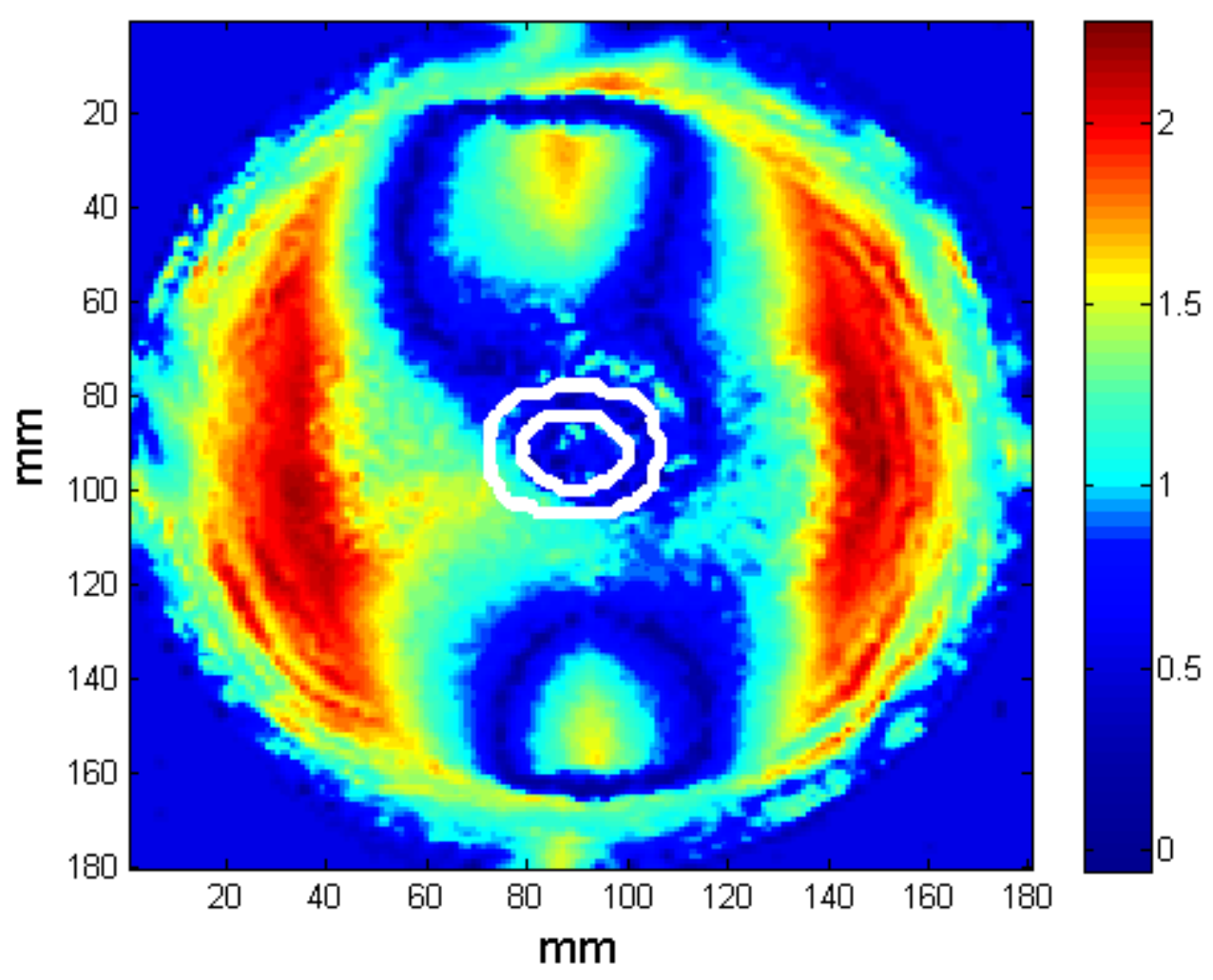

Figura 67: Mapa do índice $\gamma$ comparando as distribuições de dose obtidas com - MAGIC-f e EBT2, para os critérios de $2 \mathrm{~mm}$ e $2 \%$. As linhas brancas mostram as isodoses de $90 \%$ e de $50 \%$, respectivamente.

\subsection{Critérios do índice $\gamma: 3 \mathrm{~mm}$ e $3 \%$}

A Figura 68 apresenta o mapa do índice $\gamma$ comparando as distribuições de dose obtidas com MAGIC-fe filme EBT2 para os critérios $3 \mathrm{~mm}$ e $3 \%$. 


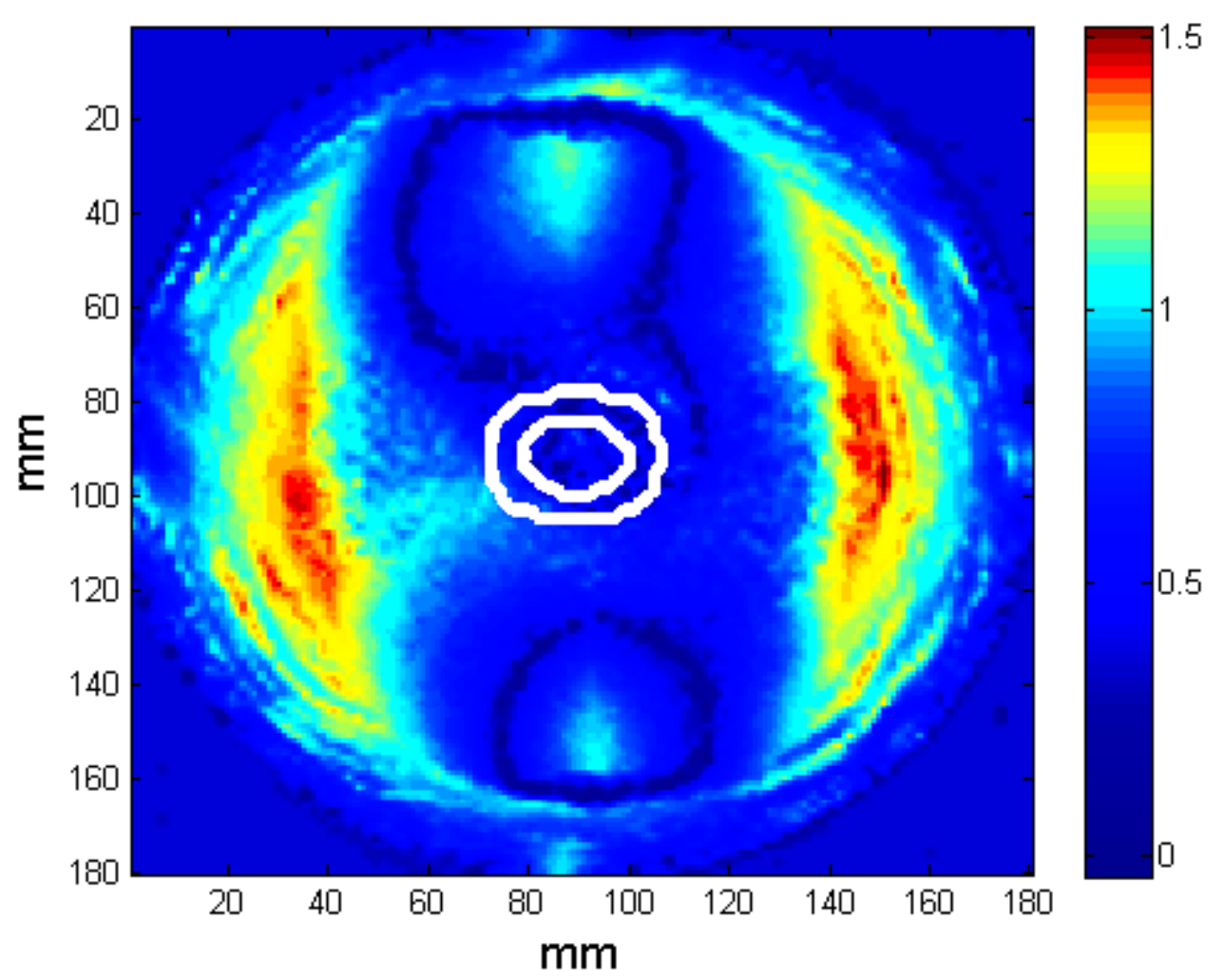

Figura 68: Mapa do índice $\gamma$ comparando as distribuições de dose obtidas com MAGIC-f e EBT2, para os critérios de $3 \mathrm{~mm}$ e $3 \%$. As linhas brancas mostram as isodoses de $90 \%$ e de $50 \%$, respectivamente.

\subsection{Critérios do índice $\gamma: 3 \mathrm{~mm}$ e $5 \%$}

A Figura 69 apresenta o mapa do índice $\gamma$ comparando as distribuições de dose obtidas com MAGIC-fe filme EBT2 para os critérios $3 \mathrm{~mm}$ e $5 \%$. 


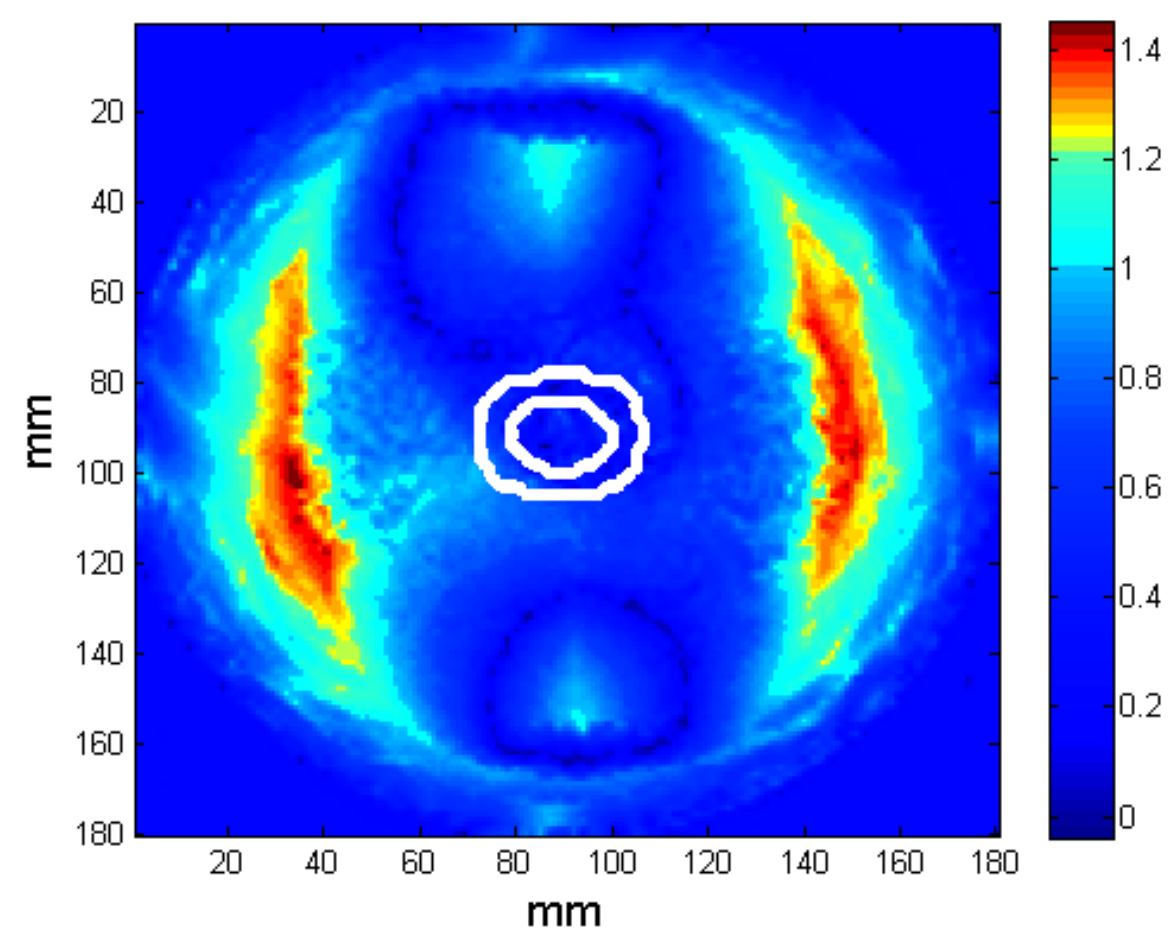

Figura 69: Mapa do índice $\gamma$ comparando as distribuições de dose obtidas com MAGIC-f e EBT2, para os critérios de $3 \mathrm{~mm}$ e $5 \%$. As linhas brancas mostram as isodoses de $90 \%$ e de $50 \%$, respectivamente.

\subsubsection{Avaliação do índice $\gamma$ entre MAGIC-f e PENELOPE}

\subsection{Critérios do índice $\gamma: 1 \mathrm{~mm}$ e 1\%}

A Figura 70 apresenta o mapa do índice $\gamma$ comparando as distribuições de dose obtidas com MAGIC- $f$ e PENELOPE para os critérios $1 \mathrm{~mm}$ e $1 \%$. 


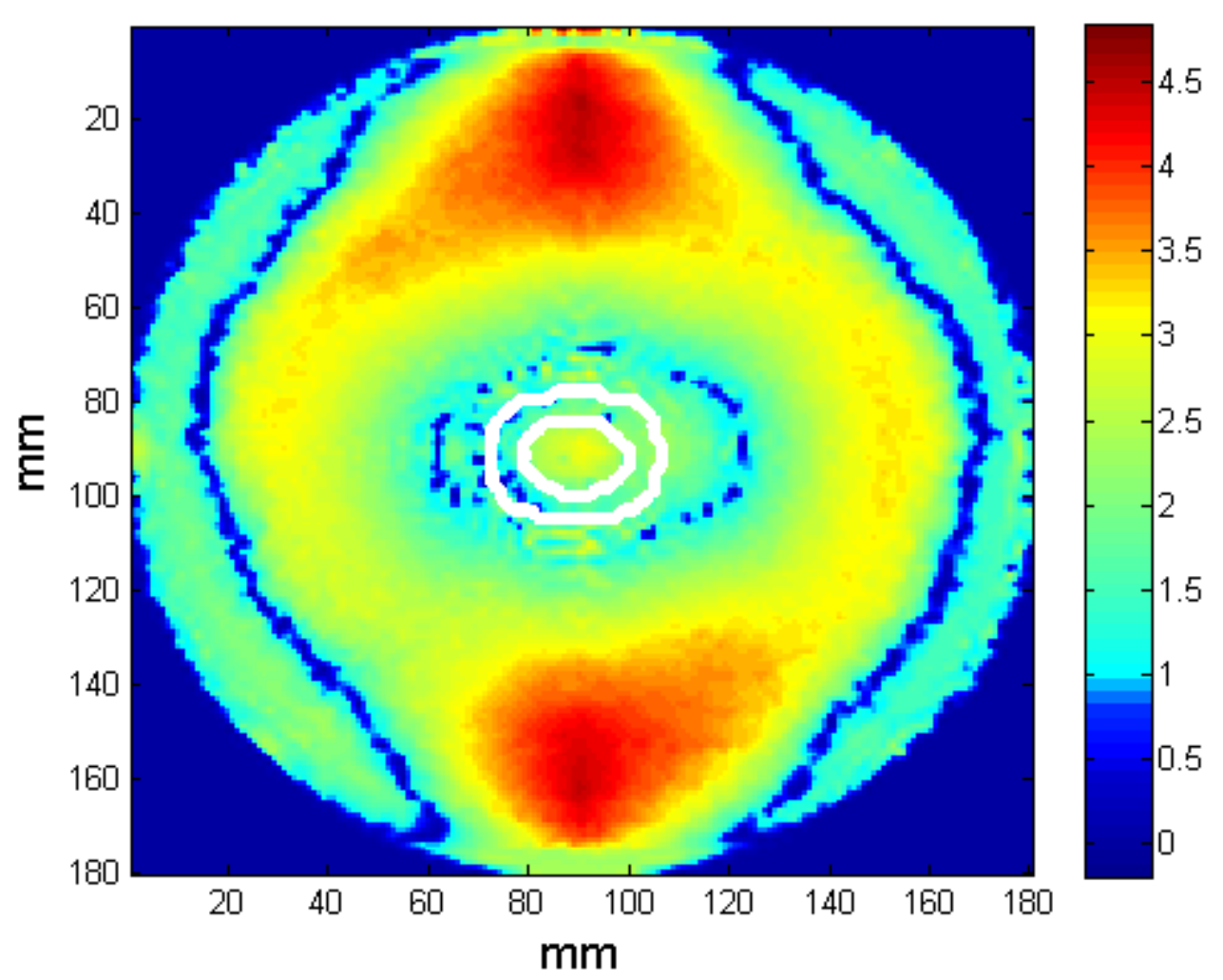

Figura 70: Mapa do índice $\gamma$ comparando as distribuições de dose obtidas com MAGIC- $f$ e PENELOPE, para os critérios de $1 \mathrm{~mm}$ e $1 \%$. As linhas brancas mostram as isodoses de $90 \%$ e de $50 \%$, respectivamente.

\subsection{Critérios do índice $\gamma: 2 \mathrm{~mm}$ e $2 \%$}

A Figura 71 apresenta o mapa do índice $\gamma$ comparando as distribuições de dose obtidas com MAGIC- $f$ e PENELOPE para os critérios $2 \mathrm{~mm}$ e $2 \%$. 


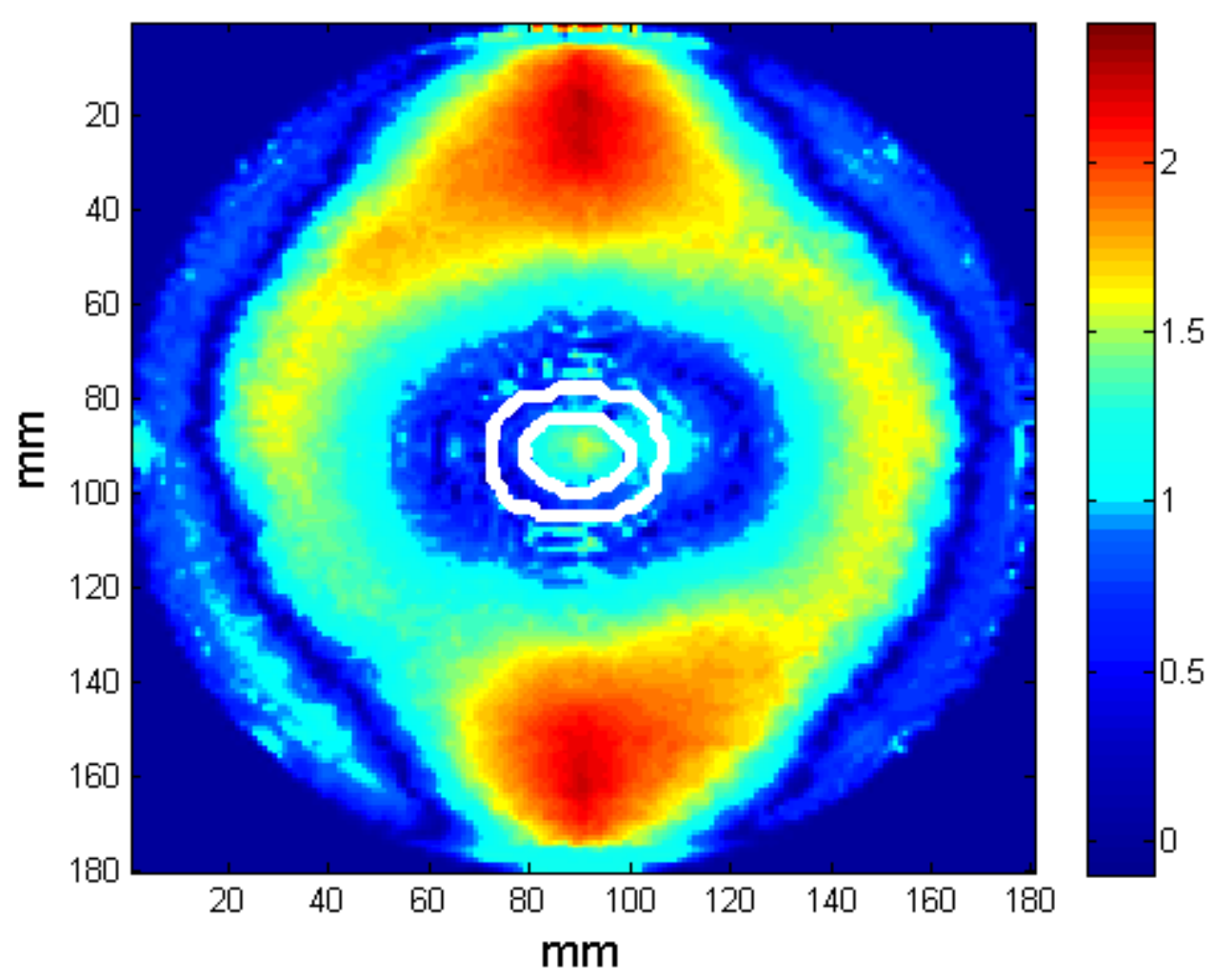

Figura 71: Mapa do índice $\gamma$ comparando as distribuições de dose obtidas com MAGIC- $f$ e PENELOPE, para os critérios de $2 \mathrm{~mm}$ e $2 \%$. As linhas brancas mostram as isodoses de $90 \%$ e de $50 \%$, respectivamente.

\subsection{Critérios do índice $\gamma: 3 \mathrm{~mm}$ e $3 \%$}

A Figura 72 apresenta 0 mapa do índice $\gamma$ comparando as distribuições de dose obtidas com MAGIC- $f$ e PENELOPE para os critérios 3 $\mathrm{mm}$ e $3 \%$. 


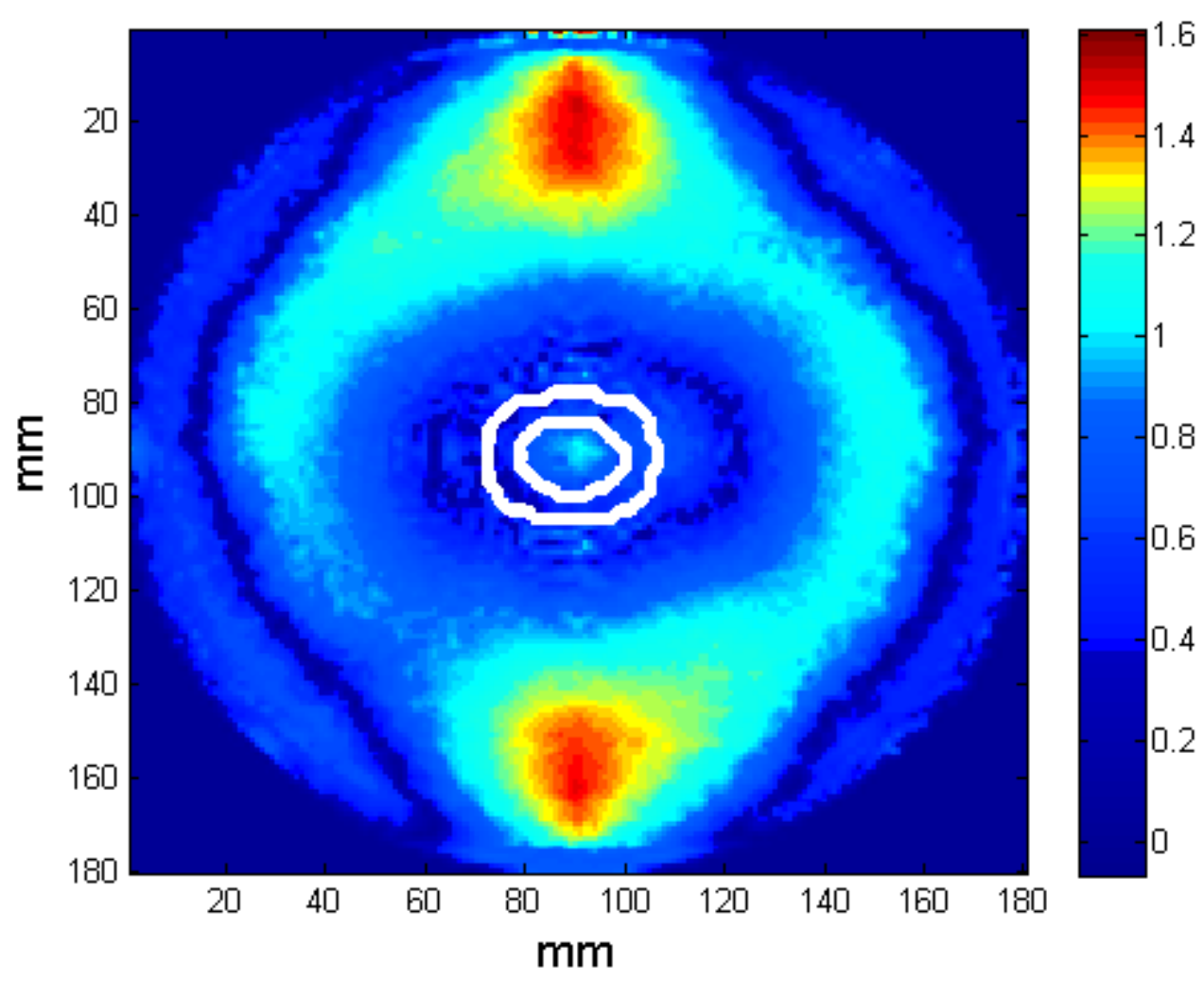

Figura 72: Mapa do índice $\gamma$ comparando as distribuições de dose obtidas com o MAGIC-f e PENELOPE, para os critérios de $3 \mathrm{~mm}$ e $3 \%$. As linhas brancas mostram as isodoses de $90 \%$ e de $50 \%$, respectivamente.

\subsection{Critérios do índice $\gamma: 3 \mathrm{~mm}$ e $5 \%$}

A Figura 73 apresenta o mapa do índice $\gamma$ comparando as distribuições de dose obtidas com MAGIC-f e PENELOPE para os critérios $3 \mathrm{~mm}$ e $5 \%$. 


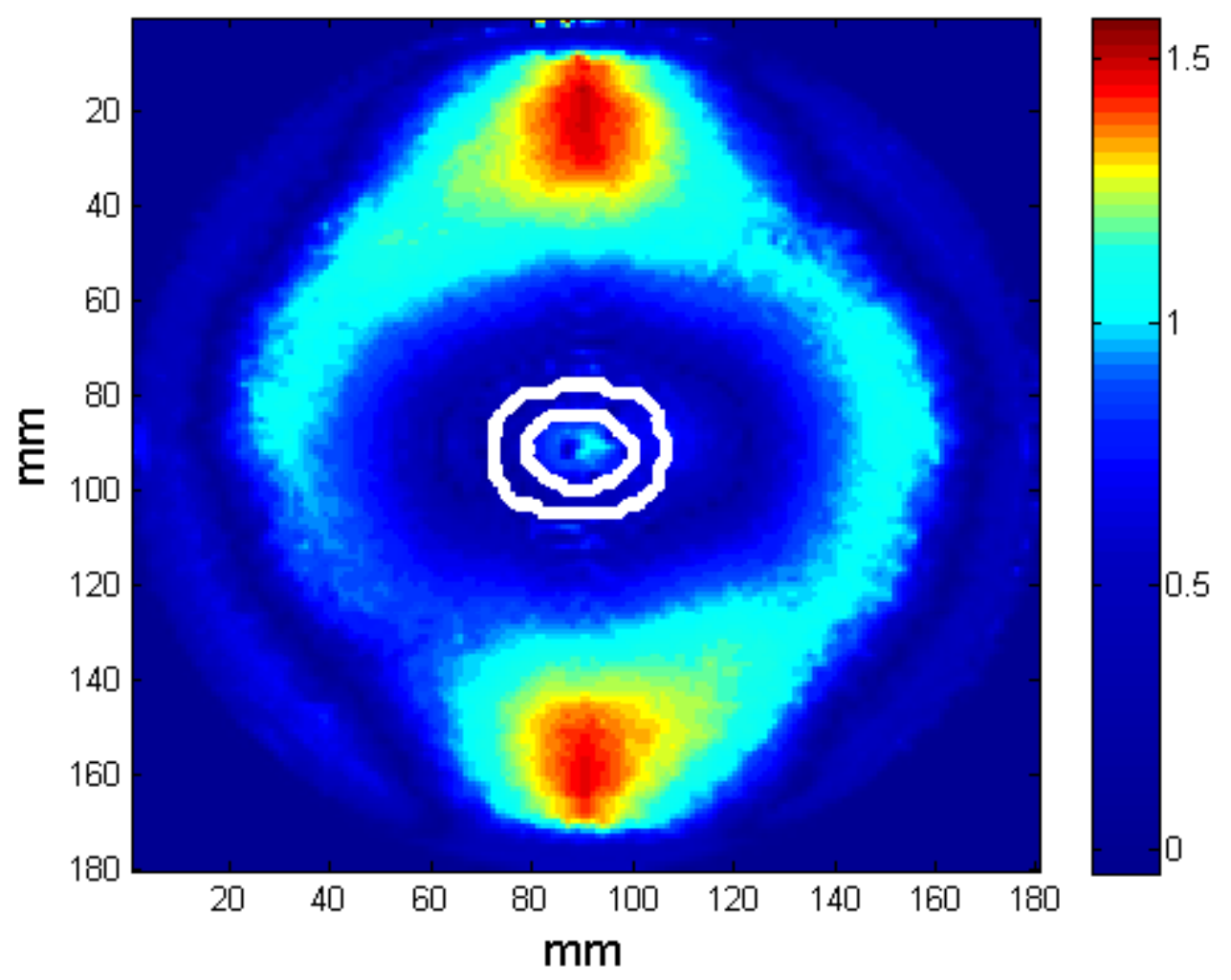

Figura 73: Mapa do índice $\gamma$ comparando as distribuições de dose obtidas com MAGIC-f e PENELOPE, para os critérios de $3 \mathrm{~mm}$ e $5 \%$. As linhas brancas mostram as isodoses de $90 \%$ e de $50 \%$, respectivamente.

4.6.1.4. Avaliação do índice $\gamma$ entre PENELOPE e filme EBT2

\subsection{Critérios do índice $\gamma: 1 \mathrm{~mm}$ e $1 \%$}

A Figura 74 apresenta o mapa do índice $\gamma$ comparando as distribuições de dose obtidas com PENELOPE e filme EBT2 para os critérios $1 \mathrm{~mm}$ e $1 \%$. 


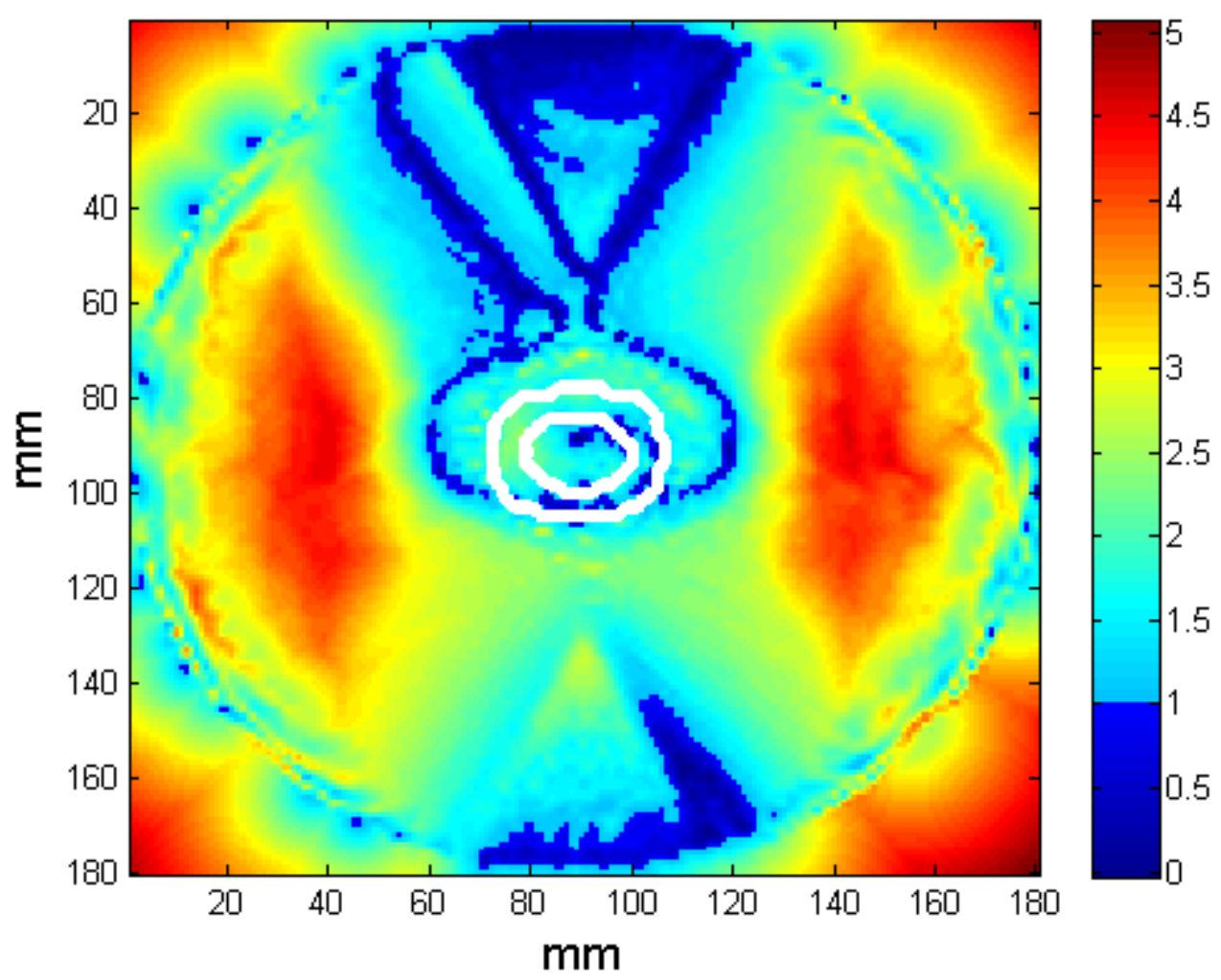

Figura 74: Mapa do índice $\gamma$ comparando as distribuições de dose obtidas com PENELOPE e EBT2, para os critérios de $1 \mathrm{~mm}$ e $1 \%$. As linhas brancas mostram as isodoses de $90 \%$ e de $50 \%$, respectivamente.

\subsection{Critérios do índice $\gamma: 2 \mathrm{~mm}$ e $2 \%$}

A Figura 75 apresenta o mapa do índice $\gamma$ comparando as distribuições de dose obtidas com PENELOPE e filme EBT2 para os critérios $2 \mathrm{~mm}$ e $2 \%$. 


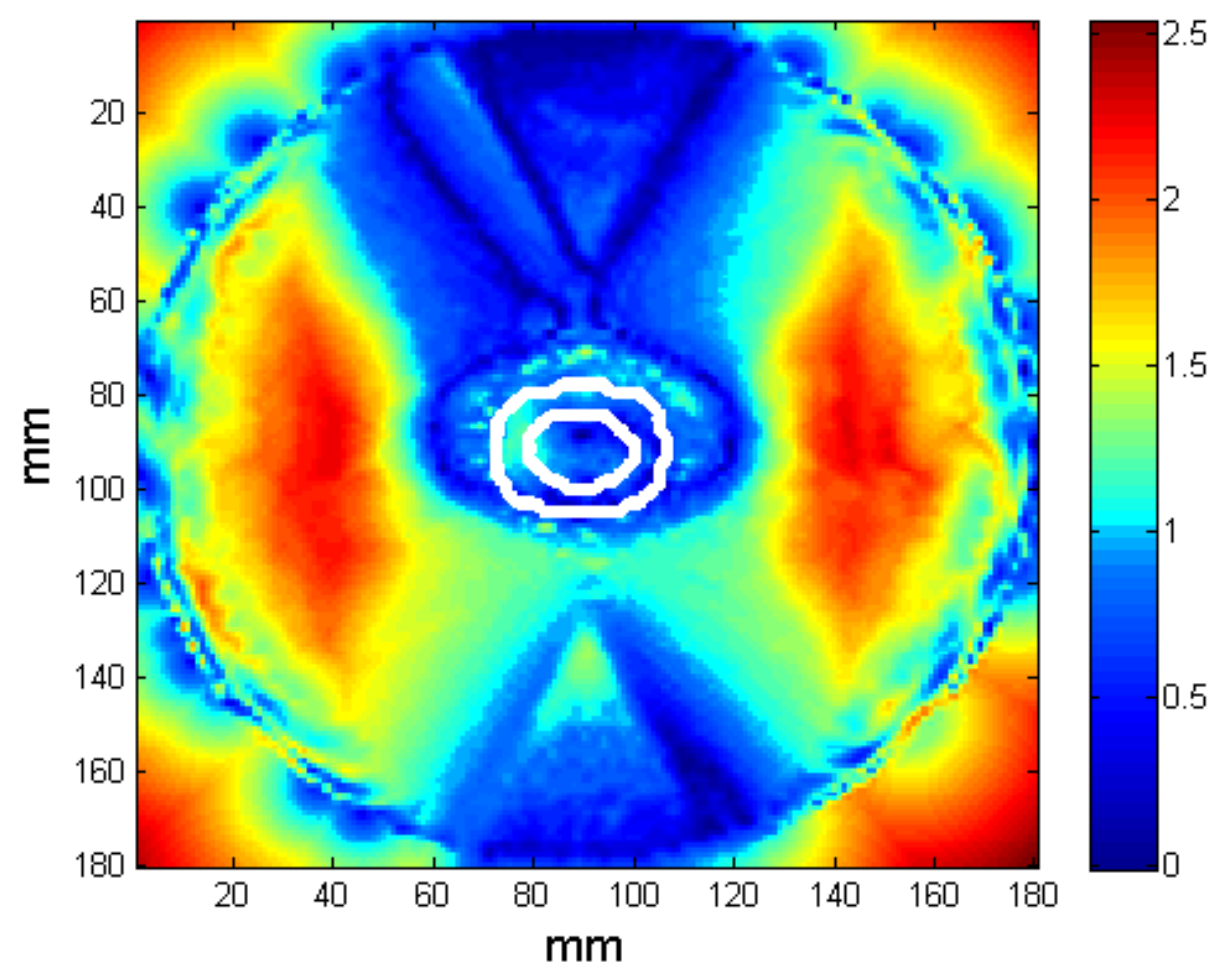

Figura 75: Mapa do índice $\gamma$ comparando as distribuições de dose obtidas com - PENELOPE e EBT2, para os critérios de $2 \mathrm{~mm}$ e $2 \%$. As linhas brancas mostram as isodoses de $90 \%$ e de $50 \%$, respectivamente.

\subsection{Critérios do índice $\gamma: 3 \mathrm{~mm}$ e $3 \%$}

A Figura 76 apresenta 0 mapa do índice $\gamma$ comparando as distribuições de dose obtidas com o PENELOPE e o filme EBT2 para os critérios $3 \mathrm{~mm}$ e $1 \%$. 


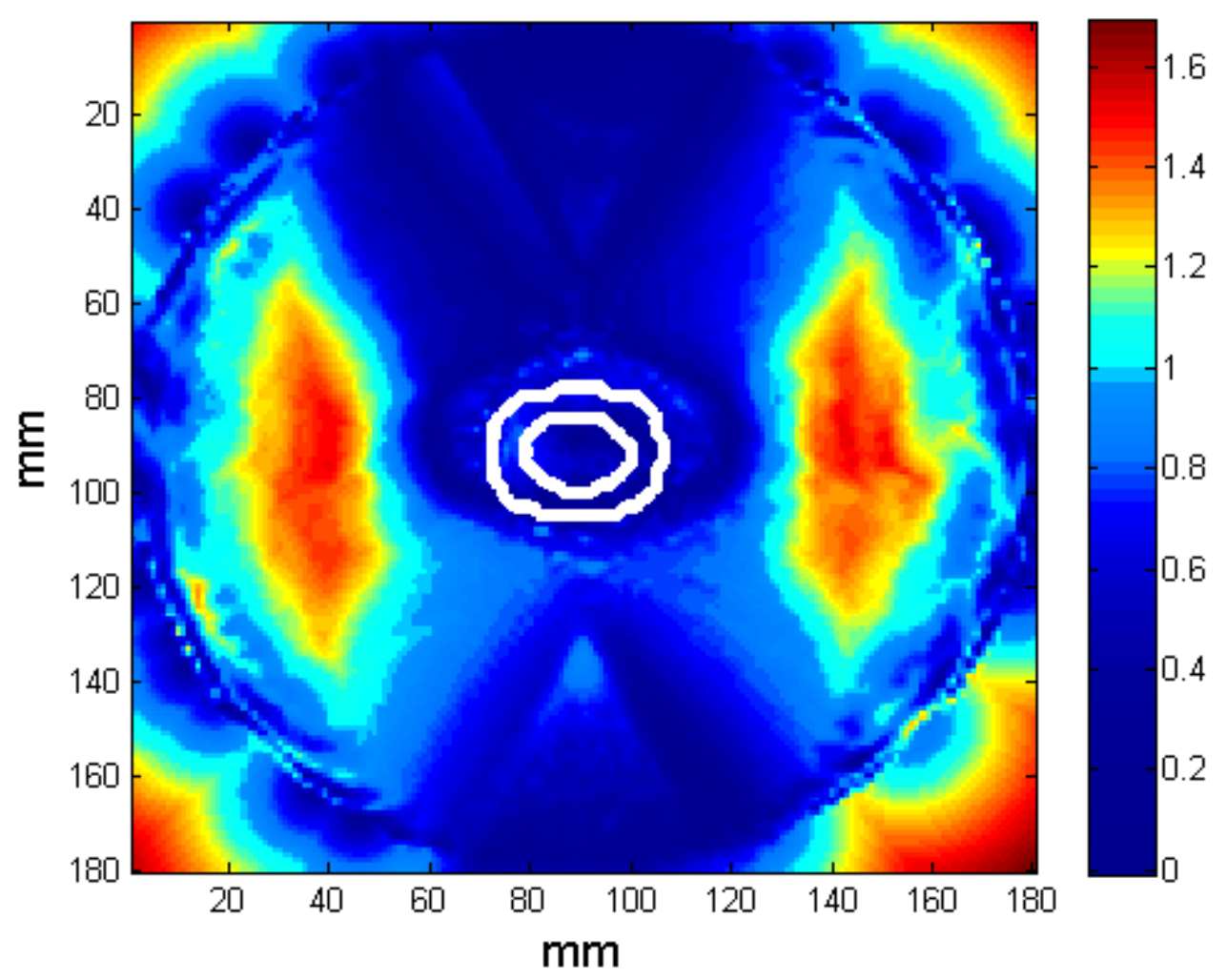

Figura 76: Mapa do índice $\gamma$ comparando as distribuições de dose obtidas com - PENELOPE e EBT2, para os critérios de $3 \mathrm{~mm}$ e $3 \%$. As linhas brancas mostram as isodoses de $90 \%$ e de $50 \%$, respectivamente.

\subsection{Critérios do índice $\gamma: 3 \mathrm{~mm}$ e $5 \%$}

A Figura 77 apresenta 0 mapa do índice $\gamma$ comparando as distribuições de dose obtidas com PENELOPE e filme EBT2 para os critérios 3 $\mathrm{mm}$ e $5 \%$. 


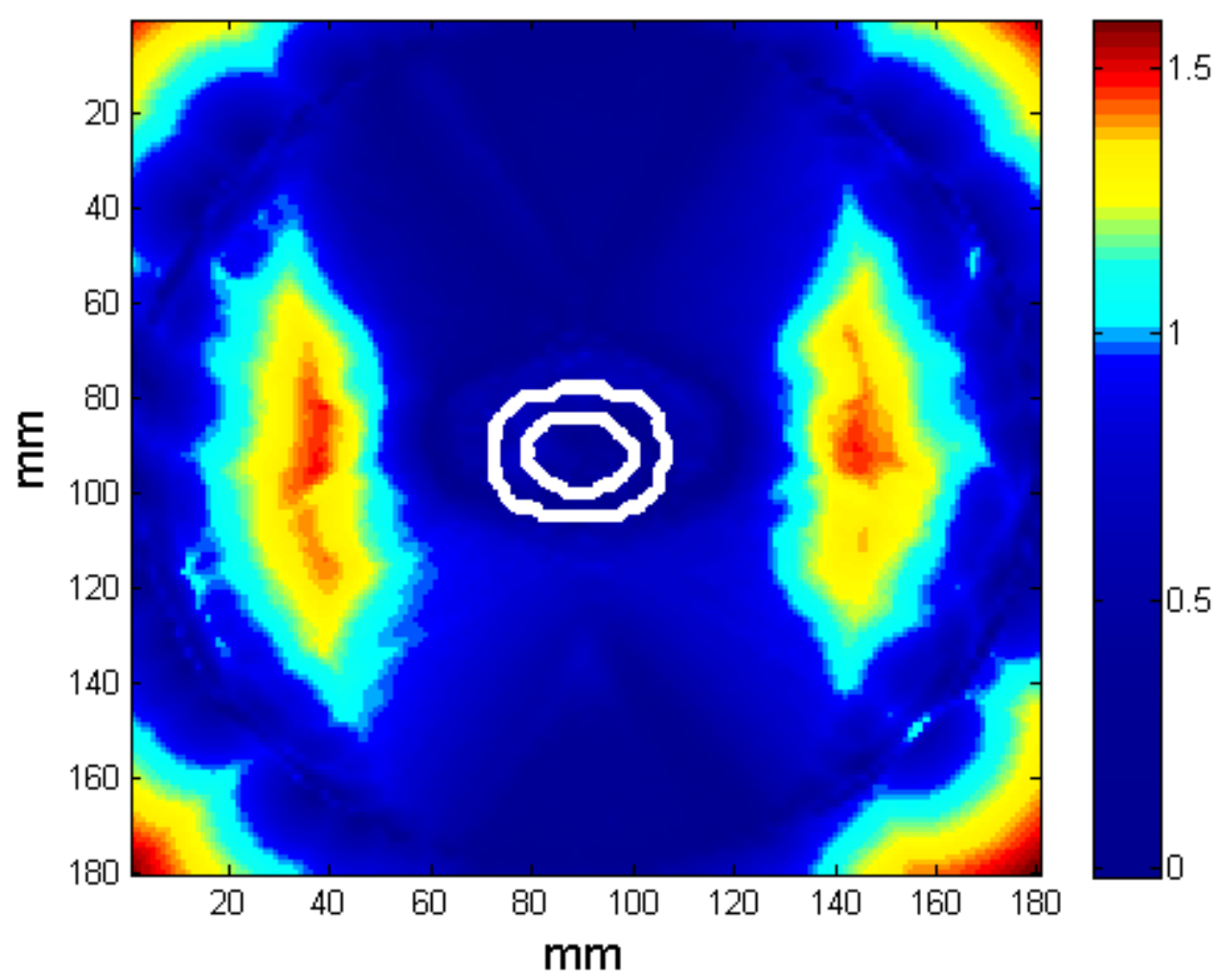

Figura 77: Mapa do índice $\gamma$ comparando as distribuições de dose obtidas com PENELOPE e EBT2, para os critérios de $3 \mathrm{~mm}$ e $5 \%$. As linhas brancas mostram as isodoses de $90 \%$ e de $50 \%$, respectivamente.

4.6.1.5. Avaliação do índice $\gamma$ entre TPS iPlan ${ }^{\circledR}$ e MAGIC-f

\subsection{Critérios do índice $\gamma: 1 \mathrm{~mm}$ e $1 \%$}

A Figura 78 apresenta 0 mapa do índice $\gamma$ comparando as distribuições de dose obtidas com TPS iPlan ${ }^{\circledR}$ e MAGIC- $f$ para os critérios $1 \mathrm{~mm} \mathrm{e} 1 \%$. 


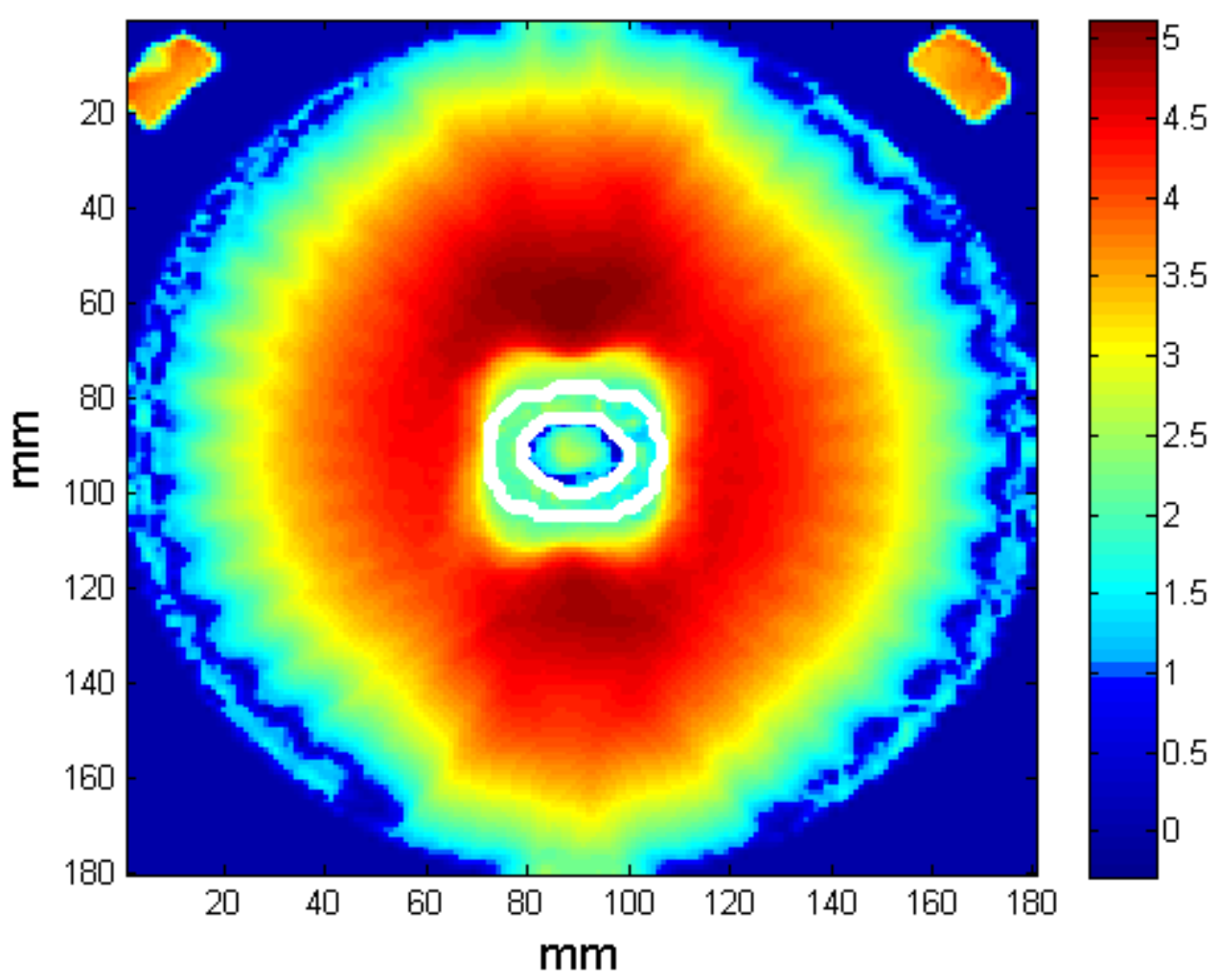

Figura 78: Mapa do índice $\gamma$ comparando as distribuições de dose obtidas com TPS iPlan ${ }^{\circledR}$ e MAGIC- $f$, para os critérios de $1 \mathrm{~mm}$ e $1 \%$. As linhas brancas mostram as isodoses de $90 \%$ e de $50 \%$, respectivamente.

\subsection{Critérios do índice $\gamma: 2 \mathrm{~mm}$ e $2 \%$}

A Figura 79 apresenta o mapa do índice $\gamma$ comparando as distribuições de dose obtidas com TPS iPlan ${ }^{\circledR}$ e MAGIC- $f$ para os critérios 2 $\mathrm{mm}$ e $2 \%$. 


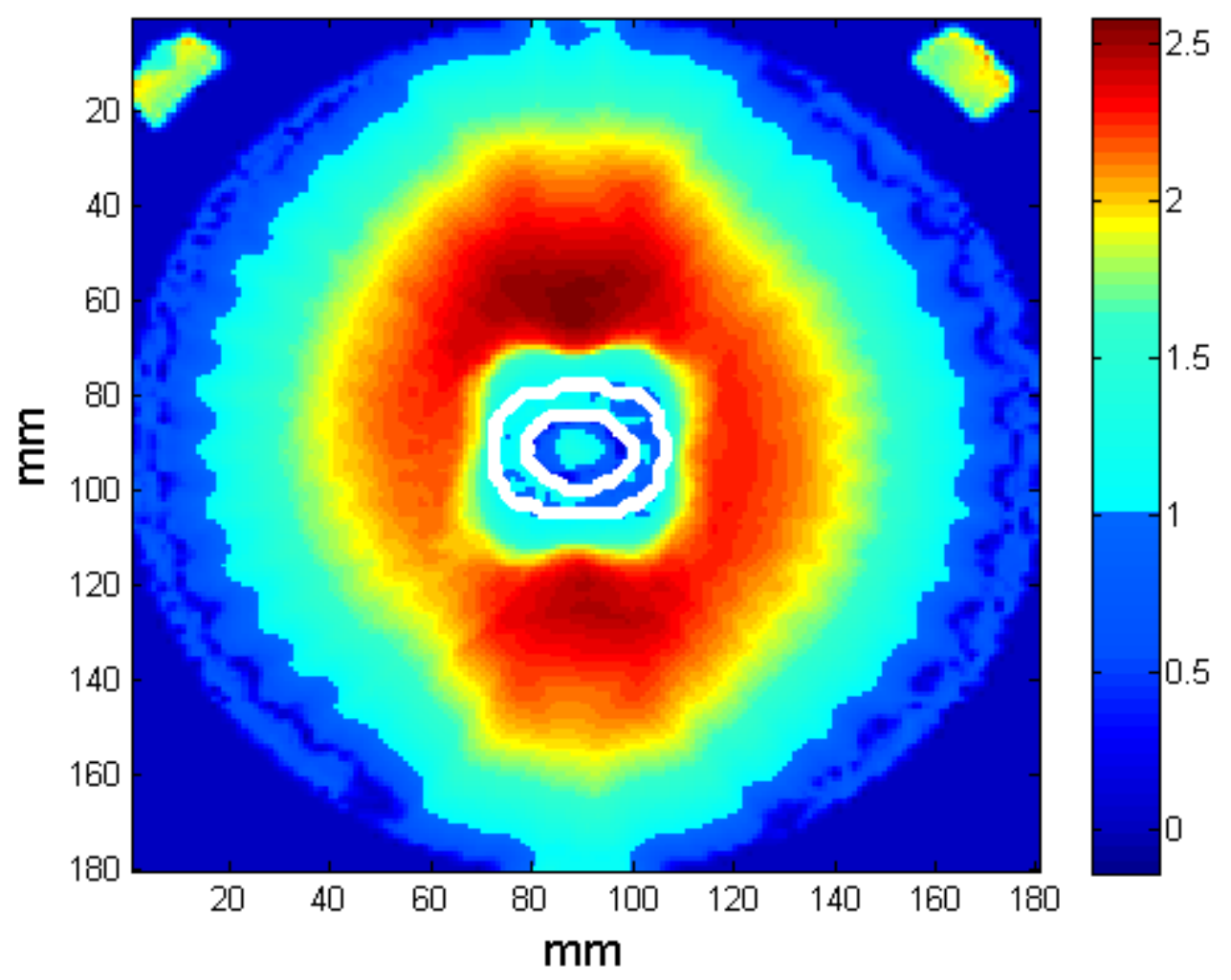

Figura 79: Mapa do índice $\gamma$ comparando as distribuições de dose obtidas com TPS iPlan ${ }^{\circledR}$ e MAGIC-f, para os critérios de $2 \mathrm{~mm}$ e $2 \%$. As linhas brancas mostram as isodoses de $90 \%$ e de $50 \%$, respectivamente.

\subsection{Critérios do índice $\gamma: 3 \mathrm{~mm}$ e $3 \%$}

A Figura 80 apresenta 0 mapa do índice $\gamma$ comparando as distribuições de dose obtidas com TPS iPlan ${ }^{\circledR}$ e MAGIC-f para os critérios 3 $\mathrm{mm}$ e $3 \%$. 


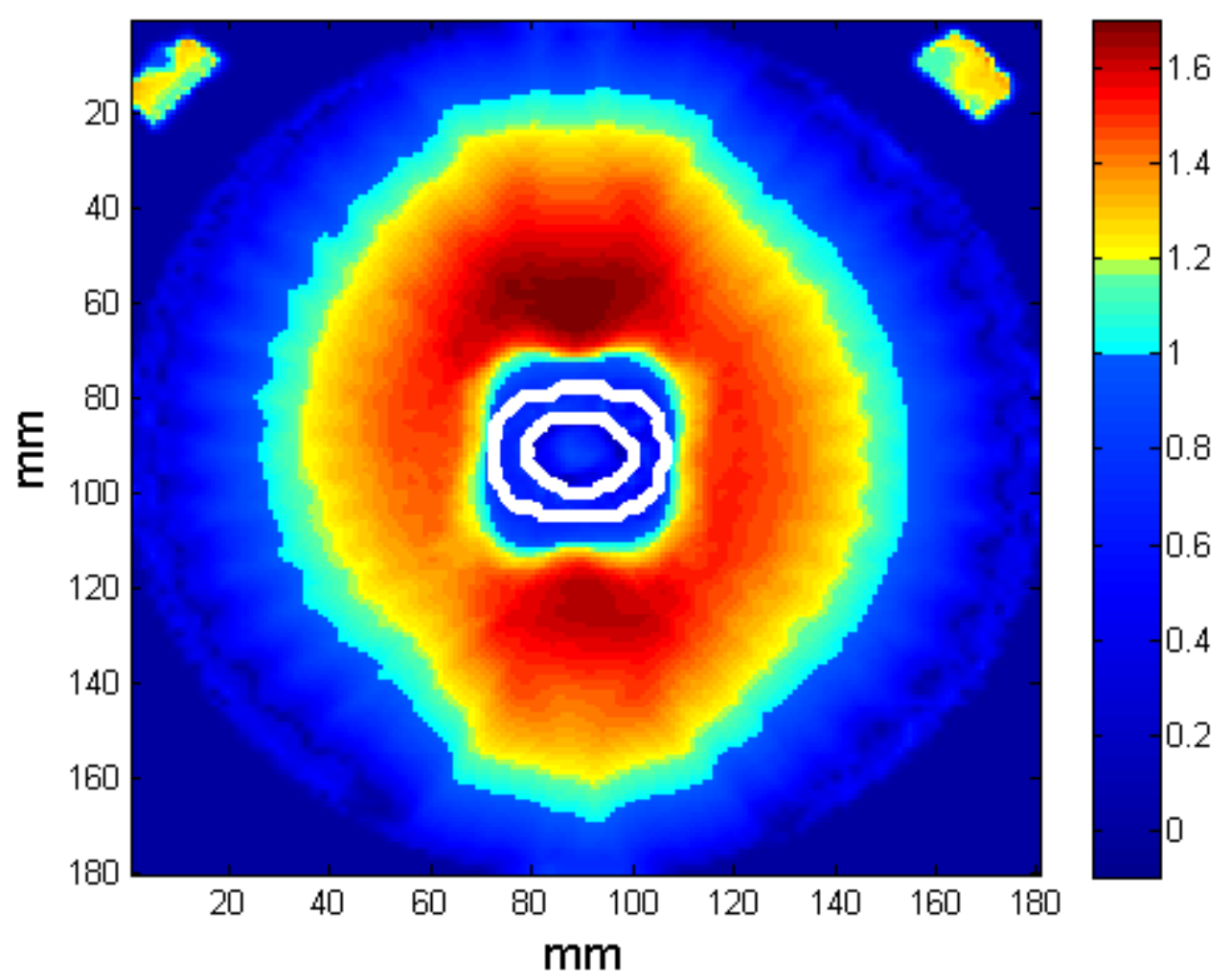

Figura 80: Mapa do índice $\gamma$ comparando as distribuições de dose obtidas com TPS iPlan ${ }^{\circledR}$ e MAGIC-f, para os critérios de $3 \mathrm{~mm}$ e $3 \%$. As linhas brancas mostram as isodoses de $90 \%$ e de $50 \%$, respectivamente.

\subsection{Critérios do índice $\gamma: 3 \mathrm{~mm}$ e $5 \%$}

A Figura 81 apresenta 0 mapa do índice $\gamma$ comparando as distribuições de dose obtidas com TPS iPlan ${ }^{\circledR}$ e MAGIC- $f$ para os critérios 3 $\mathrm{mm}$ e $5 \%$. 


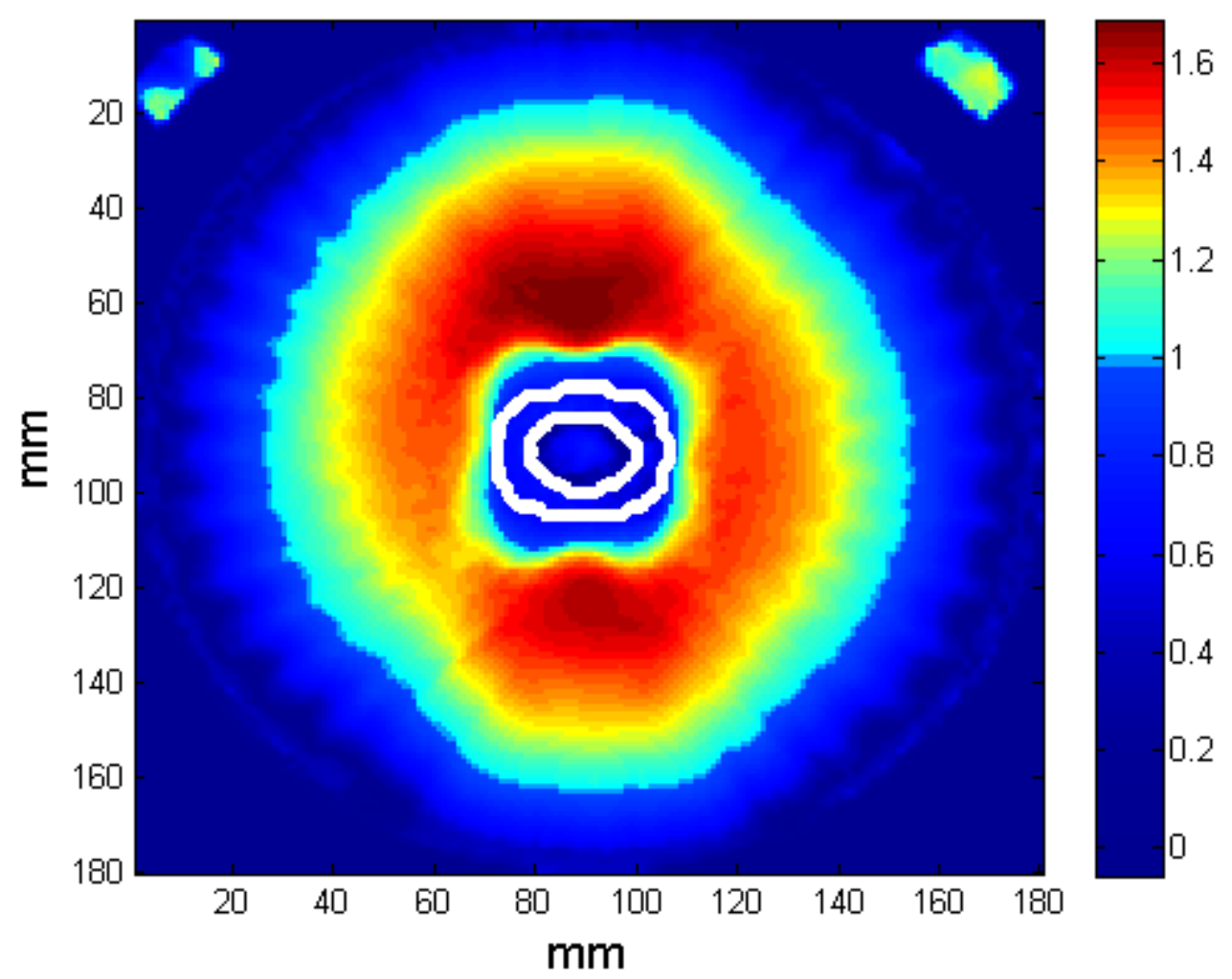

Figura 81: Mapa do índice $\gamma$ comparando as distribuições de dose obtidas com TPS iPlan ${ }^{\circledR}$ e MAGIC-f, para os critérios de $3 \mathrm{~mm}$ e $5 \%$. As linhas brancas mostram as isodoses de $90 \%$ e de $50 \%$, respectivamente.

4.6.1.6. Avaliação do índice $\gamma$ entre TPS iPlan ${ }^{\circledR}$ e EBT2

\subsection{Critérios do índice $\gamma: 1 \mathrm{~mm}$ e $1 \%$}

A Figura 82 apresenta o mapa do índice $\gamma$ comparando as distribuições de dose obtidas com TPS iPlan ${ }^{\circledR}$ e filme EBT2 para os critérios $1 \mathrm{~mm}$ e $1 \%$. 


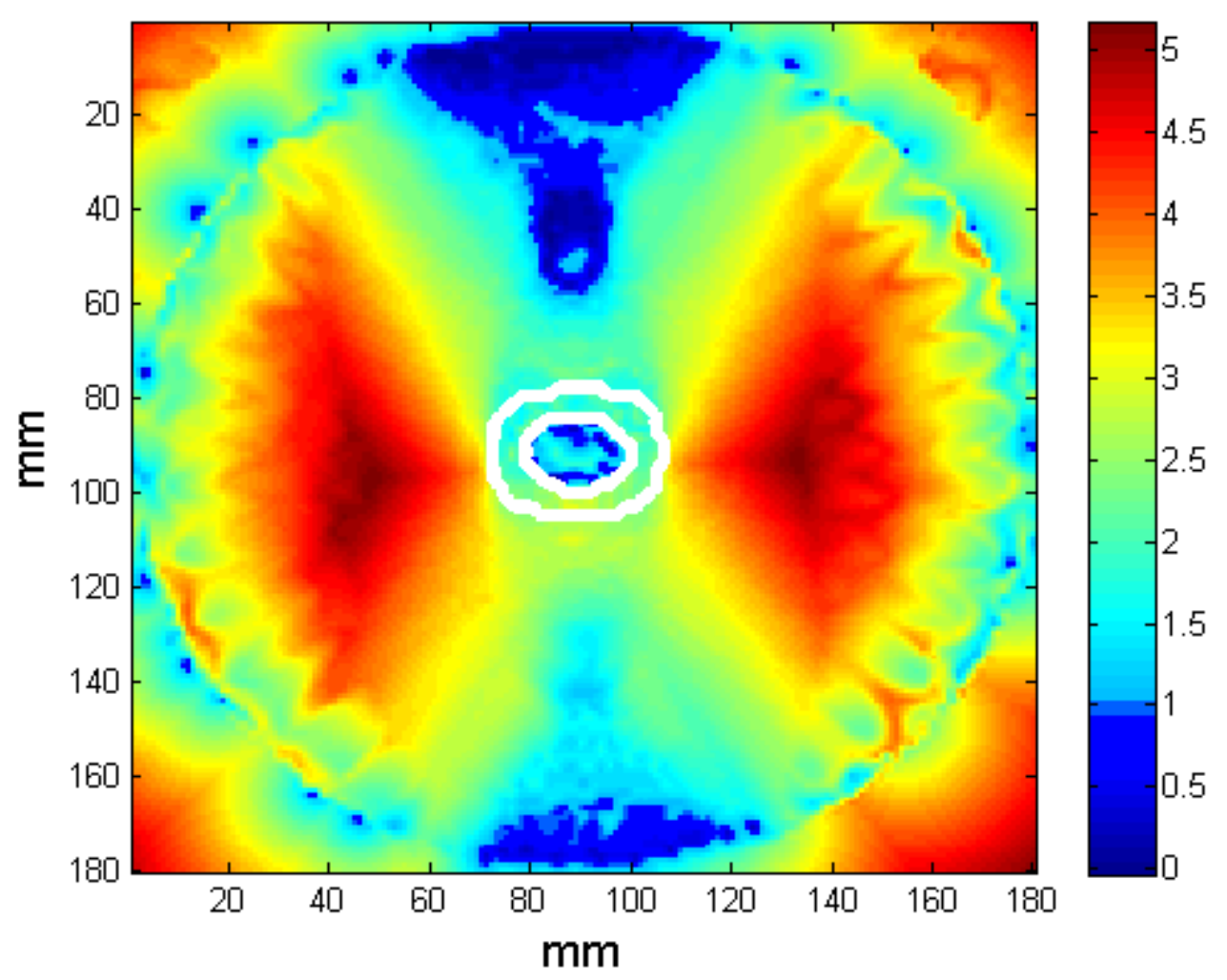

Figura 82: Mapa do índice $\gamma$ comparando as distribuições de dose obtidas com TPS iPlan ${ }^{\circledR}$ e EBT2, para os critérios de $1 \mathrm{~mm}$ e $1 \%$. As linhas brancas mostram as isodoses de $90 \%$ e de $50 \%$, respectivamente.

\subsection{Critérios do índice $\gamma: 2 \mathrm{~mm}$ e $2 \%$}

A Figura 83 apresenta 0 mapa do índice $\gamma$ comparando as distribuições de dose obtidas com TPS iPlan ${ }^{\circledR}$ e filme EBT2 para os critérios 2 $\mathrm{mm}$ e $2 \%$. 


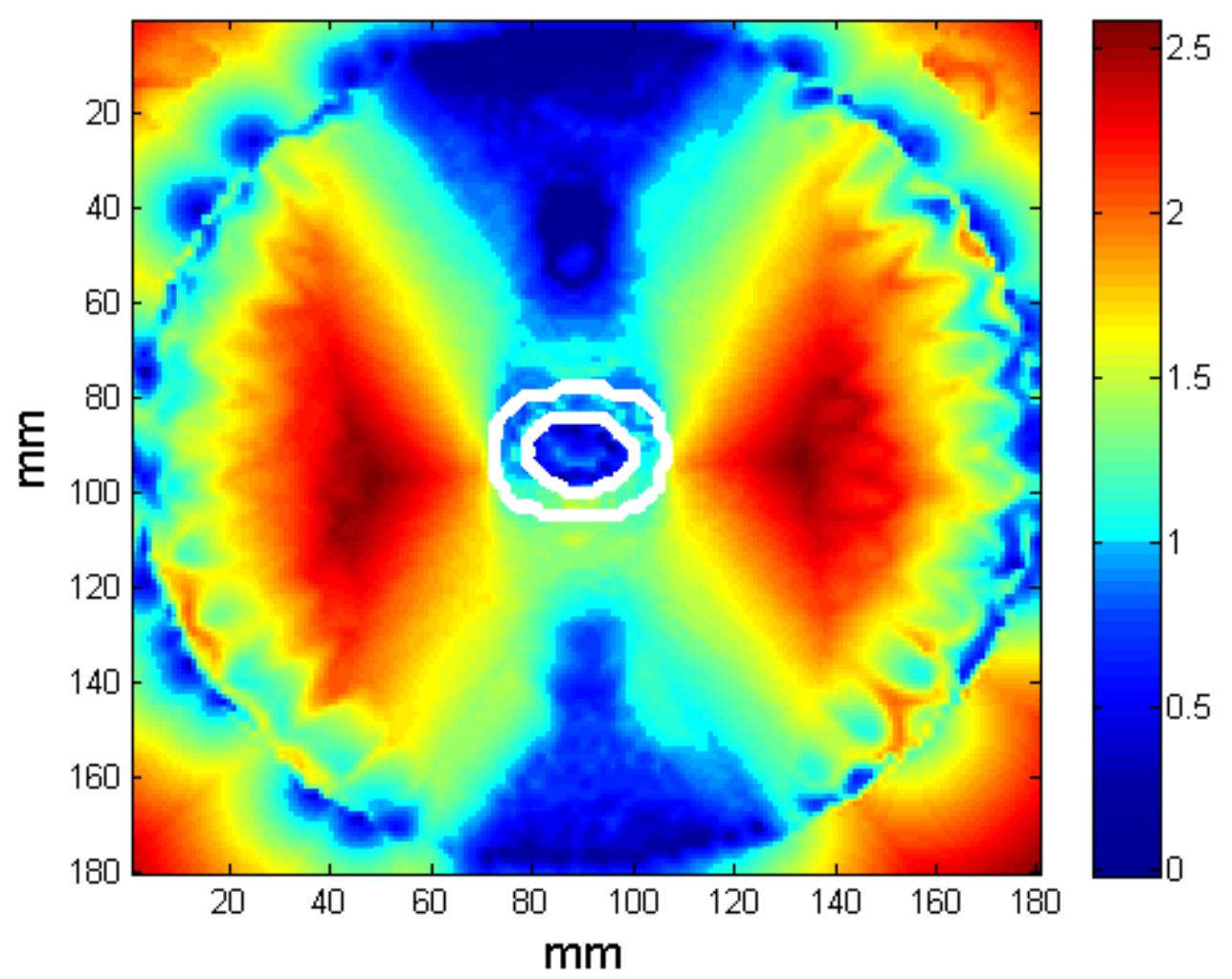

Figura 83: Mapa do índice $\gamma$ comparando as distribuições de dose obtidas com TPS iPlan ${ }^{\circledR}$ e EBT2, para os critérios de $2 \mathrm{~mm}$ e $2 \%$. As linhas brancas mostram as isodoses de $90 \%$ e de $50 \%$, respectivamente.

\subsection{Critérios do índice $\gamma: 3 \mathrm{~mm}$ e $3 \%$}

A figura 84 apresenta 0 mapa do índice $\gamma$ comparando as distribuições de dose obtidas com o TPS iPlan e o filme EBT2 para os critérios $3 \mathrm{~mm}$ e $3 \%$. 


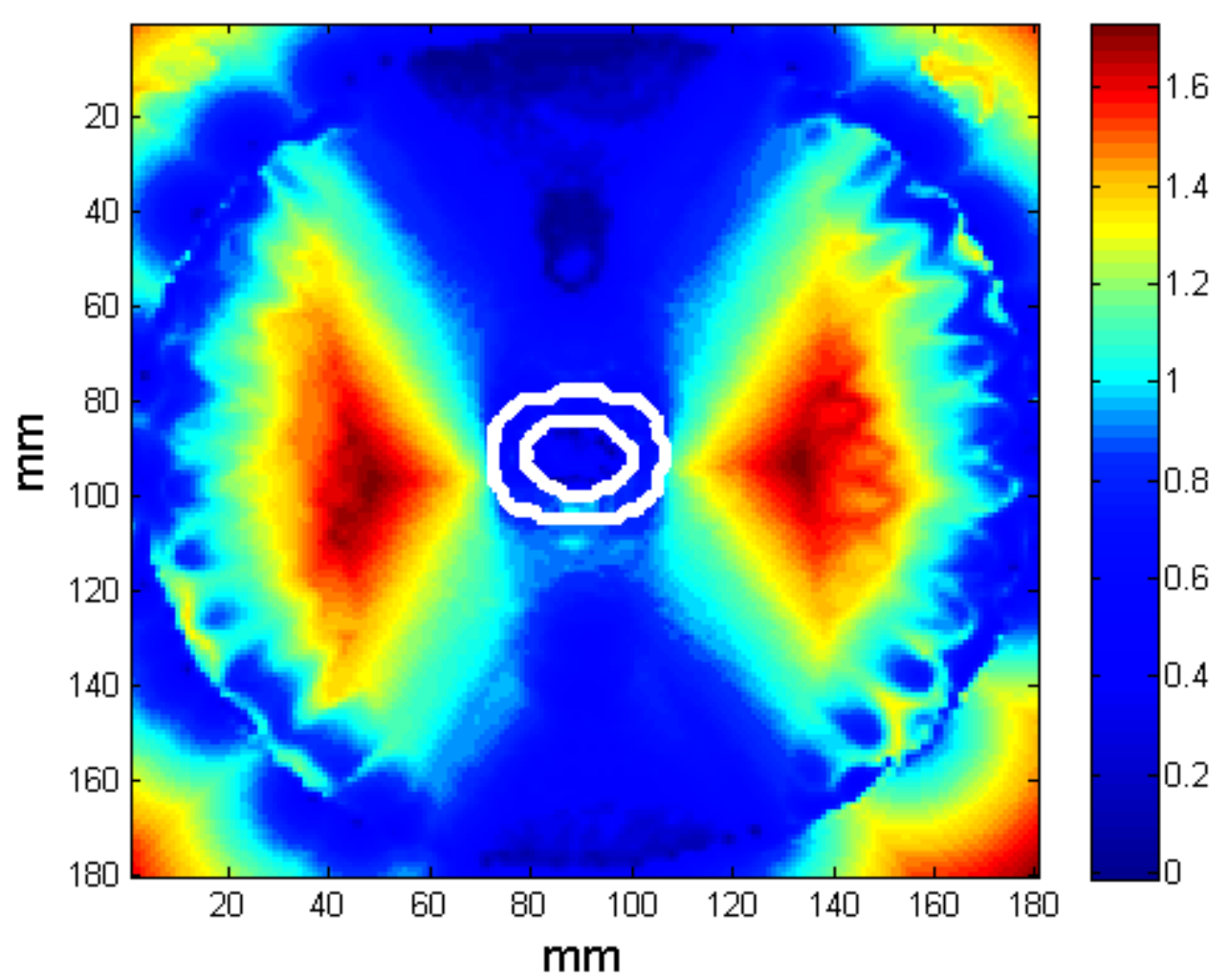

Figura 84: Mapa do índice $\gamma$ comparando as distribuições de dose obtidas com TPS iPlan ${ }^{\circledR}$ e EBT2, para os critérios de $3 \mathrm{~mm}$ e $3 \%$. As linhas brancas mostram as isodoses de $90 \%$ e de $50 \%$, respectivamente.

\subsection{Critérios do índice $\gamma: 3 \mathrm{~mm}$ e $5 \%$}

A Figura 85 apresenta o mapa do índice $\gamma$ comparando as distribuições de dose obtidas com TPS iPlan ${ }^{\circledR}$ e filme EBT2 para os critérios $3 \mathrm{~mm}$ e $5 \%$. 


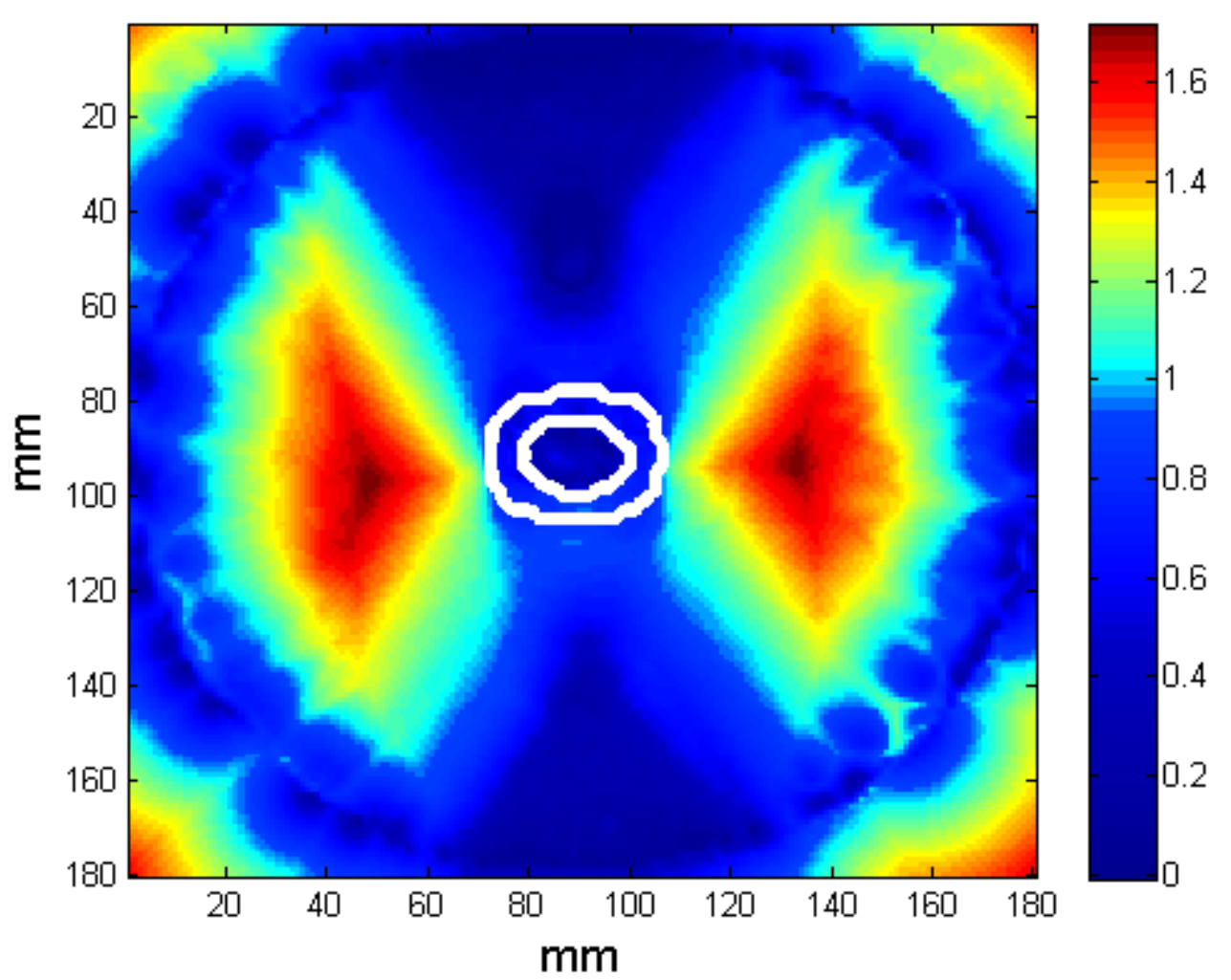

Figura 85: Mapa do índice $\gamma$ comparando as distribuições de dose obtidas com TPS iPlan ${ }^{\circledR}$ e EBT2, para os critérios de $3 \mathrm{~mm}$ e $5 \%$. As linhas brancas mostram as isodoses de $90 \%$ e de $50 \%$, respectivamente.

Uma tabulação das comparações das distribuições de dose feitas pelo índice $\gamma$ entre as ferramentas dosimétricas é mostrada na Tabela 16. A tabela mostra os percentuais de aceitação do teste de índice $\gamma$ para as isodoses de $90 \%, 50 \%$ e para o plano todo para cada um dos critérios estudados (DTA de $1 \mathrm{~mm}$ até $3 \mathrm{~mm}$ e de $1 \%$ a $5 \%$ de tolerância em dose). 
Tabela 16: Percentual de pixels dos mapas do índice $\gamma$ que foram aceitos pelo teste comparando as distribuições de dose para o caso do meningioma.

\begin{tabular}{c|c|c|c|c|c|c|c|c|c}
\cline { 3 - 10 } & \multicolumn{3}{c}{\begin{tabular}{c} 
PENELOPE e \\
\multicolumn{1}{c}{ TPS iPlan ${ }^{\circledR}$}
\end{tabular}} & \multicolumn{2}{c|}{ PENELOPE e EBT2 } & \multicolumn{3}{c}{$\begin{array}{c}\text { PENELOPE e } \\
\text { MAGIC- } f\end{array}$} \\
\cline { 2 - 10 } & $90 \%$ & $50 \%$ & Plano & $90 \%$ & $50 \%$ & Plano & $90 \%$ & $50 \%$ & Plano \\
\hline $1 \mathrm{~mm}, 1 \%$ & 28,8 & 9,0 & 10,7 & 13,8 & 13,3 & 9,7 & 0 & 5,5 & 6,2 \\
\hline $2 \mathrm{~mm}, 2 \%$ & 46,3 & 23,5 & 23,5 & 96,2 & 89,0 & 40,7 & 6,2 & 50,6 & 34,6 \\
\hline $3 \mathrm{~mm}, 3 \%$ & 100,0 & 100,0 & 73,4 & 100,0 & 100,0 & 72,6 & 98,8 & 96,2 & 68,4 \\
\hline $2 \mathrm{~mm}, 3 \%$ & 53,8 & 27,1 & 34,3 & 97,5 & 93,3 & 43,4 & 8,8 & 56,1 & 37,7 \\
\hline $3 \mathrm{~mm}, 2 \%$ & 100,0 & 94,5 & 72,1 & 100,0 & 100,0 & 70,0 & 95,0 & 97,7 & 66,8 \\
\hline $1 \mathrm{~mm}, 4 \%$ & 60,0 & 18,8 & 23,0 & 71,3 & 57,7 & 29,0 & 16,3 & 32,2 & 26,2 \\
\hline $2 \mathrm{~mm}, 4 \%$ & 60,0 & 29,8 & 38,0 & 98,8 & 97,2 & 45,4 & 17,5 & 62,3 & 41,2 \\
\hline $3 \mathrm{~mm}, 4 \%$ & 100,0 & 100,0 & 74,0 & 100,0 & 100,0 & 74,8 & 97,5 & 99,2 & 70,3 \\
\hline $1 \mathrm{~mm}, 5 \%$ & 75,0 & 23,5 & 30,0 & 72,5 & 62,8 & 32,4 & 37,5 & 48,2 & 32,6 \\
\hline $2 \mathrm{~mm}, 5 \%$ & 75,0 & 36,1 & 43,0 & 100,0 & 100,0 & 46,6 & 37,5 & 70,6 & 44,8 \\
\hline $3 \mathrm{~mm}, 5 \%$ & 100,0 & 100 & 75,5 & 100,0 & 100,0 & 76,5 & 97,5 & 99,2 & 72,2 \\
\hline
\end{tabular}

\begin{tabular}{c|c|c|c|c|c|c|c|c|c}
\cline { 3 - 10 } & \multicolumn{3}{c}{ MAGIC-fe EBT2 } & \multicolumn{3}{c|}{ TPS iPlan ${ }^{\circledR}$ e ETB2 } & \multicolumn{3}{c}{$\begin{array}{c}\text { TPS iPlan }{ }^{\circledR} \text { e } \\
\text { MAGIC- } f\end{array}$} \\
\cline { 2 - 10 } & $90 \%$ & $50 \%$ & Plano & $90 \%$ & $50 \%$ & Plano & $90 \%$ & $50 \%$ & Plano \\
\hline $1 \mathrm{~mm}, 1 \%$ & 12,5 & 13,7 & 4,2 & 20,0 & 7,1 & 7,0 & 15,0 & 5,1 & 3,0 \\
\hline $2 \mathrm{~mm}, 2 \%$ & 90,0 & 83,1 & 28,6 & 95,0 & 57,7 & 21,4 & 75,0 & 60,4 & 18,4 \\
\hline $3 \mathrm{~mm}, 3 \%$ & 100,0 & 100,0 & 69,6 & 100,0 & 99,3 & 54,0 & 100,0 & 100,0 & 42,4 \\
\hline $2 \mathrm{~mm}, 3 \%$ & 93,8 & 86,3 & 31,3 & 96,2 & 62,3 & 24,0 & 86,2 & 67,4 & 20,2 \\
\hline $3 \mathrm{~mm}, 2 \%$ & 100,0 & 100,0 & 65,6 & 100,0 & 98,8 & 51,2 & 100,0 & 100,0 & 41,3 \\
\hline $1 \mathrm{~mm}, 4 \%$ & 55,0 & 52,2 & 16,6 & 68,8 & 24,7 & 16,7 & 52,5 & 18,8 & 11,9 \\
\hline $2 \mathrm{~mm}, 4 \%$ & 93,8 & 86,3 & 34,0 & 97,5 & 65,9 & 25,8 & 93,7 & 74,1 & 22,2 \\
\hline $3 \mathrm{~mm}, 4 \%$ & 100,0 & 100,0 & 72,1 & 100,0 & 100,0 & 55,9 & 100,0 & 100,0 & 43,4 \\
\hline $1 \mathrm{~mm}, 5 \%$ & 67,5 & 60,8 & 21,0 & 76,3 & 28,9 & 18,0 & 72,5 & 26,3 & 14,8 \\
\hline $2 \mathrm{~mm}, 5 \%$ & 98,8 & 88,2 & 36,9 & 97,5 & 67,4 & 27,1 & 98,8 & 79,2 & 23,9 \\
\hline $3 \mathrm{~mm}, 5 \%$ & 100,0 & 100,0 & 74,3 & 100,0 & 100,0 & 57,1 & 100,0 & 100,0 & 44,8 \\
\hline
\end{tabular}


Com o propósito de obter um critério do índice $\gamma$ para a técnica de radiocirurgia, tendo em consideração uma concordância entre duas distribuições de dose de $100 \%$, de acordo com os resultados apresentados, encontrou-se para a isodose de $90 \%$ de todas as comparações, exceto para a analise PENELOPE e MAGIC-f, um critério mínimo de $3 \mathrm{~mm}$ de DTA e $2 \%$ em tolerância de dose. Para uma isodose de 50\% um critério mínimo de $3 \mathrm{~mm}$ de DTA e $3 \%$ em tolerância de dose. De todas as análises do plano todo, observou-se que o critério mínimo de $3 \mathrm{~mm}$ e $5 \%$ proporcionou, somente uma concordância de até $75,5 \%$ entre as distribuições de dose.

Assim, de acordo com os resultados da análise desse primeiro caso, neste trabalho adotou-se o critério de $3 \mathrm{~mm}$ DTA e $3 \%$ em tolerância de dose, para as próximas análises, buscando-se uma maior concordância nas distribuições de dose dentro do volume alvo. Nas regiões afastadas do volume alvo, em que, eventualmente, poderia se observar estruturas de risco, o critério adotado não teria a conformidade de100\%. Assim, para estas regiões,poderiase propor outro critério, que garanta as restrições de doses para orgãoes de risco, mantendo as doses dentro da tolerância nas estruturas sadias.

Conforme ao contexto citado acima, para os dois casos seguintes de radiocirurgia, o critério de índice gama será de $3 \mathrm{~mm}$ de DTA e $3 \%$ em tolerância em dose. Embora o critério adotado tenda a uma concordância de $100 \%$ entre duas distribuições de dose, este critério poderia comprometer aos órgãos de risco que estariam localizados nas isodoses mais baixas que $50 \%$.

Como citado anteriormente, não há um consenso na literatura sobre os valores dos critérios do índice $\gamma$. Desta forma, há autores que utilizam os critérios de 3 mm e $3 \%$ (Li et al, 2011; Gospishankar et al, 2011), que por sua vez difere de outros valores, como $2 \mathrm{~mm}$ e $2 \%$ da AAPM (AAMP, 2011) e 0,5 $\mathrm{mm}$ e $0,5 \%$ de outros autores (Park et al, 2011).

\subsubsection{Histograma dose-volume}

As distribuições de dose em 3D obtidas através do MAGIC-f, PENELOPE e TPS iPlan ${ }^{\circledR}$, para o caso de meningioma, foram comparados através de DVH, utilizando um programa desenvolvido na plataforma de 
Matlab $^{\circledR}$. A Figura 86 mostra a os DVH obtidos para cada ferramenta dosimétrica utilizada.

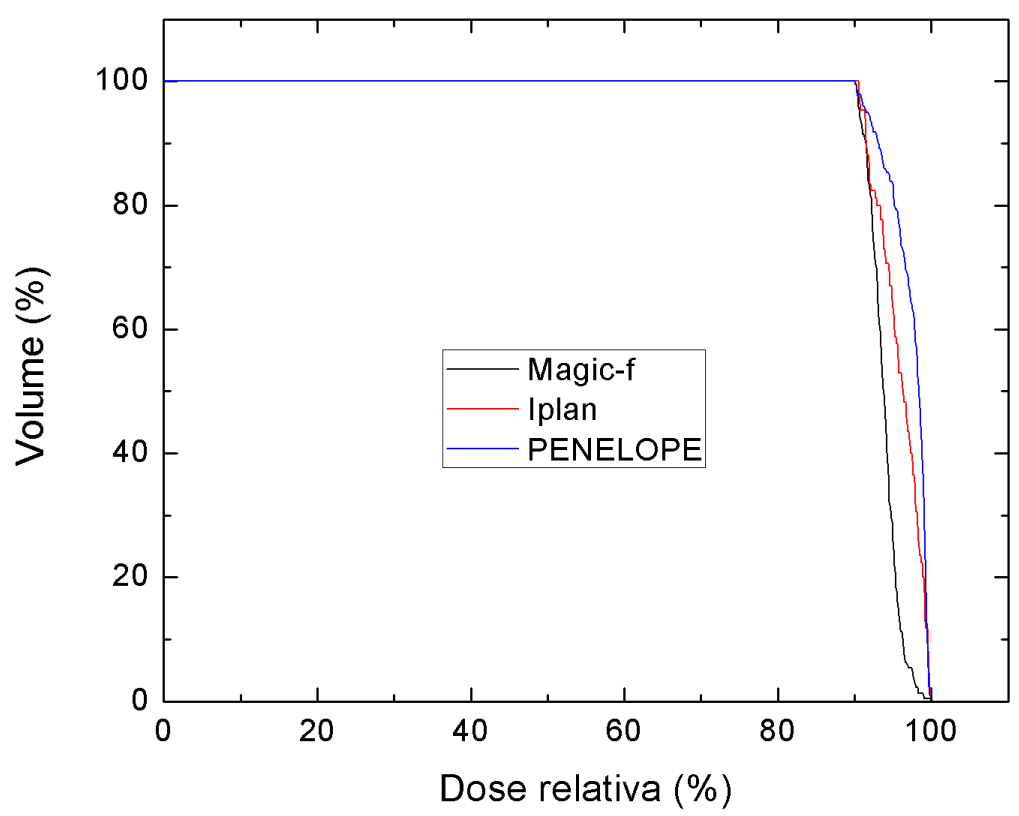

Figura 86: Curvas de DVH obtidas das distribuições de dose volumétrica das ferramentas dosimétricas: MAGIC-f, e TPS iPlan ${ }^{\circledR}$ e PENELOPE para um caso de meningioma.

Conforme os DVHs mostrados na Figura 86, todas as curvas tendem ao mesmo comportamento até, aproximadamente, $95 \%$ de dose. Após esse percentual de dose observasse uma queda abrupta na distribuição, como é característico para os DVHs de volumes alvo. No caso da curva de DVH obtida através do MAGIG-f, esta mostra um queda mais acentuada comparada com as outras curvas.

Tomando-se o DHV do TPS iPlan como referência pode-se inferir somente uma pequena porção do volume alvo recebe a dose máxima. Além disso, o DVH do PENELOPE sugere que um volume maior que o previsto pelo iPlan recebe a dose máxima. Por outro lado, o DVH do MAGIC-f sugere que um volume menor que o previsto pelo iPlan recebe a dose máxima. Para o caso da prescrição do tratamento na isodose de $95 \%$, entretanto, tanto o PENELOPE quanto o MAGIC-f preveem a adequação do planejamento em relação às restrições da prescrição. 
No planejamento de um caso clinico de radiocirurgia também são determinadas curvas de DVH para os órgãos de risco para garantia de que a quantidade de dose esteja dentro do limite de dose permitido para esse órgão.

Através de uma comparação entre as técnicas de avaliação das distribuições de dose pode-se observar que os DVH apenas trazem informações da conformidade de dose dentro de um volume específico; já através do índice gama ressaltam-se informações sobre a adequação da deposição de dose de todo o plano analisado, com informações dos pontos críticos da distribuição.

\subsubsection{Probabilidade de controle tumoral}

A Figura 87 mostra os histogramas de TCP-Volume, para o caso de meningioma, determinadas para as ferramentas dosimétricas: MAGIC- $f$, TPS iPlan ${ }^{\circledR}$ e código PENELOPE.

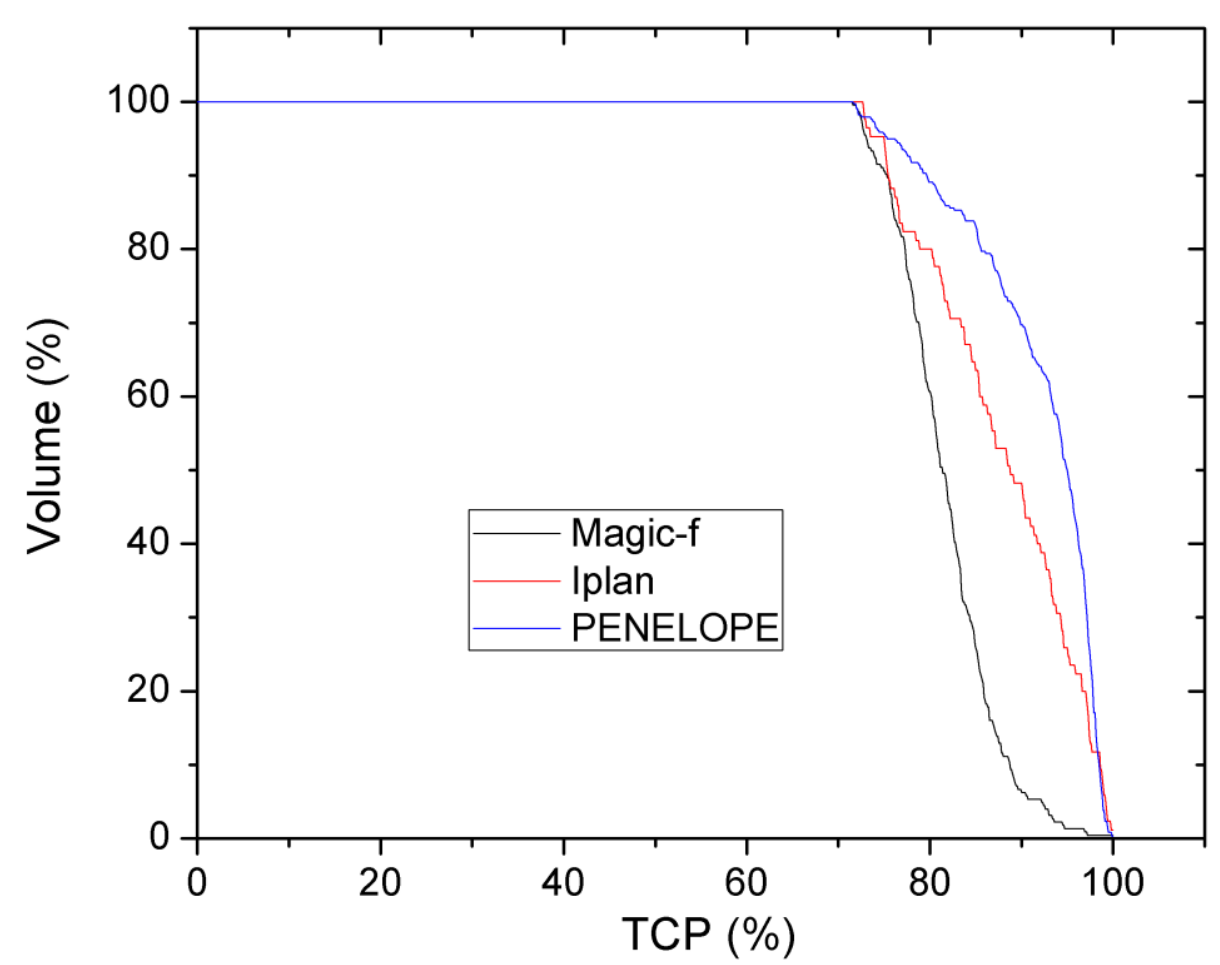

Figura 87: Histogranas de probabilidade de controle tumoral-volume, para um caso de meningioma, para as ferramentas dosimétricas: MAGIC-f, TPS iPlan ${ }^{\circledR}$ e PENELOPE, 
A Figura 87 mostra que as curvas de TCP-Volume possuem uma homogeneidade de controle tumoral de $71 \%$ em todo o volume alvo. Acima dessa porcentagem de controle tumoral, as proporções dos volumes com dado controle tumoral caem bruscamente. Pode-se, também, observar que a partir do TCP de $71 \%$ as ferramentas dosimétricas mostram respostas diferentes, com menor volume alvos TCPs para MAGIC- $f$ e os maiores volumes com altos TCPs para o PENELOPE.

A Figura 88 mostra a comparação entre as curvas de TCP-Volume e DVH obtidos com as três ferramentas dosimétricas para o caso de meningioma.

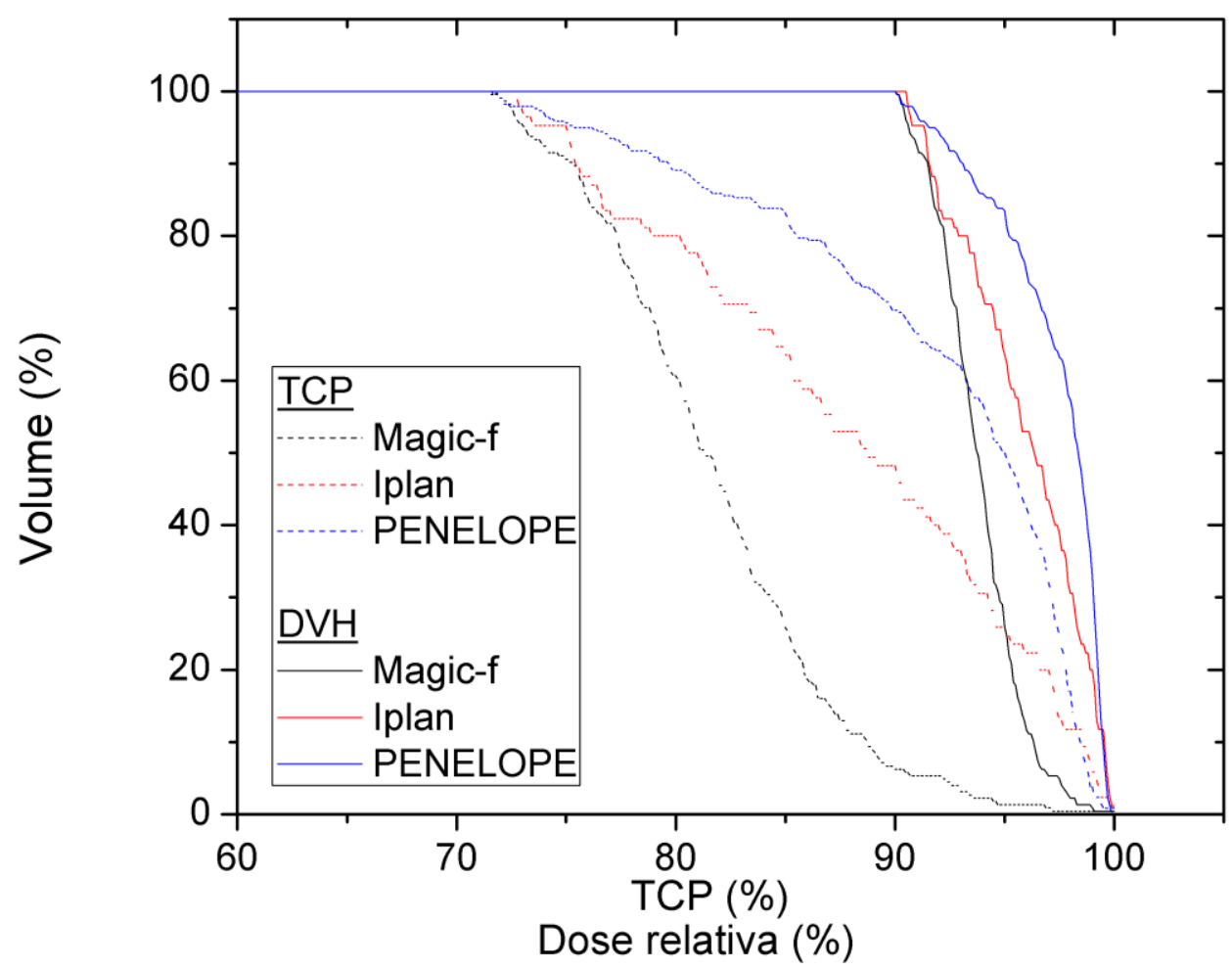

Figura 88: Curvas de TCP-Volume e DVH, para um caso de meningioma, para as ferramentas dosimétricas: MAGIC-f, TPS iPlan ${ }^{\circledR}$ e PENELOPE.

Como é mostrado na seção anterior, os DVHs para todos os casos de radiocirurgia, para todas as ferramentas dosimétricas utilizadas, possuem uma 
homogeneidade de dose, no volume alvo, de até, aproximadamente, 95\%, correspondendo à prescrição de dose do caso estudado.

Fazendo uma comparação qualitativa entre as curvas de DVH e TCPVolume, para um caso de meningioma, como mostrado na Figura 88, pode-se observar que os valores de TCP são reduzidos em comparação às valores de dose relativa, pois, conforme citado, as curvas de DVH simplesmente fornecem a informação da dose que será administrada ao volume de interesse, e conforme o modelo matemático do TCP, utilizando neste trabalho, este mostra que somente existiria um controle tumoral de, aproximadamente, $70 \%$ no volume todo.

\subsubsection{Caso 2: Melanoma}

A Figura 89 mostra as distribuições de dose, no plano central do volume alvo, obtidas com os dosímetros MAGIC- $f$ e EBT2 e com os algoritmos de simulação do TPS iPlan ${ }^{\circledR}$ e PENELOPE. 


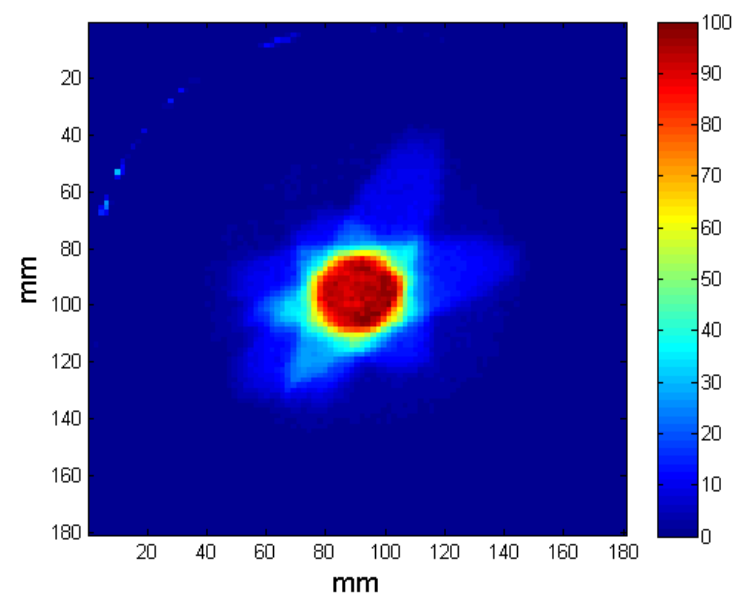

(a)

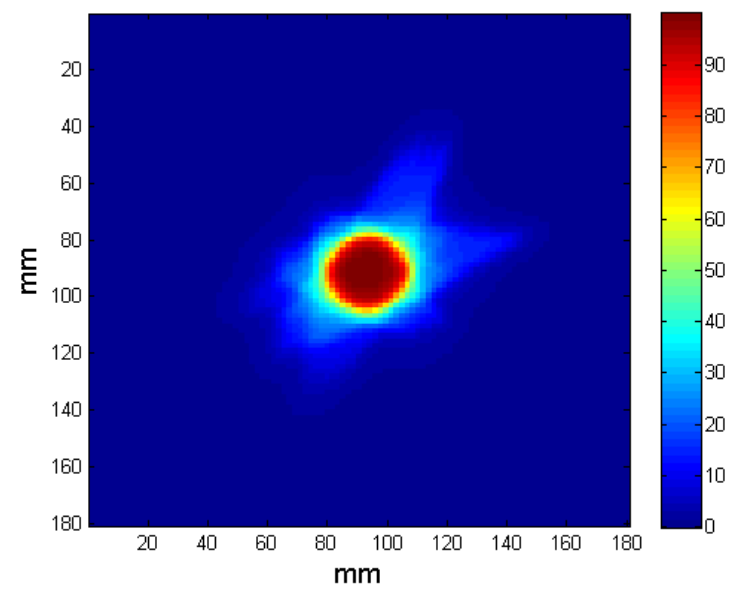

(c)

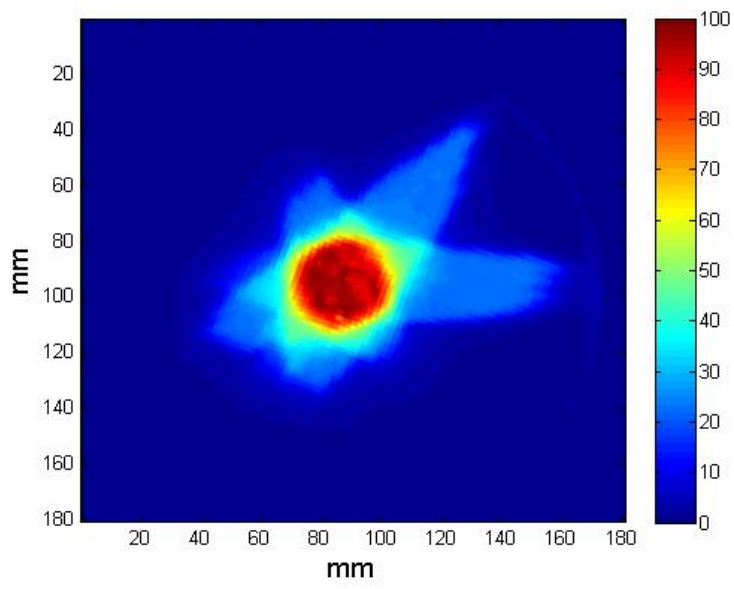

(b)

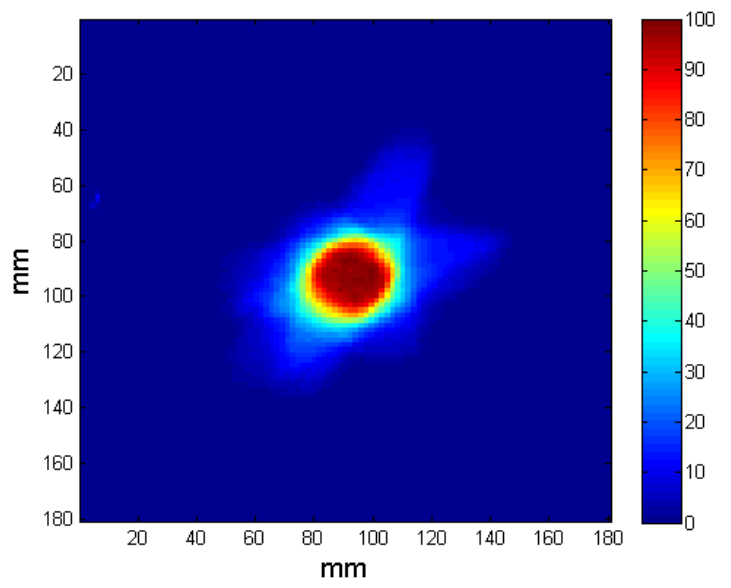

(d)

Figura 89: Distribuições de dose obtidas para uma técnica de radiocirurgia com 9 campos estáticos com as ferramentas dosimétricas: (a) MAGIC-f, (b) EBT2, (c) TPS iPlan ${ }^{\circledR}$ e (d) PENELOPE.

As distribuições de dose mostradas foram comparadas com a técnica de índice $\gamma$, com os critérios de $3 \mathrm{~mm}$ e $3 \%$ dose são mostradas nas Figura 90 à Figura 95.

\subsubsection{Avaliação do índice $\gamma$ entre PENELOPE e TPS iPlan ${ }^{\circledR}$}

A Figura 90 apresenta o mapa do índice $\gamma$ comparando as distribuições de dose obtidas com PENELOPE e TPS iPlan ${ }^{\circledR}$, para os critérios de $3 \mathrm{~mm}$ e $3 \%$. 


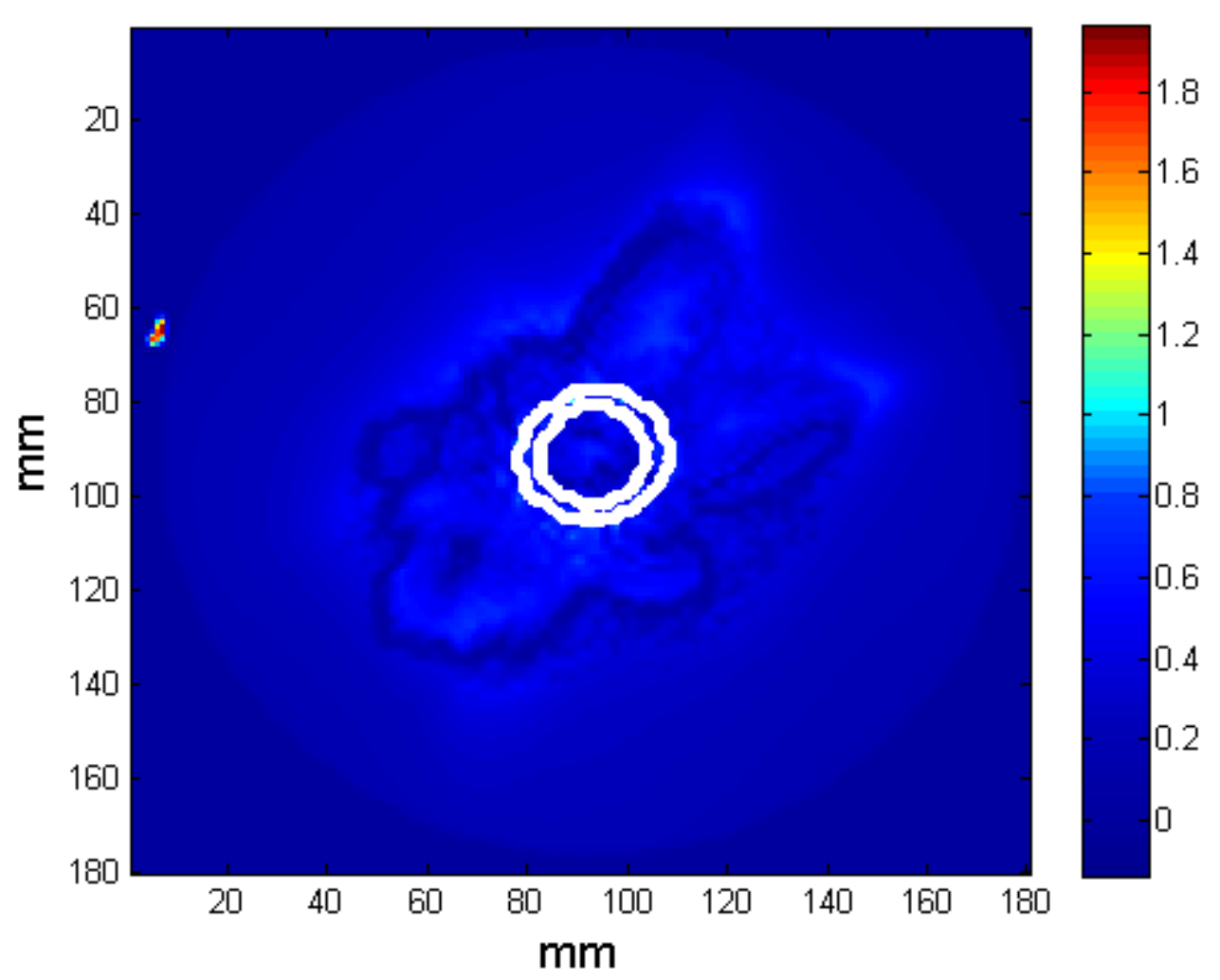

Figura 90: Mapa do índice $\gamma$ comparando as distribuições de dose obtidas com PENELOPE e TPS iPlan ${ }^{\circledR}$, para os critérios de $3 \mathrm{~mm}$ e $3 \%$. As linhas brancas mostram as isodoses de $90 \%$ e de $50 \%$, respectivamente.

4.6.2.2. Avaliação do índice $\gamma$ entre MAGIC-f e EBT2

A Figura 91 apresenta o mapa do índice $\gamma$ comparando as distribuições de dose obtidas com MAGIC- $f$ e filme EBT2, para os critérios de $3 \mathrm{~mm}$ e $3 \%$. 


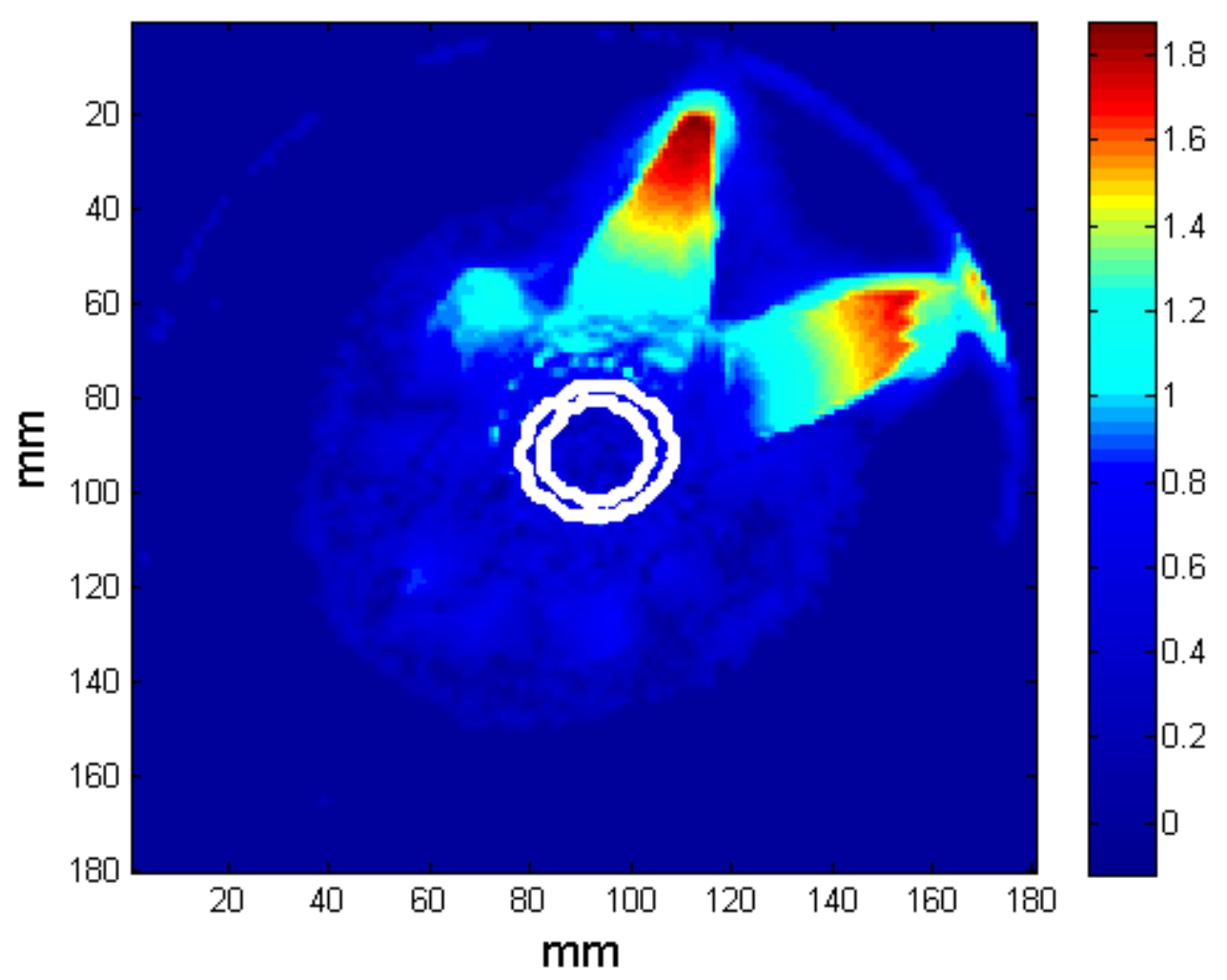

Figura 91: Mapa do índice $\gamma$ comparando as distribuições de dose obtidas com MAGIC-f e EBT2, para os critérios de $3 \mathrm{~mm}$ e $3 \%$. As linhas brancas mostram as isodoses de $90 \%$ e de $50 \%$, respectivamente.

\subsubsection{Avaliação do índice $\gamma$ entre MAGIC-f e PENELOPE}

A Figura 92 apresenta o mapa do índice $\gamma$ comparando às distribuições de dose obtidas com MAGIC-fe PENELOPE, para os critérios de $3 \mathrm{~mm}$ e $3 \%$. 


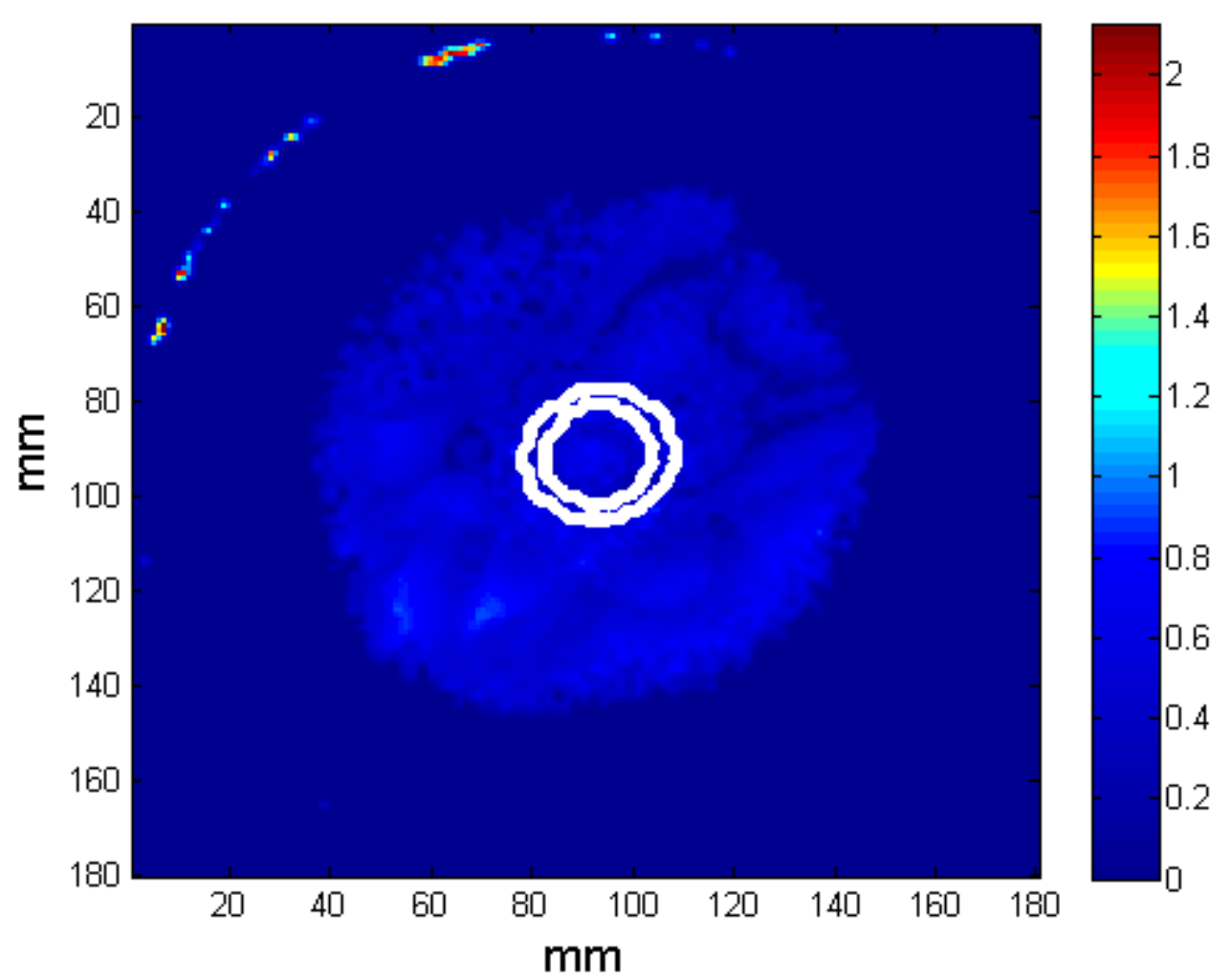

Figura 92: Mapa do índice $\gamma$ comparando as distribuições de dose obtidas com MAGIC-f e PENELOPE, para os critérios de $3 \mathrm{~mm}$ e $3 \%$. As linhas brancas mostram as isodoses de $90 \%$ e de $50 \%$, respectivamente.

4.6.2.4. Avaliação do índice $\gamma$ entre PENELOPE e EBT2

A Figura 93 apresenta o mapa do índice $\gamma$ comparando às distribuições de dose obtidas com PENELOPE e filme EBT2, para critérios de $3 \mathrm{mmm}$ e $3 \%$. 


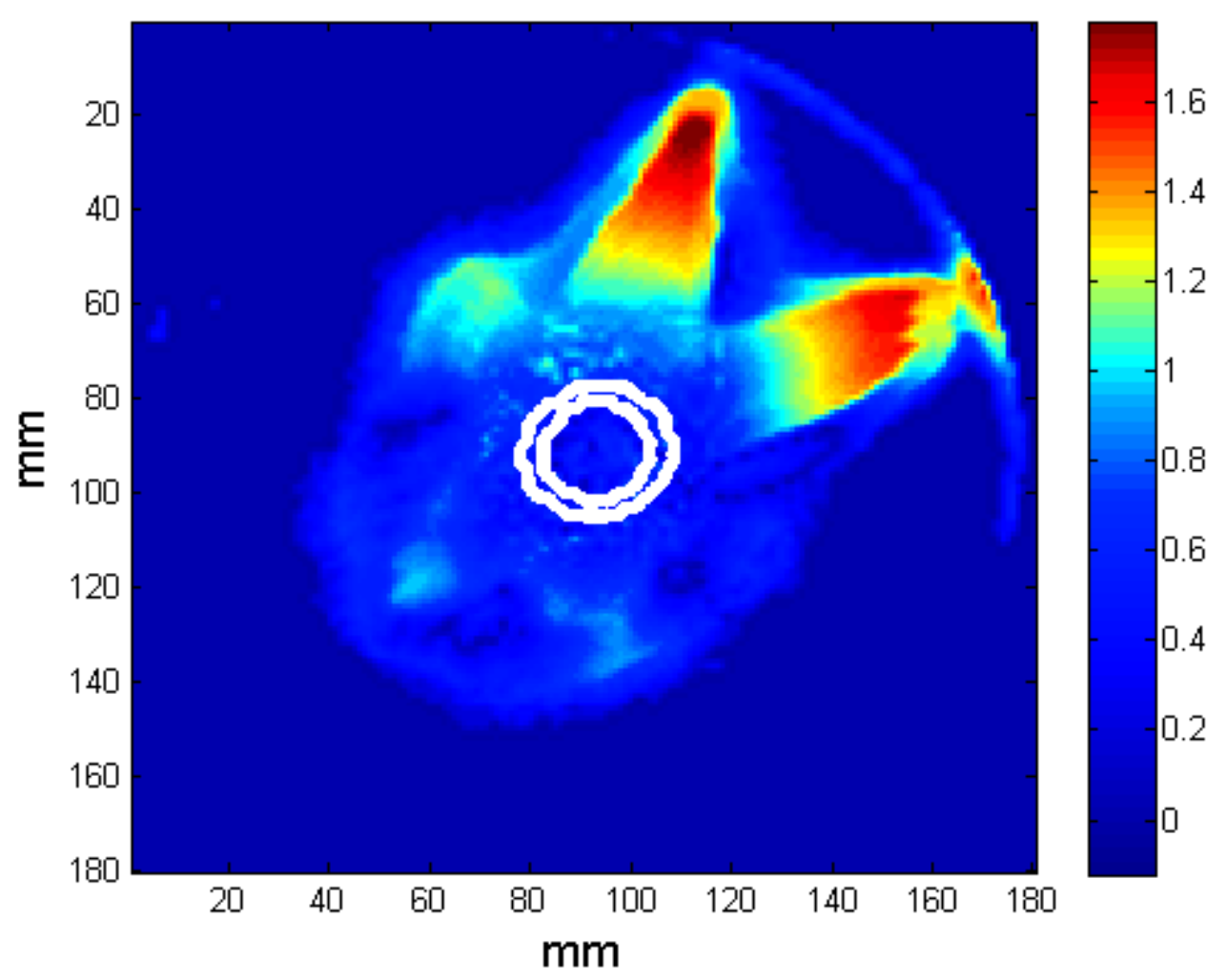

Figura 93: Mapa do índice $\gamma$ comparando as distribuições de dose obtidas com PENELOPE e EBT2, para os critérios de $3 \mathrm{~mm}$ e $3 \%$. As linhas brancas mostram as isodoses de $90 \%$ e de $50 \%$, respectivamente.

4.6.2.5. Avaliação do índice $\gamma$ entre TPS iPlan ${ }^{\circledR}$ e MAGIC-f

A Figura 94 apresenta o mapa do índice $\gamma$ comparando às distribuições de dose obtidas com TPS iPlan ${ }^{\circledR}$ e MAGIC-f, para os critérios de $3 \mathrm{~mm}$ e $3 \%$. 


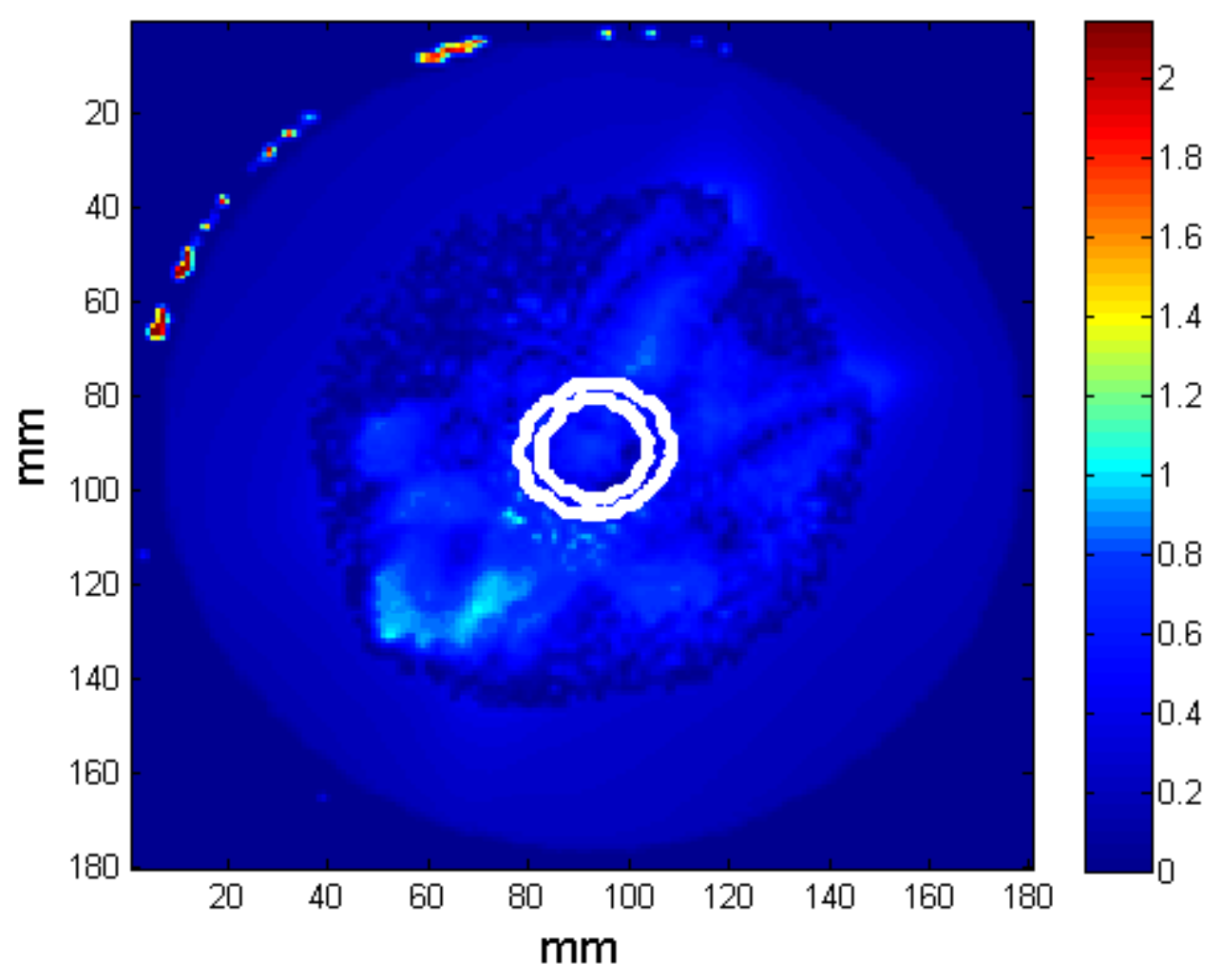

Figura 94: Mapa do índice $\gamma$ comparando as distribuições de dose obtidas com TPS iPlan ${ }^{\circledR}$ e MAGIC-f, para os critérios de $3 \mathrm{~mm}$ e $3 \%$. As linhas brancas mostram as isodoses de $90 \%$ e de $50 \%$, respectivamente.

4.6.2.6. Avaliação do índice $\gamma$ entre TPS iPlan ${ }^{\circledR}$ e EBT2

A Figura 95 apresenta o mapa do índice $\gamma$ comparando às distribuições de dose obtidas com TPS iPlan ${ }^{\circledR}$ e EBT2, para os critérios de 3 $\mathrm{mm}$ e $3 \%$. 


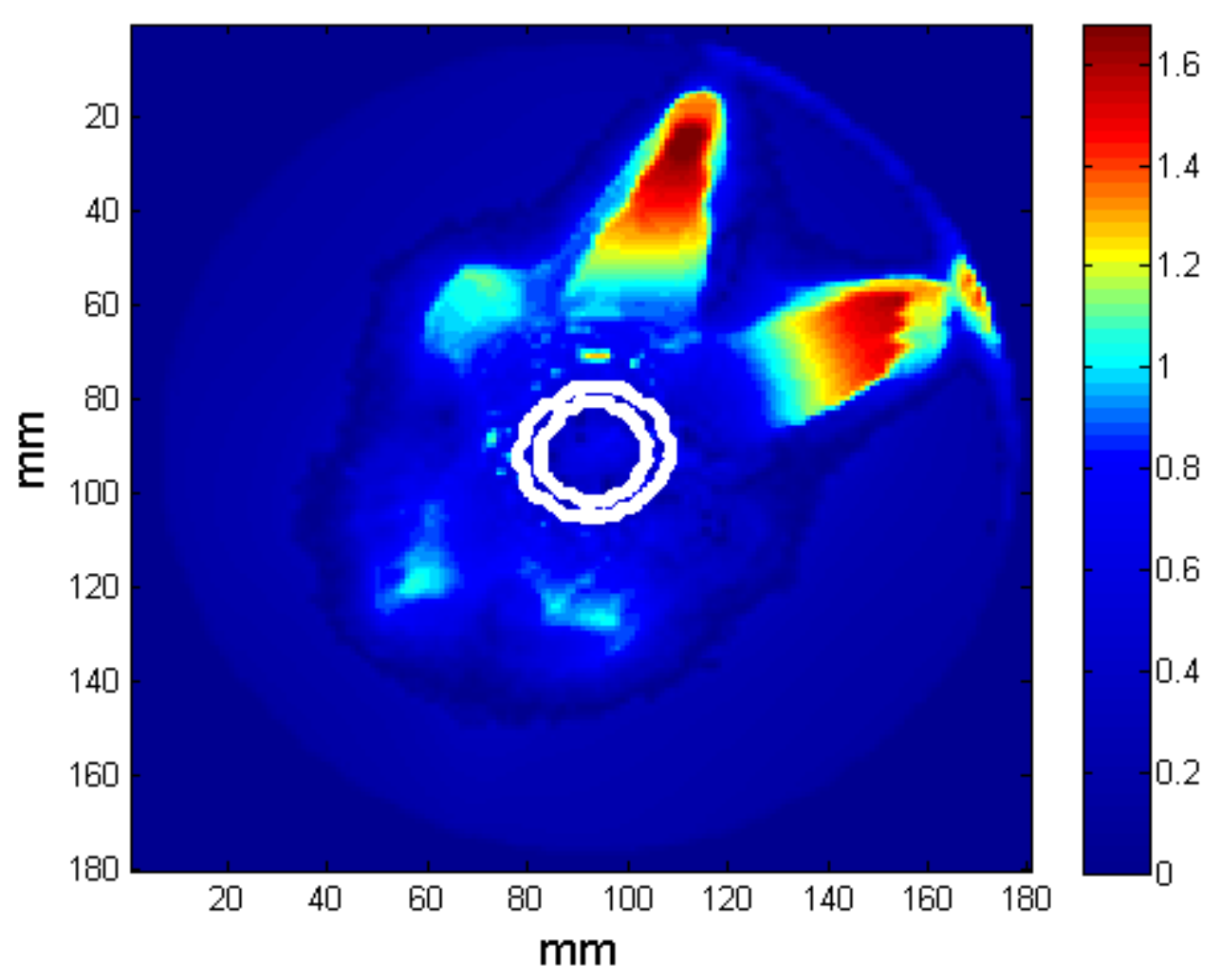

Figura 95: Mapa do índice $\gamma$ comparando as distribuições de dose obtidas com TPS iPlan ${ }^{\circledR}$ e EBT2, para os critérios de $3 \mathrm{~mm}$ e $3 \%$. As linhas brancas mostram as isodoses de $90 \%$ e de $50 \%$, respectivamente.

A Tabela 17 mostra os valores percentuais do número de pixels que passaram o teste do índice $\gamma$ para as isodoses de 90\%, 50\% e a comparação do plano todo, considerando o critério de $3 \mathrm{~mm}$ de DTA e $3 \%$ em tolerância de dose. 
Tabela 17: Percentual de pixels dos mapas do índice $\gamma$ que foram aceitos pelo teste comparando as distribuições de dose para o caso do melanoma.

\begin{tabular}{c|c|c|c|c|c|c|c|c|c} 
& \multicolumn{2}{c}{ PENELOPE - TPS } & \multicolumn{3}{c|}{ PENELOPE - Filme } & \multicolumn{3}{c}{ PENELOPE - MAGIC- $f$} \\
\cline { 2 - 9 } & $90 \%$ & $50 \%$ & plano & $90 \%$ & $50 \%$ & plano & $90 \%$ & $50 \%$ & plano \\
\hline $3 \mathrm{~mm}, 3 \%$ & 100 & 100 & 99,98 & 100 & 100 & 92,89 & 100 & 100 & 100 \\
\hline
\end{tabular}

\begin{tabular}{c|c|c|c|c|c|c|c|c|c}
\cline { 2 - 9 } & \multicolumn{2}{c}{ MAGIC-f - Filme } & \multicolumn{3}{c|}{ TPS - Filme } & \multicolumn{3}{c}{ TPS - MAGIC- } \\
\cline { 2 - 10 } & $90 \%$ & $50 \%$ & plano & $90 \%$ & $50 \%$ & plano & $90 \%$ & $50 \%$ & plano \\
\hline $3 \mathrm{~mm}, 3 \%$ & 100 & 100 & 92.75 & 100 & 100 & 94.19 & 100 & 100 & 99.9 \\
\hline
\end{tabular}

A partir dos resultados mostrados na Tabela 17 pode observar a concordância de $100 \%$ entre as comparações das distribuições de dose nas isodoses de $90 \%$ e $50 \%$. A mínima concordância, de $92,89 \%$, foi encontrada quando comparado o plano da distribuição de dose obtida como o PENELOPE e EBT2 e a máxima concordância entre planos de distribuição de dose foi 99,9\% quando comparado o TPS iPlan ${ }^{\circledR}$ e MAGIC-f.

Comparando-se os resultados obtidos na avaliação dos planos de distribuição de dose do primeiro caso de radiocirurgia estudado, pode observar que, para este segundo caso, a avaliação dos planos centrais de distribuição de dose tendem a uma concordância de $100 \%$. Este resultado obtido por ser devido a uma menor quantidade de incidências de feixes no plano, comparado com o dos arcos dinâmicos, utilizados no primeiro caso, produzindo uma distribuição volumétrica de doses menos complexa e, portanto, apresentando maior concordância entre todas as ferramentas dosimétricas utilizadas

\subsubsection{Avaliação do Histograma dose-volume}

A Figura 96 mostra os DVHs determinados para o alvo do tratamento eobtidos através do MAGIC- $f$, PENELOPE e o TPS iPlan ${ }^{\circledR}$ para um caso de meningioma. 


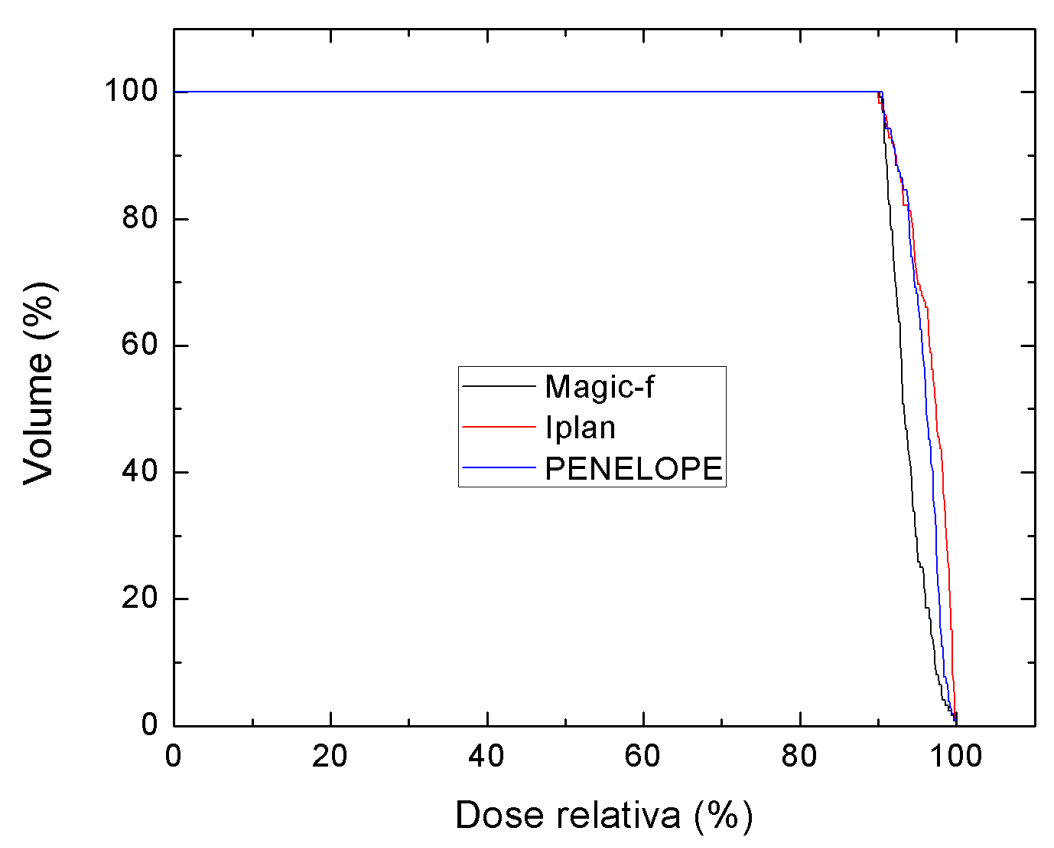

Figura 96: DVHs obtidos das distribuições de dose volumétrica das ferramentas dosimétricas: MAGIC-f, e TPS iPlan ${ }^{\circledR}$ e PENELOPE para um caso de melanoma.

A partir das curvas de DVH mostradas na Figura 96 observa-se que, como no caso do meningioma, as curvas de DVH obtidas com o MAGIC-f, TPS iPlan ${ }^{\circledR}$ e PENELOPE tem o mesmo comportamento até $95 \%$ de dose relativa; após esse percentual de dose as curvas caem rapidamente à medida que a dose relativa tende ao valor máximo. A queda mais acentuada das curvas de DVH é a da curva relacionada ao MAGIC- $f$, enquanto que as curvas do TPS iPlan ${ }^{\circledR}$ e PENELOPE mostram uma queda mais tênue comparada. Este comportamento também foi observado nas curvas de DVH do primeiro caso. Ao contrário do primeiro caso estudado, entretanto, o DVH obtido com o código PENELOPE subestima ligeiramente o volume recebendo as doses máximas do tratamento em relação ao DVH obtido pelo TPS iPlan. 


\subsubsection{Probabilidade de controle tumoral}

A figura 4 mostra as curvas de TCP-volume, para o caso de melanoma, determinadas para as ferramentas dosimétricas: MAGIC-f, TPS iPlan ${ }^{\circledR}$ e código PENELOPE.

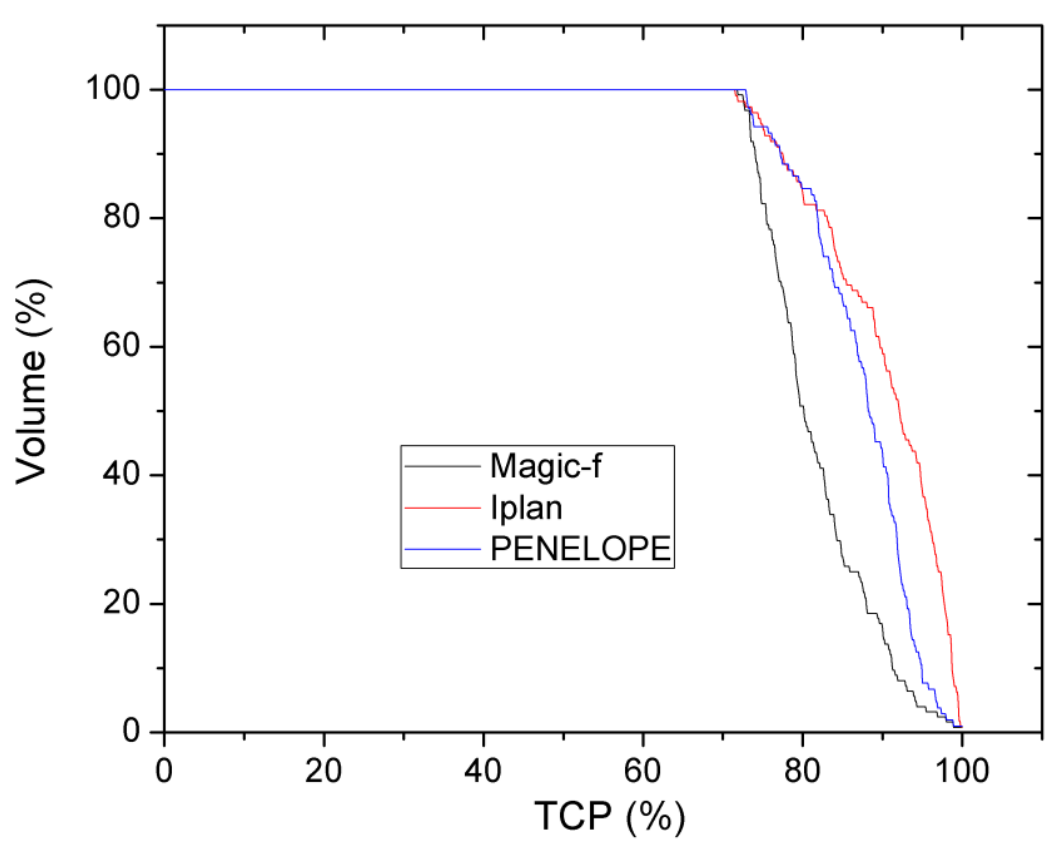

Figura 97: Histogramas de probabilidade de controle tumoral (TCP)-volume, para um caso de melanoma, para as ferramentas dosimétricas: MAGIC- $f$, TPS iPlan ${ }^{\circledR}$ e PENELOPE.

A Figura 97 mostra, de forma análoga ao do caso 1, que as curvas de TCP também possuem uma homogeneidade no volume todo de aproximadamente $72 \%$ de controle tumoral, e acima dessa porcentagem de TCP, a porcentagem de volume cai bruscamente.

A Figura 98 mostra a comparação entre as curvas de TCP-Volume e DVH obtidas com as três ferramentas dosimétricas para o caso de melanoma. 


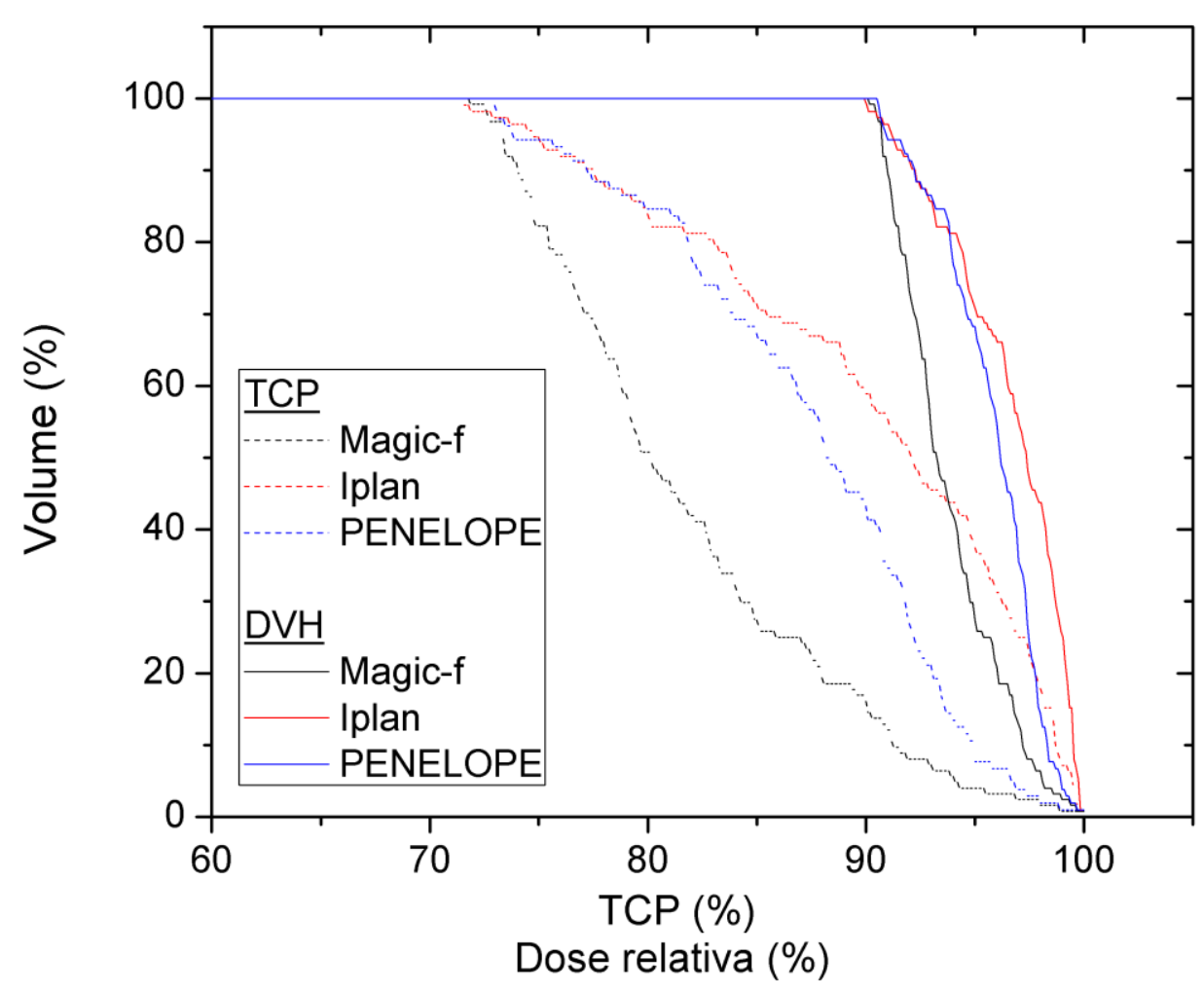

Figura 98: Curvas de TCP e DVH, para um caso de melanoma, para as ferramentas dosimétricas: MAGIC-f, TPS iPlan ${ }^{\circledR}$ e PENELOPE.

Do mesmo modo que para o caso do meningioma, as curvas de DVH para todos os casos de radiocirurgia e para todas as ferramentas dosimétricas utilizadas, possuem uma homogeneidade de dose, no volume alvo, de até aproximadamente 95\%, que é a isodose de prescrição.

Comparando-se qualitativamente as curvas de DVH e TCP-Volume, como mostrado na Figura 98, pode-se observar que os valores das curvas dos TCP-Volume são reduzidos em comparação das curvas de DVH, seguindo a mesma ordem de resposta; sendo a de menor resposta para ambas às curvas obtidas com MAGIC-f e a resposta máxima observada para o PENELOPE.

\subsubsection{Caso3: Neurinoma do acústico}

A Figura 99 mostra as distribuições de dose obtidas com o MAGIC- $f$, filme EBT2, TPS iPlan ${ }^{\circledR}$ e PENELOPE para um caso de planejamento de neurinoma do acústico, composto por 11 campos estáticos. 


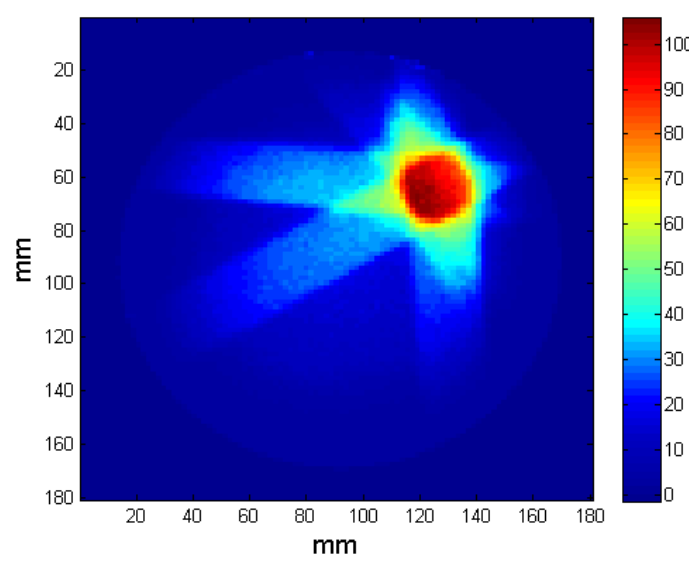

(a)

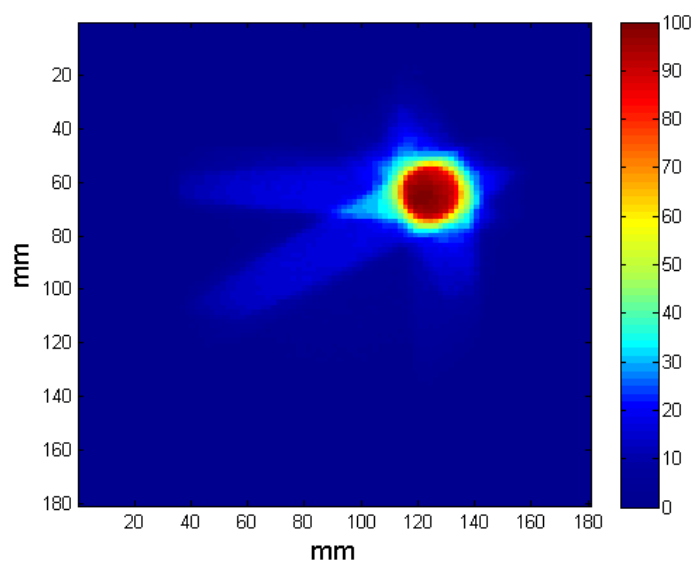

(c)

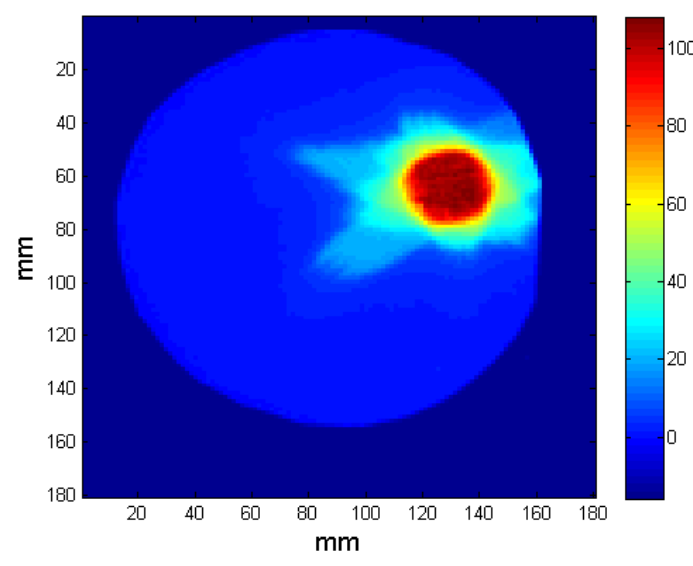

(b)

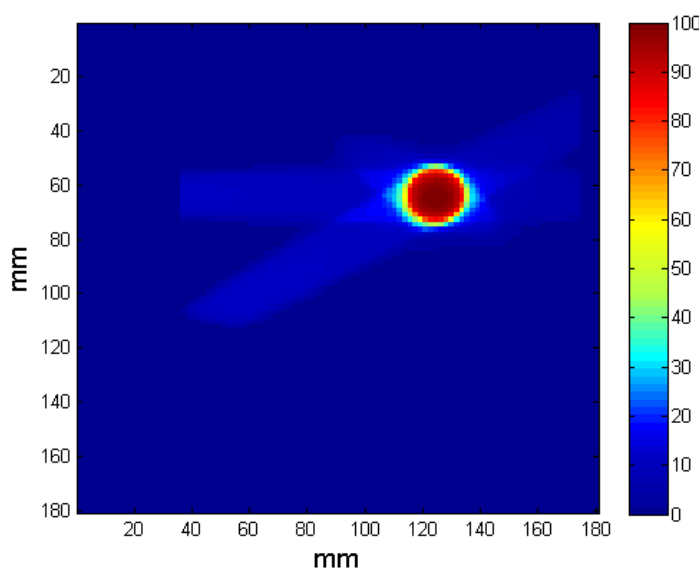

(d)

Figura 99: Distribuições de dose obtidas para uma técnica de radiocirurgia com 11 campos estáticos com as ferramentas dosimétricas: (a) MAGIC-f, (b) EBT2, (c) TPS iPlan ${ }^{\circledR}$ e (d) PENELOPE.

As distribuições de dose mostradas foram comparadas através dos mapas de índice $\gamma$, com os critérios de $3 \mathrm{~mm}$ e $3 \%$, sendo mostrados nas Figura 100 à Figura 105.

\subsubsection{Avaliação do índice $\gamma$ entre PENELOPE e TPS iPlan ${ }^{\circledR}$}

A Figura 100 mostra o mapa do índice $\gamma$ comparando as distribuições de dose obtidas com PENELOPE e TPS iPlan ${ }^{\circledR}$, para os critérios de $3 \mathrm{~mm}$ e $3 \%$. 


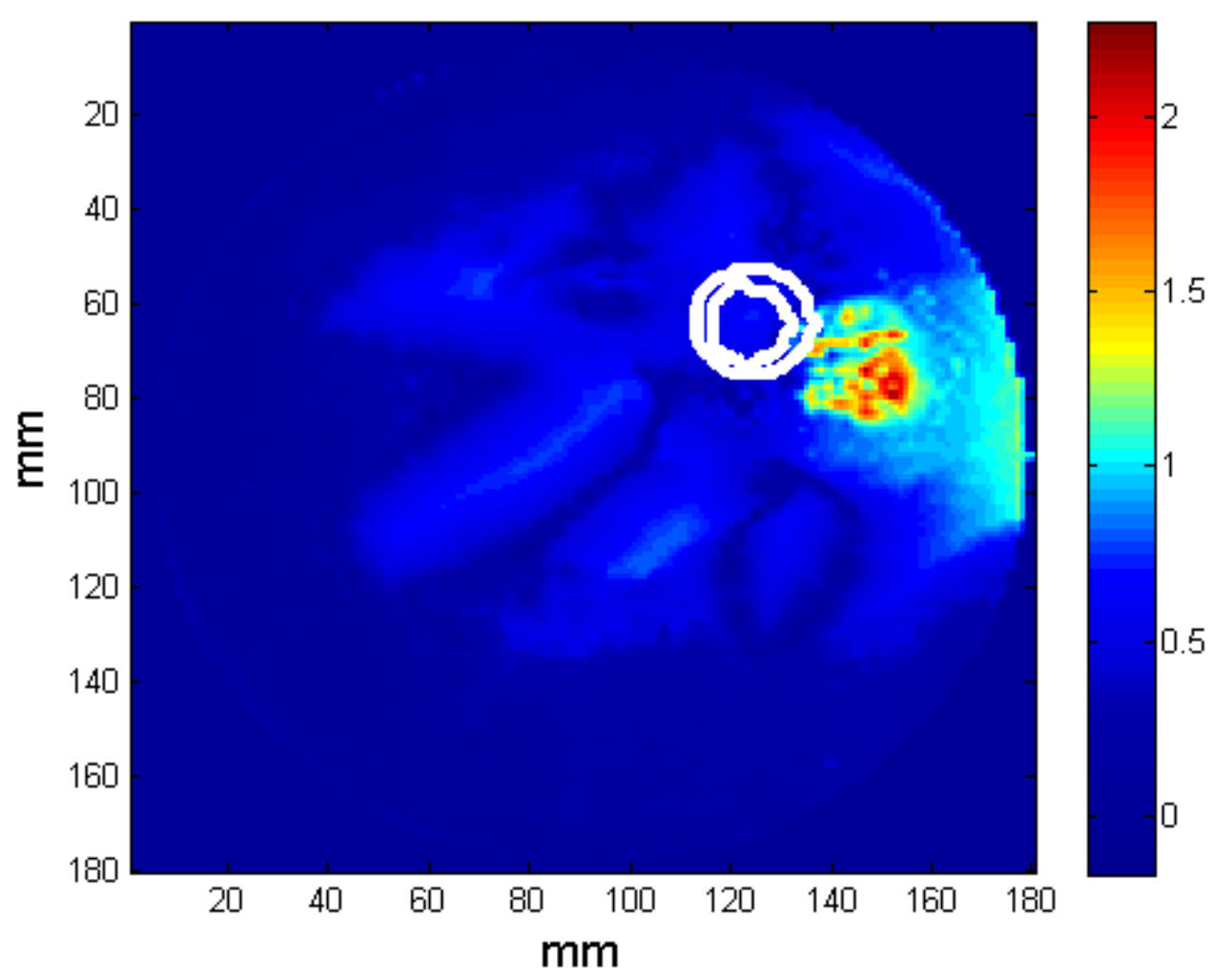

Figura 100: Mapa do índice $\gamma$ comparando as distribuições de dose obtidas com PENELOPE e TPS iPlan ${ }^{\circledR}$, para os critérios de $3 \mathrm{~mm}$ e $3 \%$. As linhas brancas mostram as isodoses de $90 \%$ e de $50 \%$, respectivamente.

4.6.3.2. Avaliação do índice $\gamma$ entre MAGIC-f e EBT2

A Figura 101 mostra o mapa do índice $\gamma$ comparando as distribuições de dose obtidas com MAGIC-f e filme EBT2, para os critérios de $3 \mathrm{~mm}$ e $3 \%$. 


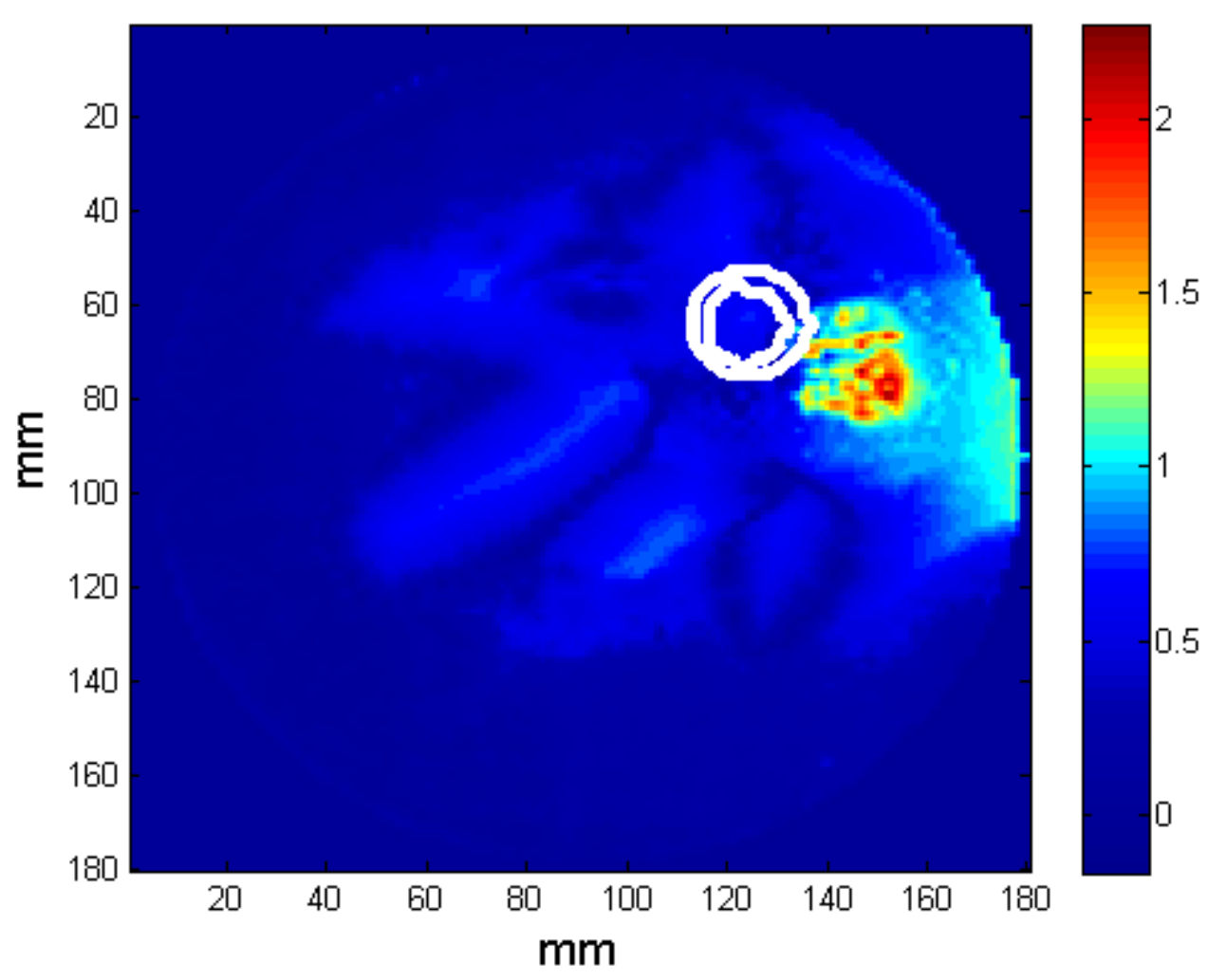

Figura 101: Mapa do índice $\gamma$ comparando as distribuições de dose obtidas com MAGIC-f e EBT2, para os critérios de $3 \mathrm{~mm}$ e $3 \%$. As linhas brancas mostram as isodoses de $90 \%$ e de $50 \%$, respectivamente.

4.6.3.3. Avaliação do índice $\gamma$ entre MAGIC-f e PENELOPE

A Figura 102 mostra o mapa do índice $\gamma$ comparando as distribuições de dose obtidas com MAGIC- $f$ e PENELOPE, para os critérios de $3 \mathrm{~mm}$ e $3 \%$. 


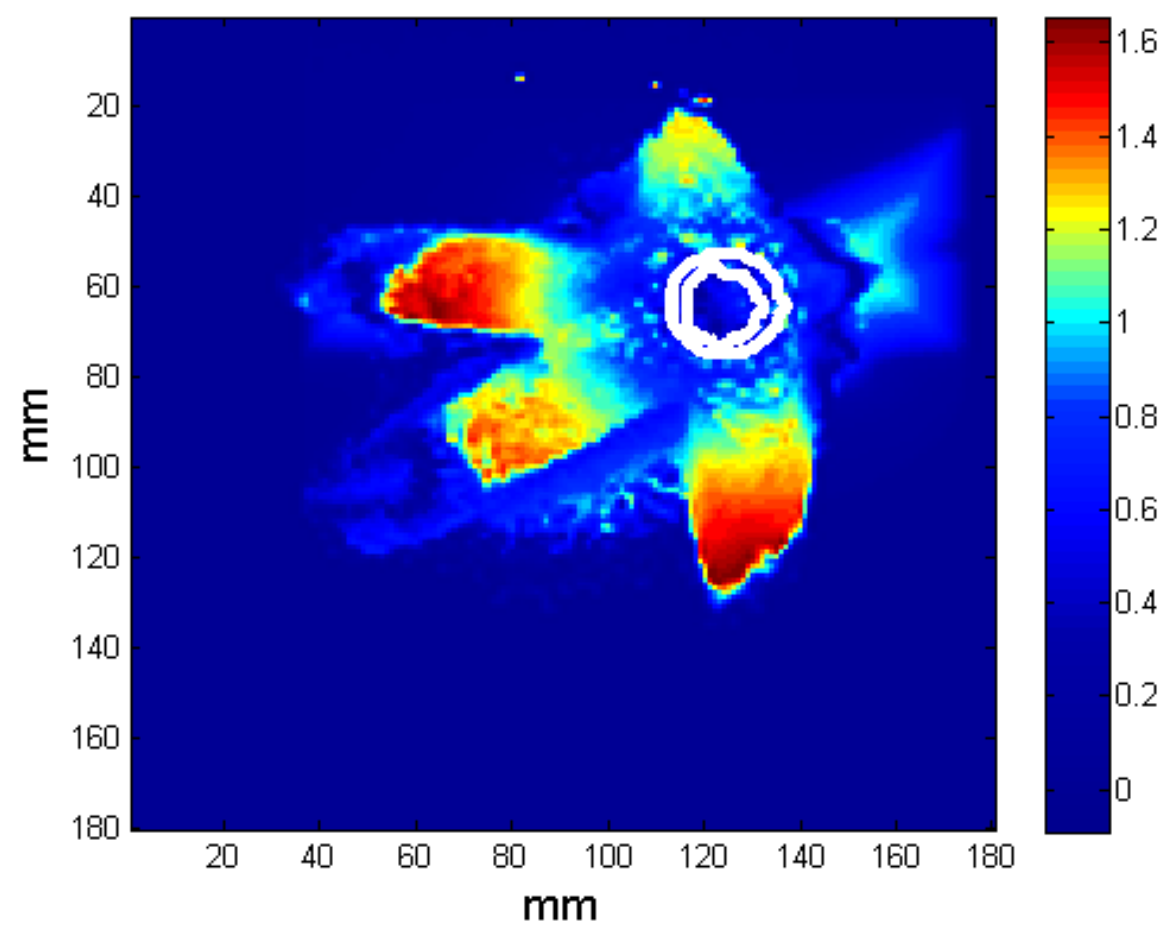

Figura 102: Mapa do índice $\gamma$ comparando as distribuições de dose obtidas com MAGIC- $f$ e PENELOPE, para os critérios de $3 \mathrm{~mm}$ e $3 \%$. As linhas brancas mostram as isodoses de $90 \%$ e de $50 \%$, respectivamente.

\subsubsection{Avaliação do índice $\gamma$ entre PENELOPE e EBT2}

A Figura 103 mostra o mapa do índice $\gamma$ comparando as distribuições de dose obtidas com PENELOPE e filme EBT2, para os critérios de $3 \mathrm{~mm}$ e $3 \%$. 


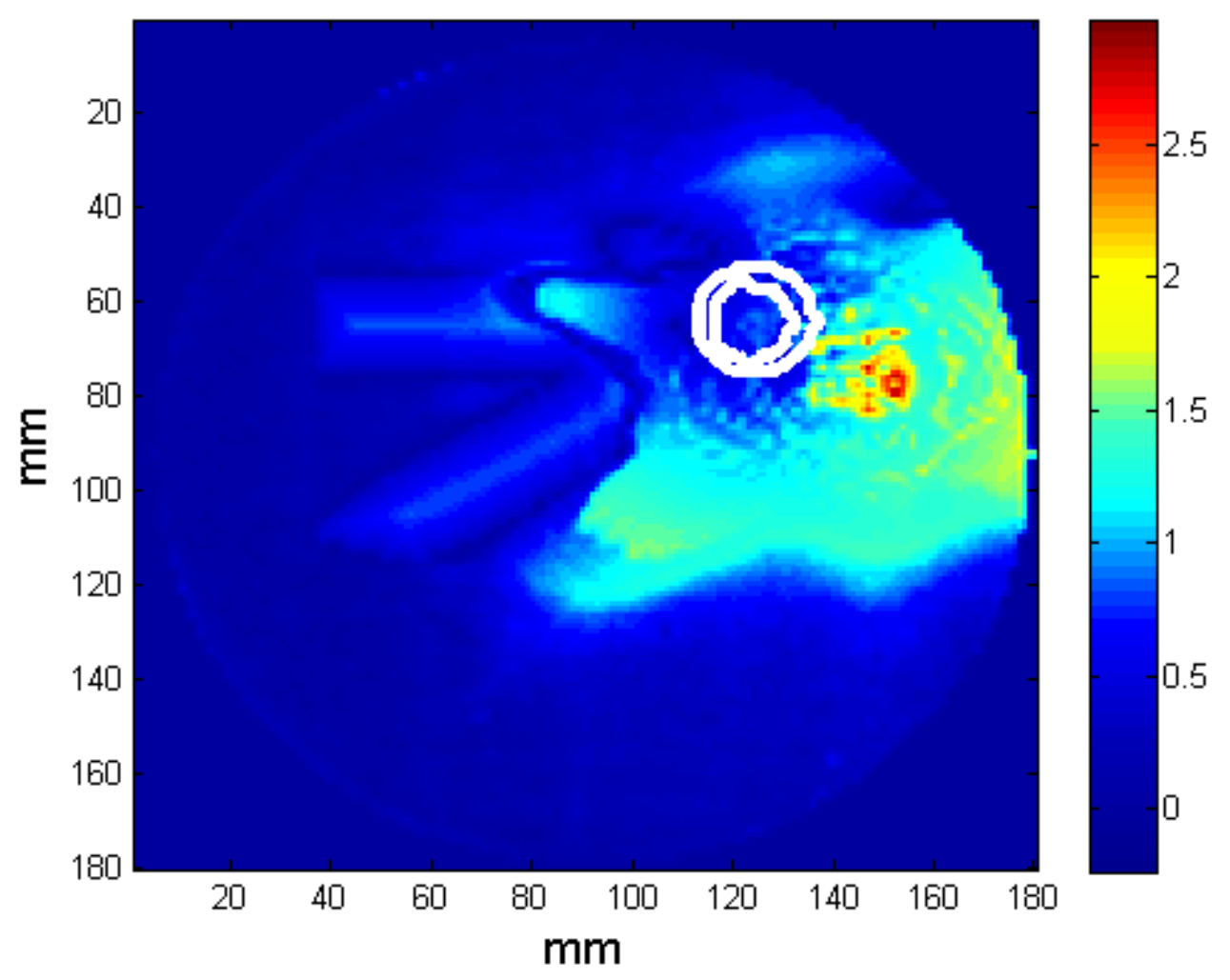

Figura 103: Mapa do índice $\gamma$ comparando as distribuições de dose obtidas com PENELOPE e EBT2, para os critérios de $3 \mathrm{~mm}$ e $3 \%$. As linhas brancas mostram as isodoses de $90 \%$ e de $50 \%$, respectivamente.

4.6.3.5. Avaliação do índice $\gamma$ entre TPS iPlan ${ }^{\circledR}$ e MAGIC-f

A Figura 104 mostra o mapa do índice $\gamma$ comparando as distribuições de dose obtidas com TPS iPlan ${ }^{\circledR}$ e MAGIC-f, para os critérios de $3 \mathrm{~mm}$ e $3 \%$. 


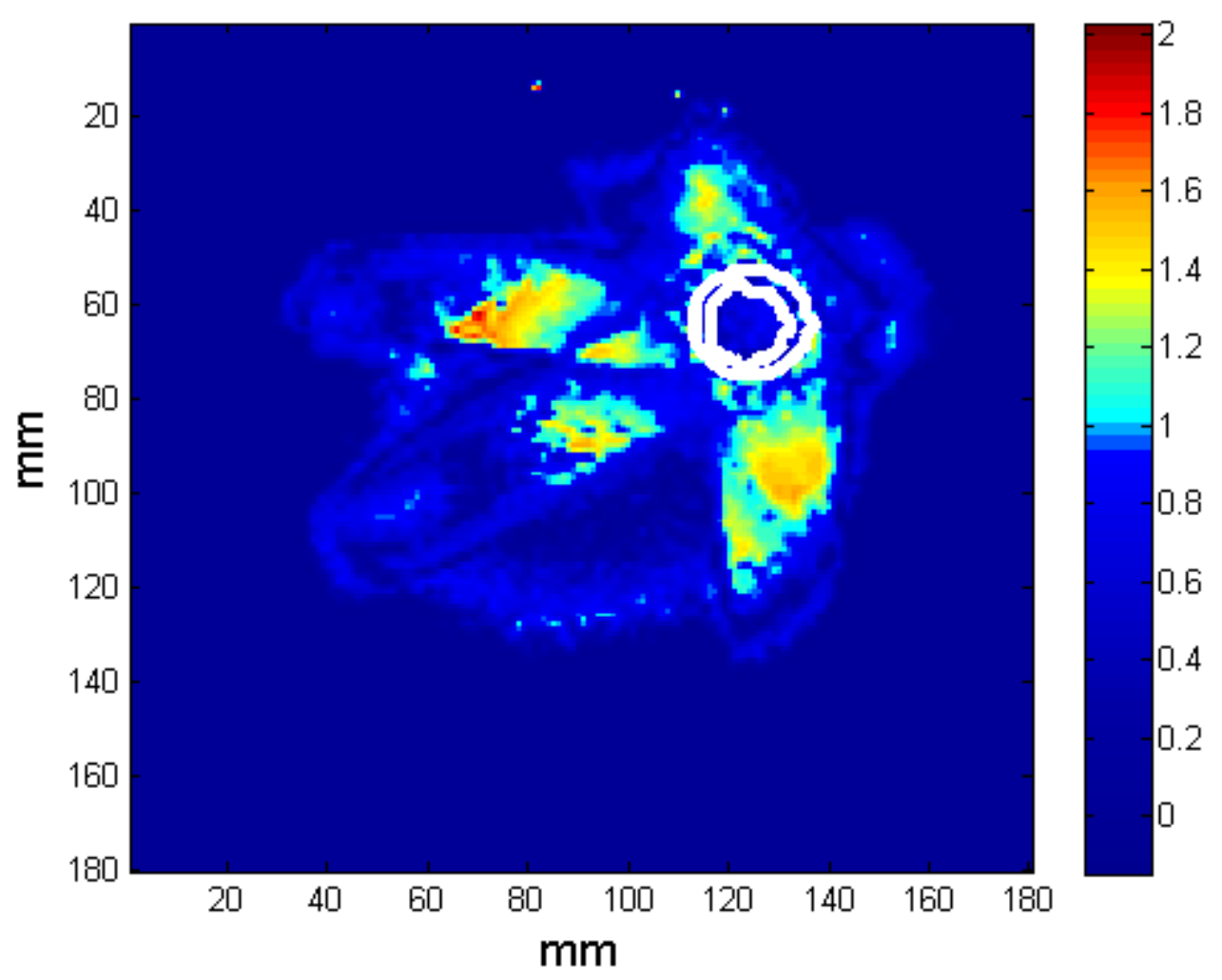

Figura 104: Mapa do índice $\gamma$ comparando as distribuições de dose obtidas com TPS iPlan ${ }^{\circledR}$ e EBT2, para os critérios de $3 \mathrm{~mm}$ e $3 \%$. As linhas brancas mostram as isodoses de $90 \%$ e de $50 \%$, respectivamente.

\subsubsection{Avaliação do índice $\gamma$ entre TPS iPlan ${ }^{\circledR}$ e EBT2}

A Figura 105 mostra o mapa do índice $\gamma$ comparando as distribuições de dose obtidas com o TPS iPlan ${ }^{\circledR}$ e EBT2, para os critérios de $3 \mathrm{~mm}$ e $3 \%$. 


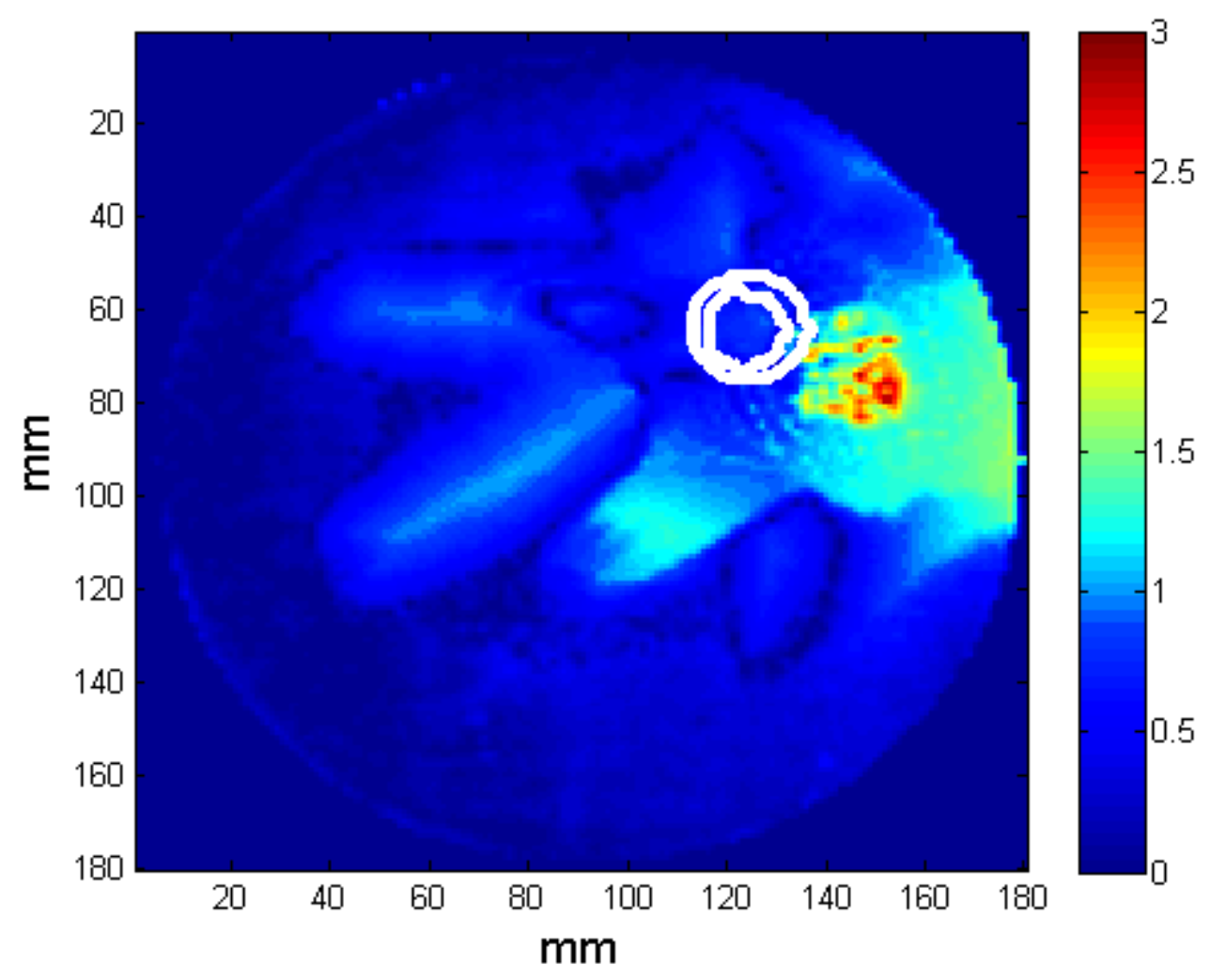

Figura 105: Mapa do índice $\gamma$ comparando s distribuições de dose obtidas com TPS iPlan ${ }^{\circledR}$ e EBT2, para os critérios de $3 \mathrm{~mm}$ e $3 \%$. As linhas brancas mostram as isodoses de $90 \%$ e de $50 \%$, respectivamente.

A Tabela 18 mostra os percentuais dos que passaram o teste do índice gama nas isodoses de $90 \%, 50 \%$ e a comparação do plano todo, considerando o critério de $3 \mathrm{~mm}$ e $3 \%$, para o caso de neurinoma do acústico.

Tabela 18: Percentual de pixels dos mapas do índice $\gamma$ que foram aceitos pelo teste comparando as distribuições de dose para o caso do neurinoma do acústico.

\begin{tabular}{|c|c|c|c|c|c|c|c|c|c|}
\hline & \multicolumn{3}{|c|}{$\begin{array}{l}\text { PENELOPE e } \\
\text { TPS iPlan }{ }^{\circledR} \\
\end{array}$} & \multicolumn{3}{|c|}{ PENELOPE e EBT2 } & \multicolumn{3}{|c|}{$\begin{array}{c}\text { PENELOPE e } \\
\text { MAGIC- } f\end{array}$} \\
\hline & $90 \%$ & $50 \%$ & plano & $90 \%$ & $50 \%$ & plano & $90 \%$ & $50 \%$ & plano \\
\hline $3 \mathrm{~mm}, 3 \%$ & 100 & 98,65 & 98,65 & 100 & 99,74 & 86,99 & 100 & 94,77 & 90.60 \\
\hline
\end{tabular}

\begin{tabular}{c|c|c|c|c|c|c|c|c|c}
\hline & \multicolumn{3}{c|}{ MAGIC-f e EBT2 } & \multicolumn{3}{c|}{ TPS iPlan $^{\circledR}$ e EBT2 } & \multicolumn{3}{c}{$\begin{array}{c}\text { TPS iPlan }{ }^{\circledR} \text { e } \\
\text { MAGIC-f }\end{array}$} \\
\cline { 2 - 9 } & $90 \%$ & $50 \%$ & plano & $90 \%$ & $50 \%$ & plano & $90 \%$ & $50 \%$ & plano \\
\hline $3 \mathrm{~mm}, 3 \%$ & 100 & 93,33 & 97,29 & 98,18 & 89,23 & 91,51 & 98,97 & 89,25 & 94,04 \\
\hline
\end{tabular}


Dos resultados apresentados na Tabela 18 observa-se que para as quatro ferramentas dosimétricas a análise das diferentes distribuições de dose, do plano central, na isodose de $90 \%$ apresentou uma concordância $100 \%$ apenas para o PENELOPE quando comparado às outras ferramentas. A boa concordância entre as distribuições do PENELOPE e do MAGIC-f também se mantiveram. Para a isodose de $50 \%$ a concordância máxima foi de $99,74 \%$, enquanto que para o plano todo a concordância máxima foi de $98,65 \%$.

A partir dos resultados obtidos nos três casos de estudo de tratamentos de radiocirurgia, observou-se a concordância de 100\% dentro das isodoses de $90 \%$ para todas as comparações utilizando os critérios de $3 \mathrm{~mm}$ e $3 \%$, evidenciando que os dosímetros MAGIC- $f$ e o filme EBT2, assim como também, o código PENELOPE, podem ser utilizados como uma ferramenta dosimétrica para a avaliação das doses dos tratamentos.

Com os critérios utilizados de $3 \mathrm{~mm}$ de DTA e diferença de dose de $3 \%$, para um caso do melanoma com prescrição de dose de 20Gy, com essas tolerâncias, poderia-se depositar uma sobredosagem de aproximadamente 19,4 Gy em estruturas ao redor do volume alvo, podendo causar danos irreversíveis a essa estrutura adjacente .

Os resultados obtidos dentro da isodose de $50 \%$ são mais heterogêneos que aqueles encontrados para as regiões de altas doses. Isso era esperado já que a técnica de radiocirurgia proporciona um alto gradiente de doses ao redor do volume alvo. Nessas regiões, valores de índice gama, para os critérios utilizados, ficaram entre $42 \%$ e $100 \%$.

\subsubsection{Avaliação do Histograma dose-volume}

A Figura 106 mostra os DVHs obtidos através do MAGIC-f, PENELOPE e o sistema de planejamento, para um caso de neurinoma do acustico. 


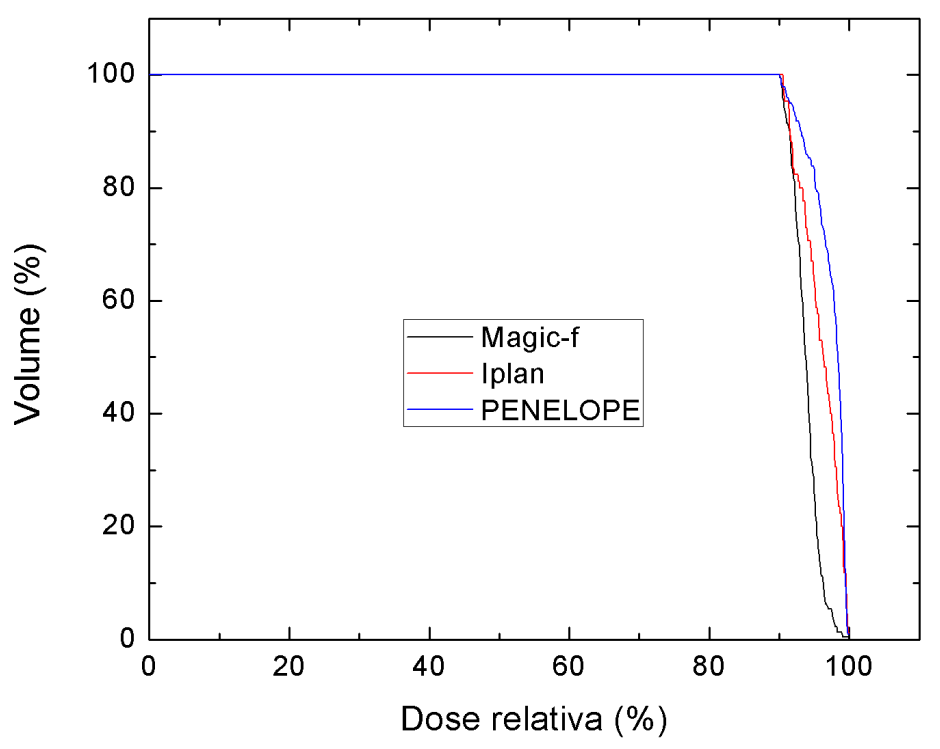

Figura 106: Curvas de DVH obtidas das distribuições de dose volumétrica das ferramentas dosimétricas: MAGIC- $f$, e TPS iPlan ${ }^{\circledR}$ e PENELOPE para um caso de neurinoma do acústico.

As curvas de DVH, para o caso de estudo de um neurinoma do acústico possuem o comportamento similar a do primeiro caso de estudo, mostrando que as curvas de DVH obtidas com o MAGIC-f, TPS iPlan ${ }^{\circledR}$ e o PENELOPE atingem uma dose relativa de $95 \%$ para um volume de $100 \%$. Da figura observa-se, ainda, a diferença da porção de volume que recebe doses relativas entre 95 e 100\% nas curvas obtidas com o MAGIC-f, TPS iPlan ${ }^{\circledR}$ e o PENELOPE, mostrando novamente uma menor porção do volume do MAGIC-f recebendo doses mais altas no tratamentoem relação a os volumes do TPS iPlan ${ }^{\circledR}$ e o PENELOPE.

Comparando-se os DVHs relativos aos três casos de radiocirurgia avaliados neste trabalho, pode observar que DVH mostraram com comportamento bastante similar e sugerindo a conformação de doses dentro do volume alvo. Todas as curvas de DVH obtidas com o MAGIC- $f$ apresentam a caracterísitca esperada de uma diminuição abrupta na porção do volume que recebe doses entre $95 \%$ e $100 \%$. Entretanto, para todos os casos, os volumes previstos pelo MAGIC-f recebendo altas doses são menores que aqueles previstos com o TPS iPlan ${ }^{\circledR}$ e o código PENELOPE. 
Dentre as ferramentas utilizadas, o MAGIC-fé a única forma experimental para a verificação tridimensional das distribuições de doses em tratamentos. A boa concordância dos parâmetros dosimétricos, das distribuições de doses, dos mapas de índice gama e dos DVHs entre o MAGIC- $f$ e as outras ferramentas dosimétricas utilizadas permite concluir que esse dosímetro possui alto potencial para utilização em verificações de doses e procedimentos dosimétricos em técnicas especiais em radioterapia, como a radiocirurgia.

\subsubsection{Probabilidade de controle tumoral}

A Figura 107 mostra as curvas de TCP-Volume, para o caso de neurinoma do acústico, determinadas para as ferramentas dosimétricas: MAGIC-f, TPS iPlan ${ }^{\circledR}$ e código PENELOPE.

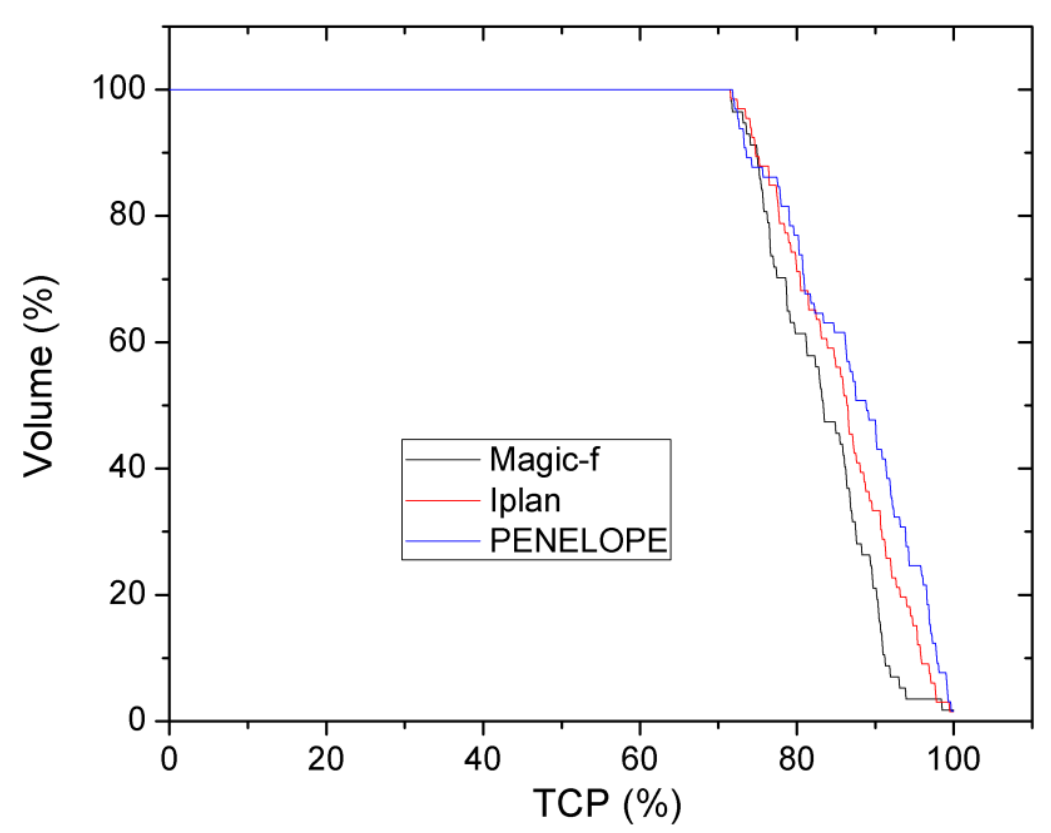

Figura 107: Histogramas de probabilidade de controle tumoral (TCP)-Volume, para um caso de neurinoma do acústico, para as ferramentas dosimétricas: MAGIC- $f$, TPS iPlan ${ }^{\circledR}$ e PENELOPE.

Como mostrado nos casos anteriores, a Figura 107 também mostra que as curvas de TCP possuem uma homogeneidade de aproximadamente de $71,5 \%$ de controle tumoral, relativo ao volume todo para o caso do neurinoma do acústico. A curva de menor percentual de volume para um dado TCP é 
obtida da distribuição do MAGIC- $f$ e a máxima resposta mostrada foi encontrada com a distribuição do código PENELOPE. Comparando-se qualitativamente os valores de TCP obtidos para os casos 1 e 2 pode-se observar que o caso 3 , os valores de TCP são mais próximos que dos outros casos.

A Figura 108 mostra as curvas de TCP-Volume e DVH para todos os volumes através do MAGIC-f, TPS iPlan ${ }^{\circledR}$ e o código PENELOPE.

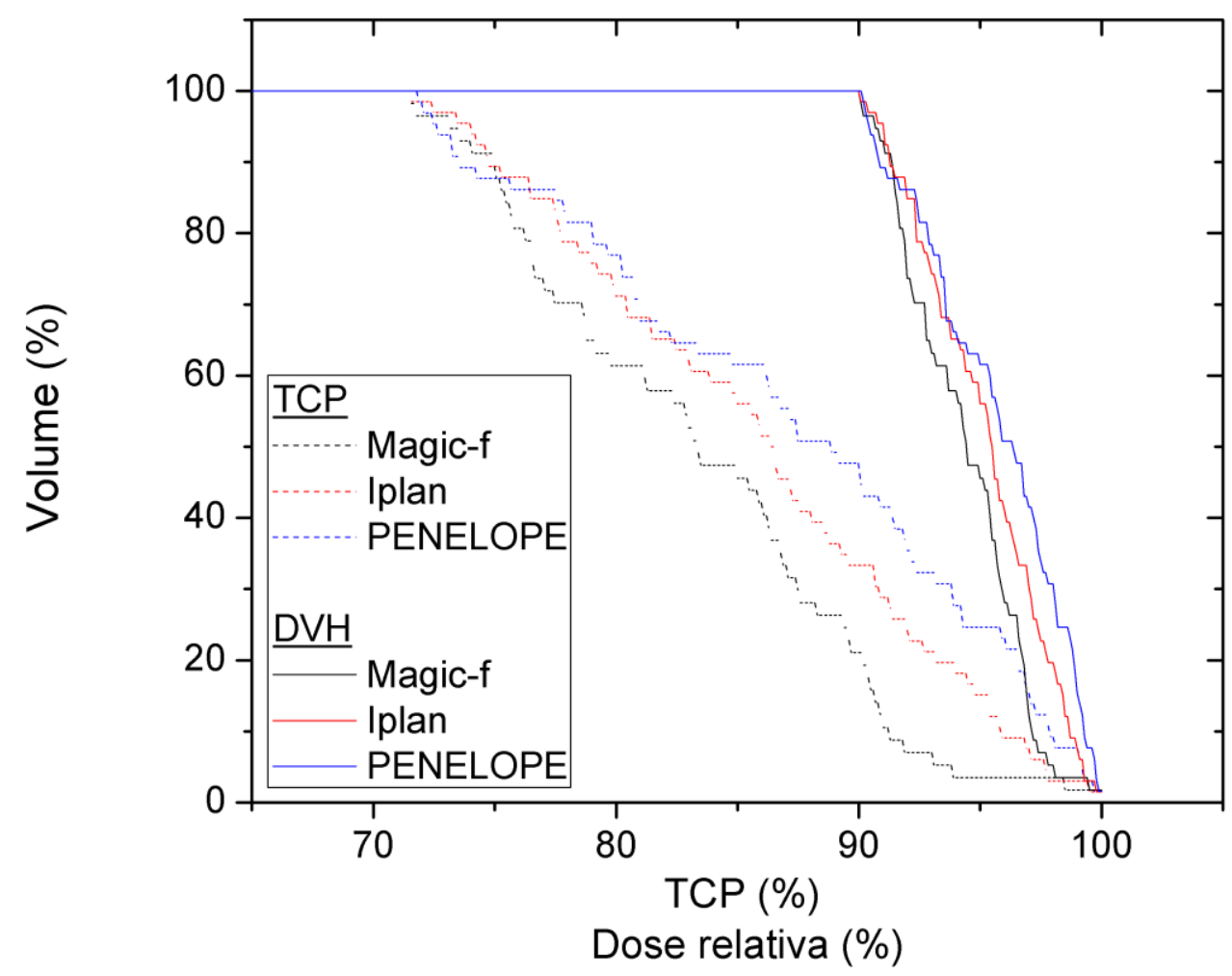

Figura 108: Histogramas de probabilidade de controle tumoral (TCP)-Volume e DVH, para um caso de neurinoma do acústico, para as ferramentas dosimétricas: MAGIC-f, TPS iPlan ${ }^{\circledR}$ e PENELOPE.

Do mesmo modo que para o caso do meningioma e do melanoma, as curvas de DVH para todos os casos de radiocirurgia e para todas as ferramentas dosimétricas utilizadas, possuem uma homogeneidade de dose até aproximadamente $95 \%$, a qual é a isodose de prescrição. Novamente, são mantidas as posições das curvas das ferramentas dosimétricas, mas há uma amplificação das diferenças observadas. 
Comparando-se qualitativamente as curvas de DVH e TCP-Volume para todos os casos estudados de radiocirurgia, pode-se apreciar que os valores dos TCP para todo o volume são reduzidos em comparação os valores de doses relativas para todo o volume, seguindo a mesma ordem de resposta em ambas as distribuições, e sendo a de menor resposta aquelas obtidas com o MAGIC-f. Essas maiores diferenças entre as curvas para o histograma TCPVolume podem ser explicadas pela forte dependência do TCP com a dose depositada em cada voxel do volume. Desta forma, pequenas heterogeneidades de doses encontradas nos DVHs são expressas de forma mais preponderante nos histogramas TCP-Volume.

Assim como a prescrição das doses nos tratamentos radioterápicos atuais é realizada em função de restrições de doses em percentuais de volumes, utilizando os DVHs para avaliação dos planos de tratamento, restrições de TCP-Volume poderiam ser utilizadas para a comparação de diferentes planos, auxiliando a decisão da escolha do melhor plano com base em uma informação biológica importante, como o TCP. Para tanto, entretanto, é necessário que restrições baseadas em TCP-Volume sejam estabelecidas e que os parâmetros radiobiológicos de tumores específicos sejam conhecidos com acurácia, o que por si só representa um desafio na prática clínica. 


\section{Conclusões}

Nesse trabalho foram estudadas e comparadas ferramentas dosimétricas para uso potencial em avaliações de doses em radioterapia: dosímetro gel polimérico MAGIC- $f$, filme radiocrômico EBT2, pacote de simulação Monte Carlo PENELOPE, além do sistema de planejamento radioterápico iPlan ${ }^{\circledR}$.

As distribuições de doses de tratamentos de neoplasias cranianas, planejadas com técnicas utilizadas em radiocirurgia, utilizando-se objetos simuladores de cabeça, mostraram-se similares. A análise dessas distribuições através de mapas de índices gama em planos dos tratamentos permitiu analisar a adequação de diferentes regiões do volume irradiado à prescrição realizada, podendo auxiliar na decisão de aceite ou recusa de planos de tratamento. Os critérios a serem adotados para essa análise, entretanto, devem ser melhor discutidos, para se adequarem aos requisitos de precisão de técnicas conformacionais em radioterapia moderna.

A avaliação dos histogramas dose-volume obtidas com MAGIC- $f$, PENELOPE e TPS iPlan ${ }^{\circledR}$ mostram-se, também similares e evidenciaram que, mesmo nos planejamentos em radiocirurgia somente uma pequena porção do volume alvo alcança uma conformidade de $100 \%$ da dose.

A incorporação de um parâmetro radiobiológico, como restrições baseadas em distribuições de probabilidade de controle tumoral versus volume alvo, nos sistemas radioterápicos poderia fornecer informações que complementariam o parâmetro físico avaliado pelo histograma dose-volume e estabelecendo uma metodologia mais adequada para comparação e decisão entre diferentes planos e técnicas de tratamento radioterápico.

Conforme aos resultados encontrados no presente trabalho pode-se afirmar que as ferramentas dosimétricas propostas, MAGIC- $f$ gel e código de simulação PENELOPE, são ferramentas com alto potencial para avaliação de doses volumétricas, geradas por campos de irradiação pequenos, coplanares e não coplanares em radioterapia. 


\section{Referências Bibliográficas}

Able C M, Thomas M D Quality assurance: Fundamental reproducibility tests for 3D treatment-planning systems. Journal of Applied Clinical Medical Physics, v.6 (3), 2005.

Aland $\mathrm{T}$, Karin $\mathrm{T}$, Kenny $\mathrm{J}$ Evaluation EBT2 film dosimetry system for radiotherapy quality assurance. Australasian Physiccal \& Engineering Science in Medicne, v.34 (2), p. 251-260, 2011.

Alexander $\mathrm{P}$, Charlesby $\mathrm{A}$, Ross $\mathrm{M}$ The degradation of solid polymethylmethacrylate by ionization radiation. Proc R Soc A, p. $223-392$, 1954.

Alva $M$, et al Caracterização da evolução temporal do sinal de RMN do gel MAGIC-f: linearidade e estabilidade dosimétrica. Anais do XIV Congresso Brasileiro de Física Médica, São Paulo, 2009.

Alva $M$, et al Monte Carlo Simulation of MAGIC- $f$ gel for Radiotherapy using PENELOPE. Journal of Physics: Conference Series 250, 012067, 2010.

American Association of Physicists in Medicine Quality assurance for robotic radiosurgery. AAPM Report TG 135, 2011.

American Association of Physicists in Medicine Radiochromic Film Dosimetry. AAPM Report 63, 1998.

American Association of Physicists in Medicine Stereostatic Radiosurgery. AAPM Report 54, 1995.

American Association of Physicists in Medicine The use of QA of biologically related models for treatment planning. AAPM Report TG 166, 2012.

Andisheh B et al Clinical and radiobiological advantages of single-dose stereotactic light-ion radiation therapy for large intracranial arteriovenous malformations. J. Neurosurg. v.111, p. 919-926, 2009.

Andrés $C$, et al A comprehensive study of the Gafchromic EBT2 radiochromic film: A comparison with EBT. Med. Phys., v.37 (12), p. 6271-6728, 2010.

Arjomandy B, et al Energy response and dose response of Gafchromic ETB2 film over a wide range of photon, electron, and proton beam energies. Med. Phys. v.37(5), p. $1942-1947,2010$.

Audet C, Schreiner LJ Radiation dosimetry by NMR relaxation time measurement of irradiated polymer solutions. Proc Soc Magn Reson Med $10^{\text {th }}$ Annual Scientific Meeting 705, 1991.

Badal A, et al Monte Carlo simulation of a realistic anatomical phantom described by triangle meshes: application to prostate brachytherapy imaging. Radiother. Oncol., v. 86, p.99-103, 2008. 
Baert AL, Knauth M, Sartor K Clinical Funtional MRI: Presurgical Funtional Neuroimaging. Ed. Spinger-Verlag, Berlin Heidelberg, 2007.

Baldock $\mathrm{C}$, et al Experimental determination of the diffusion coeficiente in 2D in ferrous sulphate gels using the finite element method Australas. Phys. Eng. Sci. Med., v. 24, p. 19-30, 2001.

Baldock $\mathrm{C}$, et al Experimental procedure for the manufacture of polycrylamide gel (PAG) for magnetic resonance imaging (MRI) radiation dosimetry. Phys. Med. Biol., v. 43, p. 695-702, 1998.

Baras $\mathrm{P}$, et al Polymer gel dosimetry using a three-dimensional MRI acquisition technique. Med. Phys., v. 29, p. 11, 2002.

Barazzuol $L$ et al A mathematical model of brain tumour response to radiotherapy and chemotherapy considering radiobiological aspects. Journal of Theorical Biology. v.262, p. 553-565, 2010.

Benavente JA Caracterização de campos de radiação beta utilizando filem radiocrômicos. Revista Brasileira de Física Médica. v.4(3), p. 71-74, 2011.

Betti OO, Derechinsky VE. Hyperselective encephalic irradiation with a linear accelerator. Acta Neurochir. Suppl., v. 33, p.385-390, 1984.

Blamek, S. Linac-based Stereotactic Radiosurgery for Brain Arteriovenous Malformations. Clinical Oncolgy, v. 23, p. 525-531, 2011.

Blinder K, Heermann DW Monte Carlo simulation in statistical physics, Berlin, Alemanha, 1988.

Bloch JC Avaliação de técnicas radioterápicas conformacionais utilizando critérios físicos e biológicos. Dissertação (Mestrado em Física Aplicada a Mediciana e Biologia) - Departamento de física, Universidade de São Paulo, Ribeiraão Preto, 2012. Disponível em: <Erro! A referência de hiperlink não é válida.. Acesso em 15 junho 2012.

Bol GH et al Fast online Monte Carlo-based IMRT planning for the MRI linear accelrator. Phys. Med. Biol. v.57, p.1375, 2012.

Boni AL Polyacrylamide gamma dosimeter. Radiat. Res., v. 14, p. 374-380, 1961.

Breen S, et al A comparison of conventional, conformal and intensity modulated coplanar radiotherapy plans for posterior fossa treatment. British J. Radio., v.77, p. 768-774, 2004.

Brualla, L. et al. Comparison between PENELOPE and electron Monte Carlo simulations of electron fields used in the treatment of conjunctival lymphoma. Phys. and Biol., v.54, p. 5469-5481, 2009.

Butson ET et al Measuring solar UV radiation with EBT radiochromic. Phys. Med. Biol. v.55, p. N487-N493, 2010a. 
Butson MJ et al Dose and absorption spectra response of EBT2 Gafchromic film to high energy $x$-ray. Australasian Physical \& Engineering Sciences in Medicine, v. 32(4), p. 196-202, 2009.

Butson MJ et al Energy response of the new EBT2 radiochromic filme t x-ray radiation. Radiation Measurement. v.45, p.836-839, $2010 \mathrm{~b}$.

Camaro PRTL, et al Implementation of a quality assurance program for computerized treatment planning system. Med. Phys., v.34 (7), 2007.

Canet D Nuclear Magnetic Resonance: Concepts and Methods. Ed Jhon Wiley \& Sons, England, 1991.

Carvajal MA, et al Monte Carlo simulation using the PENELOPE code with an ant colony algorithm to study MOSFET detectors. Phys. Med. Biol., v. 54, p. 6263-6276, 2009.

Chatterjee $S$ et al Dosimetric and radiobiological comparison of helical tomotherapy, forward-planned intensity-modulates radiotherapy and two-phase conformal plans for radical radiotherapy treatment of head and neck squalors cell carcinomas. The British Journal of Radiobiology. v.84, p. 1083-1090, 2011.

Chin LS, Regine WF. Principles and Practice of Stereotactic Radiosurgery, Boston, USA, 2008.

Cintra FB, Yoriyaz Electron absorbed dose comparison between MCNP5 and PENELOPE Monte Carlo code for microdosimetry. International Nuclear Atlantic Conference (INAC), 2009. Rio de Janeiro, 2009.

Clark B, Robar J, Nichol M Analysis of treatment parameters for conformal shaped field stereotactic irradiation: comparison with non-coplanar arcs. Phys. Med. and Biol., v. 46, p. 309-3103, 2001.

Colombo $\mathrm{F}$, et al External stereotactic irradiation by linear accelerator. Neurosurgery, v. 16, p.154-160, 1985.

Crescenti RA, et al Introducing gel dosimetry in a clinical environmental: Customization of polymer gel composition and magnetic resonance imaging parameters used 3D dose verification in radiosurgery and intensity modulated radiotherapy. Med. Phys., v. 34, p.1286-1297, 2001.

De Deene $Y$, et al $A$ basic study of some normoxic polymer gel dosimeter. Phys. Med. Biol., v. 47, p. 3441-3463, 2002.

De Deene $\mathrm{Y}$, et al An investigation of the chemical stability of a monomer/polymer gel dosimeter. Phys. Med. Biol., v.45, p. 859 - 878, 2000.

De Deene $\mathrm{Y}$, et al The fundamental radiation properties of normoxic polymer gel dosimeters: a comparison between a methacrylic acid based gel and acrylamide based gels. Phys. Med. Biol., v. 51, p. 653-673, 2006a. 
De Deene $Y$, et al Three dimensional radiation dosimetry in lung-equivalent regions by use of an radiation sensitive gel foam: Proof of principle. Med. Phys., v. 33, p. 2586-2597, 2006b.

De Deene Y. Essential characteristics of polymer gel dosimeters. Proceedings of the Third International Conference on Radiotherapy Gel Dosimetry, p.35-58, 2004a.

De Deene Y. Fundamentals of MRI measurements for gel dosimetry. Proceedings of the Third International Conference on Radiotherapy Gel Dosimetry. p.70-97, 2004b.

De Vlamynck $\mathrm{K}$, et al Dose measurements compared with Monte Carlo simulations of narrow $6 \mathrm{MV}$ multifead collimator shaped photon beams. Med. Phys., v. 26, p. 1874-1882, 1999.

Delgado JF, et al Cálculo independente de dose para tratamentos de arco dinâmico com colimador micromultimâminas. Radiobiologia Brasileria, v.39(5), p. 355-359, 2006.

Devic $S$ et al Dosimetric properties of improved GafChromic films for seven different digitizers. Med. Phys., v. 31(9), p. 1931-1946, 2004.

Drzymala RE, et al Dose-Volume Histograms. International Journal of Radiation Oncology, Biology and Physics. v. 21, p.71-78, 1991.

Falk $\mathrm{M}$, et al Real-time dynamic MLC tracking for inversely optimized arc radiotherapy. Radiotherapy Oncology, v.48, p. 1193-1197, 2010.

Fernandes JP, et al Formaldehyde increases magic gel dosimeter melting point and sensitivity. Phys. Med. Biol., v. 53, p.N1-N6, 2008.

Finger PT Radiation therapy for orbital tumors: concepts, currents use, and ophthalmic radiatioin side effects. Surv. Ophthalmol. v.54(5), p. 545-568, 2009.

Folwer JF et al Is $\alpha / \beta$ for prostate tumors really low? Radiation Oncology. v.50 (4), p. 1021-1031, 2001.

Fong PM, et al Polymer gels for magnetic resonance imaging of radiation dose distributions at normal room atmosphere. Phys. Med. Biol., v. 46, p. 31053113, 2001.

Gafchromic. International Speciality Products. 2010. Available from: http://online1.ispcorp.com/en-

US/gafchromic/SupportingDocuments/GafChromic EBT-2 20101007.pdf.

Gershkevitsh E, et al Dosimetric verification of radiotherapy treatment planning systems: Results of IAEA pilot study, Radiotherapy and Oncology. v.89, p. 338-346, 2010. 
Ghassoun J, Senhou N, Jehouani A Neutron and photon doses in high energy radiotherapy facilities and evaluation of shielding performance by Monte Carlo method. Annals of Nuclear Energy, v. 38 (10), p. 2163-2167, 2011.

Gibney GT et al Melanoma in the brain: biology and therapeutic options. Melanoma Res., v.22, p. 177-183, 2012.

Gillis S, et al An inter-centre quality assurance network for IMRT verification: resutls of the ESTRO QUASIMODO project. Radiotherapy and Oncology. v.76, p. 340-353, 2005.

Gore JC, et al Radiation dose distributions in three dimension form tomographic optical density scanning of polymer gels: I Development of an optical scanner. Phys. Med. Biol., v. 41, p. 2695-2704, 1996.

Górka B, et al Optimization of a tissue-equivalent CVD-diamond dosimeter for radiotherapy using the Monte Carlo code PENELOPE. Nucl. Instrum. Methods Phys. Res. A., v.59 (3), 578-587, 2008.

Gospishankar N, Watanabe Y, Subbiah V MRI-bases polymer gel dosiemtry for validation plans with matrices in Gamma Knife stereotactic radiosurgery. J App. Clinical Med. Phys., v.12 (2), p. 133-145, 2011.

Gotanda $T$ et al Evaluation of effective energy using radiochromic film and a step-shaped aluminum filter. Autralas. Phys. Eng. Sci. Med., v.34, p. 213-222, 2011.

Gustavsson H, et al MAGIC-type gel for three-dimensional dosimetry: Intensitymodulated radiation therapy verification. Med. Phys., v. 30, p. 1264-1271, 2003.

Guzman CS, et al Dosimetric parameters for small field sizes UsingFricke xylenol gel, thermoluminescent and film dosimeters, and an ionization chamber. Phys. Med. Biol., v. 52 , p. 1431-1439, 2007.

Hall E J Radiobiology for Radiologist. Philadelphia, 2000.

Hardcastle $\mathrm{N}$ et al High dose per fraction dosimetry of small fields with Gafchromic EBT2 film. Med. Phys., v.38 (7), p. 4081-4085, 2011.

Harms, W B et al A software tool for the quantitative evaluation of 3D calculation algorithms. Med. Phys., v.25 (10), p. 1830-1838, 1998.

Hartmann, B. Mária, M. Oliver J Technical Note: Homogeneity of Gafchromic EBT2 film. Phys. Med. Biol., v. 53 (24), p. 7013-7027, 2008.

Hayhurst, C. et al. Preatment predictors of adverse radiation effects after radiosurgery for arteriovenous malformation. In. J. Radiation Oncology Biology and Physics, v.82(2 ), p.803-808, 2012. 
Hill $B$, Venning $A$, Baldock $C$ The dose response of normoxic polymer gel dosimeters measured using X-ray CT. The British J. Radio., v.78, p. 623-630, 2005.

Ho, Anthony et al. Trigeminal neuralgia treatment dosimetry of the Cybernife. Medical Dosimetry, v.37, p.42-46, 2012.

Hong, LX et al Experience of micromultileaf collimator linear accelerator based single fraction stereotactic radiosurgery: Tumor dose inhomogeneity, conformity, and dose fall off. Med. Phys., v. 38 (3), p. 1239 - 1247, 2011.

Internacional Commission on Radiation Units and Measurements, Prescribing, Recording and Reporting Photon Beam Therapy. ICRU Report 62, Washington DC, 1999.

International Atomic Energy Agency Absorbed Dose Determination in External Beam Radiotherapy. IAEA, TRS -No.398, Vienna, IAEA, 2000.

International Atomic Energy Agency. Commissioning and quality assurance of computerized planning systems for radiation treatment of cancer. IAEA, TRS No. 430, Vienna, IAEA, 2004.

International Atomic Energy Agency. Commissioning of Radiotherapy Treatment Planning Systems: Testing for Typical External Beam Treatment Techniques. IAEA TECDOC 1583, Vienna, IAEA, 2008.

International Atomic Energy Agency. Specification and Acceptance Testing of Radiotherapy Treatment Planning Systems. IAEA TECDOC 1540, Vienna, IAEA, 2007.

International Commission on Radiation Units and Measurements, Tissue substitutes in radiation dosimetry and measurement. ICRU report 44, Bethesda, EUA, 1989.

International Commission on Radiation Units and Measurements, Prescribing, Recording and Reporting Photon Beam Therapy. ICRU report 62, Bethesda, EUA, 1999.

Ishikur AS Quality Assurance of Radiotherapy in Cancer Treatment: Toward Improvement of Patient Safety and Quality Care. Jpn J Clin Oncol. v. 38 (11), p. 723-729, 2008.

Jiang, BW et al Management of intracranial and extracranial chordomas with CyberKnife stereotactic radiosurgery. Journal of Clinical Neuroscience, v. 19 (8), p. 1101-1106, 2012.

Jin JY, Kong FMA TCP model incorporation setup uncertainty and tumor cell density variation in microscopic extension to guide treatment planning. Med. Phys. v.38 (1), p. 439-448, 2011. 
Jin JY et al Evaluation of residual patient position variation for spinal radiosurgery using the Novalis image guided system. Med. Phys. v.35 (3), p. 1087-1093, 2008.

Jung, JY et al Tomotherapy Planning and Image Registration for Planning CT Image Slice Thickness for Stereotactic Radiosurgery. Journal of the Korean Physical Society, v. 60 (1), p. 137-141, 2012.

Kang $\mathrm{YN}$, et al Development of BANG-3(R) polymer gel dosimetry system in small radiosurgical fields. J. Korean Phys. S. v.59(6), p. 3422-3427, 2011.

Karlsson $\mathrm{M}$, et al Independent Dose Calculations Concepts and Models, ESTRO Booklet nํ. 910, Brussels, ESTRO, 2010.

Kennan RP et al Hydrodynamic effects ante cross relaxation in cross linked polymer gels. Proc Intl Soc Mag Reson Med, New York, 1992.

Khan F The Physics of Radiation Therapy. Fourth Edition, Philadelphia,PA, USA, 2010.

Kim MS et al Gamma knife radiosurgery for orbital tumors. Clinical and Neurosurgery. v. 110, p. 1003-1007, 2008.

Kim Y, Tome WA Dose-painting IMRT optimization using biological parameters. Acta Oncologica. v.48 (8), p. 1374-1384, 2010.

Kim JH, Hill R, Kuncic Z An evaluation of calculation parameters in the EGSnrc/BEAMnrc Monte Carlo codes and their effect on surface dose calculation. Phys. Med. Biol., v. 57 (4), p. N267-N278, 2012.

Ko EC, Forsythe $\mathrm{K}$ Radiobiological rationale and clinical implications of hypofractionated radiotion therapy. Cancer Radiotherapie v.15(3), p. 221-229, 2011.

Koivunoro $\mathrm{H}$ et al Accuracy of the electron transport in MCNP5 and its suitability for ionization chamber response simulations: A comparison with the EGSNRC and PENELOPE codes. Med. Phys., v.39 (3), p. 1335-1344, 2012.

Landini L, Positano V, Santarelli MF Advanced Image processing in Magenteic Resonance Imaging. Ed. Talyor \& Francis, London, 2005.

Levitt SH et al Technical Basis of Radiation Therapy, Practical Clinical Applications. Spinger-Verlag Heidelber, 2012.

$\mathrm{Li} \mathrm{H}$ et al Toward a better understanding of the gamma index: Investigation of parameters with a surface-based distance method. Med. Phys. v.38 (12), p. 6730-6741, 2011.

Low DA, et al A technique for the quantitative evaluation of dose distributions. Med. Phys., v. 25, p. 656-661, 1998. 
Luci JJ, Whitney HM, Gore JC Optimization of MAGIC gel formulation for threedimensional therapy dosimetry. Phys. Med. Biol., v. 52, p. N241-N248, 2007.

Mariani M, et al Preliminary results from a polymer gel dosimeter for absrorbed dose imaging in radiotherapy. Rad. Phys. Chemis., v. 76, p. 1507-1510, 2007.

Marques, T. et al Resposta dosimétrica do gel MAGIC-f para feixes de Radioterapia: dependência energética e com a taxa de dose. Anais do XIV Congresso Brasileiro de Física Médica, São Paulo, 2009.

Martinez-Rovira, I ; Sempau, J; Prezado, Y Monte Carlo-based treatment planning system calculation engine for microbeam radiation therapy Med. Phys., v. 39 (5), p. 2829-2838, 2012.

Maryanski MJ, et al NMR relaxation enhancement in gels polymerized and cross-linked by ionizing radiation: a new approach to $3 \mathrm{D}$ dosimeter by MRI. Mag. Reson. Imaging., v. 11, p. 253-258, 1993.

Mascarenhas $\mathrm{F}$, Sa da Costa $\mathrm{M}$, Ortiz $\mathrm{M} A$ radiocirurgia esteresotáxica em tumores benignos e malignos do sistema nervoso central. Acta Méd. Port., v.18, p. 45-60, 2005.

Mazeron JJ et al Radiosurgery history. Cancer Radiotherapie, v. 16 (1), p. S2 - S4, 2012.

McNiven AL, Sharpe MB, Purdie TG A new metric for assessing IMRT modulation complexity and plan deliverability. Med. Phys., v. 37, p. 505-515, 2010.

Mesbahi A, Reily AJ, Thwaite DI Development and commissioning of a Monte Carlo photon beam model for Varian Clinac 2100EX linear accelerator. Applied Radiation and Isotopes, v. 64, p. 656 - 662, 2006.

Mijnheer B et al Quality assurance of treatment planning systems: practical examples for non-IMRT photon beams, ESTRO Booklet no. 7, Brussels, ESTRO, 2004.

Molineu A et al Results from multiple radiation of an anthropomorphic spine phantom. Med. Phys. v37, 3400, 2010.

Moskvin V, et al Monte Carlo simulation of the Leksell Gamma Knife R: I. Source modelling and calculations in homogeneous media. Phys. Med. Biol., v. 47, p.1995-2011, 2002.

Murthy $\mathrm{V}$, et al Stereotactic conformal radiotherapy for posterior fossa tumours: a modeling study for potential improvement in therapeutic ratio. Radiat. Oncol., v. 67, p. 191-198, 2003.

Oldham M, et al High resolution gel-dosimetry by optical-CT and MR scanning. Med. Phys., v. 28, p. 1436-1445, 2001.

Park $\mathrm{JH}$ et al Application of the gamma evaluation in Gamma Knife film dosimetry. Med. Phys. v.38 (10), p. 5778-5787, 2011. 
Pavoni, JF et al Tomotherapy dose distribution verification using MAGIC-f polymer gel dosimetry. Med. Phys., v. 39 (5), p. 2877 - 2884, 2012.

Pianoschi, T. et al. Estabilidade de resposta do gel MAGIC- $f$ na dosimetria de feixes clínicos: elétrons e fótons. Anais do XIV Congresso Brasileiro de Física Médica, São Paulo, 2009.

Pianoschi, T. et al. MAGIC- $f$ gel dosimetry for clinical electron beam. Journal of Physics: Conference Series 250, 012037, 2010.

Podgorsak EB et al Radiation Oncology Physics: A Handbook for Teachers and Students, Austria, 2005.

Poon E, Verhaegen F Accuracy of the photon and electron physics in GEANT4 for radiotherapy applications. Medical Physics, v. 32(6), p. 1696 - 1711, 2005.

Pooter JA, et al Computer optimization of nocoplanar beam setups improves stereotactic treatment of liver tumors. Int. J. Radiation Oncology Biol. Phys., v. 66, p. $913-922,2006$.

Puck TT, Marcus PI Action of x-ray on mammalian cells. The Journal of Experimental Medicine. v.103(5), p. 653-666, 1956.

Ramirez VJ. et al. Dosimetry of small radiation field in inhomogeneous medium using alanine/EPR minidosimeters and PENELOPE Monte Carlo simulation. Radiation Measurements, v.46, p. 941-944, 2011.

Rath F Tools For Developing A Quality Management Program: Proactive Tools (Process Mapping, Value Stream Mapping, Fault Tree Analysis, And Failure Mode And Effects Analysis). Int. J. Radiation Oncology Biol. Phys., v. 71 (1), p. S187-S190, 2008.

Ravindram BP, Faircluch L, Jaywant SM Phantom Dosimetry for conformal stereotactic radiotherapy with head and neck localizer frame. Phy. Med. Biol., v. 46, p. 1975-1984, 2001.

Rink A, Vitikin IA, Jaffray Energy dependence ( $75 \mathrm{kVp}$ to $18 \mathrm{MV}$ ) of radiocrhomic films assessed using a real-time optical dosimeter. Med. Phys., v.34, 458-463, 2007.

Rodríguez EAV, et al Dosimetric parameters estimation using PENELOPE Monte-Carlo simulation code: Model 6711 a $125 \mathrm{I}$ brachytherapy seed. Applied Radiation and Isotopes, v. 63, p. 41- 48, 2005.

Rodriguez, M; Sempau, J; Brualla, L Combined approach of variancereduction techniques for the efficient Monte Carlo simulation of linacs. Phys. Med. Biol., v. 57 (10), 2012.

Roet $\mathrm{D}$, et al Comparisons between MCNP and PENELOPE for the simulation of X-ray spectra in electron microscopy in the keV range. J.L. Nucl. Instr. and Meth. In Phys. Res. B, v.251, p. 317-325, 2006. 
Rogers DWO Reviews: Fifty years of Monte Carlo simulations for medical physics. Phys. Med. Biol., v. 51, p. r287 - r301, 2006.

Roos DE et al Stereotactic radiosurgery for acoustic neuromas: what happens long term? Int. J. Radiation Oncology Biol. Phys. v. 8(4), p. 1352-1355, 2012.

Roozen et al Evaluation of EBT radiochromic film using a multiple exposure technique. Australas. Phys. Eng. Sci. Med. v.43, p. 281-289,2011.

Ross CK et al A direct comparison of water calorimetry and Fricke dosimeter. Phys. Med. Biol., v. 34, p.23-42, 1989.

Rowe JG et al Gamma knife stereotactic radiosurgery for unilateral acoustic neuromas. J. Neurol Neurosurg Phychiatry. v. 74, p. 1536-1542, 2012.

Rubinstein R Simulation and the Monte Carlo Method. Ed John Wiley \& Sons, Canada, 1981.

Saconn PA et al Use of 3.0-T MRI for stereotactic radiosurgery planning for treatment of brain metastases: a single-institution retrospective review. Int. J. Radiat. Oncol. Biol. Phys. v.78(4), p. 1142-1146, 2010.

Salvat $F$, et al Overview of physical interactions models for photons and electron transport used in Monte Carlo code. Metrologia. v.46, S112-1138, 2009.

Salvat F, Fernández-Varea JM, Sempau J A Code System for Monte-Carlo Simulation of Electron and Photon Transport. September, France, 2005.

Scaff L Física da Radioterapia, Brasil, 1997.

Schwarche, M. et al. Estudo preliminar da distribuição de dose em pacientes com doença de Graves submetidos a exame de captação de iodo-131 utilizando simulação Monte Carlo. Revista Brasileira de Física Médica, v.4(2), p.35-38, 2010.

Sempau J, Andreo $\mathrm{P}$ Configuration of the electron transport algorithm of PENELOPE to simulate íon chambers. Phy. Med. Biol., v. 51, p. $3533-3548$, 2006.

Sempau J, et al Experimental benchmarks of the Monte Carlo code PENELOPE. J.L. Nucl. Instr. and Meth. In Phys. Res. B, v. 207(2), p. 107123, 2003.

Sempau J. et al. A PENELOPE-based system for the automated Monte Carlo simulation of clinacs anda voxelized geometries - application to far-from-axis fields. Med. Phys., v.38(11), p. 5887-5895, 2011.

Sharma SD Does Intensity-modulated stereotactic radiotherapy achieve superior target conformity than conventional stereotactic radiotherapy in different intracranial tumours? Clinal Oncology. v. 21,p. 408-416, 2009. 
Sharon Qi X, et al An estimation of radiobiological parameter for head and neck cancer cells and the clinical implications. Cancers. v.4, p. 566-580, 2012.

Sheehan, JP et al Gamma Knife surgery for the management of glomus tumors: a multicenter study Clinical article. Journal of Neurosurgery. v. 117 (2), p. 246-254, 2012.

Sheikh-Bagheri D, Rogers DW Monte Carlo calculation of nine megavoltage photon beam spectra using BEAM code. Med. Phys., v. 29, p. 391-402, 2002.

Sheng K, Molly J, Larner JM A dosimetric comparison of non-coplanar IMRT versus Helical Tomotherapy for nasal and paranasal sinus cancer. Radio. Oncol., v. 82, p. 174-178, 2007.

Shibamoto $\mathrm{Y}$ et al Radiobiological evaluation of the radiation dose used in hihgprecision radiotherapy: effect of prolonged delivery time and applicability of the linear-quadratic model. J Radiat Res. , v.53 (1), p.1-9, 2012.

Shim JB et al Comparison of linac-based fractionated stereotactic radiotherapy and tomotherapy treatment plans for intra-cranial tumors. Chinese Physics C. v. 34(11), p. 1768-1774, 2010.

Silva MSR et al Calibração do filme radiocrômico GAFCRHOMIC XR-RV2 para radiologia. Revista Brasileira de Física Médica. v.4(2), p. 45-48, 2010.

Slotman B, Solberg T D, Verellen D Extracranial Stereotactic Radiotherapy and Radiosurgery. New York, USA, 2006.

Smith HJ, Ranallo FN A non-mathematical approach to basic MRI. Ed Medical Physics Publishing Corporation, Madison-USA, 1989.

Stock M, Kroupa B, Georga D Interpretation and evaluation of the $\gamma$ index and the $\gamma$ index angle for the verification of IMRT hybrid plans. Phys. Med. Biol. v. 50, p. 399-411, 2005.

Sutherland JGH, Rogers DW Monte Carlo calculated absorber-dose energy dependence of EBT and EBT2. Med. Phys. v.37(3), p. 1110-1116, 2010.

Szeifert GY, et al Radiosurgergy and Pathological Fundamentals. Ed. Karger, Basel, 2007.

Valk J, MacLean C, Algra PR Basic principles of nuclear magnetic resonance imaging. Ed Elsevier, Amsterdam, 1985.

Van Dyk $J$ Quality assurance of radiation therapy planning system: current status and remaining challenges. Int. J. Radiation Oncology Biol. Phys. v71(1), p. S23-S27, 2008.

VAN DYK J, et al Computerized Radiation Treatment Planning Systems, Chapter 8, pp. 231-286, 2012. Disponível em: ttp://www.medicalphysics.org/apps/medicalphysicsedit/VANDYKCH08.pdf. Acesso em: may/2012. 
Verhaegen $F$ Evaluation of the EGSnrc Monte Carlo code for interface dosimetry near high-Z media exposed to kilovolt and ${ }^{60}$ Co photons. Phys. Med. Biol., v. 47, p.1691-1705, 2002.

Vlachopolou, V. et al. Peripheral dose in patients undergoing Cyberknife treatment for intracranial lesions. A single centre experience. Radiation Oncology, v.6, p.157, 2011.

Wang JZ et al Evaluation of patient setup uncertainty of optical guided frameless system for intracranial stereotactic radiosurgery. J Appl. Clinic. Med. Phys. v.11(2), p. 92-100, 2010.

Wang X, et al. Effectiveness of nocoplanar IMRT planning using a parallelized multiresilution beam angel optimization method for paranasal sinus carcinoma. Int. J. Radiation Oncology Biol. Phys., v. 63, p. 594-601, 2005.

Winiecki $J$ et al The gamma evaluation method as a routine QA procedure of IMRT, Reports of Practric. Oncol. Radioher. v.14, 162-168, 2009.

Yamamoto T, et al An integrated Monte Carlo dosimetric verification system for radiotherapy treatment planning. Phys. Med. Biol., v. 52, p. 1991, 2008.

Ye S, Naqvi S Low-energy photon dose calculations using various MCNP photon databases: dose comparison between MCNP, PENELOPE, and EGSnrc. Med. Phys., v. 32(6), p.2013 - 2013, 2005.

Yoon $\mathrm{M}$, et al Accuracy of inhomogeneity correction algorithm in intensitymodulated radiation of Head and Neck tumor. Medical Dosimetry. 32 44-51, 2007.

Yoriyaz, H Método de Monte Carlo: princípios e aplicações em Física Média. Revista Brasileira de Física Médica, v.3(1), p.141-149, 2009.

Zeidan OA Characterization and use of EBT radiochromic film for IMRT dose verification. Med. Phys. v.33(11), p. $4064-4072,2006$.

Zhu $X$ et al Improved MAGIC gel for higher sensitivity and elemental tissue equivalent 3D dosimetry. Med. Phys. v.37(1), p. 183-188, 2010. 


\section{ANEXO}

\% Programa de Leitura de imagens de Ressonância Magnética

clear

clc

$X=\operatorname{repmat}\left(\right.$ double $\left.(0),\left[\begin{array}{llll}256 & 256 & 1 & 128\end{array}\right]\right) ;$

for $p=2: 127$

filename $=$ sprintf('IM00\%04d', p);

end

$\mathrm{X}(:,:, 1, \mathrm{p})=$ dicomread (filename);

filename $=$ sprintf('IM000000');

$\mathrm{X}(:,:, 1,1)=$ dicomread (filename $)$;

montage $(X,[])$

nfat $=8$;

$\mathrm{F} 1=\operatorname{repmat}\left(\right.$ double $\left.(0),\left[\begin{array}{llll}256 & 256 & 1 & 16\end{array}\right]\right) ; \mathrm{F} 2=\operatorname{repmat}($ double(0), [256 2561 16]); F3=repmat (double(0), [256 2561 16]); F4=repmat (double(0), [256 $256116])$;

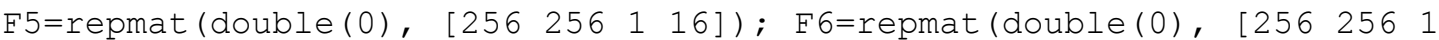
16]); F7=repmat (double (0), [256 256 1 16]); F8=repmat (double (0), [256 256 1 16$])$;

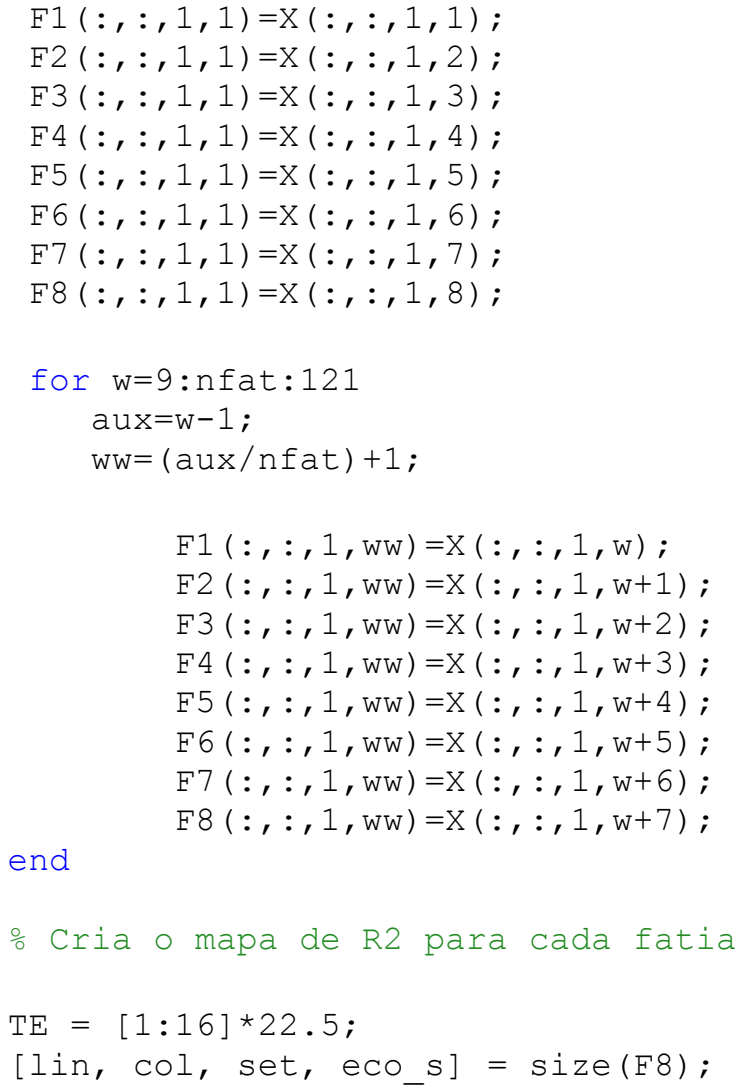

end

- Cria o mapa de R2 para cada fatia

$\mathrm{TE}=[1: 16] * 22.5 ;$

[lin, col, set, ecos] = size $(F 8)$;

for $i=1: l i n$ 


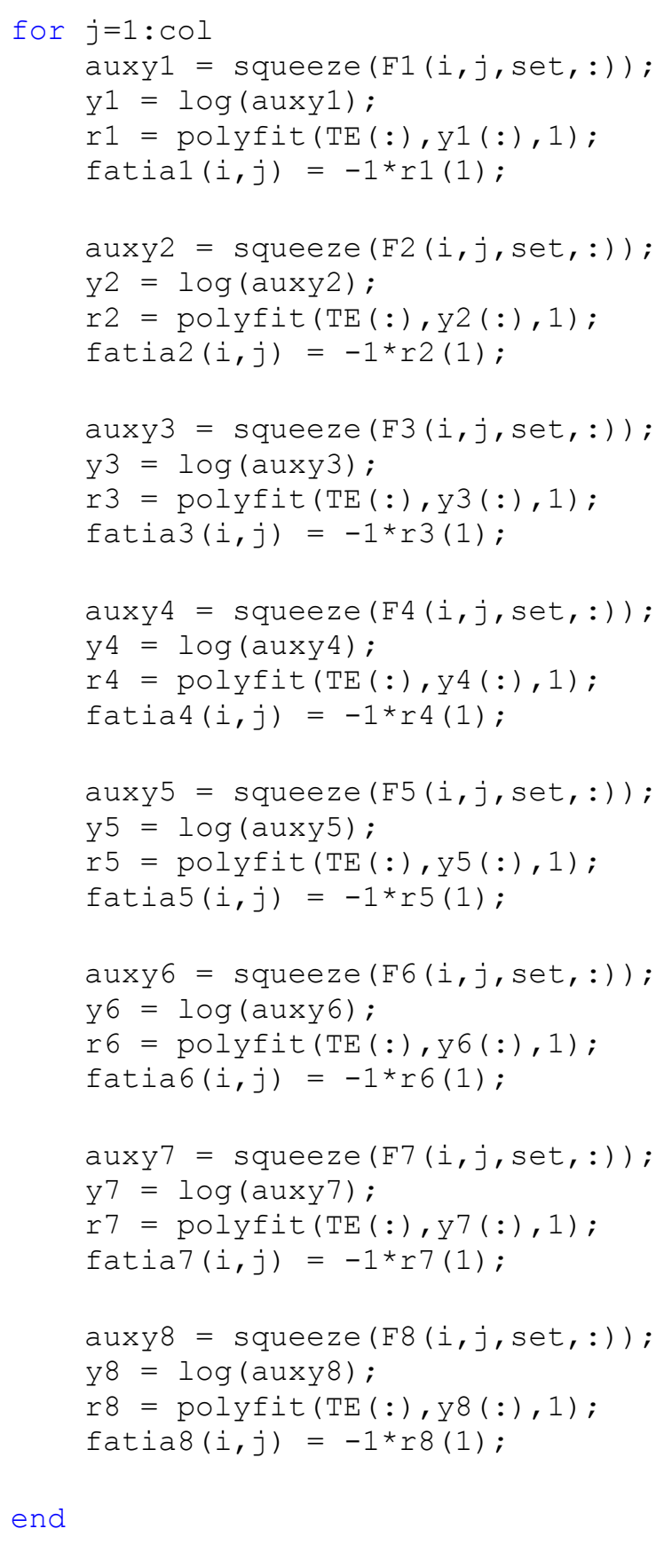

